\title{
Distribution and behavioural ecology of the sulphur-crested cockatoo (Cacatua galerita L.) in \\ New Zealand
}

by

Andrew Styche

\author{
A thesis \\ submitted to the Victoria University of Wellington \\ in fulfilment of the \\ requirements for the degree of \\ Doctor of Philosophy \\ in Biology
}

Victoria University of Wellington 2000 


\section{Abstract}

1. Sulphur-crested cockatoos (Cacatua galerita) have colonised several sites in the North Island and on Banks Peninsula in the South Island of New Zealand. Galah (C. roseicapilla) have established in the South Auckland Region of the North Island. Original colonies are thought to have established from escaped cage birds, but the origin of populations of C. galerita that have appeared over more recent years is uncertain.

2. The distribution of C. galerita in Australia and New Zealand was modelled against environmental factors using multiple logistic regression to determine which characteristics of its environment are important in defining their distribution.

3. While C. galerita distribution in New Zealand falls within the range of ambient temperature experienced by this species in Australia, models of distribution produced from multiple logistic regression revealed temperature was not the only characteristic important in defining distribution. Instead distribution was best defined by a combination of temperature, availability of cultivated land and in New Zealand the presence of open woodland vegetation.

4. Observed daily and seasonal differences in the movement, time-activity budget, habitat use and diet of cockatoos in a population stronghold (Turakina Valley, ManawatuWanganui Region) were used to provide insight into the relationship between the environmental factors characteristic of $C$. galerita distribution and the range of this species.

5. Distribution of $C$. galerita was strongly influenced by the availability of crop seed, mostly maize (Zea maize). In winter groups of $C$. galerita from a large area (probably hundreds of square kilometres) congregated into a large flock, roosting in a reserve immediately adjacent to fields of maize, their main food source at this time. By congregating in this area they reduced the amount of time needed to forage for food, especially time spent flying (the most energetically costly behaviour).

6. Despite greater energetic demands in winter, C. galerita in the Turakina Valley decreased the proportion of time spent feeding, instead increasing time spent resting. This was attributed to feeding on a very abundant food (maize), and lower energy demands 
resulting from reduced time spent flying (possible because of maize) and in feather maintenance and social behaviours.

7. Native podocarp forest remnants provided most of the non-food resource requirements of C. galerita, such as day-time refuges and nest and nocturnal roost sites. Most of their food was obtained from introduced vegetation available on the adjacent farmland, particularly cereal crops, grasses and exotic conifers. In contrast, sympatric populations of tui (Prosthemadera novaeseelandiae), bellbirds (Anthornis melanura) and New Zealand pigeons (Hemiphaga novaeseelandiae) were more arboreal and preferentially foraged in native forest and exotic angiosperm tree species.

8. Freshly fallen leaves and green branches (greenfall) were collected from 100 plots in a podocarp-broadleaf forest in the Turakina Valley. Greenfall was categorised as "unexplained" or "cockatoo-caused". Leaves and branches $(0-600 \mathrm{~mm})$ from 41 species or species groups were represented in the greenfall. Ten of these species also contributed to cockatoo-caused greenfall, including all four podocarp species and all of the epiphytic angiosperms present in the reserve.

9. Annual inputs of cockatoo-caused greenfall were compared with total foliar litter-fall measured in similar podocarp-broadleaf forests in the Orongorongo Valley, lower North Island. Although cockatoo-caused greenfall contributed only $0.08 \%$ of average litterfall, their impact was substantially greater for particular species, including $>5 \%$ of literfall recorded for Dacrydium cupressinum.

10. Defoliation of native tree and epiphyte species by $C$. galerita is considered to have potential consequences for forest dynamics, resulting in an increase in understorey vegetation, and could cause reductions in populations of some species (particularly $D$. cupressinum and rarer epiphytes). 


\section{Acknowledgements}

I wish to thank Hugh Stewart and other members of the Rangitikei Branch of the Royal Forest and Bird Protection Society whose interest initiated this study. Thanks also to Ian Stewart and John and Anne McLeay for access to their properties without which much of the fieldwork for this research would not have been possible. Further thanks to Ian Stewart for allowing me to stay in his shearers' quarters.

Thanks to Ben Bell for his supervision during the many years it took to complete this thesis. I am also grateful to Brian Dawkins for his much needed advice with statistics, to Barry Sneddon and John Dawson for identifying plant species from the few mangled leaves I brought to them and to Ralph Powlesland, Christa Mulder, Ben Bell, Terry and Debra Greene, Charlie Daugherty and Bob Brockie for providing valuable insights and advice that helped improve this work. Thanks also to Nicky Nelson and Kelly Hare for assistance making sure everything was present and in the correct place.

This work was supported by grants from the Rangitikei College Trust and Royal New Zealand Forest and Bird Protection Society Incorporated.

Lastly, this thesis could not have been done without the assistance of my dear friends Roz and Ewen Grant and of my parents. Thanks for seeing it through with me. 


\section{Table of contents}

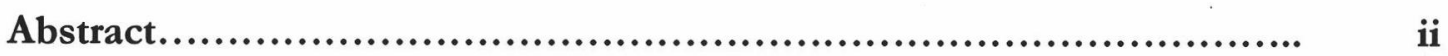

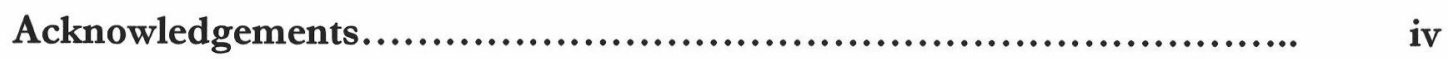

Table of contents.......................................................... v

List of tables............................................................ xi

List of figures........................................................... xiii

Chapter 1 General introduction............................................. 1

1.1 COLONISING SPECIES....................................... 1

1.1.1 The introduced parrots of New Zealand....................... 3

1.1.2 Predicting the range and impact of $C$. galerita in New Zealand...... 4

1.1.3 Structure of the thesis..................................... 5

Chapter 2 The geographic distribution of the sulphur-crested cockatoo (Cacatua galerita) in Australia and New Zealand............. 10

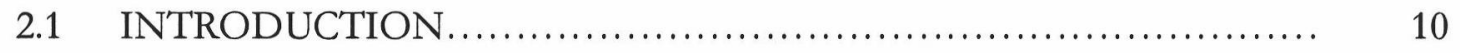

2.2 METHODS.................................................. 13

2.2.1 Cockatoo distribution data................................. 13

2.2.2 Environmental data....................................... 14

2.2.3 Data analysis........................................ 14

2.2.3.1 Univariate regression............................ 15

2.2.3.2 Multiple regression.............................. 15

2.3 RESULTS................................................ 19

2.3.1 Distribution of cockatoos in New Zealand..................... 19

2.3.1.1 Historical distribution patterns of C. galerita in the North Island ............................................. 19

2.3.1.2 Historical distribution patterns of C. galerita in the South Island........................................... 26

2.3.1.3 Historical distribution patterns of C. roseicapilla in New Zealand............................................ 26

2.3.2 Modelling distribution using logistic regression................. 31

2.3.2.1 Distribution in Australia............................. 31

2.3.2.2 Distribution in New Zealand......................... 37

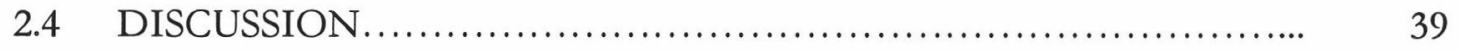


2.4.1 Distribution of cockatoos in New Zealand.

2.4.1.1 The role of invasion and dispersal in the distribution of C. galerita in New Zealand........................... 40

2.4.2 Environmental characteristics of C. galerita distribution............ 43

2.4.2.1 Temperature.................................... 43

2.4.2.2 Vegetation....................................... 46

2.4.3 Gaps in the distribution of C. galerita........................ 47

2.4.4 Limitations of analysis.................................... 48

2.4.5 Conclusion............................................... 49

\section{Chapter 3 Behaviour and habitat use of sulphur-crested cockatoos} (Cacatua galerita) in the Turakina Valley, ManawatuWanganui, New Zealand.................................... $\quad 50$

$3.1 \quad$ INTRODUCTION .............................................. 50

3.1.1 Cacatua galerita in Australia.................................. 50

3.1.2 Cacatua galerita in New Zealand............................... 51

3.1.3 Time and energy budget of C. galerita....................... 52

3.1 .4 Study area............................................... 55

3.2 METHODS.................................................. 57

3.2.1 Collection of behavioural observations........................ 57

3.2.2 Data analysis............................................ 60

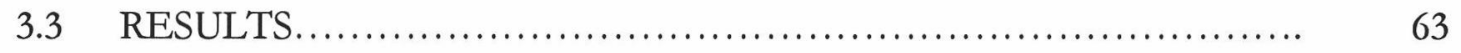

3.3.1 Population size and organisation........................... 63

3.3.1.1 Cacatua galerita roost sites............................ 63

3.3.1.2 Activity at the roost.............................. 65

3.3.1.3 Variation in population size of C. galerita................. 65

3.3.1.4 Diurnal variation in C. galerita numbers within the study area.......................................... 66

3.3.1.5 Monthly variation in C. galerita numbers recorded at roosts............................................. 68

3.3.1.6 Monthly variation in C. galerita population size............ 70

3.3.1.7 Cacatua galerita population changes associated with crop cycles and breeding............................. $\quad 70$

3.3.2 Movement patterns and feeding ranges of C. galerita............ 72 
3.3.2.1 Variation in size of C. galerita flocks leaving and entering the observation area................................

3.3.2.2 Flight paths and general patterns of movement of $C$. galerita........................................ 73

3.3.2.3 Cacatua galerita foraging distances..................... 80

3.3.3 Cacatua galerita flock size at foraging sites...................... 85

3.3.3.1 Diurnal variation in size of foraging flocks.............. 85

3.3.3.2 Seasonal variation in C. galerita foraging flock size........ 87

3.3.3.3 Variation in C. galerita foraging flock size in association with habitat................................... 87

3.3.3.4 Flock size in relation to different behavioural activities... $\quad 89$

3.3.4 The time-activity budget of C. galerita....................... 91

3.3.4.1 Variation in C. galerita behaviour...................... 91

3.3.4.2 Diurnal variation in C. galerita behaviour................. 91

3.3.4.3 Seasonal variation in C. galerita behaviour............... 94

3.3.4.4 Behaviours associated with habitat types.............. 96

3.3.4.5 Seasonal variation in energetic costs of activities of $C$. galerita........................................ 97

3.3.5 Habitat use by C. galerita.................................. 98

3.3.5.1 Habitat availability and variation in habitat use by $C$. 98 galerita.

3.3.5.2 Habitat patch use by C. galerita...................... 100

3.3.5.3 Breeding behaviour.............................. 100

3.3.5.4 Diurnal variation in C. galerita habitat use............... 106

3.3.6 Foraging ecology of C. galerita............................... 109

3.3.6.1 Food availability.................................. 109

3.3.6.2 Cacatua galerita feeding behaviour in maize............... 109

3.3.6.3 Diet of C. galerita................................. 111

3.3.6.4 Caloric counts of foods eaten by C. galerita.............. 116

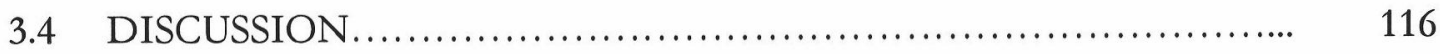

3.4.1 Population size........................................ 116

3.4.2 Factors affecting flock forming behaviour of C. galerita........... 117

3.4.3 Seasonal effects on behaviour, diet and numbers of C. galerita...... 118

3.4.4 Habitat use.......................................... 120

3.4.5 Breeding activity..................................... 121 
Chapter 4 The impact of sulphur-crested cockatoos (Cacatua galerita) on native bird and forest communities in the Turakina Valley

4.1 INTRODUCTION.

4.2 METHODS.

4.2 .1 Study area............................................. 127

4.2.2 Niche measures........................................ 128

4.2.3 Greenfall............................................... 130

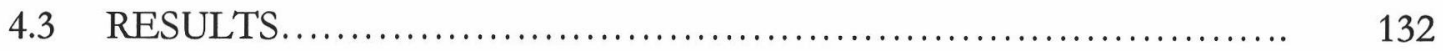

4.3.1 Habitat segregation of bird species in the Turakina Valley........ 132

4.3.1.1 Use of plant species................................ 132

4.3.1.2 Foraging heights............................... 138

4.3.1.3 Substrate......................................... 139

4.3.1.4 Niche breadth and overlap.......................... 142

4.3.2 Impact on native plant species............................ 143

4.3.2.1 Vegetation....................................... 143

4.3.2.2 Intensity of greenfall............................ 145

4.3.2.3 Intensity of cockatoo-caused greenfall................. 149

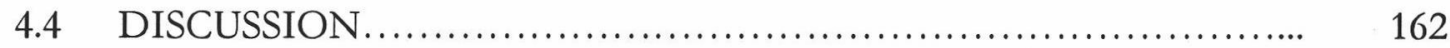

4.4.1 Competition............................................ 162

4.4.1.1 Foraging segregation of C. galerita, P. novaeseelandiae, $A$. melanura and $H$. novaeseelandiae........................ 162

4.4.1.2 Potential overlap between C. galerita and other native bird species in New Zealand.............................. 164

4.4.2 Impact on native vegetation............................. 165

4.4.2.1 The nature and extent of damage to native tree and shrub species by C. galerita............................... 165

4.4.2.2 Comparison of cockatoo-caused greenfall with other studies of litter-fall in New Zealand................. 167

4.4.3 Conclusion............................................. 169

Chapter 5 General summary and conclusion........................ 171

5.1 SUMMARY................................................ 171

5.1.1 The role of climate in defining the range of C. galerita........... 171 
5.1.1.1 Effects of temperature on distribution

5.1.1.2 Effects of cultivating land.

5.1.1.3 Gaps in the distribution of C. galerita in New Zealand and Australia.

5.1.2 Factors of C. galerita ecology affecting their distribution.

5.1.2.1 Advantages of flock forming behaviour for C. galerita.....

5.1.2.2 Use of native vegetation by $C$. galerita.................. 175

5.1.3 Impact on native forest ecosystems........................ 176

5.2 RECOMMENDATIONS....................................... 178

5.2.1 Limitations and achievements of the present study.............. 178

5.2.2 Recommendations for future research....................... 179

5.2.2.1 Breeding biology................................. 179

5.2.2.2 Banding studies................................ 179

5.2.2.3 Genetic analysis................................. 179

5.2.2.4 Basal metabolic rate.............................. 180

5.2.2.5 Foraging/diet studies............................. 180

Chapter 6 Options for the management of cockatoos in New Zealand.. 182

6.1 POTENTIAL IMPACTS OF COCKATOOS IN NEW ZEALAND..... 182

6.2 ISSUES RELATED TO COCKATOO MANAGEMENT.............. 183

6.2.1 The legal status of cockatoos in New Zealand................... 183

6.2.2 Population responses to control........................... 183

6.2.3 Public ownership of a highly mobile and valuable species........ 184

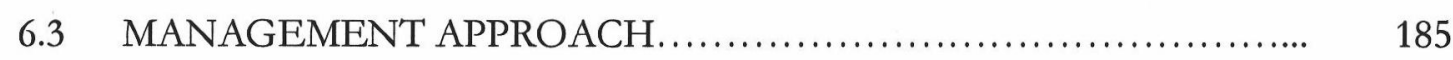

6.3.1 Options for the management of cockatoos..................... 185

6.3.1.1 Do nothing..................................... 186

6.3.1.2 Site management................................... 186

6.3.1.3 Species management.............................. 187

6.3.2 Methods of control...................................... 187

6.3.2.1 Shooting......................................... 188

6.3.2.2 Scaring devices.................................. 188

6.3.3.3 Farm management............................... 188

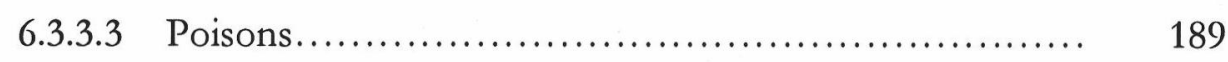

6.3.3.3 Traps......................................... 189 
References.

Appendix 1 Site records of sulphur-crested cockatoo (Cacatua galerita) and galah (C. roseicapilla) in New Zealand........................

Appendix 2 Variation in the number of cockatoos present in the vicinity of the Turakina Valley study area.....

Appendix 3 Vegetation composition of 100 plots in Sutherland's Bush

Reserve. 


\section{List of tables}

\section{Chapter 2}

Table 2.1 Habitat variables used to describe climate, topography, land-cover and agricultural features in Australia.

Table 2.2 Habitat variables used to describe climate, topography, land-cover and agricultural features in New Zealand...................... 17

Table 2.3 Single-variable logistic regressions using Australian data.......... 32

Table 2.4 Results of multiple regression analysis of presence-absence of C.g. galerita in Australia...................................... 33

Table 2.5 Single-variable logistic regression using New Zealand data........ 38

Table 2.6 Results of multiple regression analysis of presence-absence of $C$. galerita in New Zealand....................................... 39

\section{Chapter 3}

Table 3.1 Terms used to describe behaviour of C. galerita.................. 59

Table 3.2 Habitat types based on vegetational characteristics............... 60

Table 3.3 Energy content of plant parts........................... 62

Table 3.4 Roosts occupied by C. galerita in the Turakina Valley study area.... 64

Table 3.5a Number of C. galerita roosting at five observation areas (dawn)..... 68

Table 3.5b Number of C. galerita roosting at five observation areas (dusk)...... $\quad 68$

Table 3.6 Monthly record of the number of $C$. galerita entering and leaving

Sutherland's Bush roost and the surrounding Sutherland's observation area....................................... $\quad 85$

Table 3.7 Frequency of the various $C$. galerita flock sizes.................. 87

Table 3.8 Frequency of $C$. galerita activities recorded in each of five diurnal periods................................................. 94

Table 3.9 Frequency of C. galerita activities recorded in each season.......... 95

Table 3.10 Frequency of C. galerita activities recorded in each of seven habitat

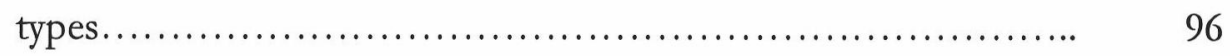

Table 3.11 The energetic costs of behaviours for C. galerita................. 97

Table 3.12 Breakdown of surface cover by habitat classification............. 99

Table 3.13 Nest sites of C. galerita in the Turakina Valley.................... 105

Table 3.14 Egg production by C. galerita in the Turakina and Pohangina Valleys................................................... 
Table 3.15 Plant species and species associations in which C. galerita were observed feeding.

Table 3.16 Estimated seasonal averages for daily intake by $C$. galerita..........

\section{Chapter 4}

Table 4.1 Habitat variables used to describe the foraging dimensions of $C$. galerita, P. novaeseelandiae, $A$. melanura and $H$. novaeseelandiae...........

Table 4.2 Plant species used by Prosthemadera novaeseelandiae, Anthornis melanura, Hemiphaga novaeseelandiae and Cacatua galerita............. 134

Table 4.3 Calculations of niche breadth and standardised niche breadth..... 142

Table 4.4 Competition coefficients..................................... 143

Table 4.5 Competition coefficients determined for seasonal overlap......... 144

Table 4.6 Average leaf weights of species contributing to greenfall.......... 147

Table 4.7 Contributions of plant species to unexplained and cockatoocaused greenfall.

Table 4.8 Comparison of mean monthly unexplained and cockatoo-caused greenfall. ....

Table 4.9 Measures of $C$. galerita use of Sutherland's Bush Reserve.

Table 4.10 Correlations between cockatoo-caused greenfall and abundance of plant species occurring in vegetation survey plots.

Table 4.11 Frequency of various branch sizes of podocarps contributing to the unexplained and cockatoo-caused greenfall.................. 


\section{List of figures}

\section{Chapter 2}

Figure 2.1 Distribution of Cacatua galerita in the North Island: key............ 21

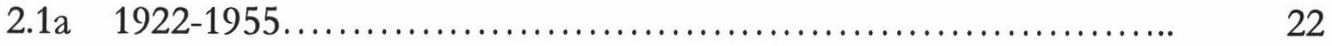

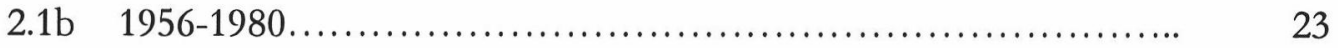

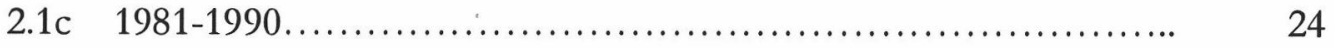

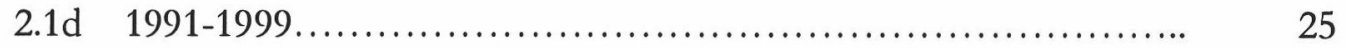

Figure 2.2 Distribution of Cacatua galerita in the South Island: key............. 27

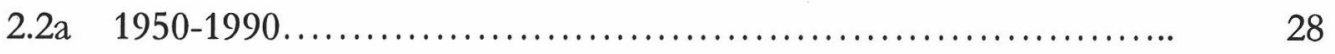

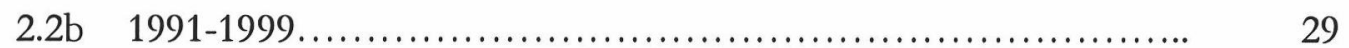

Figure 2.3 Distribution map, produced from field records, of Cacatua roseicapilla in the in New Zealand between 1959-1999..............

Figure 2.4 Percent of degree and quarter-degree blocks containing Cacatua galerita galerita along gradients of extreme and average daily maximum and minimum temperature.

Figure 2.5 Percent of degree and quarter-degree blocks containing Cacatua galerita galerita along gradients of average annual rainfall, altitude, vegetation and landuse.

Figure 2.6 Distribution map of Cacatua galerita galerita in Australia, produced by logistic modelling of presence-absence data....

Figure 2.7 Distribution map of Cacatua galerita in New Zealand, produced by logistic modelling of presence-absence data.

Figure 2.8 Possible patterns of Cacatua galerita dispersal in the North Island...

\section{Chapter 3}

Figure 3.1 Monthly variation in flock sizes of Cacatua galerita in New Zealand 52

Figure 3.2 Location of the Turakina Valley study area...................... 56

Figure 3.3 Location of six observation areas in the Turakina Valley study site 58

Figure 3.4 Variation in the active day of Cacatua galerita....................... 67

Figure 3.5 Diurnal variation in the mean number of birds present in the study area..................................................... 69

Figure 3.6 Number of Cacatua galerita present in the Turakina Valley study area 71

Figure 3.7 Diurnal variation in the size of flocks of Cacatua galerita............ 74

Figure 3.8 Seasonal variation in the size of flocks of Cacatua galerita........... 75 
Figure 3.9 Diurnal variation in the use of flight paths by Cacatua galerita: key... 76

3.9a Early morning...................................... 77

3.9b Late morning......................................... 77

3.9c Mid-day.............................................. 78

3.9d Mid-afternoon......................................... 78

3.9e Late afternoon......................................... 79

Figure 3.10 Seasonal variation in the use of flight paths by Cacatua galerita: key.. 81

$3.10 \mathrm{a} \quad$ Late spring............................................. 82

3.10b Summer........................................... 82

3.10c Autumn................................................ 83

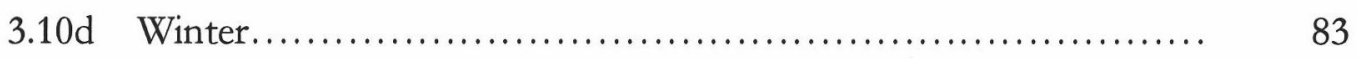

$3.10 \mathrm{e} \quad$ Early spring.......................................... 84

Figure 3.11 Diurnal variation in the number of Cacatua galerita seen foraging together.

Figure 3.12 Seasonal variation in the number of Cacatua galerita seen foraging together

Figure 3.13 Variation in the size of flocks seen feeding, resting and flying.....

Figure 3.14 Seasonal variation in the habitats used by Cacatua galerita...........

Figure 3.15 Seasonal variation in the diurnal activity of Cacatua galerita......... 93

Figure 3.16 Patches of habitat used by foraging groups of Cacatua galerita: key.. 101

$3.16 \mathrm{a}$ Late spring.......................................... 102

3.16b Summer.............................................. 102

$3.16 \mathrm{c}$ Autumn.............................................. 103

3.16d Winter............................................... 103

$3.16 \mathrm{e}$ Early spring.......................................... 104

Figure 3.17 Diurnal variation in habitat used by Cacatua galerita............... 107

Figure 3.18 Diurnal variation in the distribution of feeding observations of Cacatua galerita. .

Figure 3.19 Flowering and fruiting times of some plant species exploited by

Cacatua galerita.

\section{Chapter 4}

Figure 4.1 Approximate layout of vegetation survey lines and plot markers in Sutherland's Bush Reserve. 
Figure 4.2 Foraging height distribution of four bird species in the Turakina

Valley....

Figure 4.3 Foraging substrates used by four species of bird in the Turakina

Valley.

Figure 4.4 Distribution of large podocarp trees and different vegetation types in Sutherland's Bush Reserve.

Figure 4.5 Distribution of greenfall in Sutherland's Bush Reserve.

Figure 4.6 Average monthly dry weights of greenfall.

Figure 4.7 Distribution of cockatoo-caused greenfall in Sutherland's Bush

Reserve 


\section{Chapter 1}

\section{General introduction}

The native New Zealand parrots include twelve species and subspecies belonging to three genera in the family Psittacidae, five of which are found on offshore islands only (Turbott 1990; Boon et al. submitted). Most are arboreal herbivores, frugivores and insectivores (Atkinson and Millener 1991; O'Donnell and Dilks 1994; Moorehouse 1997; Greene 1998a). All of the main island species have suffered severe range decreases and population declines following human settlement of New Zealand, particularly during the European phase of colonisation (Forshaw 1989; Heather and Robertson 1996). At the same time five parrot species have colonised New Zealand, of which two (sulphur-crested cockatoo, Cacatua galerita, and eastern rosella, Platycercus eximius) have become widespread. Platycercus eximius favour lightly wooded farmland, but may also enter dense forest, occupying a similar habitat to redcrowned parakeets (Cyanorampbus novaezelandiae novaezelandiae) (Greene 1998a; Wright and Clout 2001). Cacatua galerita favour open farmland and have no ecologically functional equivalents in the native bird fauna of New Zealand. The invasion of New Zealand by grassland species, such as cockatoos, reflects broad changes in the landscape here.

\subsection{COLONISING SPECIES}

A major concern for conservation in New Zealand is the potential for introduced (exotic) species to displace native species and possibly to alter the disturbance regimes, or the community structure, in often fragmented native habitats. New Zealand has been inundated with a suite of exotic flora and fauna introduced over the last 150 years, the result of deliberate human action or through natural range expansion, following changes to the landscape resulting from human activities (Thomson 1922; Mayr 1965; Diamond and Veitch 1981; King 1984; Bell 1991). The majority of 'new' species originate from the Northern Hemisphere (Thomson 1922; Fleming 1962; Williams 1973; Godley 1975; Long 1981; King 1984), whereas much of the indigenous fauna of New Zealand has its origin in Australia, and Australia continues to be a significant contributor of those species becoming established (Falla 1953; Fleming 1962; Wodzicki 1965; Bull and Whitaker 1975; Forster 1975; Watt 1975; King 1984; Bell 1991). 
Why should so many species successfully colonise New Zealand? Rapid turnover of faunal communities is characteristic of islands (Mayr 1965; Lodge 1993a, 1993b; Vitousek et al. 1997), though floral communities in old insular areas, such as New Zealand, tend to suffer very limited replacement (Mayr 1965). The recent series of colonisations differ from the past because they include replacement of native floral communities with wholly exotic communities over a large area (Healy and Edgar 1980; Webb et al. 1988). The extensive and concerted alteration of the landscape and spreading of exotic flora by humans has produced habitat types new to New Zealand.

The paucity of a characteristic open country fauna suggests that, other than in the inland Otago region and alpine zones, there was no continuing history of non-forested land in New Zealand prior to human colonisation (McKlay 1974; Forster 1975; Watt 1975; Holdaway 1990). Now approximately $50 \%$ of the land surface is open country or modified grassland, the most extensive changes coming from the fragmentation and clearance of lowland and coastal forests (Wodzicki 1965; Godley 1975; Salmon 1975; Ward 1976; King 1984, 1990). These changes, while contributing to the extinction or range contraction of many endemic species, may nevertheless have created new and favourable conditions for the successful establishment of a diverse new fauna.

By far the majority of exotic species are found in the lowland and more highly disturbed habitats (Bull and Whitaker 1975; Diamond and Veitch 1981; Townsend 1991; Daugherty et al. 1993). Wodzicki (1965) found that seventy five percent of the established bird species inhabited modified environments only, and none were found in native habitats only. Studies by McKlay (1974), Diamond and Veitch (1981) and Holdaway (1990) have shown that invading bird species were uncommon in undisturbed native habitats, but that the proportion of exotic species increased with an increasing level of disturbance to the environment.

While some introduced species have received considerable research attention, there are many others about which very little is known. Of greatest concern are those species that have spread throughout a wide range of habitats within New Zealand and are seen to be having detrimental effects on its native biota and/or agriculture (Townsend 1991). For economic and conservation reasons mammalian species have received most attention from researchers. Also well studied are game species, including both mammals and birds (Williams 1983). Many species have been overlooked or have not yet been considered a sufficient threat to the native environment or to agriculture to warrant attention from researchers. Introduced birds, through their numbers, variety and habits, contribute to the modification of New Zealand's 
native ecological communities and also have a significant impact on agricultural and horticultural production. Although several agriculturally significant species of birds have been studied, for example the common myna (Acridotberes tristis) (Wilson 1973), rook (Corrus frugilegus) (Purchase 1973) and starling (Sturnus vulgaris) (Coleman 1977), there are many more for which only limited distributional and ecological data have been recorded.

\subsubsection{The introduced parrots of New Zealand}

In 1872, Captain F. W. Hutton wrote "It is remarkable that we have no representatives of the cockatoos and grass-paroquets so common in Australia and Tasmania, for our own climate is quite suitable for them". Over the last 150 years five species of Australian parrots have become established in New Zealand. They are P. eximius, crimson rosella (P. elegans), rainbow lorikeet (Trichoglossus baematodus) (family Psittacidae), and C. galerita and galah (C. roseicapilla) (family Cacatuidae) (Heather and Robertson 1996; Greene 1998b). These species are found on the two main islands and some inshore islands in the Hauraki Gulf (Turbott 1990; Heather and Robertson 1996; Greene 1998b; Higgins 1999). Like the majority of native parrots, the introduced rosellas and lorikeet eat a combination of foliage, fruit, seeds, nectar and insects (Higgins 1999). The cockatoos represent a guild new to the New Zealand avian fauna (granivorous, arid adapted and largely terrestrial: Homberger 1991).

There are 18 species of cockatoo, all of which occur naturally in Australia, Indonesia and Melanesia (Forshaw 1989). Cockatoos are large thickset birds with short tails, heavy bills and moveable conspicuous crests, body lengths ranging from $350 \mathrm{~mm}$ to $690 \mathrm{~mm}$ between the smallest and largest species (Forshaw 1989). Raiding introduced crops, orchards and exotic plantations is not uncommon among cockatoos, of which eight species, including C. galerita and C. roesicapilla, are considered pests in Australia (Pigeon 1970; Saunders 1974; Bennett 1978, in Noske 1980; Noske 1980; Halse 1986; Temby and Emison 1986; Anderson 1996).

The preferred natural habitat of $C$. galerita is tall open forest, riverine woodland and tall sclerophyll forest, with access to grassland (Bennett 1978, in Noske 1980). Greatest densities are reached where there is a mosaic of open woodland and cultivated grassland communities (Noske 1980; Forshaw 1989). The diet of C. galerita consists predominantly of seeds, but they also have been recorded feeding on fruit, nuts, bulbous roots (tubers), bulbs, corms, rhizomes, young shoots, flowering heads, and nectar; algae (Durvillea sp., Macrocystis augustifolia); fungi; and the larvae and eggs of Coleoptera, Diptera, Hymenoptera and Orthoptera (Noske 1980; Halse 1986; Lepschi 1993; Higgins 1999). Due to extensive 
clearing and modification of their original habitat, many populations have been forced to supplement their diet from alternative sources, such as seed from introduced weed species and cereal crops (Noske 1980; Emison and Nicholls 1992). During the breeding season, May to September in the north of Australia and August to January in the south, C. galerita move in pairs or small family parties within a home range (Forshaw 1989). Most of their resource requirements are obtained from native habitats within this range (Bennett 1978 in Noske 1980). During winter the small parties concentrate into flocks that can contain hundreds of individuals (Forshaw 1989). It is at this time of year that seeds from introduced crops are ripening and can constitute the bulk of the diet of the birds (Noske 1980).

Typical habitat of C. roseicapilla in Australia is semi-arid to arid savannah woodland, open grassland and cultivated farmland (Pigeon 1970; Forshaw 1989). Cacatua roseicapilla are predominantly ground feeders, their diet consisting mostly of seeds, corms and rhizomes (Pigeon 1970; Forshaw 1989). They are less gregarious than C. galerita and are most frequently seen in pairs or small flocks but sometimes aggregate into flocks containing hundreds of birds (Forshaw 1989).

\subsubsection{Predicting the range and impact of $C$. galerita in New Zealand}

Cacatua galerita occupy a wide native range (C. g. galerita from $10^{\circ}$ to $44^{\circ}$ south) and are present from sea level to the tallest mountain ranges of eastern Australia (Blakers et al. 1984). Human-made modificatons to the environment, including clearance of forest and planting cereal crops, have resulted in the expansion of their range in eastern Australia (Noske 1980; Higgins 1999). They have also proven to be successful colonisers, establishing new populations on islands in New Guinea and Indonesia, Western Australia and New Zealand (Higgins 1999).

Cacatua roseicapilla occupy nearly all of continental Australia, only absent from the central deserts, though are uncommon in heavily forested areas (Blakers et al. 1984). Introduction of grain crops, particularly wheat, and possibly improved water supplies for stock have allowed considerable recent extensions in the range of this species (Pigeon 1970). They have also successfully colonised Tasmania (human introductions bolstering natural recent immigration) and New Zealand (Higgins 1999).

In Australia range size of introduced birds was significantly related to number released and number of introduction attempts and also to presence of climatically suitable habitat (Duncan 
et al. 2001). Climatic variables, such as temperature, are generally accepted as the primary forces shaping species' ranges (Root 1988b; Gentilli 1992; Lodge 1993a; Duncan et al. 2001), and are important in determining invasion success. Studies in California of fish (Moyle and Light 1996), Argentine ant (Linepithema bumile) (Holway 1998), and Mediterranean fruit fly (Ceratitis capitata) (Carey 1996b) invasions suggest that if abiotic factors are appropriate for an exotic species, then that species is likely to successfully invade, regardless of the biota already present.

Establishment of birds in New Zealand has been assessed in relation to number introduced, life history traits, presence of plumage dichromatism and geographic range and habitat use in their country of origin (Veltman et al. 1996; Duncan 1997; Green 1997; Sorci et al. 1998; Legendre et al. 1999). Successful establishment was related closely to greater propagule size. Of secondary importance were life history traits (including high fecundity and small body size), having monochromatic plumage and presence of suitable habitat (as measured by surface area of similar habitat). In a related study, range size of birds introduced to New Zealand was most closely associated to the number released and number of introduction attempts, and secondarily the presence of suitable habitat and having a greater range size overseas (Duncan et al. 1999).

There are no written records of the number released or number of introduction attempts (accidental and intentional) of C. galerita or for C. roseicapilla in New Zealand. Clearly sufficient birds were released, or sufficient attempts made to start several populations, but there is no information available for predicting the pattern of invasion (that is, their potential range) or of the consequences of this invasion.

In this study I intend to address the following questions:

1. Is climate the most important determinant of $C$. galerita range limit, and if not, what factor(s) are important in defining C. galerita distribution?

2. What factors of $C$. galerita ecology affect their habitat selection and distribution?

3. What is the impact of $C$. galerita on native forest ecosystems within their range?

\subsubsection{Structure of the thesis}

This thesis is divided into six chapters. The current chapter (chapter 1) provides a preamble to the introduced birds of New Zealand, focusing on C. galerita (the subject of this study) and introduces the main questions dealt with by this research. The following three (results) 
chapters address one or more of these questions as well as providing general ecological information on this species. The main questions addressed by each of these chapters are as follows.

Chapter 2 brings together distributional records of C. galerita and C. roseicapilla in New Zealand. This and similar distributional information for C. galerita in Australia are examined in order to determine which underlying environmental characteristics are important in defining their distribution. The following hypotheses are used to address the questions of (1) importance of temperature in defining distribution of C. galerita; (2) other factors important in defining their distribution; and (3) their response to these variables.

\section{Hypothesis 2.1}

Characteristics of the environment that effect C. g. galerita distribution in Australia will also affect the range limits of the species in New Zealand.

\section{- Prediction 1}

- Upper and lower temperature limits to C. g. galerita distribution in Australia will define the range of this species in New Zealand.

\section{- Prediction 2}

- Cacatua galerita will be limited by the availability of vegetation suitable for a seed eating bird that spends most time foraging on the ground. In New Zealand this habitat will be provided by the grasses and arable crops available on farmland.

\section{Hypothesis 2.2}

Cacatua galerita will occupy all blocks with suitable habitat in Australia and New Zealand.

- Prediction

- Cacatua galerita will only be seen in blocks where the environment is suitable for their existence and all blocks of this habitat will be occupied.

Chapter 3 examines the aspects of $C$. galerita ecology that relate to the environmental factors that effect their distribution. In this chapter I report on fluctuations in flock size and activity, habitat use, feeding behaviour and foods of $C$. galerita in the Turakina Valley, Manawatu- 
Wanganui, and also examine the adaptations, such as flock forming behaviour and exploitation of arable land, used by $C$. galerita to overcome the greater energetic costs of winter. These questions will be addressed by the following hypotheses.

\section{Hypothesis 3.1}

Flock forming behaviour of C. galerita is an adaptation to feeding on temporally available and localised food sources.

- Prediction

- Increase in flock forming behaviour will be associated with feeding on temporally available and localised food. Conversely, decrease in flocking will be associated with feeding on widespread food sources.

\section{Hypothesis 3.2}

Increased costs of thermoregulation in winter will be met by a change in behaviour; to conserve energy, or find more food by either investing more time searching or by switching to a more energy rich and/or abundant food source.

- Prediction 1

- To meet the increased thermoregulatory costs of winter, C. galerita will increase the proportion of time spent resting and decrease time spent in other behaviours.

- Prediction 2

- To meet the increased thermoregulatory costs of winter, C. galerita will increase the proportion of time spent feeding and decrease time spent in behaviour not associated with feeding.

- Prediction 3

- To meet the increased thermoregulatory costs of winter, C. galerita will switch to a more energy rich and/or abundant food source.

Hypothesis 3.3

Most resource requirements for C. galerita will be provided by modified (non-native) environments. 
- Prediction

- Being largely granivorous, C. galerita will obtain most food from agricultural land.

Chapter 4 examines the impact of $C$. galerita on native forest ecosystems in New Zealand. Impact of C. galerita is evaluated by their overlap in resource use with three native bird species (tui Prosthemadera novaeseelandiae, bellbird Anthornis melanura and New Zealand pigeon Hemiphaga novaeseelandiae), and the nature and extent of their impact on native tree and shrub species in forest remnants in the Turakina Valley. The impact of $C$. galerita is addressed by the following hypotheses.

\section{Hypothesis 4.1}

The food requirements of $C$. galerita are obtained from introduced plants located on farmland.

- Prediction 1

- Cacatua galerita diet will consist of seed from arable crops and pasture plants (grasses and introduced pasture weeds, such as thistles).

- Prediction 2

- Recause most of their food is ódtained from modified '(non-native) environinents and mostly from the ground, C. galerita will not compete with native forest birds for food and/or foraging sites.

Hypothesis 4.2

Cacatua galerita do not significantly impact on native forest tree and shrub species.

- Prediction 1

- Impact on native tree species will be restricted to emergent podocarp trees greater than $15 \mathrm{~m}$ in height.

- Prediction 2

- The impact of C. galerita will not be sufficient to affect survival of individual trees or forest structure. 
Chapter 5 is the general discussion and reviews the significance of the study as a whole; the theories presented in Chapter One; and suggests possible future areas of research.

Chapter 6 outlines issues relating to the public attitudes towards these birds and their impact (on conservation values and agricultural production). Advantages and disadvantages of various management options available for controlling the impacts of $C$. galerita (and $C$. roseicapilla) are presented. 


\section{Chapter 2}

\section{The geographic distribution of the sulphur-crested cockatoo (Cacatua galerita) in Australia and New Zealand}

\subsection{INTRODUCTION}

The sulphur-crested cockatoo (Cacatua galerita) is a native of Australia, Tasmania, New Guinea and the Aru Islands of Indonesia (Frith 1977; Long 1981; Blakers et al. 1984; Forshaw 1989). Four subspecies of C. galerita have been recognised (Forshaw 1989). Cacatua g. fittroyii occurs across northern Australia to the Gulf of Carpentaria, and C. g. galerita occurs in eastern Australia from northern Queensland to southeast South Australia and Tasmania. Cacatua g. eleonora and C. g. triton occur in Indo-Malaya. Forshaw (1989) suggests that C. g. galerita is "almost certainly the race introduced to New Zealand".

Cockatoos in Australia have proven capable of adapting to novel environments (Pigeon 1970; Saunders 1974, 1980; Temby and Emison 1986; Emison and Nicholls 1992; Andreson 1996). Land clearance, cropping, grazing and other agricultural practices have resulted in range contractions and expansions of $C$. galerita throughout their native range, while direct intervention by humans has led to its successful introduction to Western Australia, several small islands in Indonesia and the Pacific, and to New Zealand (Long 1981; Forshaw 1989; Higgins 1999).

Cacatua galerita were first recorded in New Zealand by Thomson (1922) who noted that "this species is frequently to be seen on the Waitakere Ranges (Auckland), where it appears to have established itself'. Further populations were later recorded at Wellsford and the Hunua Ranges (Auckland), Glen Murray and Onewhero (Waikato), the Turakina Valley (ManawatuWanganui) and in the Wainuiomata Valley (Wellington) (Oliver 1930, 1955; Classified Summarised Notes (CSN) 1950). Most of these populations were attributed to released, or escaped, caged birds (Bull et al. 1985), although some populations may have resulted partly from wind-assisted immigrants blown across from Australia (Waller 1959; Lever 1987).

Published records of distribution up to 1985 indicated that $C$. galerita were restricted to much the same range as the earlier reported populations. That is, in Auckland and the Western 
Waikato, and in the watersheds of the Turakina and Rangitikei rivers, with small groups, or single birds, in Northland (Waller 1959; Martin 1962; Martin and Bartlett 1963; Bull et al. 1985; CSN). Since the early 1980s there has been an increase in the area over which the species has been reported, including its appearance in the east of the North Island, Wellington, and in the South Island at Banks Peninsula (Canterbury), the Catlins (OtagoSouthland) and Greymouth (West Coast) (Heather and Robertson 1996; CSN). Over the same period a second species of cockatoo (the galah, C. roseicapilla) has become established in the Waikato and around the western edge of the Hauraki Gulf (Auckland), and a single bird was reported from Winchmore (Canterbury) (CSN 1995).

Environmental factors, such as temperature and rainfall, are important in demarcating species ranges by directly acting on physiological tolerances or through their influence on vegetation (Wardle 1981; Root 1988a, 1988b; Gentilli 1992; Crist 1998). Some species are highly habitat specific and thus are limited by the distribution of their favoured habitat (Gibbons et al. 1995), while others may be limited by climate (Caughley et al. 1987; Root 1988a, 1988b). The distributions of many species will be limited by a combination of several factors. If a species distribution is to be understood it is essential to know what habitat factors are influencing them. This information can also allow us to make predictions about the potential range limits of species that are invading into a region with a different and/or overlapping geophysical environment to their environment of origin.

Methods used to measure the affect of mapped environmental variables on species distribution include classification trees (Walker 1990), the generalised linear family of regression (Ben-Shahar and Skinner 1988; Walker 1990; Osborne and Tigar 1992; Buckland and Elston 1993; Gates et al. 1994; Gibbons et al. 1995; Augustin et al. 2001; Pearce et al. 2001), discriminant functions (Caughley et al. 1987), principal components analysis (Brown and Stillman 1993) and correspondence analysis (Ben-Shahar and Skinner 1988). Most studies of factors underlying avian distributions have been undertaken on a limited geographic scale, often within the species range (Osborne and Tigar 1992; Brown and Stillman 1993; Gibbons et al. 1994). In these studies characteristics of vegetation (often on a fine scale), nest site availability and recording effort were important determinants of range.

On a broader geographic scale, climatic variables, such as temperature, are generally accepted as the primary forces shaping species' ranges (Root 1988b; Gentilli 1992; Lodge 1993a; Duncan et al. 2001), and are important in determining invasion success (Lodge 1993a; Carey 1996b; Moyle and Light 1996; Holway 1998). Root (1988a) found that $60.2 \%$ of avian 
species in the Continental United States had range limits associated with temperature, although characteristics of vegetation, and secondarily precipitation, were most frequently associated with the range limits of seed eating birds. Distribution patterns were linked to the physiological demands of maintaining Basal Metabolic Rate in the face of colder temperatures (Root 1988b). Wilson (1973) suggests common myna (Acridotheres tristis) are limited to north of $40^{\circ}$ latitude in New Zealand because the shorter summers further south limited the period of peak food production (measured by abundance of invertebrates) so restricting the birds' ability to successfully rear chicks. Gentilli (1992) showed significant relationship between species' ranges and rainfall, which defined characteristics of vegetation diversity and height, however, the effect of temperature on species ranges was not considered in this study.

In this chapter I shall determine the extent to which C. galerita and C. roseicapilla are established in New Zealand. I will also present evidence of the affect that abiotic environmental variables, and broad-scaled characteristics of vegetation and disturbance (human landuse) have on C. galerita distribution in Australia and New Zealand. The evaluation of $C$. galerita distribution is intended to provide greater understanding of this species' range and invasion success. The following hypotheses are intended to address the questions raised in this chapter.

\section{Hypothesis 2.1}

Characteristics of the environment that effect C. g. galerita distribution in Australia will also affect the range limits of the species in New Zealand.

\section{- Prediction 1}

- Upper and lower temperature limits to C. g. galerita distribution in Australia will define the range of this species in New Zealand.

- Prediction 2

- Cacatua galerita will be limited by the availability of vegetation suitable for a seed eating bird that spends most time foraging on the ground. In New Zealand this habitat will be provided by the grasses and arable crops available on farmland. 
Hypothesis 2.2

Cacatua galerita will occupy all blocks with suitable habitat in Australia and New Zealand.

- Prediction

- Cacatua galerita will only be seen in blocks where the environment is suitable for their existence and all blocks of this habitat will be occupied.

\subsection{METHODS}

\subsubsection{Cockatoo distribution data}

Data on C. galerita distribution in Australia were taken from the Royal Australian Ornithologists Union The Atlas of Australian Birds (Blakers et al. 1984). The distribution of C. g. galerita was separated from the other races of $C$. galerita according to the information on species ranges in Forshaw (1989). For the logistic regression, simple presence-absence data were recorded in each of 805 degree blocks (one-degree latitude by one-degree longitude) used for the construction of the Australian bird atlas. Records of $C$. galerita from Western Australia were not used when fitting models.

The distribution of cockatoos in New Zealand was obtained from unpublished and published records, mainly CSN, but also from observations of other authors (Thomson 1922; Oliver 1930, 1955; Waller 1959; Martin 1962; Martin and Bartlett 1963; Bull et al. 1985; Buckingham 1989; Speirs 1989) and is provided in Appendix 1. The grid reference (latitude, longitude) was determined for each record when the place-name given could be located, and the year, month and number of birds seen were also included when this information was provided. From these data a composite map of C. galerita and C. roseicapilla distribution was constructed. For logistic regression, C. galerita were scored as present or absent in each of 626 quarterdegree blocks covering New Zealand and the larger near-shore islands.

Presence/absence data were used in modelling C. galerita distribution because there was no record of abundance in The Atlas of Australian Birds (Blakers et al. 1984). Furthermore, recorded observations of $C$. galerita in New Zealand were incidental and were not an accurate reflection of the population present in an area. Discrimination on the grounds of presence of breeding populations could not be used because there are no published records of $C$. galerita breeding in New Zealand. 


\subsubsection{Environmental data}

Environmental data were derived from maps of Australia and New Zealand available in published literature. These maps were then digitised and a pre-formatted one-degree (Australia) or quarter-degree (New Zealand) grid was overlaid. Eighteen environmental variables from Australia (Table 2.1) and 17 from New Zealand (Table 2.2) were measured from these maps in the following way. For continuous features, such as climate, altitude, vegetation and landuse, the dominant category in the block was scored. Other variables were classified according to the presence or absence of species or dominant structural features, such as intensity of landuse by humans and broad-scaled vegetational characteristics. These particular variables were chosen partly because it was thought that they might affect bird distributions at this scale but also because the maps were readily available. The same variables were used for Australia and New Zealand, in most cases, to allow closer comparison of $C$. galerita distribution between the two countries.

\subsubsection{Data analysis}

The effect of environmental variables on C. galerita distribution was estimated using binomial logistic regression (Hosmer and Lemshow 1989; Christensen 1997). This form of regression uses a linear combination of independent variables to explain the variance in a dependent variable having only two states. Here the dependent variable was the presence or absence of C. galerita. Logistic regression has the advantage of being able to use variables with uneven precision, such as environmental variables measured at different geographic scales, allows both continuous and discrete data to be used and can predict the level of effect rather than simply the correlation between variables.

Logistic regression generates a value constrained between 0 and 1 for each square, which may be regarded as the probability of occurrence of, in this instance, C. galerita. A species might be expected to exhibit physiological tolerance over part of the gradient, decreasing tolerance once the threshold has been reached and then intolerance over the remainder, thus producing a sigmoid-type curve (Osborne and Tigar 1992). Where variables are non-linearly related to the dependent variable logistic regression has the advantage of applying a logit transformation to the data (Walker 1990). In many cases the logit transformation may linearise the relationship; and in other cases may convert an asymmetric peaked relationship 
into a symmetrical one, to which a Gaussian response curve can then be fitted, allowing the assumption of normality to be met.

Statistica (Statsoft 1994) and SPSS (SPSS 1999) software packages were used to fit the models.

Each of the following procedures were run twice, first with Australian data and then with the New Zealand data.

\subsubsection{Univariate regression}

Univariate regressions of the presence-absence data on each of the environmental variables were calculated. The predictive accuracy of each variable was assessed using a coefficient of determination $\left(\mathrm{R}^{2}\right)$ and a chi-square test (Wald Statistic) on the variation of the regression coefficient. The shape of the relationship between the presence of $C$. galerita (C. g. galerita in Australia) and each of the environmental variables was determined from the regression coefficients.

\subsubsection{Multiple regression}

Presence/absence models were fitted to the complete data set using a generalized additive procedure (Bowerman et al. 1986; SPSS 1999), with forward stepwise selection of variables. For the Australian dataset all combinations of 2 variable models were fitted.

Table 2.1. Habitat variables used to describe climate, topography, landcover and agricultural features of Australia.

\begin{tabular}{|c|c|c|}
\hline Variable & Meaning & Source \\
\hline $\min T$ & $\begin{array}{l}\text { Extreme minimum temperature (1961- } \\
\text { 1990). }\end{array}$ & $\begin{array}{l}\text { Australian Bureau of Meteorology } \\
\text { (no date) }\end{array}$ \\
\hline$x \min$ & $\begin{array}{l}\text { Average daily minimum temperature (1961- } \\
\text { 1990). }\end{array}$ & $\begin{array}{l}\text { Australian Bureau of Meteorology } \\
\text { (no date) }\end{array}$ \\
\hline $\max T$ & $\begin{array}{l}\text { Extreme maximum temperature (1961- } \\
\text { 1990). }\end{array}$ & $\begin{array}{l}\text { Australian Bureau of Meteorology } \\
\text { (no date) }\end{array}$ \\
\hline$x \max$ & Average daily maximum temperature (1961- & Australian Bureau of Meteorology \\
\hline
\end{tabular}




\begin{tabular}{|c|c|c|}
\hline & 1990). & (no date) \\
\hline rain & Average annual rainfall (1961-1990). & $\begin{array}{l}\text { Australian Bureau of Meteorology } \\
\text { (no date) }\end{array}$ \\
\hline alt & $\begin{array}{l}\text { Dominant altitude category within square. } \\
\text { The five categories were: }<0 \mathrm{~m} ; 0-200 \mathrm{~m} \text {; } \\
\text { 200-400 m; 400-1000 m; 1000-2000 m; and } \\
>2000 \mathrm{~m} \text {. }\end{array}$ & Anon 1998 \\
\hline veg & $\begin{array}{l}\text { Dominant vegetation category within square } \\
\text { (from 1780s vegetation cover). The four } \\
\text { categories were: grassland and sedgeland, } \\
\text { herbland and unvegetated salt lakes; scrub } \\
\text { and heath, shrubland and open shrubland; } \\
\text { open woodland; and closed forest, open } \\
\text { forest and woodland. }\end{array}$ & Anon 1990 \\
\hline grass-herb & $\begin{array}{l}\text { Presence or absence of grassland and } \\
\text { sedgeland, herbland or unvegetated salt } \\
\text { lakes within square. }\end{array}$ & Anon 1990 \\
\hline scrub-heath & $\begin{array}{l}\text { Presence or absence of scrub and heath, } \\
\text { shrubland or open shrubland within } \\
\text { square. }\end{array}$ & Anon 1990 \\
\hline open woodland & $\begin{array}{l}\text { Presence or absenceof open woodland } \\
\text { within square. }\end{array}$ & Anon 1990 \\
\hline forest & $\begin{array}{l}\text { Presence or absence of closed forest, open } \\
\text { forest or woodland within square. }\end{array}$ & Anon 1990 \\
\hline Landuse & $\begin{array}{l}\text { Dominant landuse category within square. } \\
\text { The three categories were: non-agricultural; } \\
\text { pastoral; and arable. }\end{array}$ & Plumb (1982) \\
\hline$c r o p$ & $\begin{array}{l}\text { Presence or absence of outdoor horticulture } \\
\text { within square. }\end{array}$ & Plumb (1982) \\
\hline fstry & $\begin{array}{l}\text { Presence or absence of exotic forest } \\
\text { plantations within square. }\end{array}$ & Plumb (1982) \\
\hline wheat & $\begin{array}{l}\text { Presence or absence of wheat (Triticum spp.) } \\
\text { crops within square. }\end{array}$ & Plumb (1982) \\
\hline pink & $\begin{array}{l}\text { Presence or absence of Cacatua leadbeateri } \\
\text { within square. }\end{array}$ & $\begin{array}{l}\text { Blakers et al. (1984) The Atlas of } \\
\text { Australian Birds }\end{array}$ \\
\hline corella & $\begin{array}{l}\text { Presence or absence of } C \text {. sangrinea within } \\
\text { square. }\end{array}$ & $\begin{array}{l}\text { Blakers et al. (1984) The Atlas of } \\
\text { Australian Birds }\end{array}$ \\
\hline galah & $\begin{array}{l}\text { Presence or absence of } C \text {. roseicapilla within } \\
\text { square. }\end{array}$ & $\begin{array}{l}\text { Blakers et al. (1984) The Atlas of } \\
\text { Australian Birds }\end{array}$ \\
\hline
\end{tabular}


Table 2.2. Habitat variables used to describe climate, topography, landcover and agricultural features of New Zealand.

\begin{tabular}{|c|c|c|}
\hline Variable & Meaning & Source \\
\hline $\min T$ & $\begin{array}{l}\text { Extreme minimum temperature (1961- } \\
\text { 1990). }\end{array}$ & $\begin{array}{l}\text { National Institute of Water and } \\
\text { Atmospheric Research, New } \\
\text { Zealand }\end{array}$ \\
\hline$x$ min & $\begin{array}{l}\text { Average daily minimum temperature (1961- } \\
\text { 1990). }\end{array}$ & $\begin{array}{l}\text { National Institute of Water and } \\
\text { Atmospheric Research, New } \\
\text { Zealand }\end{array}$ \\
\hline $\max T$ & $\begin{array}{l}\text { Extreme maximum temperature (1961- } \\
\text { 1990). }\end{array}$ & $\begin{array}{l}\text { National Institute of Water and } \\
\text { Atmospheric Research, New } \\
\text { Zealand }\end{array}$ \\
\hline$x \max$ & $\begin{array}{l}\text { Average daily maximum temperature (1961- } \\
\text { 1990). }\end{array}$ & $\begin{array}{l}\text { National Institute of Water and } \\
\text { Atmospheric Research, New } \\
\text { Zealand }\end{array}$ \\
\hline rain & Average annual rainfall (1961-1990). & $\begin{array}{l}\text { National Institute of Water and } \\
\text { Atmospheric Research, New } \\
\text { Zealand }\end{array}$ \\
\hline alt & $\begin{array}{l}\text { Dominant altitude category within square. } \\
\text { The five categories were: }<0 \text { m; 0-200 m; } \\
\text { 200-400 m; } 400-1000 \mathrm{~m} ; 1000-2000 \mathrm{~m} \text {; and } \\
>2000 \mathrm{~m} \text {. }\end{array}$ & Anon (1998) \\
\hline veg & $\begin{array}{l}\text { Dominant vegetation category within square } \\
\text { (from } 1780 \text { s vegetation cover). The four } \\
\text { categories were: grassland, herbfield and } \\
\text { no vegetation; scrubland; grassland and } \\
\text { forest; and forest. }\end{array}$ & Kirkpatrick (1999) \\
\hline grass-berb & $\begin{array}{l}\text { Presence or absence of pasture, tussock } \\
\text { grassland, alpine herbfields, dune } \\
\text { vegetation or no vegetation within square. }\end{array}$ & Kirkpatrick (1999) \\
\hline scrub-heath & $\begin{array}{l}\text { Presence or absence of scrubland, grassland } \\
\text { and scrub or forest and scrub within } \\
\text { square. }\end{array}$ & Kirkpatrick (1999) \\
\hline $\begin{array}{l}\text { open } \\
\text { woodland }\end{array}$ & $\begin{array}{l}\text { Presence or absence of grassland and forest } \\
\text { mosaic within square }\end{array}$ & Kirkpatrick (1999) \\
\hline forest & $\begin{array}{l}\text { Presence or absence of indigenous or exotic } \\
\text { forest within square }\end{array}$ & Kirkpatrick (1999) \\
\hline
\end{tabular}




$\begin{array}{lll}\text { landuse } & \text { Dominant landuse category within square. } & \text { Kirkpatrick (1999) } \\ & \text { The three categories were: non- } & \\ & \text { agricultural; pastoral; and arable. } & \text { Kirkpatrick (1999) } \\ \text { non-ag } & \text { Presenceor absenceof non-agricultural } & \\ & \text { landuse within square. } & \text { Kirkpatrick (1999) } \\ \text { pastoral } & \text { Presence or absence of pastoralism within } & \\ & \text { square. } & \text { Kirkpatrick (1999) } \\ \text { arable } & \text { Presenceor absence of cash crops (mostly } & \\ & \text { cereals) within square. } & \text { Kirkpatrick (1999) } \\ \text { crop } & \text { Presence or absence of outdoor horticulture } & \\ & \text { within square. } & \text { Kirkpatrick (1999) } \\ \text { fstry } & \text { Presence or absence of exotic forest } & \\ & \text { plantations within square. } & \end{array}$

After completion of this process any variable that showed no significant effect (alpha $=0.01$ ) was not used in further steps. For the New Zealand dataset all combinations of 2 and 3 variable models were fitted and the same process was used to eliminate variables with limited or no effect. To reduce the complexity of the models interactions were not included in their construction. Dummy variables containing presence-absence data were created for the categorical variables landuse and veg.

The predictive accuracy of each model was assessed using a coefficient of determination (Nagelkerke $\mathrm{R}^{2}$ ) and a chi-square test (Wald Statistic) on the variation of the regression coefficients. The prediction error of the final models developed was evaluated using crossvalidation (Augustin et al. 2001; Pearce et al. 2001). For each dataset the cases were randomly allocated into 5 subsets and the developed models were fitted to a reduced dataset, comprised of 4 of these subsets. The developed model was fitted to all combinations of four subsets from each dataset. Variation in the regression coefficients produced from the reduced sets and in the ability of the models to correctly predict presence in the unselected dataset are used to measure the accuracy of the model. Variables that consistently showed no significant effect when fitted to these sub-groups were discarded. 


\subsection{RESULTS}

\subsubsection{Distribution of cockatoos in New Zealand}

\subsubsection{Historical distribution patterns of C. galerita in the North Island}

The locations of C. galerita sightings in the North Island from 1922-1999 (Figure 2.1a-d) are as follows.

1922-1955. The first record of C. galerita in New Zealand was from the Waitakere Ranges, west of Auckland city. Over the next three decades further sightings of C. galerita were reported from Wellsford (Kaipara Harbour, Northland), South Auckland, western Waikato, the Turakina Valley (Manawatu-Wanganui) and Wainuiomata (Wellington), all located on the western coast of the North Island. The only indication of the numbers of birds present for any of these early records was a single bird reported in the Wainuiomata Valley in 1950.

1956-1980. Over this period the populations in the western Waikato and Turakina Valley greatly increased, with flocks of hundreds of birds being recorded in each of these areas. Mean flock size for this period was 30.9 (s.d. $=79.01, \mathrm{n}=32$ ). New locations where $C$. galerita were sighted included: (1) Houhora and Whangarei in Northland; and (2) along the Puniu River in the Waikato. There were no records from Wellington or Wellsford over this period.

1981-1990. Cacatua galerita occupied many of the same areas where they were present in previous years. There was no apparent increase in the size of flocks reported from the earlier period $($ mean $=19.6$, s.d. $=36.58, \mathrm{n}=115)(\mathrm{t}=-1.16$, d.f. $=145, \mathrm{P}=0.25)$. Cacatua galerita, last seen in the Wellington area between 1950-1955, were recorded again in 1986 after which they appeared to become widespread along the west coast of the Wellington Region. A significant change in the distribution of $C$. galerita was the appearance of these birds east of the dividing ranges in the Bay of Plenty, Hawkes Bay and the eastern Manawatu and Wairarapa (eastern Wellington) Regions. Many of the records from the eastern North Island were made towards the later part of this period, often preceded by sightings of birds close to low points or saddles in the dividing ranges between the west and east coasts. For example, C. galerita were recorded at Lake Rotoiti (1983) and Otanewainuku (1984) before appearing at Rangiuru in the eastern Bay of Plenty in 1988; and at Pahiatua (1985) before the first record of the species in Hawkes Bay (along the Tukituki River in 1986) and Wairarapa (Masterton 
1989) (Figure 2.1c). Caution must be taken in interpreting any relationship between these sightings because each record could potentially have arisen from a new invasion.

1991-1999. The most noticeable change over this period was the shift in the focus of $C$. galerita sightings from South Auckland and northwestern Waikato towards the south. Cacatua galerita were also seen over a wider area of the Wairarapa, although the flocks seen remained small (1-5 birds). There was no substantial change $(t=-1.4975$, d.f. $=211, \mathrm{P}=0.14)$ in the size of flocks reported between 1981-1990 and 1991-1999. Mean size of flocks seen in this period was 13.1 (s.d. $=24.41, \mathrm{n}=98$ ), though the size of flocks reported from the Waitakere Ranges and North Shore of Auckland City appear to have increased from a maximum flock size of 13 birds between 1981-1990 to 60 birds in 1991-1999 (Appendix 1). 


\section{Key}

Altitude

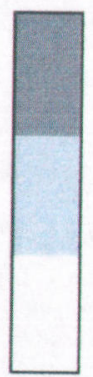

Flock size

- 1

- 2-3

- 4-10

- 11-20

- 21-100

$>100$

- number not given

Figure 2.1. Distribution maps produced from field records of Cacatua galerita in the North Island. Circle size indicates maximum recorded flock size for that location. 


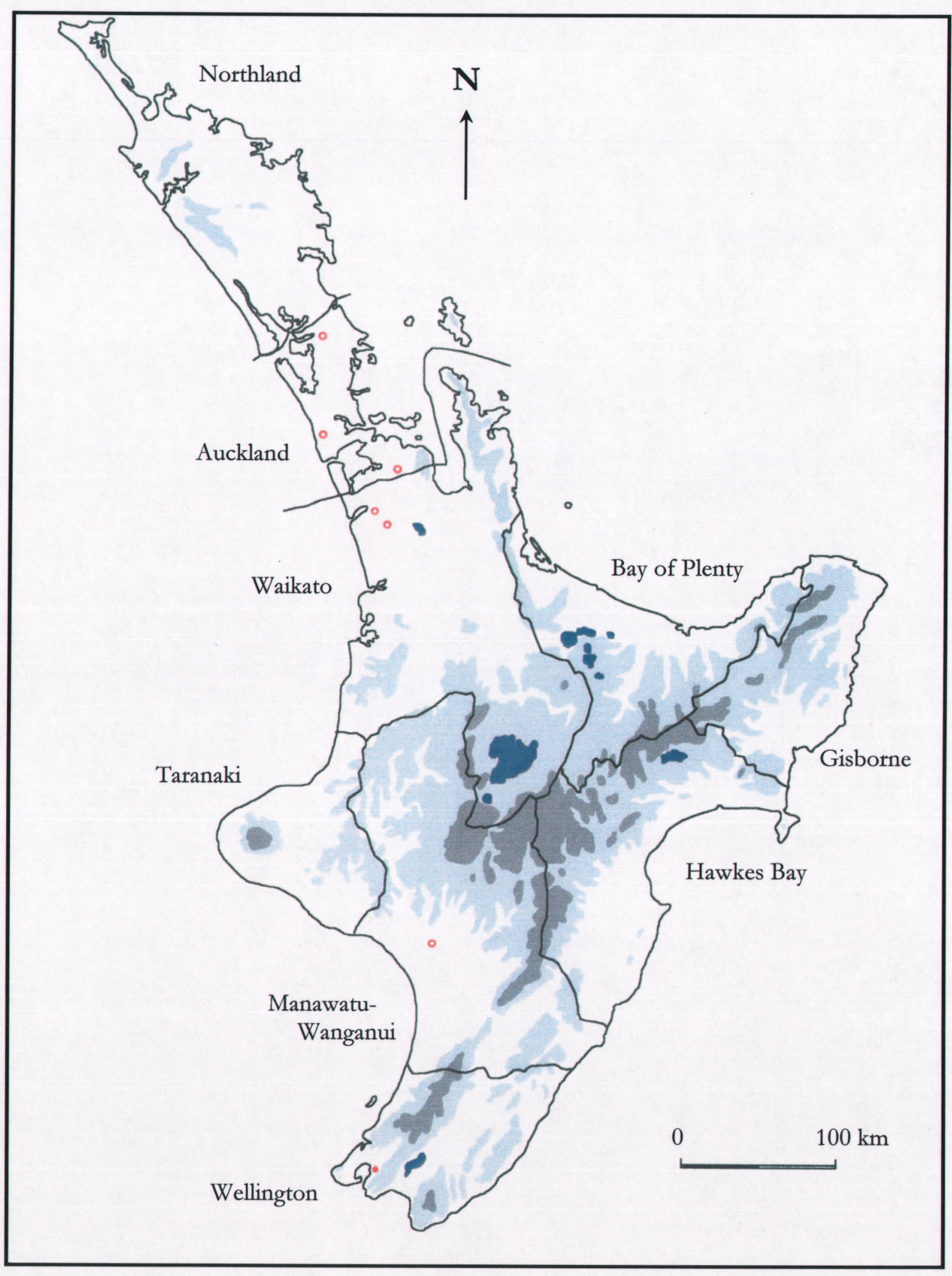

(a) $1922-1955$ 


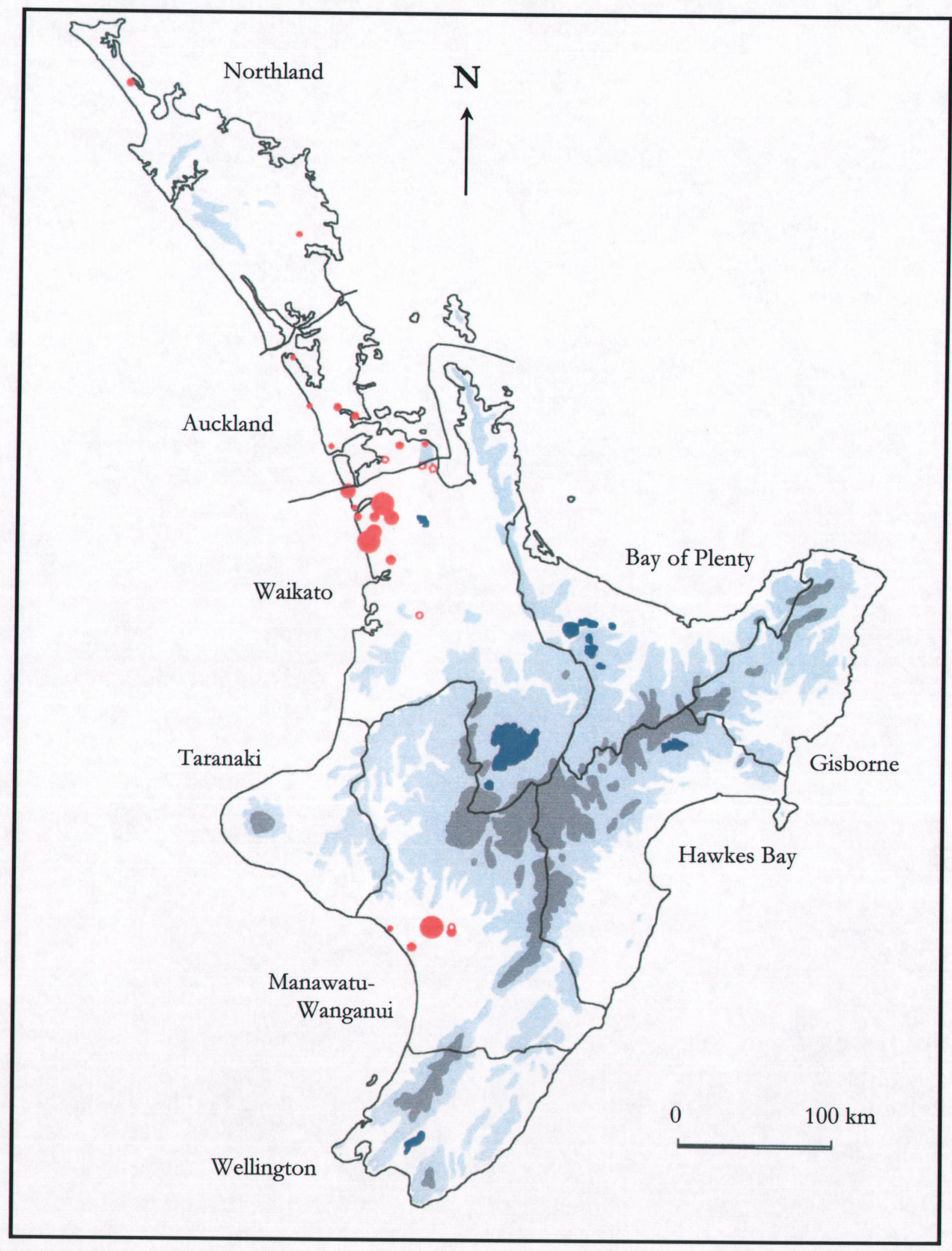

(b) $1956-1980$ 


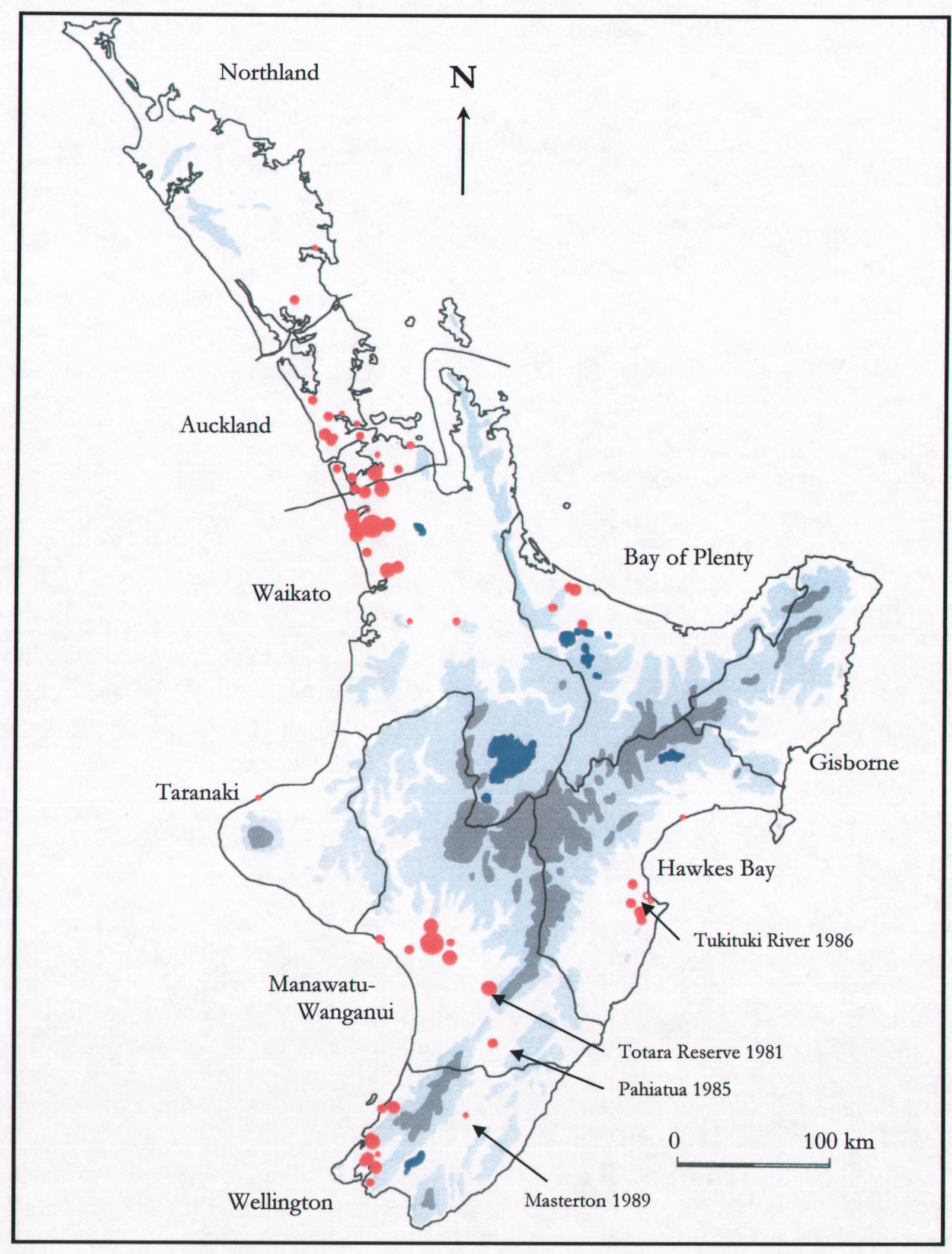

(c) $1981-1990$ 


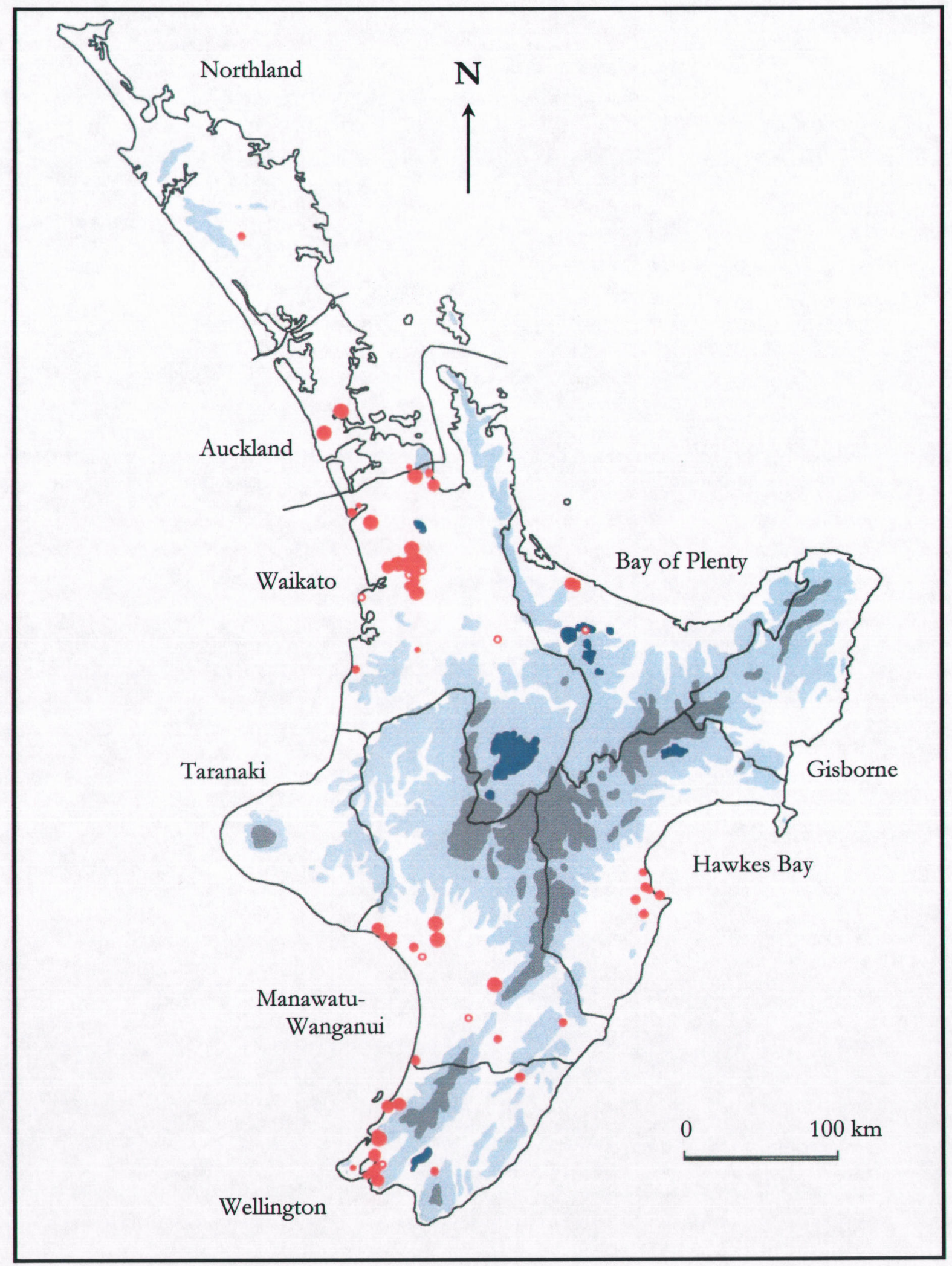

(d) 1991-1999 


\subsubsection{Historical distribution patterns of C. galerita in the South Island}

The appearance of $C$. galerita in the South Island dates from approximately 30 years after the first records of the species in the North Island. Furthermore, the species is not as widespread or abundant as it is in the North Island. The locations of C. galerita sightings in the South Island from 1950-1999 (Figure 2.2a-b) are as follows.

1950-1980. Cacatua galerita were first reported from Diamond Harbour on northern Banks Peninsula, where between 5-8 birds were seen during the 1950's. Later, in 1975, C. galerita were reported in the south facing valleys of the Peninsula, near the township of Little River.

1981-1990. Cacatua galerita were recorded from three areas during this period. New locations include: (1) several sightings of single birds (and one pair) on the West Coast; and (2) a series of sightings from the Catlins (south Otago-Southland). Size of flocks reported were small, ranging from $1-7$ birds $($ mean $=2.4$, s.d. $=1.96, \mathrm{n}=16)$.

1991-1999. In contrast to the widespread appearance of C. galerita in the previous 10 years, birds were only reported from Banks Peninsula, though there may still be a small number in the Catlins. The size of flocks observed on Banks Peninsula ( mean $=18.5$, s.d. $=11.8, \mathrm{n}=$ 10) had significantly increased from the previous 10 years $(t=5.4$, d.f. $=24, P=0.0001)$, with flocks of 30-40 birds recorded around the Kaituna Valley and Little River.

\subsubsection{Historical distribution patterns of C. roseicapilla in New Zealand}

The published record of C. roseicapilla in New Zealand dates from 1959 when a pair, presumed to be escaped cage birds, were observed at Clevedon (South Auckland) (Figure 2.3). There were no further records of this species until 1975 when a single bird was observed on Muriwai Beach north of Auckland. From the 1980s there has been an increasing incidence of reported sightings, including one record from the South Island, and these flocks appear to be increasing in size (from an average of 6 birds/flock (s.d. $=3.7, \mathrm{n}=$ 8) between 1980-1990 to 15.2 birds/flock (s.d. = 15.23, $\mathrm{n}=13$ ) between 1991-1999), though the difference was not significant $(t=1.66$, d.f. $=19, \mathrm{P}=0.11)$. Most records have come from the northern Waikato and South Auckland, including some islands in the Hauraki Gulf. 


\section{Key}

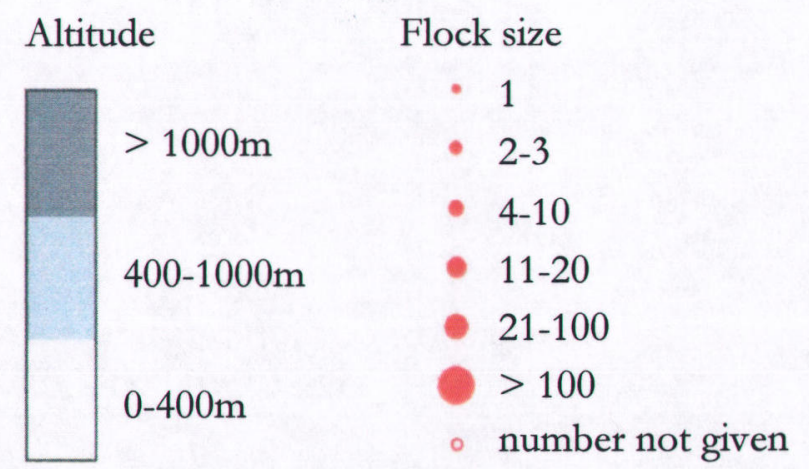

Figure 2.2. Distribution maps produced from field records of Cacatua galerita in the South Island. Circle size indicates maximum recorded flock size for that location. 


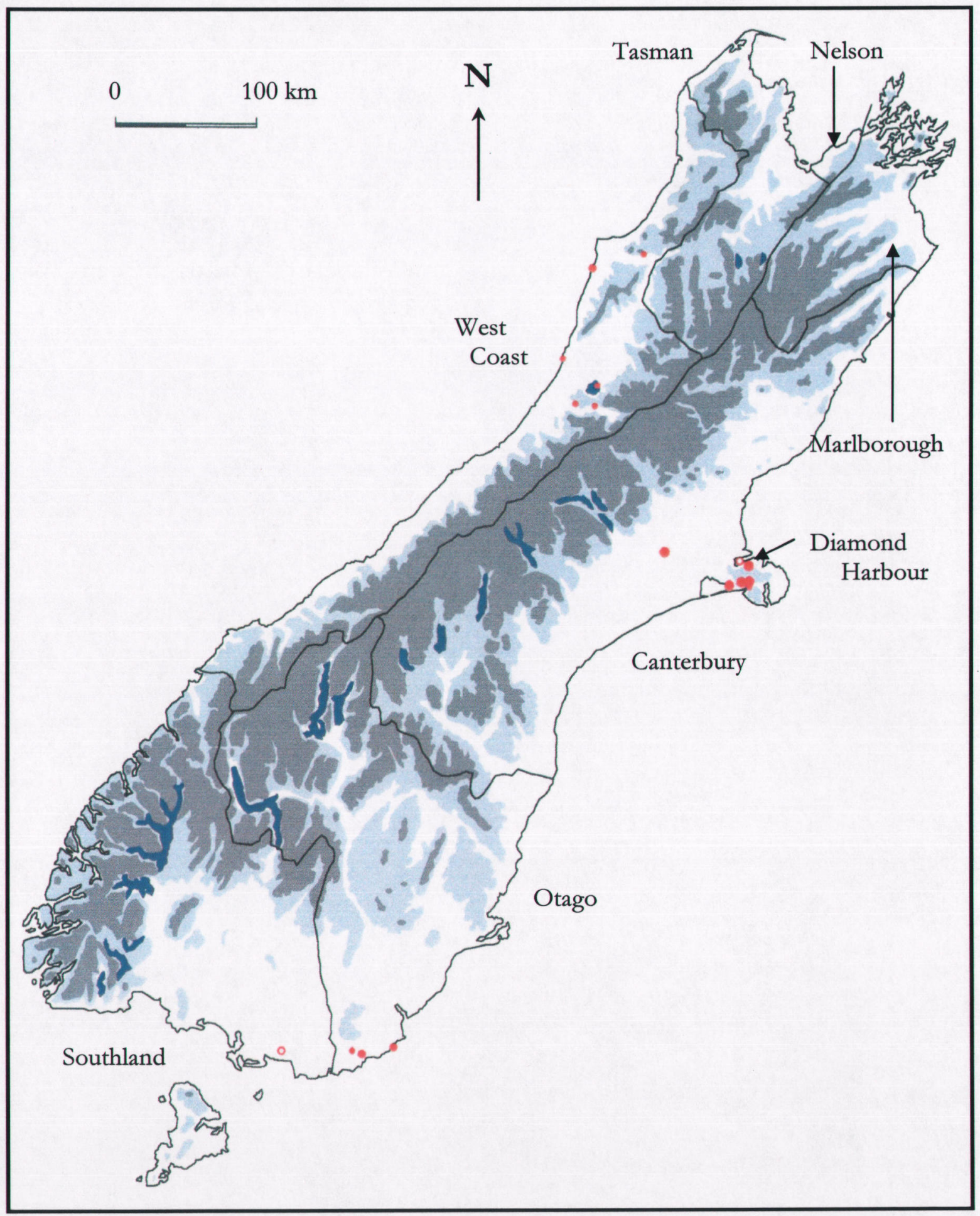

(a) $1950-1990$ 


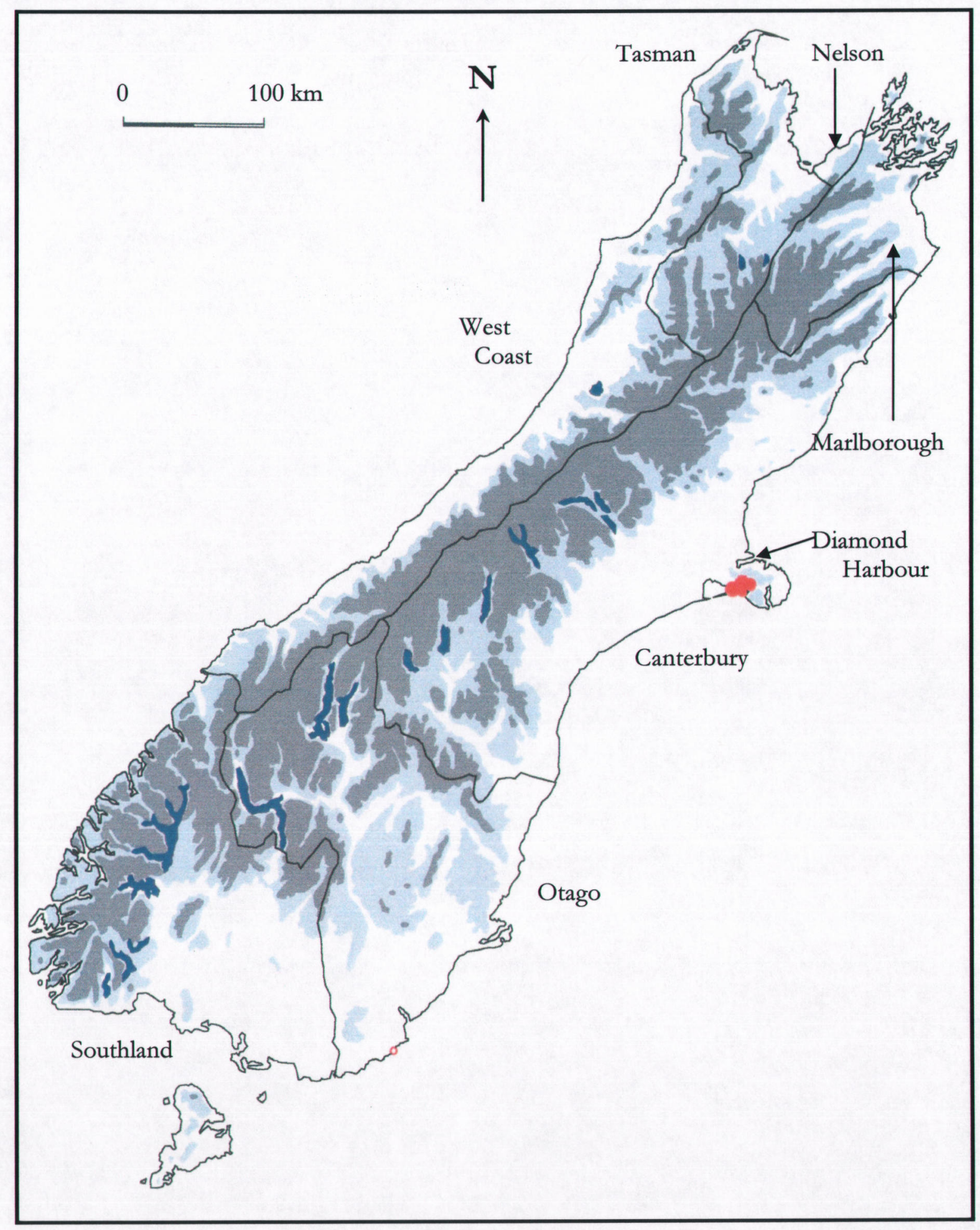

(b) 1991-1999 


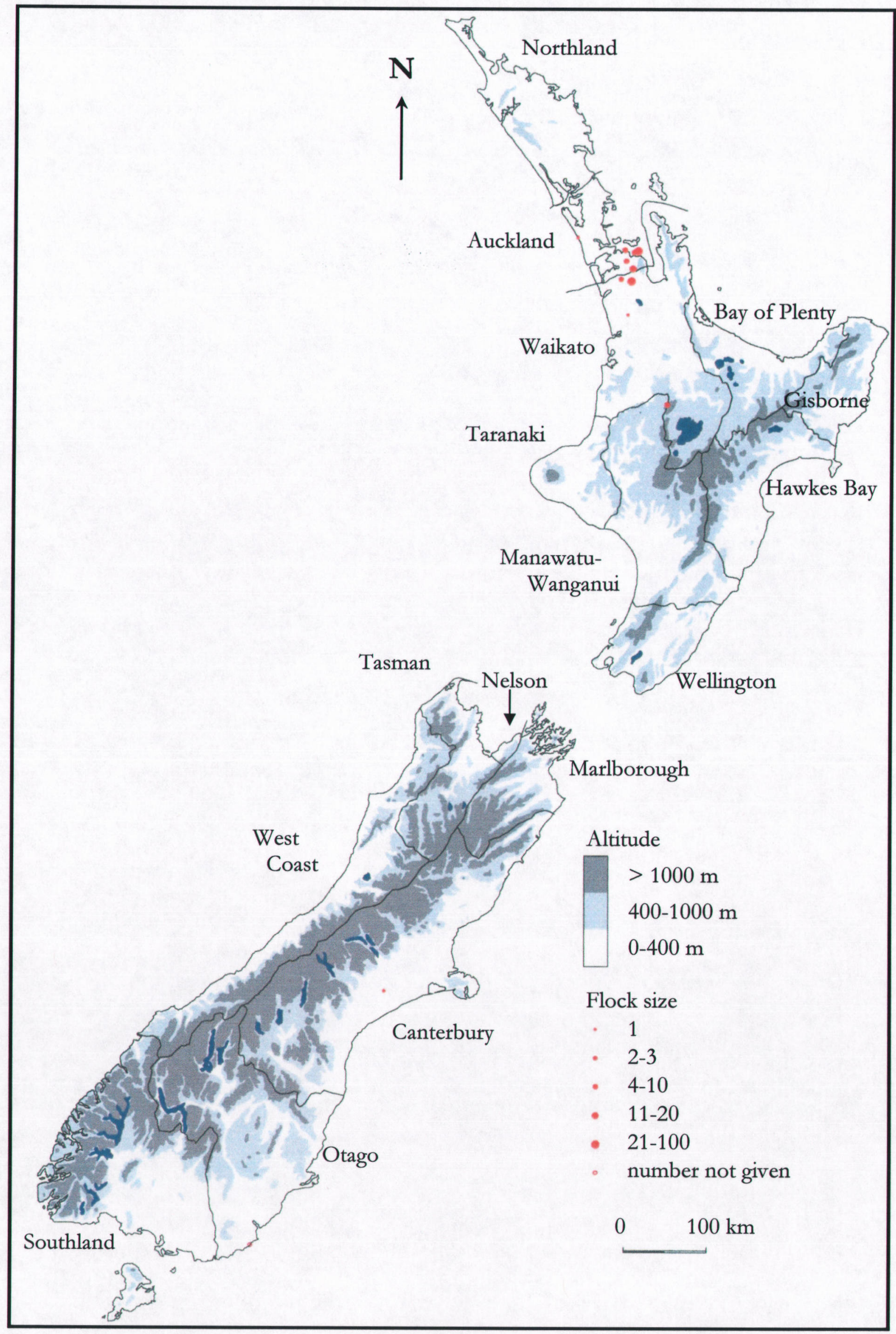

Figure 2.3. Distribution map produced from field records of Cacatua roseicapilla in New Zealand from 1959 to 1999 . Circle size indicates maximum recorded flock size for that location. 


\subsubsection{Modelling distribution using logistic regression}

\subsubsection{Distribution in Australia}

Fourteen of the 18 predictor variables used to examine distribution of C. g. galerita in Australia (Table 2.3) appeared to be significantly related $(\mathrm{P}<0.0001)$ with the presence of these birds. Five variables (veg, forest, shrub, max T, rain) each accounted for more than $20 \%$ of the variation in the distribution of this species. The best single predictive variable was veg $\left(R^{2}=0.3398\right)$, which was positively related to C. g. galerita presence. Cacatua g. galerita occupied squares across the whole range of temperatures measured (Figure $2.4 \mathrm{a}-\mathrm{d}$ ), but were significantly less common as temperature increased. Occupation of squares increased with increasing height and density of vegetation and intensity of landuse for agriculture (Figure $2.5 \mathrm{a}, \mathrm{d}$ ).

The 'best' two-variable models incorporated measures of maximum temperature (xmax, $\max T)$ and presence of scrub-heath vegetation, which were negatively and significantly associated with presence; explaining up to $48 \%$ of the variation in distribution of C. g. galerita. The model

\section{Logit $($ presence $)=33.586-(1.216 \times \max T)-(0.627 \times \min T)-(3.022 \times$ scrub-heath $)-$ $(1.702 \times$ non-ag $)+(1.695 \times$ wheat $)$}

explains $63.6 \%$ of the variation in the distribution of C. g. galerita and describes significant avoidance of areas with high maximum temperature (or alternatively preference of areas with lower temperature), scrub-heath and non-agricultural landuse; and preference for areas where wheat (Triticum aestivum) is grown. The regression coefficients for this model were not significantly different (less than one standard error) from the mean coefficient range calculated from the assessment sets (Table 2.4).

There were several models that explained a similar amount of the variation in C. g. galerita distribution. For example, replacing $\max T$ with $x \max$, or wheat with crop produced no significant change in the amount of variation explained ( $t$ tests, d.f. $=8, \mathrm{P}$ 's $<0.5$ ). 
Table 2.3. Single-variable logistic regression using Australian data showing the regression coefficients obtained for each environmental variable, percentage of variation explained $\left(R^{2}\right)$ and probability values $(\mathrm{P})$ based on the Wald Statistic.

\begin{tabular}{|c|c|c|c|c|c|}
\hline Environmental variable & Constant & Coefficient & SE & $\mathbf{P}$ & $\mathbf{R}^{2}$ \\
\hline $\min T$ & 1.3281 & -0.2343 & 0.0533 & 0.0000 & 0.0346 \\
\hline$x \min$ & 5.2774 & -0.4564 & 0.0608 & 0.0000 & 0.0909 \\
\hline $\max T$ & 24.9793 & -1.1443 & 0.1010 & 0.0000 & 0.2526 \\
\hline$x \max$ & 9.1563 & -0.5620 & 0.0549 & 0.0000 & 0.1638 \\
\hline rain & -2.8620 & 1.1734 & 0.1020 & 0.0000 & 0.2092 \\
\hline alt & -0.3965 & -0.2081 & 0.0991 & 0.0360 & 0.0056 \\
\hline veg & 2.1060 & 1.4913 & 0.1093 & 0.0000 & 0.3398 \\
\hline grass-herb & -0.7426 & -0.0157 & 0.1881 & 0.0934 & 0.0000 \\
\hline scrub-beath & 0.3514 & -2.5665 & 0.1924 & 0.0000 & 0.2714 \\
\hline open woodland & -0.4922 & -0.6916 & 0.1618 & 0.0000 & 0.0231 \\
\hline forest & -2.4423 & 2.8150 & 0.2071 & 0.0000 & 0.2995 \\
\hline landuse & 1.5953 & 1.1342 & 0.0135 & 0.0000 & 0.1028 \\
\hline crop & -0.9784 & 3.2120 & 0.4375 & 0.0000 & 0.1293 \\
\hline fstry & -0.9360 & 2.7278 & 0.3905 & 0.0000 & 0.0982 \\
\hline wheat & -0.9411 & 1.4519 & 0.2268 & 0.0000 & 0.0571 \\
\hline pink & -0.7055 & -0.1715 & 0.1796 & 0.3398 & 0.0011 \\
\hline corella & -0.5754 & -0.3496 & 0.1516 & 0.0214 & 0.0066 \\
\hline galah & -1.6677 & 1.0574 & 0.2567 & 0.0000 & 0.0226 \\
\hline
\end{tabular}

An analysis of the residuals from these models inidicated that there was significant autocorrelation (d.f. $=804$, P's $<0.0001$ ), though variance was constant. Although one should be cautious about treating the Chi-squared probabilities given as being necessarily accurate (due to autocorrelation and lack of normality of the residuals), the extremely low Pvalues suggest there is a significant relationship between the model and the distribution of $C$. g. galerita.

The probabilities obtained from the logistic model for presence of $C$. g. galerita in sample squares were mapped against actual/recorded presence of this species (Figure 2.6). The filled circles and crosses indicate recorded presence (the crosses occurring where the model fails to predict a recorded presence). A good fit to the model, and therefore greater reliability in the predictions, would show many large filled circles and few open large circles, small filled 
circles and crosses. This model was able to correctly predict presence of C. g. galerita in $67.8 \%$ (using a cut off value of 0.5 ) of squares, and the complete dataset and evaluation sets were not significantly different $\left(\chi^{2}\right.$, d.f. $=1$, P's $\left.<0.1\right)$ in their ability to correctly classify presence. The evaluation datasets were also able to correctly estimate presence in the assessment sets $\left(\chi^{2}\right.$, d.f. $=1$, P's $\left.<0.1\right)$.

Table 2.4. Results of multiple regression analysis of presence-absence of Cacatua galerita galerita in Australia.

\begin{tabular}{lccccc}
$\begin{array}{l}\text { Variable } \\
\text { Wald }\end{array}$ & df & Significance & $\begin{array}{c}\text { Mean regression } \\
\text { coefficient } \\
\text { (evaluation set) }\end{array}$ & $\begin{array}{c}\text { Standard } \\
\text { error }\end{array}$ \\
\hline maxT & 78.940 & 1 & 0.000 & -1.221 & 0.045 \\
minT & 56.154 & 1 & 0.000 & -0.628 & 0.024 \\
scrub-heath & 100.860 & 1 & 0.000 & -3.022 & 0.074 \\
non-ag & 24.438 & 1 & 0.000 & -1.702 & 0.089 \\
wheat & 21.843 & 1 & 0.000 & 1.695 & 0.034 \\
Constant & 97.001 & 1 & 0.000 & 33.586 & 1.140
\end{tabular}

Nagelkerke R2

0.636

The data for Australia do not support prediction 1 (hypothesis 2.2). Cacatua g. galerita do not occur in all squares that the model predicted they could. In the north many of the squares where presence is predicted are occupied by the closely related C. g. fitzroyi (Figure 2.6). The native range of C. g. galerita does not extend to Western Australia, although this species has successfully colonised this area following releases of cage birds in Perth (Figure 2.6). 

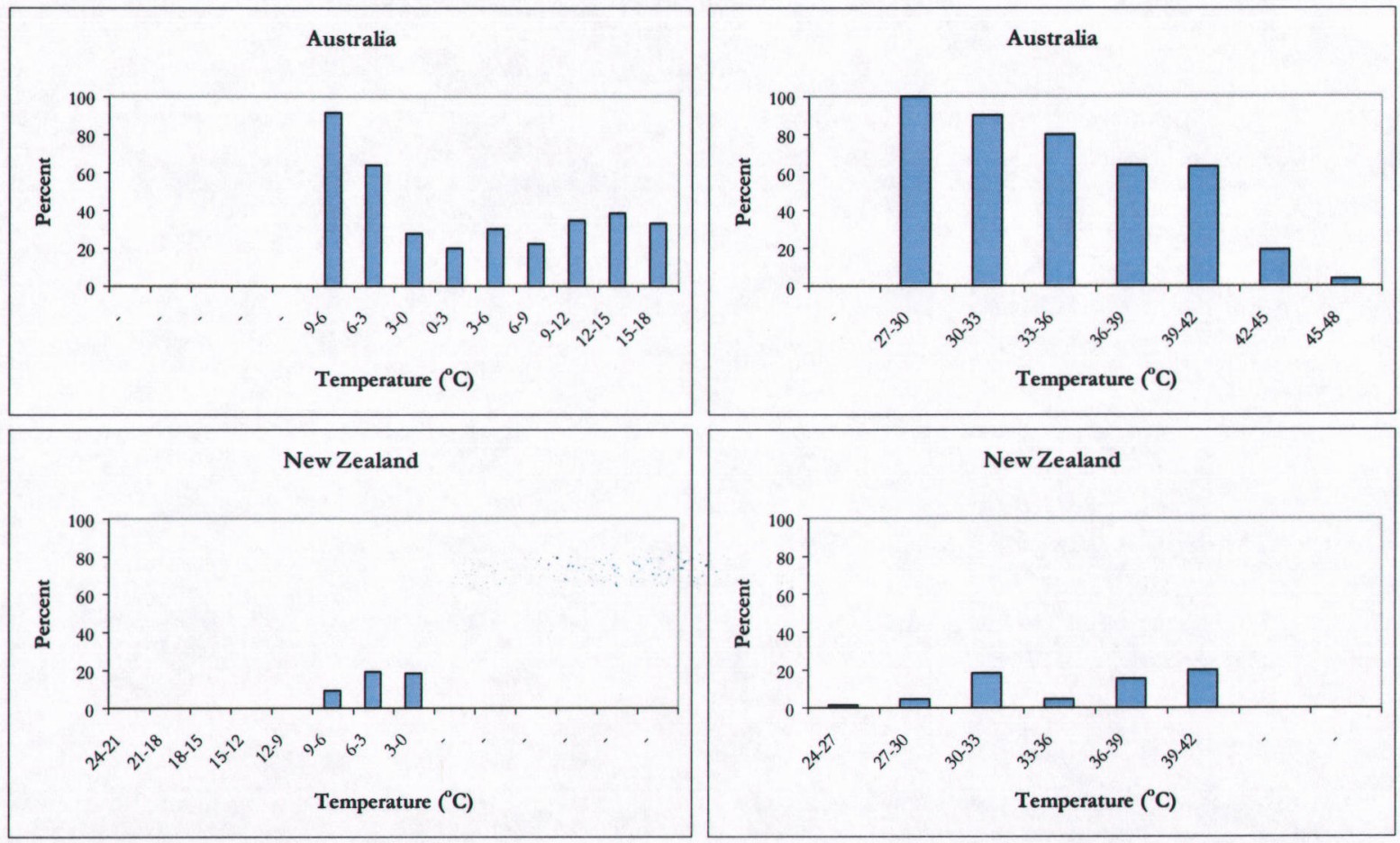

(a) Minimum recorded temperature $(\min T)$

(c) Maximum recorded temperature $(\max T)$
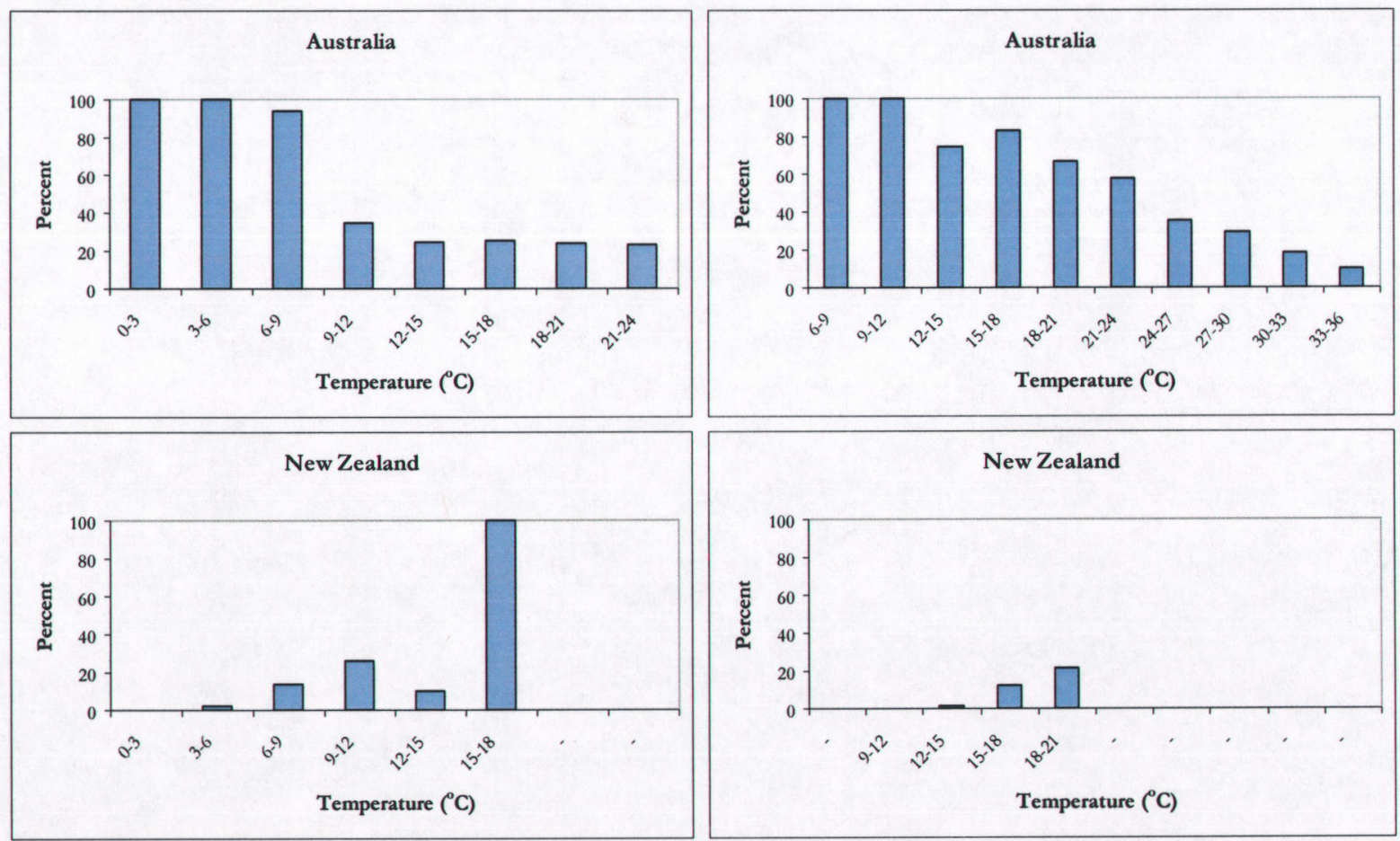

(b) Average daily minimum temp (xmin)

(d) Average daily maximum temp (xmax)

Figure 2.4. Percent of degree (Australia: $\mathrm{n}=805$ ) and quarter-degree (New Zealand: $\mathrm{n}=626$ ) blocks containing Cacatua galerita galerita along gradients of extreme and average daily maximum and minimum temperature. The extent of measurements along the $x$-axis denotes the recorded limits of the variable. 

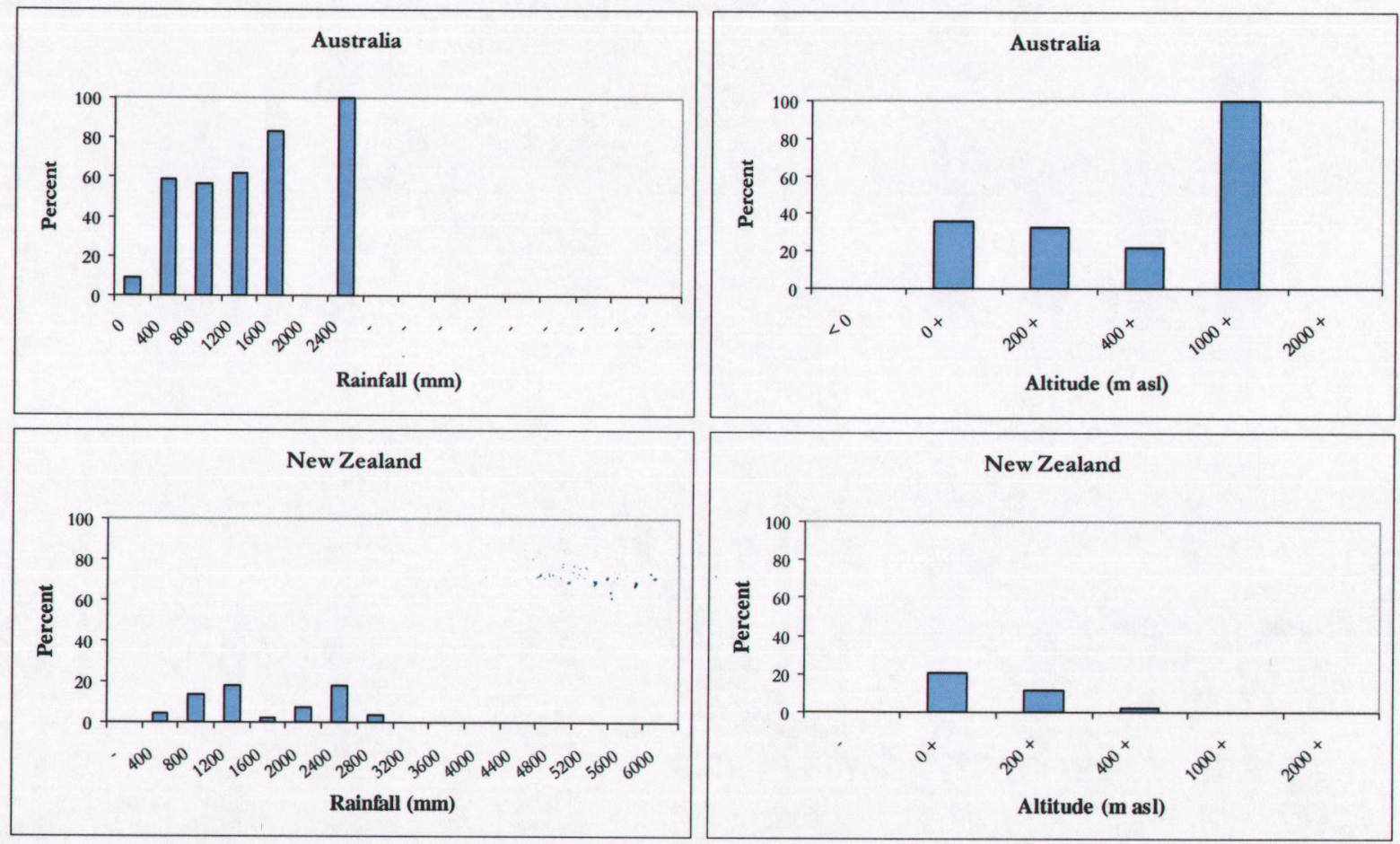

(a) Average annual rainfall (rain)

(c) Altitude (alt)
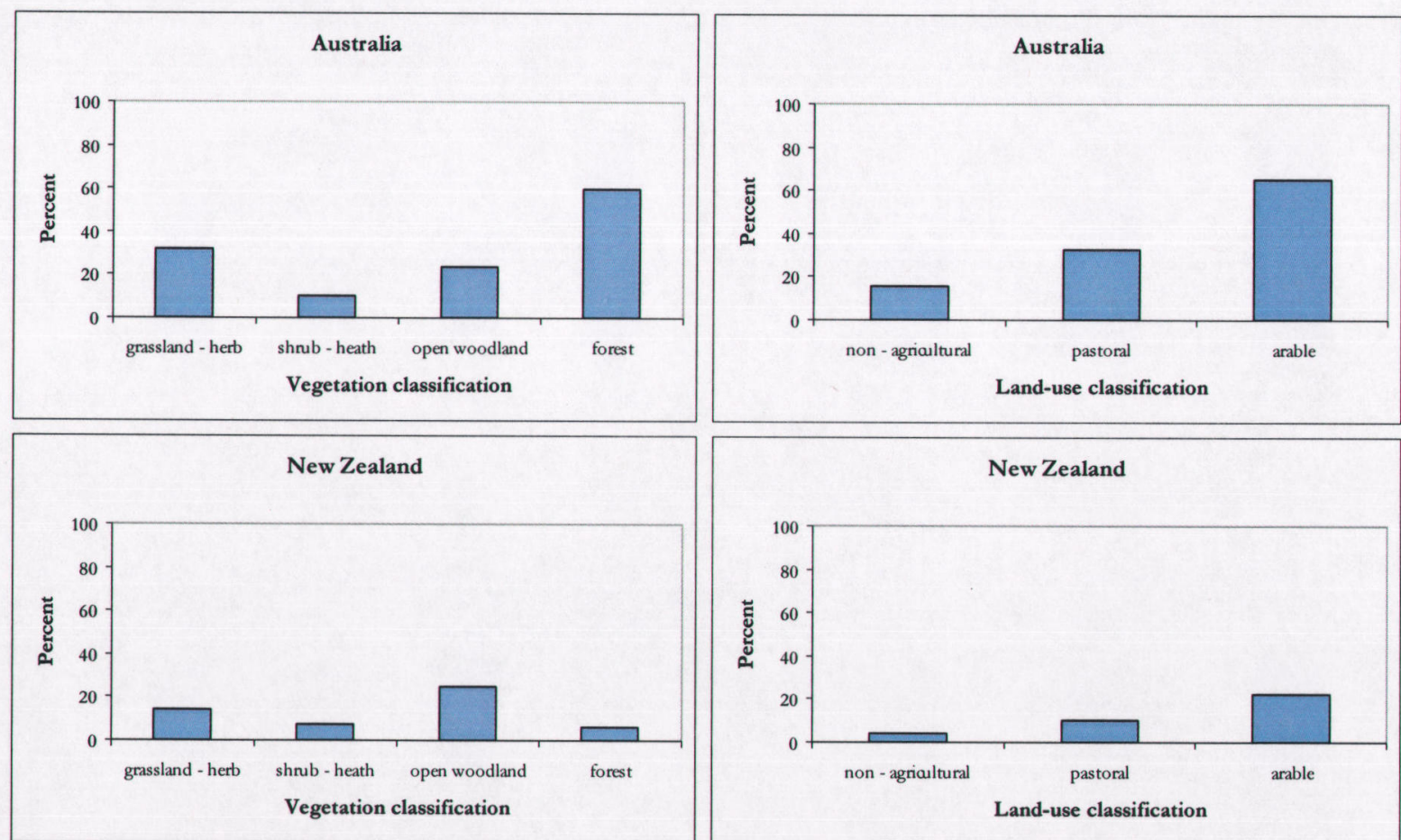

(b) Dominant vegetation category (veg)

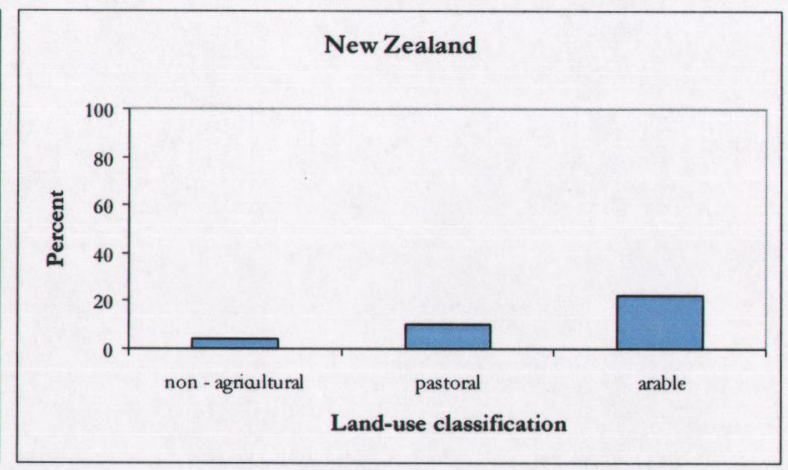

Dominant land-use category (land-use)

Figure 2.5. Percent of degree (Australia: $n=805$ ) and quarter-degree (New Zealand: $n=626$ ) blocks containing Cacatua galerita galerita along gradients of average annual rainfall, altitude, vegetation and land-use. The extent of measurements along the $x$-axis denotes the recorded limits of the variable. 


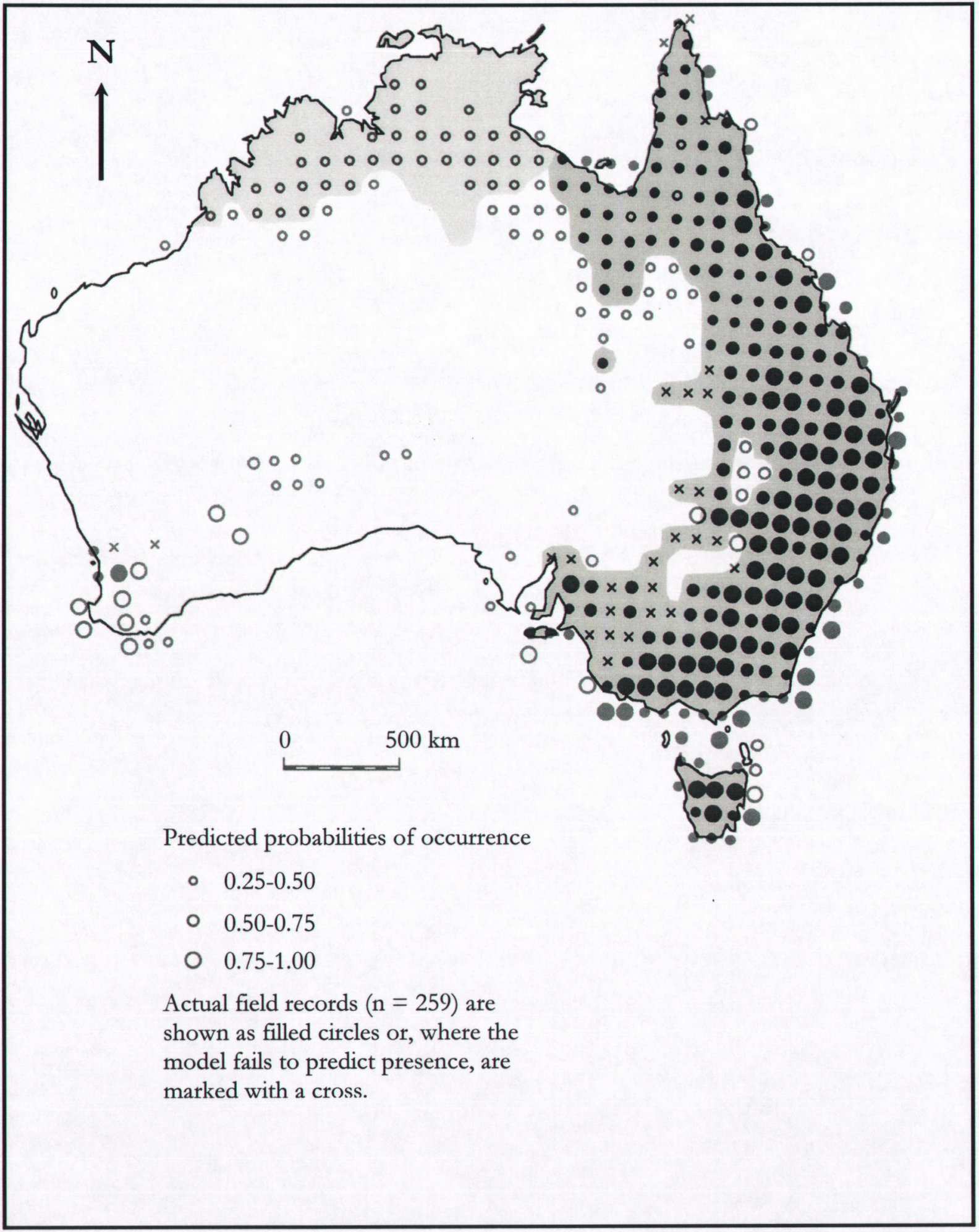

Figure 2.6. Distribution map of Cacatua galerita galerita in Australia produced by modelling using presence/absence data. 


\subsubsection{Distribution in New Zealand}

Nine variables used to examine C. galerita distribution in New Zealand (Table 2.5) appear to be significantly related $(\mathrm{P}<0.01)$ with the presence of these birds. Values for $\mathrm{R}^{2}$ were lower than those obtained from Australia. Five variables significant in explaining C. galerita distribution in Australia were not found to be significant in New Zealand. Differences for two, characteristics of vegetation (shrub/scrub-heath and forest), are likely to reflect differences in species composition and may also reflect differences in structure of these vegetation types between the two countries. One variable (alt) that was not significant in Australia was in New Zealand. Surprisingly precipitation (rain) did not appear to be significant in New Zealand.

My data do support prediction 1 (hypothesis 2.1). Cacatua galerita in New Zealand occupied squares within the temperature range experienced by these birds in Australia, but there was a trend towards increasing occupation of squares with warmer temperatures compared to increased occupancy of squares with cooler temperatures in Australia (Figure 2.4a-d). Cacatua galerita were not seen in parts of the country with an extreme minimum recorded temperature less than $-9^{\circ} \mathrm{C}$ (Figure 2.4a) or average daily minimum temperature less than $3^{\circ} \mathrm{C}$ (Figure 2.4b). The environment occupied by C. galerita in Australia is significantly warmer and drier than the environment experienced by birds in New Zealand ( $t$ tests, d.f. $=321$, P's $<0.001$ ). Cacatua galerita also occupied a greater range of altitude $(t=2.139$, d.f. $=321, P=0.033)$ in Australia than in New Zealand and they occur at higher altitudes in Australia (Figure 2.5c).

Of the models tested

\section{Logit $($ presence $)=-12.190+(0.789 \times x$ min $)+(1.224 \times$ woodland $)+(1.414 \times$ arable $)$}

explained the most variation $(29.8 \%)$ in C. galerita distribution in New Zealand (Table 2.6) and describes significant preference for areas with greater mean minimum temperature (or avoidance of areas with low temperature), open woodland and arable landuse. This model and the model for C. g. galerita distribution in Australia support prediction 2 (hypothesis 2.1).

Although much of the distribution of C. galerita in New Zealand is not accounted for, and there was significant autocorrelation ( $r=0.1362$, d.f. $=625, P=0.0006)$, there is still significant evidence (P's $<0.001$ ) (Table 2.6) that the variables are strongly associated with the distribution of this species. The regression coefficients for this model were not 
significantly different (less than one standard error) from the mean coefficient range calculated from the evaluation sets (Table 2.6).

Table 2.5. Single-variable logistic regression using New Zealand data showing the regression coefficients obtained for each environmental variable, percentage of variation explained $\left(\mathrm{R}^{2}\right)$ and probability values $(\mathrm{P})$ based on the Wald Statistic. The software program Statistica did not produce standard error (SE) and P-values for grass-herb.

\begin{tabular}{|c|c|c|c|c|c|}
\hline $\begin{array}{l}\text { Environmental } \\
\text { variable }\end{array}$ & Constant & Coefficient & $\mathrm{SE}$ & $\mathbf{P}$ & $\mathbf{R}^{2}$ \\
\hline $\min T$ & -7.0251 & 0.7478 & 0.1347 & 0.0000 & 0.0488 \\
\hline$x \min$ & -13.9285 & 1.0680 & 0.1580 & 0.0000 & 0.0810 \\
\hline $\max T$ & -7.1573 & 0.2621 & 0.1234 & 0.3400 & 0.0055 \\
\hline$x \max$ & -17.4798 & 1.0885 & 0.1895 & 0.0000 & 0.0616 \\
\hline rain & -1.5287 & -0.1581 & 0.0769 & 0.0401 & 0.0053 \\
\hline alt & -0.1730 & -1.1070 & 0.1885 & 0.0000 & 0.0726 \\
\hline veg & -1.5048 & -0.3352 & 0.1162 & 0.0040 & 0.0149 \\
\hline grass-herb & -21.5546 & 19.5294 & - & - & 0.0160 \\
\hline shrub & -3.3844 & 1.2909 & 0.7314 & 0.0781 & 0.0057 \\
\hline open woodland & -2.9751 & 1.8375 & 0.2814 & 0.0000 & 0.0822 \\
\hline forest & -2.6391 & 0.5830 & 0.3578 & 0.1037 & 0.0043 \\
\hline landuse & -4.1361 & 0.9588 & 0.1821 & 0.0000 & 0.0514 \\
\hline non-ag & -2.0338 & -0.1745 & 0.3209 & 0.5868 & 0.0005 \\
\hline pastoral & -2.1327 & -0.0529 & 0.3051 & 0.8624 & 0.0000 \\
\hline arable & -3.2852 & 1.9608 & 0.3153 & 0.0000 & 0.0777 \\
\hline crop & -2.4773 & 1.8354 & 0.3177 & 0.0000 & 0.0655 \\
\hline fstry & -2.4785 & 0.5866 & 0.2683 & 0.0291 & 0.0078 \\
\hline
\end{tabular}

The probabilities obtained from the logistic model for presence of $C$. galerita in sample squares in New Zealand were mapped in a similar format to that used to map their distribution in Australia (Figure 2.7). This model was able to correctly predict presence of $C$. galerita in $89.8 \%$ (using a cut off value of 0.5 ) of squares. The complete dataset and evaluation sets were not significantly different $\left(\chi^{2}\right.$, d.f. $=1$, P's $\left.<0.1\right)$ in their ability to correctly classify presence. The evaluation datasets also correctly estimated presence in the assessment sets $\left(\chi^{2}\right.$, d.f. $=1$, P's $\left.<0.1\right)$. 
Table 2.6. Results of multiple regression analysis of presence-absence of Cacatua galerita in New Zealand.

\begin{tabular}{lcccccc}
\hline Variable & Wald & df & Significance & $\begin{array}{c}\text { Mean regression } \\
\text { coefficient } \\
\text { (evaluation set) }\end{array}$ & $\begin{array}{c}\text { Standard } \\
\text { error }\end{array}$ \\
\hline xmin & 18.623 & 1 & 0.000 & 0.794 & 0.023 \\
woodland & 16.069 & 1 & 0.000 & 1.235 & 0.068 \\
arable & 17.993 & 1 & 0.000 & 1.410 & 0.123 \\
Constant & 35.986 & 1 & 0.000 & -12.257 & 0.261
\end{tabular}

Nagelkerke $\mathrm{R}^{2}$

0.298

As for Australia, prediction 1 (hypothesis 2.2) is not supported by my New Zealand data. Cacatua galerita have not been recorded in all squares in New Zealand where the model predicted they could occur. Many squares on the border of their current known distribution are not occupied, and they are mostly absent from Northland and the east coast of the North Island, which appear to provide suitable habitat for this species (Figure 2.7). Conversely they have been recorded in many squares where the model predicts absence, for example, Southland and the West Coast of the South Island (Figure 2.7).

\subsection{DISCUSSION}

\subsubsection{Distribution of cockatoos in New Zealand}

Cacatua galerita had become established in the North Island of New Zealand by 1930, by which time most of the lowland forests had been cleared and replaced with exotic grasses (King 1984). Although a recent arrival, this species has achieved a wide distribution in the North Island, with populations recorded in most regions with extensive area below $400 \mathrm{~m}$ asl and their range appears to be expanding. Most of the increase in range is through gradual expansion from original centres of establishment; however, some apparently new founder populations have appeared, particularly in the east coast of the North Island. In the South Island C. galerita are presently restricted to only two locations, Banks Peninsula and the 
Catlins (Southland/Otago). Despite an apparent increase in abundance on Banks Peninsula, these birds have not increased their range.

Cacatua roseicapilla became established in the South Auckland area in the late 1950's or early 1960 's. This population has increased in number, but has generally remained within the South Auckland area, with only one or two individuals being recorded further afield. While C. roseicapilla currently occupy an area with intensive horticulture and arable cropping, little can be determined about the factors affecting the distribution of this species, other than suggesting a strong influence of invasion history.

\subsubsection{The role of invasion and dispersal in the distribution of C. galerita in New Zealand}

A large number of native New Zealand bird species originally colonised from Australia, including nine species of birds known to have self-colonised during the period of European settlement (Falla 1953; Fleming 1962; Turbott 1990; Bell 1991). This number could be larger except for the uncertainty about which exotic species recently seen in the wild have actually become established as self-sustaining populations rather than being bolstered by vagrants. Having only a single record of a possible vagrant C. galerita (Waller 1959) it is impossible to determine the contribution, if any, that this source of birds may have had to the establishment of the species in New Zealand, but it is most likely that the original C. galerita populations were established from birds introduced by humans.

Internationally, few records are kept of the number, origin and fate of cage birds, and as a result the source of many wild populations cannot be accurately determined (Temple 1992; Greenwood 1995). Although there are no records of C. galerita having been intentionally released by Acclimatisation Societies, they are popular as cage birds, some presumably escaping from captivity to establish wild colonies (Thomson 1922; Long 1981; Bull et al. 1985; G. Galpin personal communication). The distribution of C. galerita, particularly in the early 1900 's, was most likely a reflection of these invasion events.

Given the uneven coverage (both spatial and temporal) of recording of cockatoo populations in New Zealand it is not possible to determine whether populations arising since the earlier establishment of this species have arisen from further invasion events or from dispersal. Cockatoo species in Australia have been recorded dispersing over very long distances and many species are also nomadic during the early stage of their lives and/or at certain times of year (Saunders 1980; Rowley 1983; Smith and Moore 1992; Higgins 1999). 


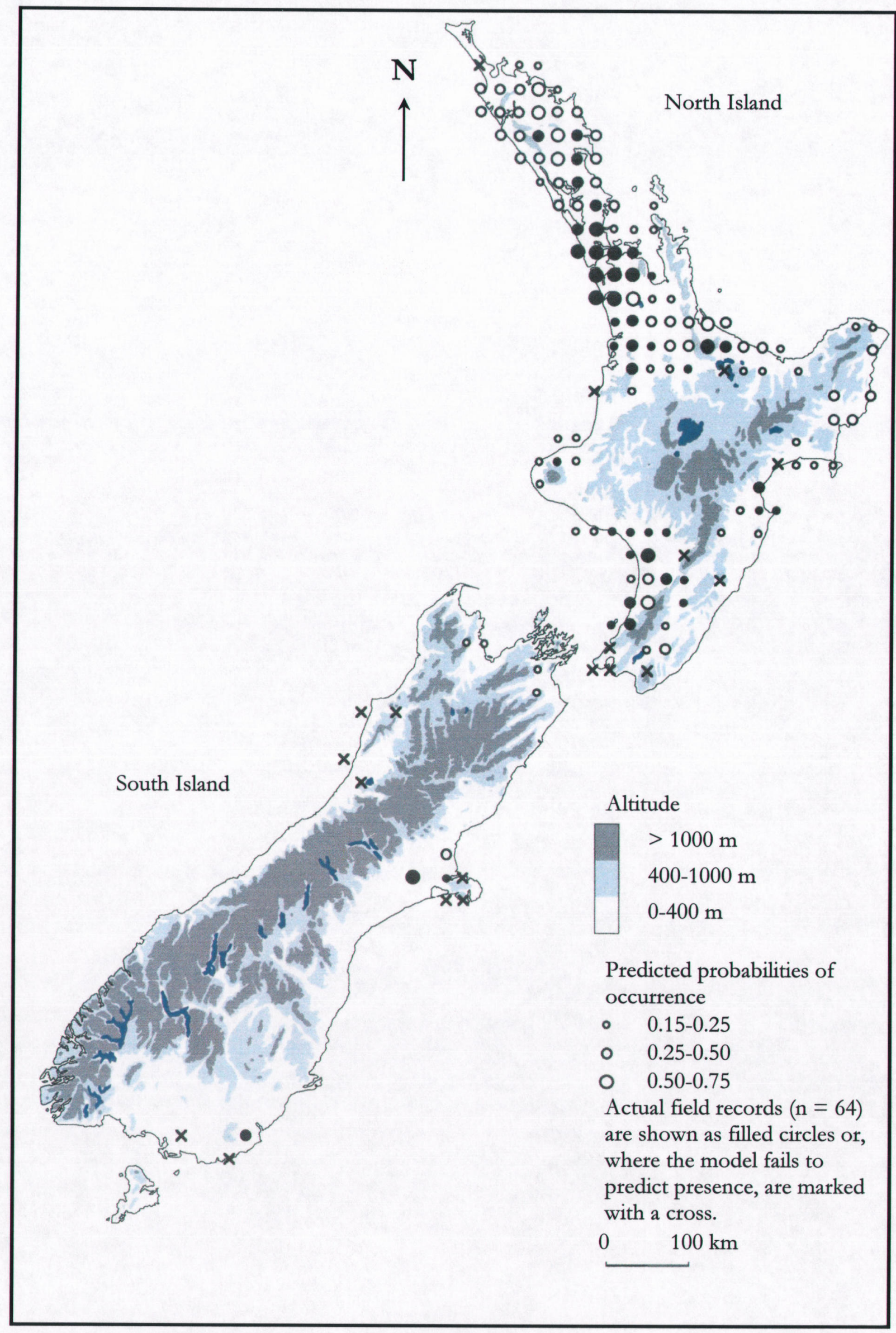

Figure 2.7. Distribution map of Cacatua galerita in New Zealand produced by modelling using presence/absence data. 
Although no similar studies of dispersal have been carried out on C. galerita, nomadic flocks have been recorded, and these birds have been seen undertaking local movements, including crossing between the mainland of Australia and nearby islands (Noske 1980; Higgins 1999).

The largest aggregations of C. galerita (western Waikato and the Turakina River catchment) are among the oldest and most persistent populations. Since the 1960's flocks of hundreds of $C$. galerita have been seen in these two areas. Most of the increase in range is related to the appearance of birds in areas directly adjacent to the earlier records of the species suggesting there is gradual dispersal from these parent populations. The records of $C$. galerita far from these parent populations are not easily explained because of the factors outlined above.

Carey (1996a, 1996b) proposed an "invasion stream" model to explain the wide spacing between areas where Mediterranean fruit fly (Ceratitis capitata) were seen, providing an alternative to the assumption that each new record represents a separate invasion. The proximity of flocks to low passes through the dividing ranges of the North Island prior to the species appearance in the east of the island could be a result of channelling effects of terrain on dispersing birds (Figure 2.8). If C. galerita populations on the west and east coasts are linked by dispersal, attempts to manage their impact in one area (for example, to protect fruit and nut crops in the Bay of Plenty) may require management of populations on both coasts.

At present it is not possible to determine the relatedness between (apparently) different $C$. galerita populations. Relatedness between individuals within and between populations can be determined from studies of their DNA, and I recommend such studies be undertaken on $C$. galerita. This information will not only enable us to determine relatedness between populations, but may also shed light on how these birds disperse. For example, do they disperse in small groups of related individuals or do new populations form from aggregations of randomly dispersing individuals.

Resource managers (in agricultural and conservation sectors) are often required to budget years in advance for the costs of surveillance and/or control of pest species. For example, Regional Councils are required by an Act of Parliament (Biosecurity Act 1993) to create Regional Pest Management Strategies that have a life of five years. Having accurate information about the distribution of pest species allows managers to predict which species must be included in their management plans. Lacking accurate maps of distribution (often the case for species in the early stages of invasion) and information on the relatedness between different populations, managers must rely on predictions of distribution and 
abundance. Although determinants of abundance were not examined here, factors affecting distribution were investigated and the results of this analysis are discussed below.

\subsubsection{Environmental characteristics of $C$. galerita distribution}

The distribution of C. galerita was influenced by a wide range of environmental variables, including (measures of) temperature, rainfall, altitude, vegetation and intensity of human landuse. No single variable had an overriding effect on the distribution of this species. Rather, its distribution (in both Australia and New Zealand) was best defined by a combination of variables, including temperature and characteristics of vegetation and intensity of human landuse (with cultivated areas being favoured).

\subsubsection{Temperature}

While the upper temperature range experienced by $C$. galerita in Australia was not reached in New Zealand, the lower temperature limit to C. galerita in Australia did define the temperature range of this species in New Zealand.

There was no strict temperature limit to the distribution of $C$. galerita in Australia, these birds occupying squares through the full range of temperature recorded; however, there was a marked decrease in occurrence when maximum recorded temperature exceeded $39^{\circ} \mathrm{C}$. Drop off in presence above this temperature may represent the limit of the physiological tolerance to heat for this species (that is, the upper critical temperature limit: Robbins 1993), but could reflect changes in vegetation that are determined by temperature. For example, C. galerita exhibited a significant negative response to low scrubby vegetation, heath, grassland and sedgeland that characterise the vegetation in hotter areas.

Lower mean daily minimum temperature ranges of C. galerita were $0-3^{\circ} \mathrm{C}$ in Australia and 3$6^{\circ} \mathrm{C}$ in New Zealand. The environment in Australia did not appear to test the lower critical temperature limit of C. g. galerita, these birds occurring in squares (even increasing rate of occupancy) where the lowest temperatures were recorded; however, the New Zealand environment does appear to test the lower critical temperature limit of these birds. For example, C. galerita have not been seen in areas of New Zealand where the extreme minimum recorded temperature was below $-9^{\circ} \mathrm{C}$ (equal to the lower limit experienced by this species in Australia) despite the considerable area available to them. 


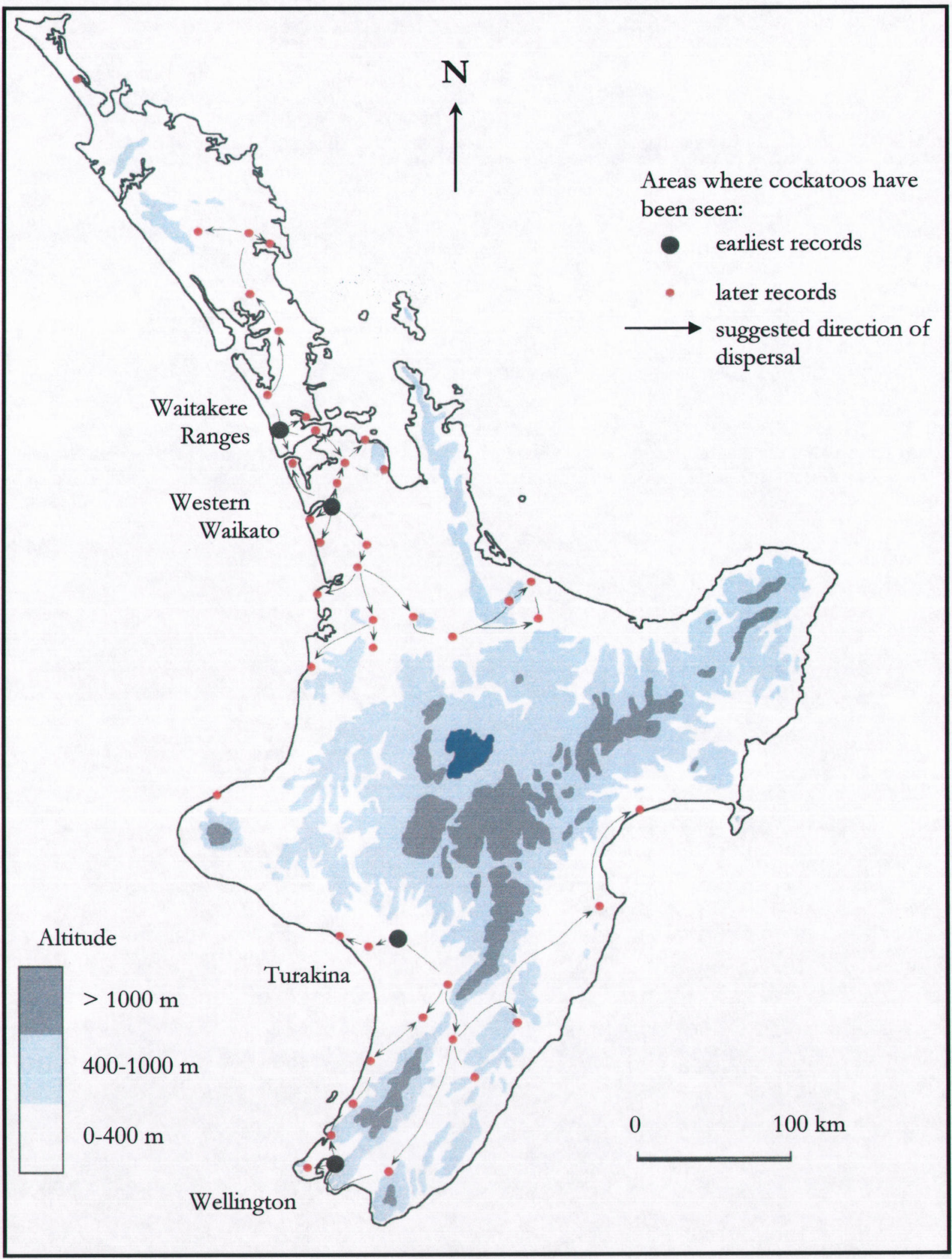

Figure 2.8. Possible patterns of Cacatua galerita dispersal in the North Island, New Zealand. 
The lower critical temperature limit (below which increased metabolic heat production is required if body temperature is to remain constant) has been found to vary according to weight, whether the bird is active or inactive (resting) and also differs between passerines and non-passerines (Robbins 1993). The temperature range in which thermoregulation can occur without increasing metabolic heat production is termed the thermoneutral zone and is bounded by the upper and lower critical temperatures of a species. Animals will generally select environments with ambient temperatures within their thermoneutral zone if given a chance (Robbins 1993).

Values for lower critical temperature thresholds for non-passerine birds are given by

$$
\mathrm{Y}=\mathrm{T}_{\mathrm{b}}-38.3 \mathrm{X}^{0.31}
$$

for inactive animals, and

$$
\mathrm{Y}=\mathrm{T}_{\mathrm{b}}-27.1 \mathrm{X}^{0.25}
$$

for active animals; where $\mathrm{T}_{\mathrm{b}}=$ body temperature (estimated at $39.6^{\circ} \mathrm{C}$ (inactive) and $41.5^{\circ} \mathrm{C}$ (active)), and $\mathrm{X}=$ body weight in kilogrammes (from Robbins 1993). For C. galerita (body weight $0.895 \mathrm{~kg}$ : averaged from wieghts given in Higgins 1999) the lower critical temperature limits are $2.35^{\circ} \mathrm{C}$ (inactive) and $15.14^{\circ} \mathrm{C}$ (active).

The lower critical limit for inactive non-passerine birds of this size falls within the range of mean daily minimum temperature experienced by $C$. galerita, while the lower critical temperature when active is approximate to the average daily maximum of temperature where these birds are recorded in New Zealand. The lack of observations of these birds in New Zealand where mean daily measures of temperature fall below $3^{\circ} \mathrm{C}$ (minimum) and $12^{\circ} \mathrm{C}$ (maximum) might represent an inability of these birds to maintain a stable body temperature at lower ambient temperatures. Intolerance of low ambient temperatures may also explain lack of sightings of these birds above $400 \mathrm{~m}$ asl.

Root (1988b) found a strong relation between northern boundary limits of passerine birds and their basal metabolic rate (BMR). Northern boundary limits occurred where the energy needed to compensate for a colder environment was greater than 2.45 times BMR, and this limit was consistent for all of the species tested. Measurement of the BMR of C. galerita could be used to test the low critical temperature limits suggested in this study. 


\subsubsection{Vegetation}

Characteristics of vegetation were also significant factors in determining C. galerita distribution. In both Australia and New Zealand C. galerita distribution was significantly and positively associated with the presence of arable land, where abundant seed producing cereal crops are grown.

Importantly, other characteristics of vegetation also play a significant role in defining the distribution of $C$. galerita. In Australia response to vegetation was defined by absence from areas with low growing vegetation, vegetation which is also typical of areas receiving higher temperature and that were not used for agriculture. Cacatua g. galerita distribution did exhibit a positive response to the presence of forest and woodland, but the effect was not significant when the variables wheat or crop were added. In New Zealand C. galerita exhibited a negative response to the presence of forest, but the presence of open woodland (patches of trees in grassland) was a significant and positive factor defining their distribution.

For the purposes of this study vegetation was divided into structurally similar categories, but differences in species composition, small-scale differences in structure, and underlying temperature, rainfall and fertility vary significantly between the two countries. Distribution of C. galerita might be better defined by particular plant species, or vegetational structure that was masked by the categories (or even the scale of the categories) used here. Cockatoos are hole-nesters and require large trees, with suitable cavities or rotten timber allowing nest excavation, which are not available in low growing scrub and heath vegetation. In New Zealand, presence of woodland (small pockets of forest within a predominantly grassland and arable landscape) may be important for successful breeding of these birds. Conversion of natural habitats, particularly forest, to farmland has caused the decline of many bird populations, reducing the number of nesting sites, and opens birds to greater competition for remaining sites, for example, with possums (Noske 1980) and other hole nesting birds (Green 1983; Anderson 1996), and may thereby restrict distribution and abundance. Trees may also provide an important source of food when seeds in grassland become scarce. The availability and distribution of trees in these instances have been shown to affect the distribution and breeding success of white-tailed black cockatoos (Calyptorbinchus baudinii) (Saunders 1974, 1980). 
Observations of habitat use by C. galerita in Australia suggest they are an 'edge' species, obtaining most of their resource requirements, including shelter and breeding sites, from forest and woodland habitats and feeding in adjacent grassland, most of which is now used for agriculture (Bennett 1978 in Noske 1980; Emison and Porter 1978; Noske 1980). Farmland provides an abundant source of food, especially for herbivorous and seed eating birds (Clarke et al. 1986; Owen and Black 1991). In Australia, cereal crops and exotic conifer plantations provide a source of seeds during winter when natural food sources may be scarce, and for some populations have almost completely replaced the natural foods (Saunders 1974, 1980; Noske 1980; Temby and Emison 1986; Emison and Nicholls 1992). There was also a significant and positive association between the distribution of C. galerita and the presence of cultivated land in New Zealand. Whether the seeds from cereal crops grown in these cultivated areas, or some underlying factors represented by the presence of these crops (for example, presence of fertile soil or favourable growing conditions), are important to C. galerita is not known, but the large aggregations of these birds reported in the Waikato were all observed feeding on maize (Zea maize) (CSN). While grassland may be an important resource for C. galerita in New Zealand, this habitat is very widespread and any relationship may be hidden by this fact.

Rainfall did not appear to be important in defining distribution, but may act indirectly through its effect on other variables. For example, rainfall is an important factor in determining plant species distributions, therefore, indirectly defining the distribution of species that depend on that vegetation (Caughley et al. 1987; Root 1988b; Gentilli 1992). Root (1988a) found strong associations between the distributional limits of seed-eating birds and vegetation, which in turn was closely related to rainfall. Rainfall has also been associated with species diversity, greater rainfall relating to greater plant species diversity, which in turn leads to greater bird species diversity (Gentilli 1992).

\subsubsection{Gaps in the distribution of $C$. galerita}

Hypothesis 2.2 (prediction 1) is not supported by the evidence presented here. Cacatua galerita do not use all of the area that the models suggest is suitable. For example, there appears to be acceptable habitat for this species in northern and southwestern Australia (Figure 2.7). The suitability of the environment in southwestern Australia is indicated by the fact that this species has successfully established near Perth, Western Australia (Blakers et al. 1984). Caughley et al. (1987) and Gentilli (1992) suggest the climate of the deserts of central Australia act as a barrier to the dispersal of species between the east and west of the 
continent. The absence of C. g. galerita from Western Australia indicates the central deserts, whether through high temperatures, aridity or lack of suitable refuges or food sources have also blocked their dispersal. In northern Australia the subspecies C. g. fitzroyii occupies most of the acceptable habitat, and here the distribution of $C$. g. galerita may be restricted by competition (or by a hybrid zone: Hewitt 1989) between this race and C. g. fitzroyii.

There are also many places in New Zealand where C. galerita have been seen, but which do not appear to have a suitable habitat (such as the West Coast of the South Island), while other areas appear to be appropriate, but C. galerita have not been seen there (such as Marlborough in the South Island, and the Gisborne Region of the North Island). During the early stages of invasion distribution may be related more closely to invasion history (where the birds were released) than to the preferred habitat of the species. All site records were used in the calculation of the distribution models, despite some records being potentially of free ranging tame birds or recently escaped cage birds that were not necessarily in areas of suitable habitat and may not have become established in the wild. Alternatively, C. galerita distribution may follow a pattern of source and sinks (Pulliam 1988; Smith et al. 1996), with successful production of juveniles in some areas maintaining populations nearby where the habitat is not appropriate and productivity falls below mortality. Distinguishing between these hypotheses is not possible on the basis of the evidence presented here.

\subsubsection{Limitations of analysis}

The models used in this study did not explain a large part of the observed variation in $C$. galerita distribution for both Australia and New Zealand populations (36.4-70.2\% unexplained). Several factors may be responsible. Firstly, the methodology for determining C. galerita range in New Zealand might over or under estimate distribution, either because birds were included that were not part of an established population or because some populations have not been recorded. A second possibility is, because only a limited number of environmental characteristics likely to effect bird distribution were measured, factors important in determining distribution might not have been included. For example, C. galerita may only need small pockets of forest for breeding but these areas may be overlooked in large-scale descriptions of vegetation.

Alternatively, the relationship between the environmental attributes selected and C. galerita distribution may have been obscured by the broad sampling scale used. For example, the Australian environment does not appear to test the tolerance of C. g. galerita to altitude, cold 
temperature or rainfall, there being no maximum altitude, minimum temperature and rainfall boundary to its distribution (this species occupied the highest, wettest and coldest blocks on the continent). The apparent lack of these environmental boundaries may be an artefact of the braod sampling scale used. That is, the scale used in mapping distribution may have been too broad to determine effects. For altitude, rainfall and temperature, squares were categorised according to the dominant structural feature. A wider range of temperature, rainfall and/or altitude were often present in these squares, and this is where C. galerita might occur or their presence might exclude these birds from the square. Distinguishing between these hypotheses is not possible using the accounts of $C$. galerita distribution that are currently available because of the broad geographic scale at which their presence was recorded.

\subsubsection{Conclusion}

Cacatua galerita are widespread in the North Island of New Zealand and appear to be spreading. In the South Island the species is localised and in the last decade the range over which they have been seen has decreased. Visual analysis of their mapped distribution suggests they are limited by altitude. Cacatua roseicapilla are localised, but increasing in number. Other than the likely influence of invasion history, little is known about what factors effect distribution of this species in New Zealand.

Statistical modelling of $C$. galerita distribution revealed the main effects on distribution were temperature (defined by upper limit of tolerance to temperature in Australia and lower limit of tolerance to temperature in New Zealand), use of land for cereal cropping and characteristics of vegetation. The range of temperature experienced by C. galerita in New Zealand falls within the limits of temperature experienced by this species in Australia; however, temperature was not the only factor significant in influencing their distribution. Presence of cultivated land was a significant and positive factor defining distribution in both Australia and New Zealand, while presence of open woodland was positively associated with their presence in New Zealand, but not in Australia.

Not all areas that the models predicted as being suitable for C. galerita (in both Australia and New Zealand) were occupied by these birds. This was attributed to failure to identify and include all of the factors important in defining C. galerita distribution, which was exacerbated by the survey scale used in mapping their distribution, and to barriers to dispersal in Australia (represented by the central deserts) and invasion history in New Zealand. 


\section{Chapter 3}

\section{Behaviour and habitat use of sulphur-crested cockatoos (Cacatua galerita) in the Turakina Valley, Manawatu-Wanganui, New Zealand}

\subsection{INTRODUCTION}

\subsubsection{Cacatua galerita in Australia}

In their natural range (Australia, New Guinea and several of the associated islands) sulphurcrested cockatoos (Cacatua galerita) exploit a wide variety of habitats, including rainforest, wet and dry sclerophyll forest, woodland and savannah, and human modified areas, such as agricultural land, urban areas and pine (Pinus spp.) plantations (Ridpath and Moreau 1966; Noske 1980; Blakers et al. 1984; Higgins 1999). Cacatua galerita are considered to be more abundant in heavily wooded areas, although uncommon in continuous forest, preferring edges of remnants in partly clear areas (McEvey 1965; Emison and Porter 1978; Noske 1980; Higgins 1999).

Most studies of $C$. galerita have been small-scale, with scattered notes on distribution and diet (Higgins 1999). The diet of C. galerita consists predominantly of seeds, but they also have been recorded feeding on fruit, nuts, bulbous roots (tubers), bulbs, corms, rhizomes, young shoots, flowering heads, and nectar; algae (Durvillea sp., Macrocystis augustifolia); fungi; and the larvae and eggs of Coleoptera, Diptera, Hymenoptera and Orthoptera (Noske 1980; Halse 1986; Lepschi 1993; Higgins 1999). Noske (1980) suggests that before clearing for agriculture in Australia, C. galerita were more arboreal, feeding on the fruits and seeds of many native trees.

Due to this species' economic importance to agriculture in Australia, a few more detailed studies of the species' diet, habitat use and abundance in crop-growing areas have been carried out (Noske 1980; Emison and Nicholls 1992). Like many other Australian parrots, C. galerita have taken advantage of the cereals, herbs and trees introduced by Europeans to supplement their diet of native plants (Frith 1977; Noske 1980; Friend 1982; Blakers et al. 1984; Halse 1986; Forshaw 1989; Emison and Nicholls 1992; Higgins 1999). Where grain 
crops were available, $C$. galerita exploited them in preference to other foods for most of the year, although seeds of native and introduced grasses are eaten in spring.

\subsubsection{Cacatua galerita in New Zealand}

Published information on distribution, abundance and diet of C. galerita in New Zealand consists mainly of single observations on particular foods and single records of where birds were sighted. The most significant populations are in the Auckland, Waikato and ManawatuWanganui Regions. The largest reported population (400 birds: Martin and Bartlett 1963) is located in the Turakina Valley, east of Wanganui.

Cacatua galerita in New Zealand have been recorded feeding on haystacks (Oliver 1930); nuts of macrocarpa (Cupressus macrocarpa) (Martin and Bartlett 1963); the base of young needles and terminal growth points of Pinus spp., seed capsules of wattles (Racosperma spp.), fruit of apples (Malus domestica), walnuts (Juglans regia), maize (Zea maize) seed, inkweed (Phytolacca octandra) berries and manuka (Kunzea ericoides) seed (CSN 1975, 1976, 1977, 1982, 1987, 1989, 1991, 1994, 1996); and seeds and fruit of kahikatea (Dacrycarpus dacrydioides), rimu (Dacrydium cupressinum) and matai (Prumnopitys taxifolia) (Speirs 1989; CSN 1984, 1990).

Many of the natural foods of $C$. galerita are not available in New Zealand. Perennial grasses dominate the pastures there, both in number of species and abundance (Langer 1973). Flowering and seed production for the majority of these grasses occurs between September and March (Hubbard 1954; Langer 1973; Lambrechtsen 1992), but peak abundance is likely to be over a shorter period, and would be further limited by grazing livestock. While the amount of food available in native forests may be sufficient to maintain many native bird populations, some species (such as kakapo Strigops babroptilus, kaka Nestor meridionalis and kakariki Cyanoramphus spp.) require full mast events to initiate widespread and successful breeding (O’Donell and Dilks 1994; Moorehouse 1997).

Cereal crops, plantation forest trees and food trees found on farmland could potentially provide an abundance of large seeds, favoured by C. galerita (Rowley et al. 1989), throughout the year. Maize and Pinus spp. are grown in both regions of New Zealand (Waikato and Manawatu-Wanganui) where C. galerita numbers are greatest. 


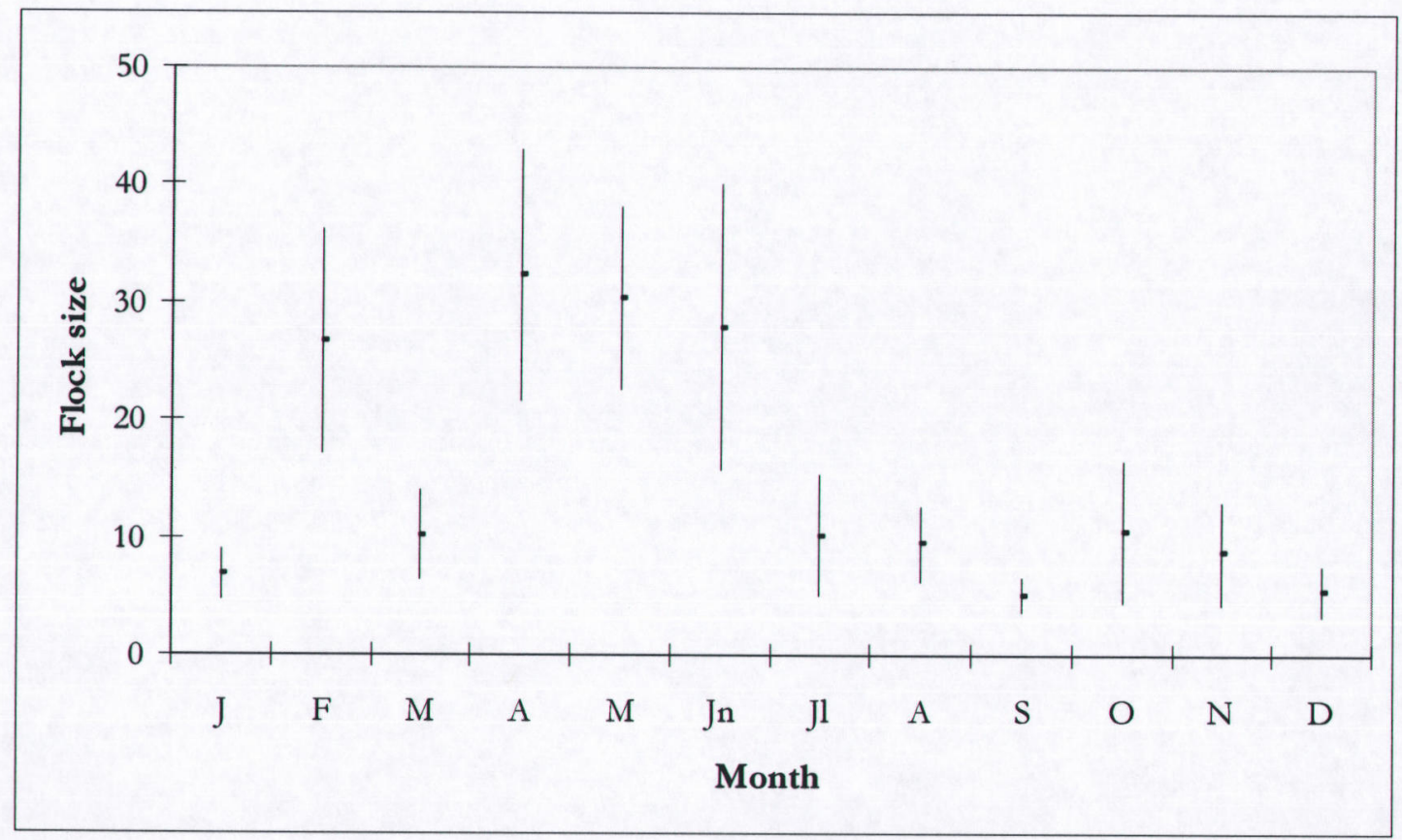

Figure 3.1. Monthly variation in flock sizes of Cacatua galerita in New Zealand. Values represent mean flock size ( \pm one standard error) for each month based on combined records from 19502000 . 


\subsubsection{Time and energy budget of $C$. galerita}

Winter and the breeding season are energetically stressful times for birds. They face greater thermoregulatory costs (maintaining a stable body temperature in the face of colder ambient temperatures) and must expend energy on gonad development, incubation and chick rearing (Weathers et al. 1984; Robbins 1993). These costs must be met by greater energy input (either by increasing time spent feeding, eating more calorifically rich food, or burning fat deposits) or spending less time on energetically expensive behaviour, such as flying, social activity, feather maintenance and feeding (Verbeek 1972; Magrath and Lill 1983; Robbins 1993; Madison and Robel 2001). Birds may decrease density, so decreasing intraspecific competition if foraging on widespread, uncommon and predictable foods (Magrath and Lill 1983; Delestrade 1994), or increase density if feeding on transient and localised food sources (Cannon 1984; Westcott and Cockburn 1988; Delestrade 1994). A potential benefit of flocking in winter is that large flocks are likely to include experienced individuals that know where food can be found, or are more efficient at finding unpredictable foods, allowing improved survival of young birds over their first winter (Delestrade 1994).

In Australia flock sizes and population density of $C$. galerita were greatest in winter when nomadic flocks congregated in a small section of their home range, while smallest mean flock sizes were recorded in spring, coinciding with breeding and when the birds were feeding on widely distributed food sources (Noske 1980). The proportion of the active day of birds spent feeding was greater between the months of March and November than December and February (summer) (Emison and Nicholls 1992). Records of C. galerita abundance in New Zealand indicate that flock size varies seasonally, being largest in autumn and winter and lowest in summer (Figure 3.1). If winter flocking does occur in New Zealand, the presence of experienced birds would reduce the time spent searching for food (flying) and so birds might be expected to spend more time feeding. Cacatua galerita might also switch to a more energy rich food source, as seen in P. elegans (Magrath and Lill 1983), potentially allowing a reduction in feeding effort if combined with better foraging ability. Alternatively, C. galerita could conserve energy by adopting less energy expensive behaviours.

This chapter provides baseline ecological data on C. galerita in New Zealand, extending what is known of this species from studies in Australia and providing insight into the role of arable land and small forest patches (native and exotic) in the daily resource requirements of this species in New Zealand. The methods used by $C$. galerita to meet the energetic demands of winter and breeding are addressed by the following three hypotheses. 


\section{Hypothesis 3.1}

Flock forming behaviour of $C$. galerita is an adaptation to feeding on temporally available and localised food sources.

- Prediction

- Increase in flock forming behaviour will be associated with feeding on temporally available and localised food. Conversely, decrease in flocking will be associated with feeding on widespread food sources.

\section{Hypothesis 3.2}

Increased costs of thermoregulation in winter will be met by a change in behaviour; to conserve energy, or find more food by either investing more time searching or by switching to a more energy rich and/or abundant food source.

\section{- Prediction 1}

- To meet the increased thermoregulatory costs of winter, C. galerita will increase the proportion of time spent resting and decrease time spent in other behaviours.

- Prediction 2

- To meet the increased thermoregulatory costs of winter, C. galerita will increase the proportion of time spent feeding and decrease time spent in behaviour not associated with feeding.

- Prediction 3

- To meet the increased thermoregulatory costs of winter, C. galerita will switch to a more energy rich and/or abundant food source.

\section{Hypothesis 3.3}

Most resource requirements for $C$. galerita will be provided by modified (non-native) environments.

- Prediction

- Being largely granivorous, C. galerita will obtain most food from agricultural land. 


\subsubsection{Study area}

The Turakina Valley study area $\left(39^{\circ} 54^{\prime} \mathrm{S}, 175^{\circ} 19^{\prime} \mathrm{E}\right)$ comprises $72 \mathrm{~km}^{2}$ and falls within an area of low hill country, up to 600 metres altitude (Figure 3.2). The nearest climate stations are at Ferriby Station, approximately $1 \mathrm{~km}$ east of the study area, and Wanganui, approximately 28 $\mathrm{km}$ south west of the study area. Annual rainfall measured at Ferriby Station averaged 955 $\mathrm{mm}$ over the period 1961-1990, with rainfall spread evenly throughout the year (National Institute of Water and Atmospheric Research (NIWA) observations, 1961-1990). Average annual temperature is within a band of $13-14^{\circ} \mathrm{C}$ (Kirkpatrick 1999). Extreme daily averages of temperature measured at Wanganui ranged from $9.9^{\circ} \mathrm{C}$ to $17.1^{\circ} \mathrm{C}$ (NIWA, 1961-1990). The growing season extends from spring through to autumn, though growth may slow during summer, depending on the regularity of rainfall, and in winter, due to low temperatures. The predominant pre-human vegetation of tall podocarp-broadleaf forest has been almost completely cleared (Ward 1976; Anderson 1977). Most of the area is now used for semi-intensive, or intensive, sheep and cattle grazing, with occasional cropping on river terraces (Ward 1976). The major vegetation type in the study area is a perrenial rye (Lolium perenne) dominated mixture of exotic pasture grasses containing a wide variety of herbaceous weeds. Several introduced tree species, mostly of European and North American origin, are grown in timber plantations, or as hedgerows and windbreaks. Other species have been planted to control flooding and land slippage, for ornamentation and to provide food. 


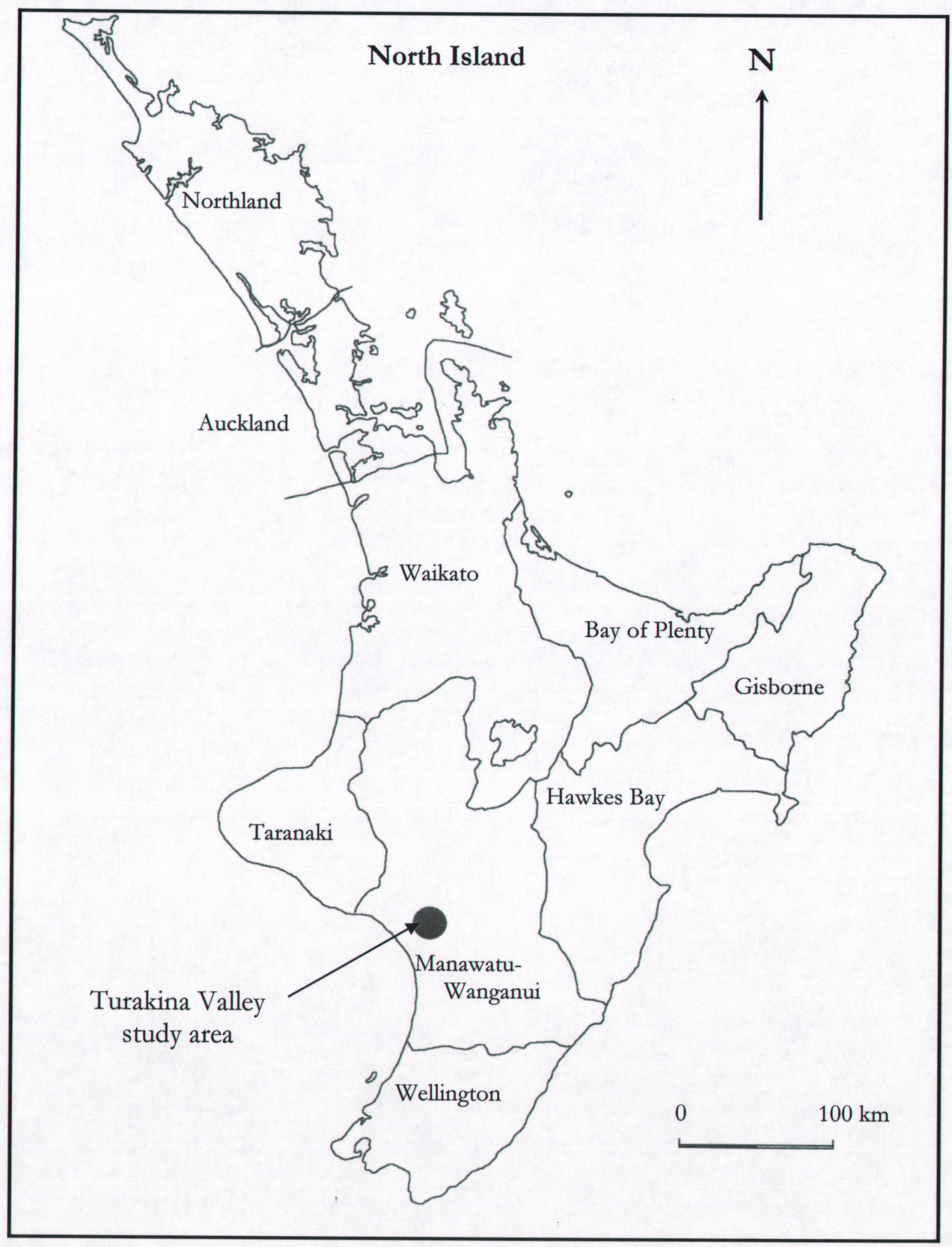

Figure 3.2. Location of the Turakina Valley study site. 


\subsection{METHODS}

\subsubsection{Collection of behavioural observations}

Every four weeks, from November 1992 to October 1993, I made field trips of eight to nine days to the study area. One day (30-60 minutes before sunrise to 30-60 minutes after sunset) was spent in each of six locations (observation areas) within the study area (Figure 3.3) noting flock size, activity, habitat use, numbers present and timing. A pair of $8 \times 30$ binoculars and a 13-40 x telescope were used to observe birds. Cacatua galerita in the Turakina Valley were extremely wary of humans and would either mob or flee when disturbed. As a consequence they were rarely observed at a distance of less than 100 metres, and were frequently observed at distances greater than 500 metres. Getting closer to these birds often risked disrupting their normal behaviour patterns so was not attempted. This restricted the selection of methods that could be used to monitor behaviour of these birds. For example, closely following marked individuals was not possible. Observations were made from a hide in the Sutherland's area, and from a vehicle or prominent hilltop at the other five locations.

Behaviour was recorded using an instantaneous sampling method (Altmann 1974), with a sample interval of 15 minutes. This method was selected because it allowed data to be obtained from a large number of individuals and is appropriate for estimating precent of time spent in various activities. I was also able to simultaneously collect information on flock size and movements. Eleven broad and easy to define activities were recorded (Table 3.1). Single behavioural states were recorded for every bird in view at each sampling time, taking 0-180 seconds to cover all birds visible during the scan. When large numbers of C. galerita were present ( $>100$ birds), the number present (or in view) and their activities were closely monitored prior to sampling to speed up the sampling time. Feeding records were collected simultaneously with other behavioural data. One bird feeding on one food type constituted one feeding record (Magrath and Lill 1983). It was often impossible to see exactly what individual birds were eating due to the distance from which they were observed, so mostly only the species or site on which they were feeding was recorded.

The habitat was divided into seven categories (habitat types) (Table 3.2) based on vegetation characteristics and observations of habitat use by $C$. galerita in the Turakina Valley between July 1991 and October 1992 (A. Styche personal observation). Each habitat type was further divided according to where it was located within the study area. 


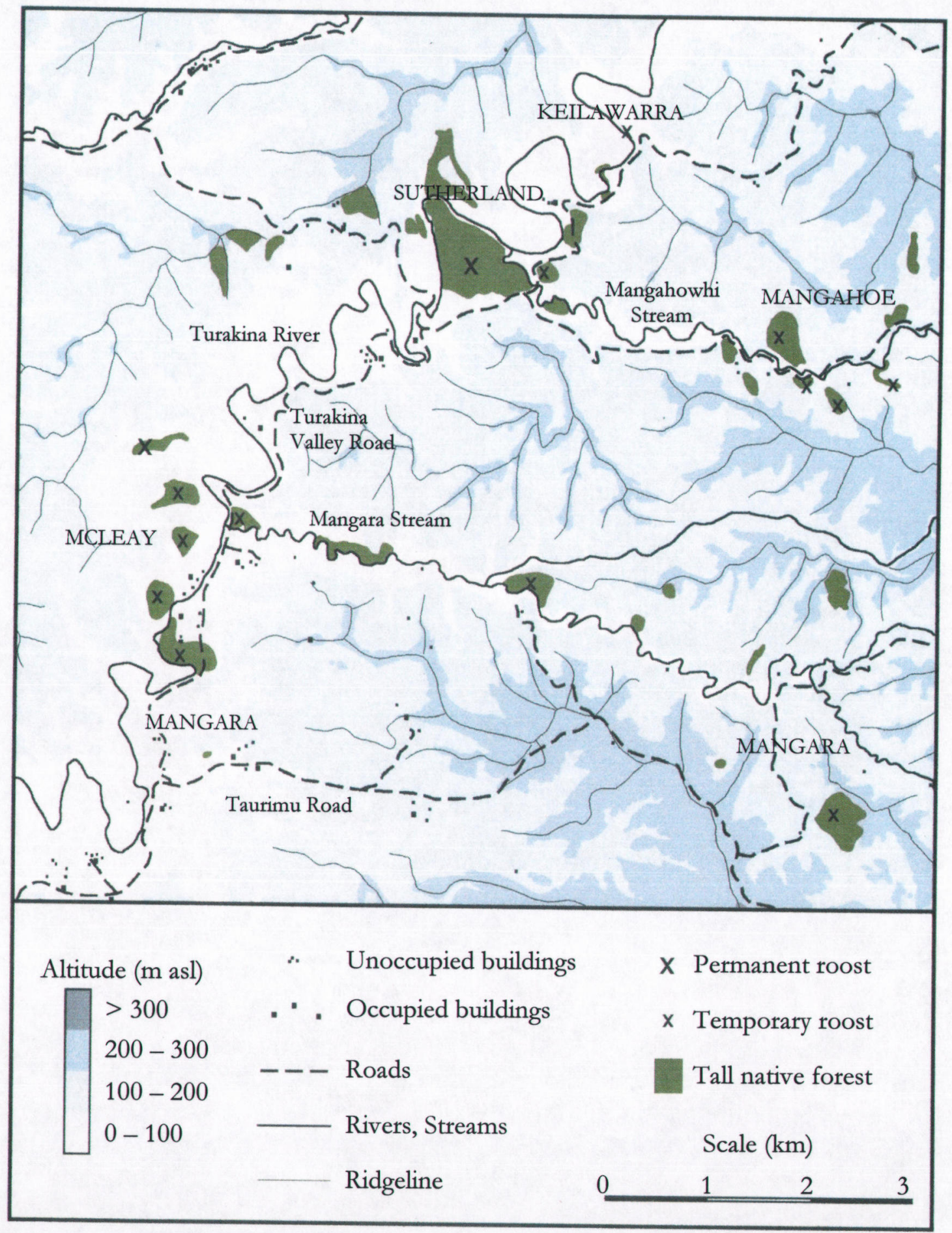

Figure 3.3. Location of six observation areas (indicated by capital letters) in the Turakina Valley study site. 
Independent stands of trees, crops and areas of pasture were recorded separately within the overall habitat type. Birds were recorded according to which block of a particular habitat they were in. Availability of foods likely or known to be eaten by C. galerita was obtained from field observations and from the literature. This information was presented here as an indication of the time of availability only. I did not obtain measures of abundance.

Table 3.1. Terms used to describe behaviour of Cacatua galerita. Behaviour categories taken from Noske (1980) and Magrath and Lill (1983).

\begin{tabular}{|c|c|}
\hline Term & Interpretation \\
\hline \multicolumn{2}{|l|}{ Resting } \\
\hline Resting & Standing or sitting immobile, with head movement only. \\
\hline Resting alert & $\begin{array}{l}\text { Standing or sitting, with associated body movement, but not engaged in } \\
\text { any other behaviour. }\end{array}$ \\
\hline \multicolumn{2}{|l|}{ Feeding } \\
\hline Feeding & $\begin{array}{l}\text { Manipulation of and reaching for food items, ingestion, pecking at or } \\
\text { grasping dead or live branches. Drinking was included in this category. }\end{array}$ \\
\hline \multicolumn{2}{|l|}{ Locomotion } \\
\hline Flying & All flights except chasing or fighting. \\
\hline Climbing & $\begin{array}{l}\text { Walking and/or climbing in a tree for more than one body length } \\
\text { without simultaneous feeding. }\end{array}$ \\
\hline \multicolumn{2}{|c|}{ Self-maintenance } \\
\hline Autopreening & Bill wiping, scratching, shaking, stretching and preening. \\
\hline Rain-bathing & $\begin{array}{l}\text { "Bathing" in heavy rain. Birds hung upside down or spread out over a } \\
\text { branch, with wings outstretched and feathers ruffled. }\end{array}$ \\
\hline \multicolumn{2}{|l|}{ Social Activity } \\
\hline Allopreening & $\begin{array}{l}\text { Preening of one bird by another, occasionally simultaneous between a } \\
\text { pair of birds. }\end{array}$ \\
\hline Display & Vocalising, possibly including crest displays and bobbing motion. \\
\hline Fighting & $\begin{array}{l}\text { Physical conflict between birds involving contact, often resulting in a } \\
\text { flight chase. }\end{array}$ \\
\hline Nest attendance & Nest hollow inspection, and attending eggs and nestlings. \\
\hline
\end{tabular}

Information on reproductive behaviour (timing and nest site selection) was obtained opportunistically during collection of data for other projects, and during collection of timebudget analysis data. Productivity from a sample of nests was recorded from nests where 
chicks were taken for pets. This information was provided by J. Edge (grouped together here as Pohangina nests) and P. Corliss and G. Butters (grouped together here as Turakina nests).

Table 3.2. Habitat types based on vegetational characteristics.

\begin{tabular}{|c|c|}
\hline Term & Interpretation \\
\hline \multicolumn{2}{|l|}{ Native } \\
\hline Tall native forest & $\begin{array}{l}\text { Tall }(\geq 20 \mathrm{~m}) \text { primary native forest containing many large }(>25 \mathrm{~m}) \\
\text { emergent podocarp trees. }\end{array}$ \\
\hline Low native forest & $\begin{array}{l}\text { Low }(\leq 15 \mathrm{~m}) \text { regrowth native vegetation dominated by Kunzea ericoides, } \\
\text { Leptospermum scoparium and low growing broadleaf canopy species. }\end{array}$ \\
\hline \multicolumn{2}{|l|}{ Exotic tree } \\
\hline Non-pine exotic & $\begin{array}{l}\text { Mostly Populus spp. and Salix spp., but including small areas of other } \\
\text { exotic angiosperm trees. }\end{array}$ \\
\hline Cupressus macrocarpa & Macrocarpa \\
\hline Pinus spp. & Pines \\
\hline \multicolumn{2}{|l|}{ Modified ground } \\
\hline Grassland & $\begin{array}{l}\text { Grassed paddocks and weedbanks. Includes bare ground and temporary } \\
\text { pools of water. }\end{array}$ \\
\hline Crop & $\begin{array}{l}\text { Land used for growing crops. Includes maize (Zea maire), choumollier } \\
\text { (Brassica oleracea) and ploughed paddocks. }\end{array}$ \\
\hline
\end{tabular}

\subsubsection{Data analysis}

It was impossible to observe C. galerita in each of the six areas concurrently; therefore I collected data over several days. These data were then treated as if they had been obtained in one day, and collectively they illustrate one composite daily activity record (as in Verbeek 1972). I estimated the total numbers at each observation area each month and used this to estimate the population within the study site for that month. The number of $C$. galerita in an observation area was calculated by recording the movement of birds into and out of the area throughout the day. Every bird was counted as it left or entered the area being surveyed, and the direction of flight (north, northeast, east, southeast, south, southwest, west and northwest), time of day and number of birds remaining in the area (if possible to determine) was noted. Foraging group size was defined as the number of birds engaged in the same 
activity in the same block of habitat. Other birds engaged in different activities at the same time or in a separate habitat block were counted as a different group.

For analysis, each observation day was divided into five daytime units of equal length (defined as early morning, late morning, mid-day, mid-afternoon and late afternoon). Length varied with the seasonal variation in daylength, ranging from two hours (eight sampling intervals) in winter to three hours (12 sampling intervals) in summer. The 'active day' was defined as the interval between sunrise or the time of first appearance of a cockatoo (whichever was earliest) and sunset or time of last sighting of a cockatoo in the evening (whichever was latest). Birds were assumed to be roosting from sunset to sunrise, when poor lighting prevented observation. All times mentioned in analyses relate to Standard Time. Initially, comparison of activity was to be between months, but because few records were obtained in some months data were grouped into seasons and comparisons were made between seasons. For the purposes of this study I have defined the seasons as: late spring = November; summer = December-February; autumn = March-May; winter $=$ June-August; and early spring $=$ September-October.

Aerial photos (1:25000 scale), purchased from New Zealand Aerial Mapping Limited (Napier), were used for mapping the birds' movements and habitats. Using a Minimop digitizer, the areas of certain habitat types were calculated.

Chi-square and t tests (Sokal and Rohlf 1981) were used to test for goodness of fit of diurnal and seasonal data. Where possible the number of categories of flock sizes was reduced to limit the number of cells containing fewer than five samples. Despite this, small sample sizes in some categories and the lack of independence of data in some serial studies (such as comparison of flock sizes between times of day and between seasons) means that values achieved for Chi-square and t tests should only be taken as an indication of what is occurring. Pearson's product-moment correlation (Devarenne 1997) was used to test for correlation between population size and the incidence of nesting activity and flock size.

Basal Metabolic Rate (BMR) (Magrath and Lill 1983; Weathers et al. 1984; Robbins 1993) and the energetic costs of thermoregulation, foraging, maintenance and reproduction have not been measured for C. galerita, and determining them was beyond the resources available for this study. Instead, the energetic costs (as multiples of BMR) were estimated from the literature using: night roosting $=1$ (Weathers et al. 1984; Robbins 1993); day-time resting = 1.98 (Robbins 1993); Feeding = 2.19 (Weathers et al. 1984); autopreening, rain-bathing, 
allopreening and display $=2.18$ (estimated from Weathers et al. 1984); climbing $=2.8$

(Magrath and Lill 1983); and Flying $=14$ (Robbins 1993). Because caloric values for many of the actual species eaten by C. galerita were not known, estimates were calculated from values obtained for related plant groups taken from the literature (Table 3.3). Calculations of energy intake presented here (mostly based on values for seeds) must be considered as estimates because no account was taken of the difference in foraging efficiency of $C$. galerita in different habitats. Furthermore, these birds may have been consuming other plant parts, however, little difference has been found in the metaboliseable energy available in different plant parts and invertebrates (Golley 1961; Robbins 1993).

Table 3.3. Energy content of plant parts.

\begin{tabular}{|c|c|c|c|}
\hline & Plant group/taxa & $\begin{array}{c}\text { Energy value } \\
(\mathrm{kcal} / \mathrm{g})\end{array}$ & Source \\
\hline Thistles & Compositae & $\begin{aligned} & 5.381 \\
(s e= & 0.166, n=5)\end{aligned}$ & Kendeigh and West 1965 \\
\hline $\begin{array}{l}\text { Introduced annual } \\
\text { and perennial herbs }\end{array}$ & Dicotyledons & $\begin{array}{c}5.072 \\
(\mathrm{se}=0.077, \mathrm{n}=37)\end{array}$ & Kendeigh and West 1965 \\
\hline Bare ground & $\begin{array}{l}\text { Vegetable matter } \\
\text { (roots) }\end{array}$ & 4.72 & Golley 1961 \\
\hline Pasture & Gramineae & $\begin{array}{c}4.573 \\
(\mathrm{se}=0.005, \mathrm{n}=16)\end{array}$ & Kendeigh and West 1965 \\
\hline Zea maize & Gramineae & 4.371 & Kendeigh and West 1965 \\
\hline $\begin{array}{l}\text { Introduced } \\
\text { deciduous and } \\
\text { evergreen trees }\end{array}$ & Dicotyledons & $\begin{array}{c}5.072 \\
(\mathrm{se}=0.077, \mathrm{n}=37)\end{array}$ & Kendeigh and West 1965 \\
\hline Introduced conifers & $\begin{array}{l}\text { Cupressaceae and } \\
\text { Pinaceae }\end{array}$ & 6.1 & Robbins 1993 \\
\hline $\begin{array}{l}\text { Native evergreen } \\
\text { trees }\end{array}$ & Dicotyledons & $\begin{array}{c}5.072 \\
(\mathrm{se}=0.077, \mathrm{n}=37)\end{array}$ & Kendeigh and West 1965 \\
\hline Native conifers & Podocarpaceae & 6.1 & Robbins 1993 \\
\hline $\begin{array}{l}\text { Dead tree } \\
\text { invertebrates }\end{array}$ & $\begin{array}{l}\text { Combined value for } \\
\text { insects and annelids }\end{array}$ & 4.99 & Golley 1961 \\
\hline
\end{tabular}




\subsection{RESULTS}

\subsubsection{Population size and organisation}

\subsubsection{Cacatua galerita roost sites}

All C. galerita roost sites were located in native forest, predominantly podocarp forest, with a canopy height greater than 20 metres, although occasionally birds roosted in tawa (Beilschmiedia tawa) and $K$. ericoides dominated forest where the canopy height was less than 20 metres (Figure 3.3). Cacatua galerita showed no apparent preference for roost sites with or without (the result of stock browsing) understorey vegetation. Eight of the 15 known roosts had little or no understorey vegetation, including one of the permanent roosts. Proximity to human dwellings did not appear to affect use of forest patches for temporary roosts or for nesting (all but the Keilawarra roost were also used for nesting), but the two permanent roosts were distant from human habitation (Figure 3.3).

A total of 15 roost sites was identified within the study area, with an average size of 9.9 ha (s.d. = 12.9, range 1.5-53.7 ha). There were two permanent roosts, which were in use during every month of the year, while the other roosts were occupied during 1 to 11 of the 13 surveys between November 1992 and October 1993 (Table 3.4). The largest roosting aggregations were at the two permanent roosts, ranging from $59.4-100 \%$ of birds recorded returning to roost at dusk. Between May and August most of the birds were resident in the McLeay roost $(58.5-96.1 \%$ of birds recorded in the area at dusk). Fewer roosts were occupied between autumn and winter than between spring and summer $(t=3.932$, d.f. $=11$, $\mathrm{P}=0.002$ ) (Table 3.4).

In the Sutherland's roost there appeared to be some segregation of the roosting flock into separate groups. Most birds roosted in tall podocarp trees in the centre of the reserve; however, there was a small number that regularly roosted separately from the main flock. Segregation of the roosting flock was most pronounced when birds nested, pairs remaining close to nest trees, but was maintained by this group throughout the year. These birds, consisting of about five individuals (the actual number varying during the year with the onset of nesting and addition of fledglings in December), were observed roosting every evening in a cluster of podocarps (alongside a regularly used nest tree) at the edge of the reserve. These same birds were also regularly seen by day to rest together in the same area, while the remainder of the population roosted in a dense stand of podocarps in the core of the reserve. 
Table 3.4. Roosts occupied by Cacatua galerita in the Turakina Valley study area each month from November 1992 to October 1993. ' $x$ ' indicates roost occupied during that month.

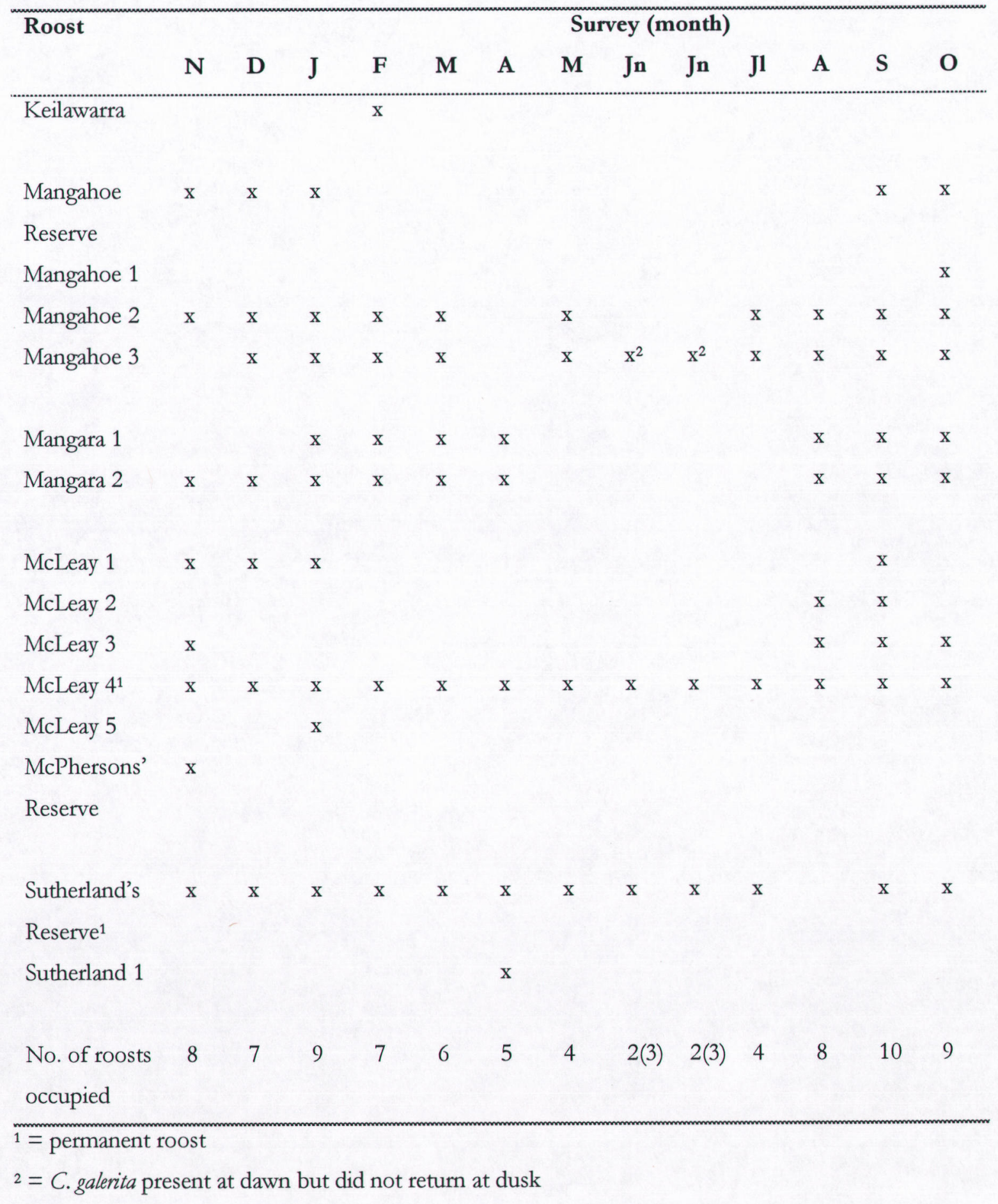




\subsubsection{Activity at the roost}

Cacatua galerita roosted communally in the middle and lower branches of densely foliaged canopy trees. At sunrise birds began moving from their roosts, either singly or in small groups, to prominent positions gathering in sparsely foliaged emergents. The first birds appeared on average 6.5 minutes after sunrise (s.d. $=19.86$ minutes, range $=15$ minutes before to 53 minutes after sunrise) (Figure 3.4). Seasonally, C. galerita appeared later in summer (mean 36 minutes, range $=15-53$ minutes after sunrise) than in winter $(t=-3.724$, d.f. $=5, P=0.014)$ and spring $(t=-3.508$, d.f. $=4, P=0.025)$, while the difference between summer and autumn was not significant $(t=-2.675$, d.f. $=4, P=0.056)$. After rising they rested, occasionally engaging in preening activity, until the sun appeared over the local horizon, at which time the flock began to disperse to forage. Individuals called sporadically between rising and departing from the roost, but generally remained silent. Weather conditions, such as rain, cloud cover and mist, did not appear to affect the timing of dispersal.

Flocks of C. galerita returned to roost sites late in the afternoon or early evening. Upon arriving at the roost site most birds settled into prominent sparsely foliaged emergents. They seldom called at this time. As light levels decreased they became more active, with flocks circulating between prominent perches and densely foliaged trees lower in the canopy. During this period of activity, calling was frequent decreasing only as the birds settled into roosting trees, but sometimes continuing until well after dark. On average, the last birds moved into roosting trees, and thus out of sight, 11.5 minutes after sunset (s.d. $=8$ minutes, range $=1-32$ minutes), with little variation in the timing of this activity during the year ( $\mathrm{t}$ tests, d.f. $=4-5$, P's $=0.195-0.517$ ) (Figure 3.4).

Based on the first appearance of $C$. galerita in the morning until the last sighting of these birds in the evening, the longest active day was recorded in November (900 minutes) and the shortest day was recorded late in June (570 minutes).

\subsubsection{Variation in population size of C. galerita}

The population of C. galerita within the study area was estimated by counting the number of birds using roosts at six locations within this area, encompassing most of the known roost sites. This was not a closed population, the annual and daily home range of these birds extended beyond the area under investigation. As a result, there was considerable monthly 
and diurnal variation in population size. The population, taken as the number of C. galerita recorded roosting at five of the six locations combined (no birds were recorded roosting at the Taurimu observation area) (Table 3.5), ranged from 52 to 310 individuals (0.007-0.043 per hectare), with greatest numbers recorded in winter and least numbers in summer and early spring.

\subsubsection{Diurnal variation in C. galerita numbers within the study area}

There was pronounced diurnal variation in the number of C. galerita within the study area (Figure 3.5), with a decrease in the mean number of birds present from early to late morning $(\mathrm{t}=3.869$, d.f. $=271, \mathrm{P}<0.001)$ and an increase in the mean number from mid- to late afternoon $(\mathrm{t}=-3.178$, d.f. $=262, \mathrm{P}=0.002)$. Although numbers varied between late morning and mid-afternoon, differences were not significant ( $t$ tests, d.f. $=254$, P's $=0.073-$ 0.748). Seasonally, diurnal variation in number of birds within the study area was greater in late spring and summer ( $t$ tests, d.f. $=22-72$, P's $<0.001$ : except between early morning and late morning in late spring, $\mathrm{t}=2.595$, d.f. $=23, \mathrm{P}=0.016)$ and less extreme in autumn ( $\mathrm{t}$ tests, d.f. $\left.=52-58, \mathrm{P}^{\prime} \mathrm{s}=0.012-0.568\right)$, winter (t tests, d.f. $=64-68, \mathrm{P}$ 's $\left.=0.023-0.944\right)$ and early spring ( $\mathrm{t}$ tests, d.f. $=40-42$, P's $=0.003-0.088$ ) (Figure 3.5 ). Early spring was most similar to the overall pattern of diurnal variation in numbers. 


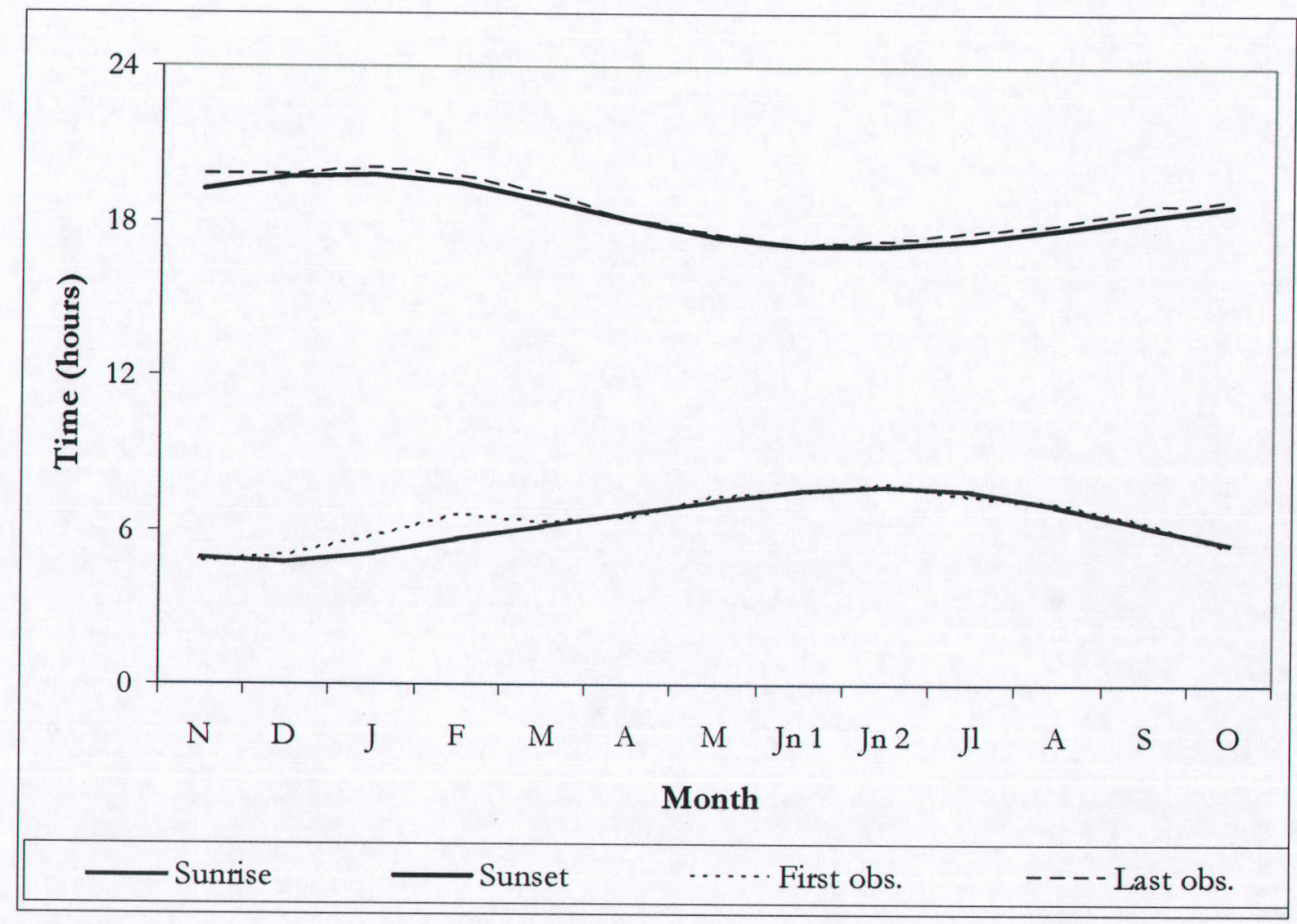

Figure 3.4. Variation in the active day of Cacatua galerita in the Turakina Valley from November 1992 to October 1993. 'First obs.' represents the time when birds were first seen in the observation area; and 'Last obs,' represents the latest time in the day when they were seen. 
Table 3.5. Number of Cacatua galerita roosting at five observation areas of the Turakina Valley study site at four weekly intervals between November 1992 and October 1993.

(a) Cacatua galerita population counted at dawn

\begin{tabular}{|c|c|c|c|c|c|c|c|c|c|c|c|c|c|}
\hline \multirow{2}{*}{$\begin{array}{l}\text { Observation } \\
\text { area }\end{array}$} & \multirow[b]{2}{*}{$\mathbf{N}$} & \multirow[b]{2}{*}{ D } & \multirow[b]{2}{*}{$\mathbf{J}$} & \multicolumn{10}{|c|}{ Survey (month) } \\
\hline & & & & $\mathbf{F}$ & $\mathbf{M}$ & $\mathbf{A}$ & $\mathbf{M}$ & Jn & Jn & $\mathrm{J} 1$ & $\mathbf{A}$ & $S$ & $\mathbf{O}$ \\
\hline Sutherland & 123 & 72 & 46 & 61 & 55 & 113 & 28 & 14 & 34 & 8 & 40 & 47 & 14 \\
\hline McLeay & 6 & 41 & 14 & 30 & 12 & 44 & 123 & 260 & 260 & 298 & 78 & 42 & 24 \\
\hline Mangahoe & 8 & 9 & 25 & 48 & 13 & - & 10 & $2^{1}$ & $8^{1}$ & 4 & 6 & 10 & 25 \\
\hline Mangara & - & - & 20 & 9 & 17 & 6 & - & - & - & - & 7 & 8 & 2 \\
\hline Keilawarra & - & - & - & 3 & - & - & - & - & - & - & - & - & - \\
\hline Estimated total & 137 & 122 & 105 & 151 & 97 & 163 & 161 & 276 & 302 & 310 & 131 & 107 & 65 \\
\hline
\end{tabular}

${ }^{1}=$ roosts occupied in the morning but not the following evening.

(b) Cacatua galerita population counted at dusk

\begin{tabular}{|c|c|c|c|c|c|c|c|c|c|c|c|c|c|}
\hline \multirow{2}{*}{$\begin{array}{l}\text { Observation } \\
\text { area }\end{array}$} & \multirow[b]{2}{*}{$\mathbf{N}$} & \multirow[b]{2}{*}{ D } & \multirow[b]{2}{*}{$\mathbf{J}$} & \multicolumn{10}{|c|}{ Survey (month) } \\
\hline & & & & $\mathbf{F}$ & $\mathbf{M}$ & A & $\mathbf{M}$ & Jn & Jn & J1 & $\mathbf{A}$ & $S$ & O \\
\hline Sutherland & 119 & 38 & 46 & 61 & 51 & 74 & 36 & 13 & 25 & 8 & 45 & 36 & 14 \\
\hline McLeay & 6 & 41 & 14 & 37 & 23 & 44 & 88 & 263 & 259 & 298 & 79 & 42 & 24 \\
\hline Mangahoe & 8 & 9 & 21 & 11 & 9 & - & 11 & - & - & 4 & 6 & 10 & 12 \\
\hline Mangara & - & - & 20 & 9 & 17 & 10 & - & - & - & - & 5 & 8 & 2 \\
\hline Keilawarra & - & - & - & 3 & - & - & - & - & - & - & - & - & - \\
\hline $\begin{array}{l}\text { Estimated } \\
\text { total }\end{array}$ & 133 & 88 & 101 & 121 & 100 & 128 & 135 & 276 & 284 & 310 & 135 & 96 & 52 \\
\hline
\end{tabular}

\subsubsection{Monthly variation in C. galerita numbers recorded at roosts}

A comparison between population estimates, taken from counts of $C$. galerita using roosts at dawn and dusk, shows much variation for each observation area and in total (Table 3.5). Six of the 13 surveys involved a difference between dawn and dusk of less than 10 birds and may result from inaccuracies in counting birds as they entered or left the area. Some birds were also caught in cage traps and so were removed permanently from the population. The total number lost to the population from this source, or from shooting and other sources of mortality during the course of this study are not known. 

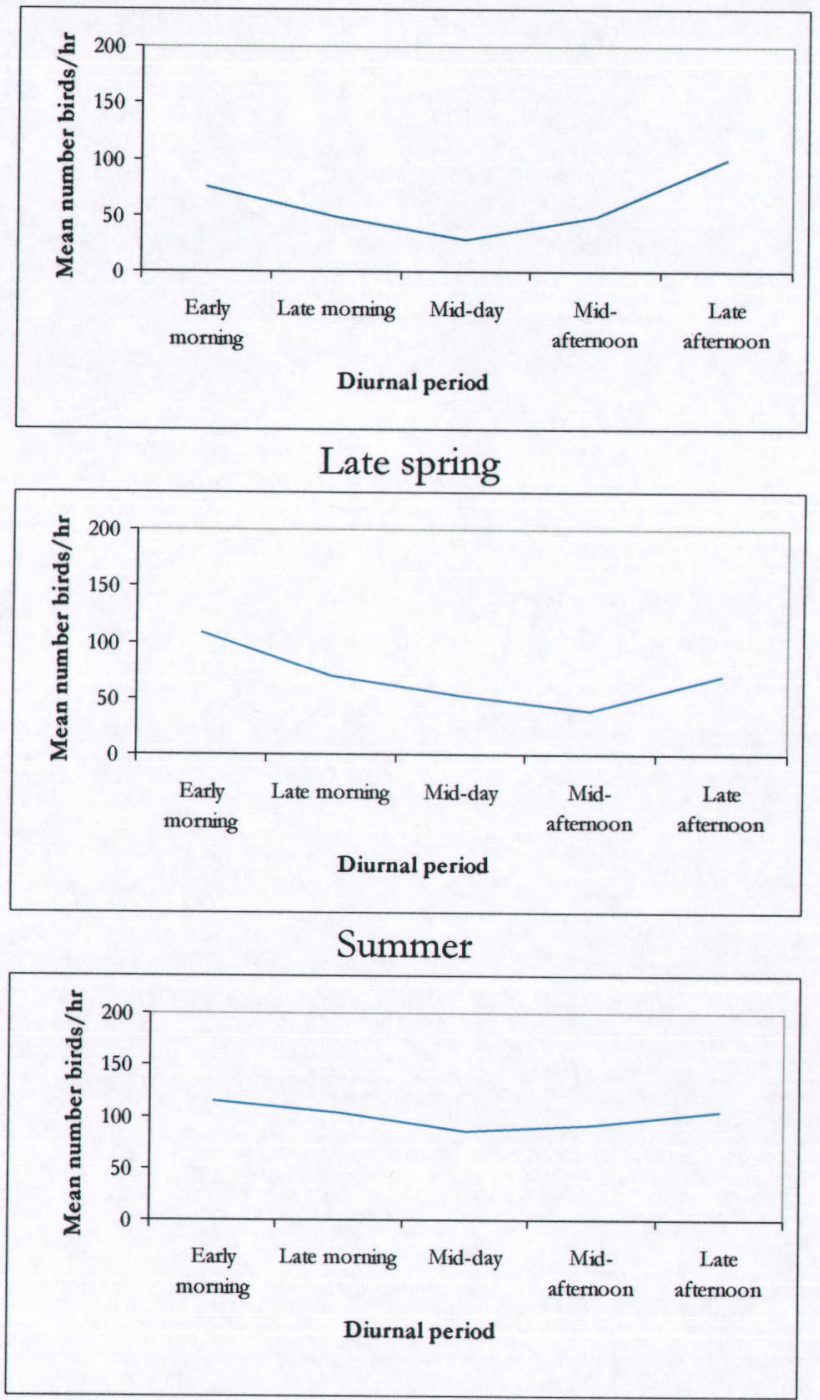

Autumn

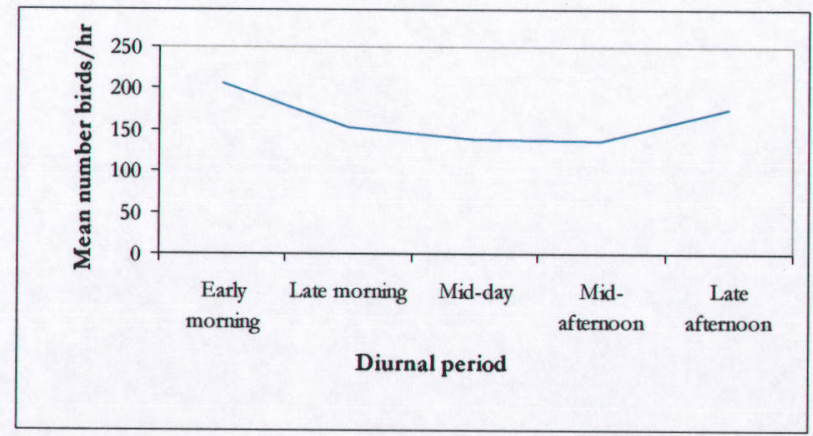

Winter

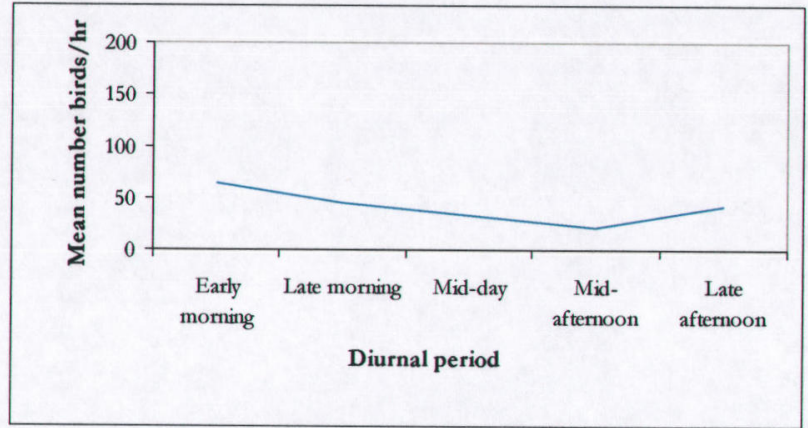

Early spring

Figure 3.5. Mean number of Cacatua galerita present in the study area during each diurnal period (November 1992 to October 1993). Monthly data have been averaged for each season. 
There were also some larger inconsistencies between dawn and dusk counts, with the most significant variation being recorded during summer and autumn (after the breeding season). During the months of December, February, April and May there were between 26 and 35 fewer birds recorded in the evening than in the morning (Table 3.5). These differences were the result of a large variation in the number returning to a particular roost. Variation in numbers did not occur at the same roost on each occasion, roosts in the Sutherland's, McLeay and Mangahoe observation areas contributing to variation on different months.

\subsubsection{Monthly variation in C. galerita population size}

Large increases in the population of C. galerita from March to April and from May to June 1993 followed a period of considerable fluctuation in population size between November and March that showed no consistent pattern of change (Table 3.5). Peak numbers were reached in July, followed by a rapid decrease in the number of birds resident in the study area during August. Smaller decreases in the number present occurred in each successive month, until reaching the lowest population size in October.

An increase in the number of $C$. galerita using two roosts, one in the Sutherland's area and one in the McLeay's area, along the Turakina River (Figure 3.3) between April and July followed decreases in the number at, or abandonment of, several other roosts within the study site (Table 3.5). A survey of landowners over a wider area, although in no way complete, revealed a similar decrease in numbers of $C$. galerita at roosts beyond the study site during the same period (Appendix 2). The decrease in the number of C. galerita resident in these two permanent roosts (occupied in every month during this study) at the end of winter coincided with an increase in the number using roosts directly adjacent to these permanent roost sites.

\subsubsection{Cacatua galerita population changes associated with crop cycles and breeding activity}

Increases in the population of C. galerita in April and June of 1993 coincided with the ripening of maize (April) and the beginning of the maize harvest (June) (Figure 3.6). Most of the birds in the first influx roosted at the permanent roost at Sutherland's Bush. After April these birds, plus most of the population from the Sutherland's roost, moved down to the permanent roost on the McLeay's property, which was located beside the maize fields. All subsequent flocks entering the area fed with, and roosted with, the birds at the McLeay's roost. 


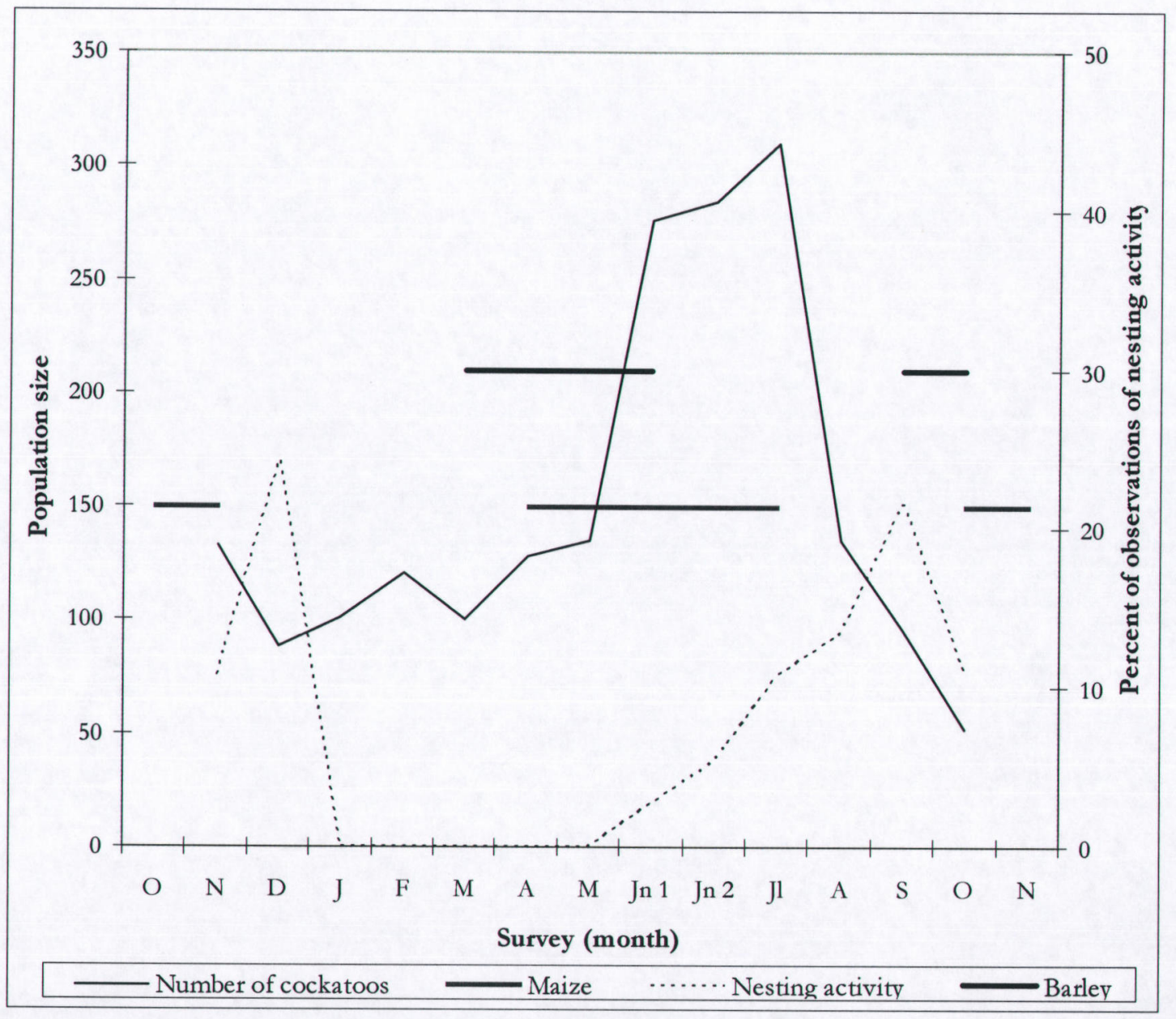

Figure 3.6. Number of Cacatua galerita present in the Turakina Valley study site (dusk counts) in relation to nesting activity and crop cycles. Nesting activity and availability of crop seed are based on observations within the study area over this period. 
Declines in the population followed soon after the completion of the maize harvest, which occurred in July 1993 (Figure 3.6). There was a significant positive correlation ( $r=0.6998$, d.f. $=13, \mathrm{P}=0.0077$ ) between $C$. galerita population size (based on flock counts) and the presence of maize. There was no relationship between population size and the incidence of nesting activity $(r=-0.1709$, d.f. $=13, \mathrm{P}=0.5767)$. Although the decrease in population size between July and August coincided with an increase in nest attendance, activity at nest sites was first seen in early June 1993 when the population was increasing (Figure 3.6).

\subsubsection{Movement patterns and feeding ranges of $C$. galerita}

\subsubsection{Variation in size of C. galerita flocks leaving and entering the observation area}

Flights between roosts and feeding grounds took up a large part of the daily activity of $C$. galerita. The flocks observed in the Turakina Valley, dispersing from and entering observation areas, ranged in size from 1 to 122 birds, with an average of 5.2 birds per flock (s.d. $=10.0, \mathrm{n}$ $=1200$ ). Although most flocks tended to be small (median flock size $=2$ ), mean flock size is likely to have been underestimated as many of the flocks recorded as dispersing in small groups were part of larger, loosely cohesive foraging flocks.

Flock sizes varied significantly between times of day $\left(\chi^{2}=58.8\right.$, d.f. $\left.=28, \mathrm{P}<0.001\right)$. Although the number of flocks of 1 or 2 birds remained relatively constant through the day, there were proportionally more large flocks (11 or more birds) recorded during the early morning and mid-afternoon than at other times of day (Figure 3.7). This result was strongly influenced by the flock sizes seen in winter $\left(\chi^{2}=56.4\right.$, d.f. $\left.=28, \mathrm{P}<0.001\right)$ when there were significantly more flocks of 11 or more birds in the early morning and mid-afternoon. For the other seasons, the differences in the proportion of flocks sizes observed were weakly significant (late spring: $\chi^{2}=38.4$, d.f. $=24, P=0.031$ ) or not significant (summer: $\chi^{2}=30.18$, d.f. $=20, P=0.067$; autumn: $\chi^{2}=30.2$, d.f. $=24, P=0.179$; and early spring: $\chi^{2}=21.269$, d.f. $=20, P=0.381)$.

Flock sizes showed a significant difference between seasons $\left(\chi^{2}=169\right.$, d.f. $\left.=28, \mathrm{P}<0.001\right)$. A large part of this variation was contributed by the difference in the number of lone birds recorded in each season. Lone birds were observed more frequently ( $35.8 \%$ of flocks) than any other flock size. In summer and spring lone birds comprised 49 and $53 \%$ of all flocks recorded, whereas in winter lone birds constituted only $17 \%$ of flocks (Figure 3.8). There was no significant difference in flock sizes seen in late spring and summer $(t=1.75$, d.f. $=$ 
458, P > 0.1); however, flock sizes increased significantly between summer and autumn $(\mathrm{t}=$ 3.77 , d.f. $=507, \mathrm{P}<0.001)$, and autumn and winter $(\mathrm{t}=3.29$, d.f. $=598, \mathrm{P}<0.001)$, then decreased significantly from winter to early spring $(t=5.89$, d.f. $=525, \mathrm{P}<0.001)$. Winter showed the greatest difference in the frequencies of the various flock sizes from all other seasons, having the largest mean flock size (mean $=8$, s.d. $=14.6, \mathrm{n}=387$ ) compared to other seasons (range of means $=3.14-5.12$ ), and including the only records of flocks consisting of more than 100 birds.

\subsubsection{Flight paths and general patterns of movement of C. galerita}

Most movements were along valleys. Ridges were crossed at few locations and generally at a saddle between adjoining valleys. The most heavily used flight paths were along the Turakina River, radiating out from the major communal roosts at Sutherland's Bush and the McLeay's property (Figure 3.9a-e). Stands of tall native forest acted as centres for the dispersal and aggregation of flocks. Most birds moved away to feeding sites early in the morning, often showing consistency in movement. Many of these flight paths went past vacated nest sites or roosts, which were frequently visited, from which these groups dispersed further afield (Figure 3.9a-b). About mid-day, most activity in the observation area was centred on the Sutherland's roost as flocks moved there to day rest before dispersing again early in the afternoon (Figure 3.9c-d). Late in the afternoon, or earlier in winter, groups of C. galerita began moving back towards their roosts, again frequently visiting vacated roosts and nest sites along the way (Figure 3.9e).

The sites used by C. galerita, especially for feeding, changed seasonally depending on seed cycles and breeding activity. Such changes caused a related change in bird movements. 


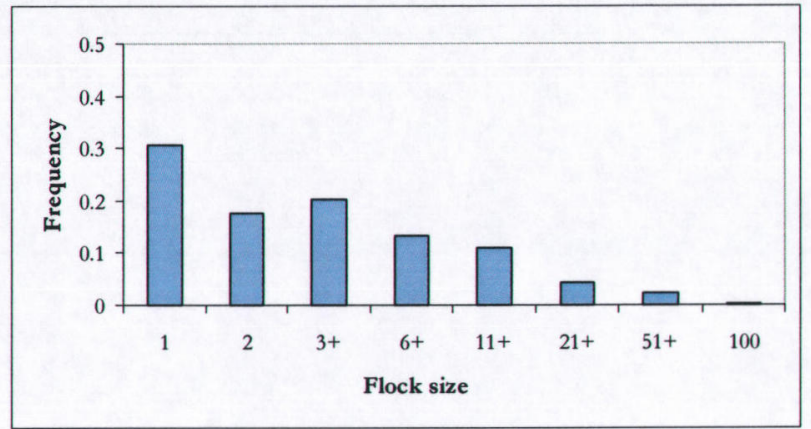

Early morning $(\mathrm{n}=261)$

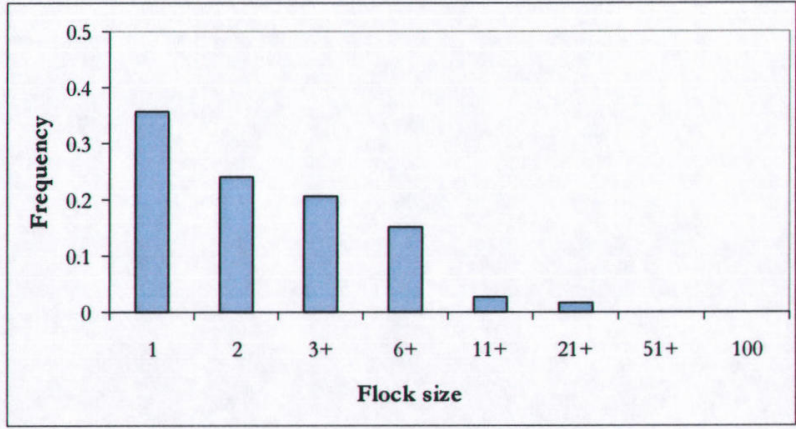

Late morning $(\mathrm{n}=179)$

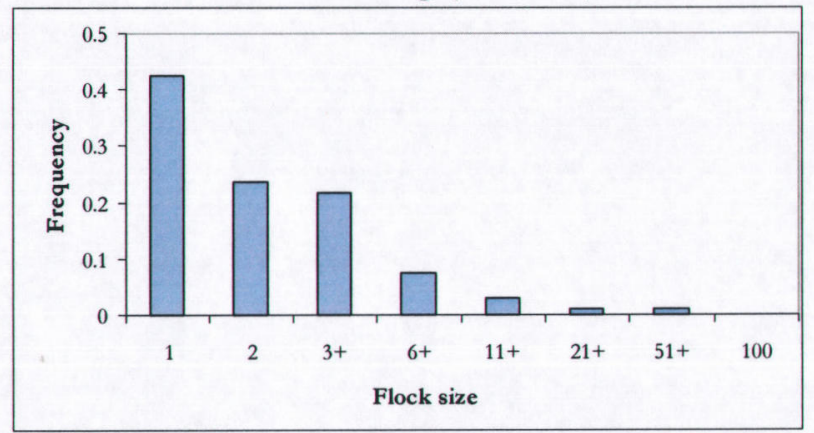

Mid-day $(n=106)$

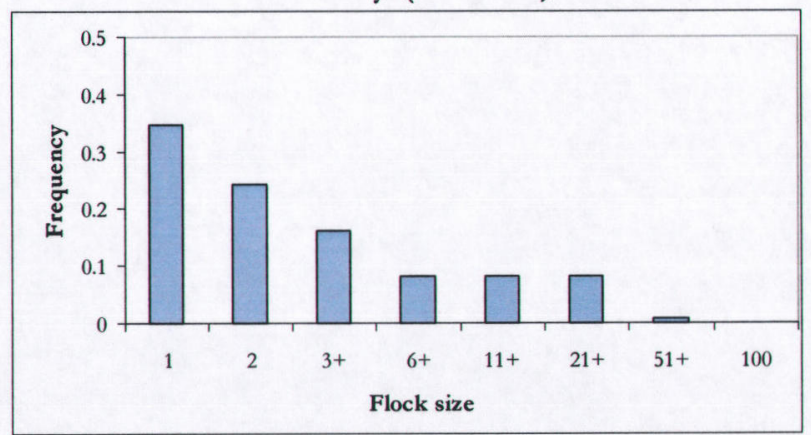

Mid afternoon $(n=136)$

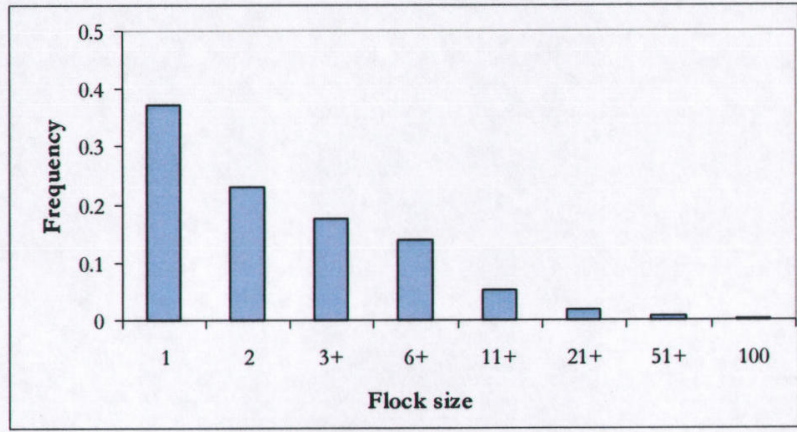

Late afternoon $(\mathrm{n}=518)$

Figure 3.7. Diurnal variation in the size of flocks of Cacatua galerita recorded flying into and out of the observation areas. Values represent combined records from all seasons. 

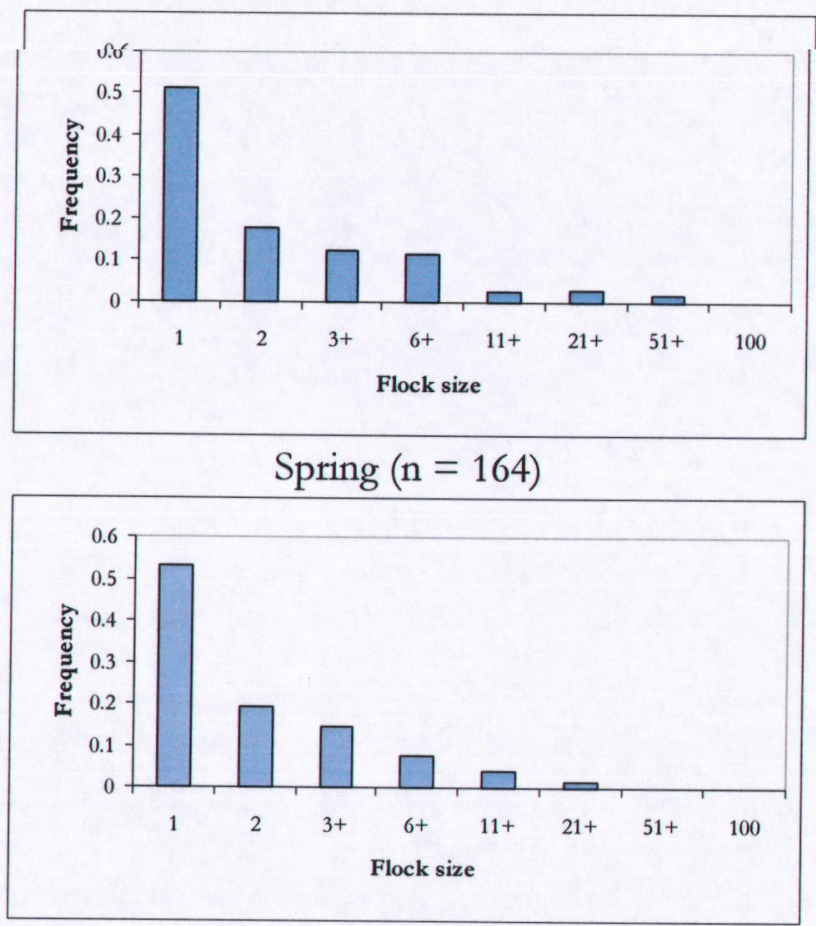

Summer $(n=296)$

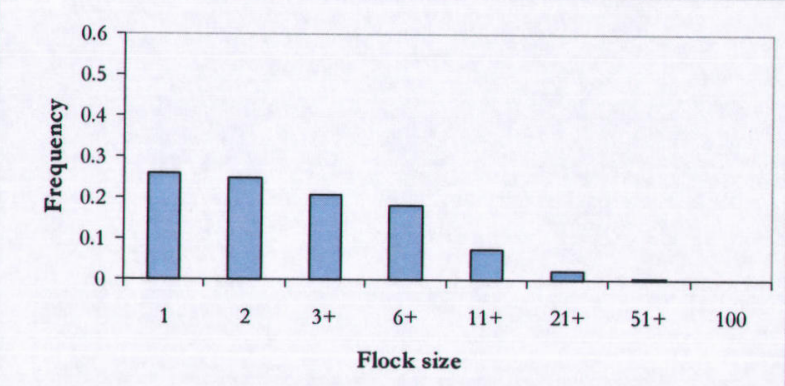

Autumn $(\mathrm{n}=213)$

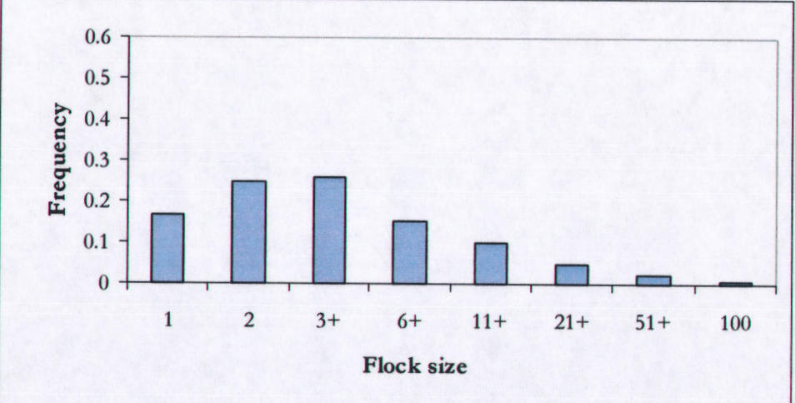

Winter $(\mathrm{n}=387)$

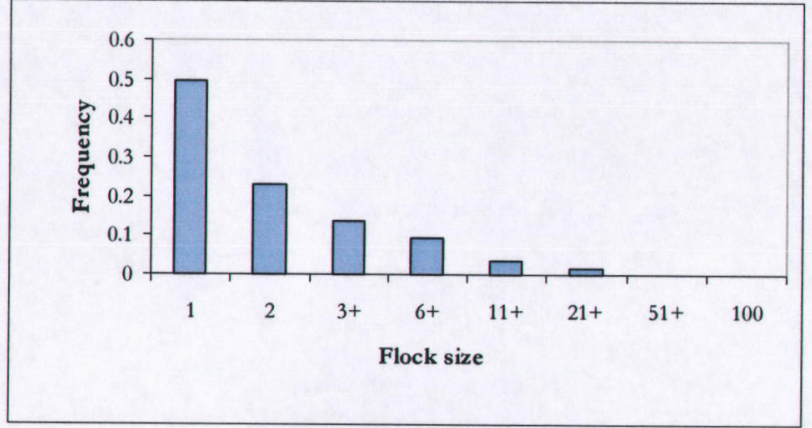

Spring $(\mathrm{n}=140)$

Figure 3.8. Seasonal variation in the size of flocks of Cacatua galerita recorded flying into and out of the observation areas. 
Altitude ( $\mathrm{m}$ asl)

$$
\left[\begin{array}{l}
>300 \\
200-300 \\
100-200 \\
0-100
\end{array}\right.
$$
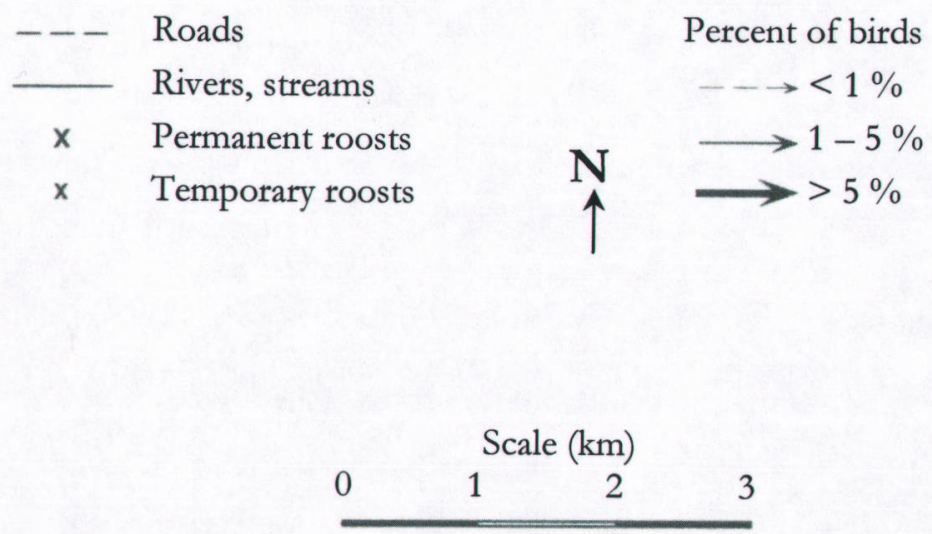

Figure 3.9. Diurnal variation in the use of flight paths by Cacatua galerita in the Turakina Valley between November 1992 and October 1993. Arrows idicatepercent of birds and direction travelled. Values represent combined record from all seasons. 


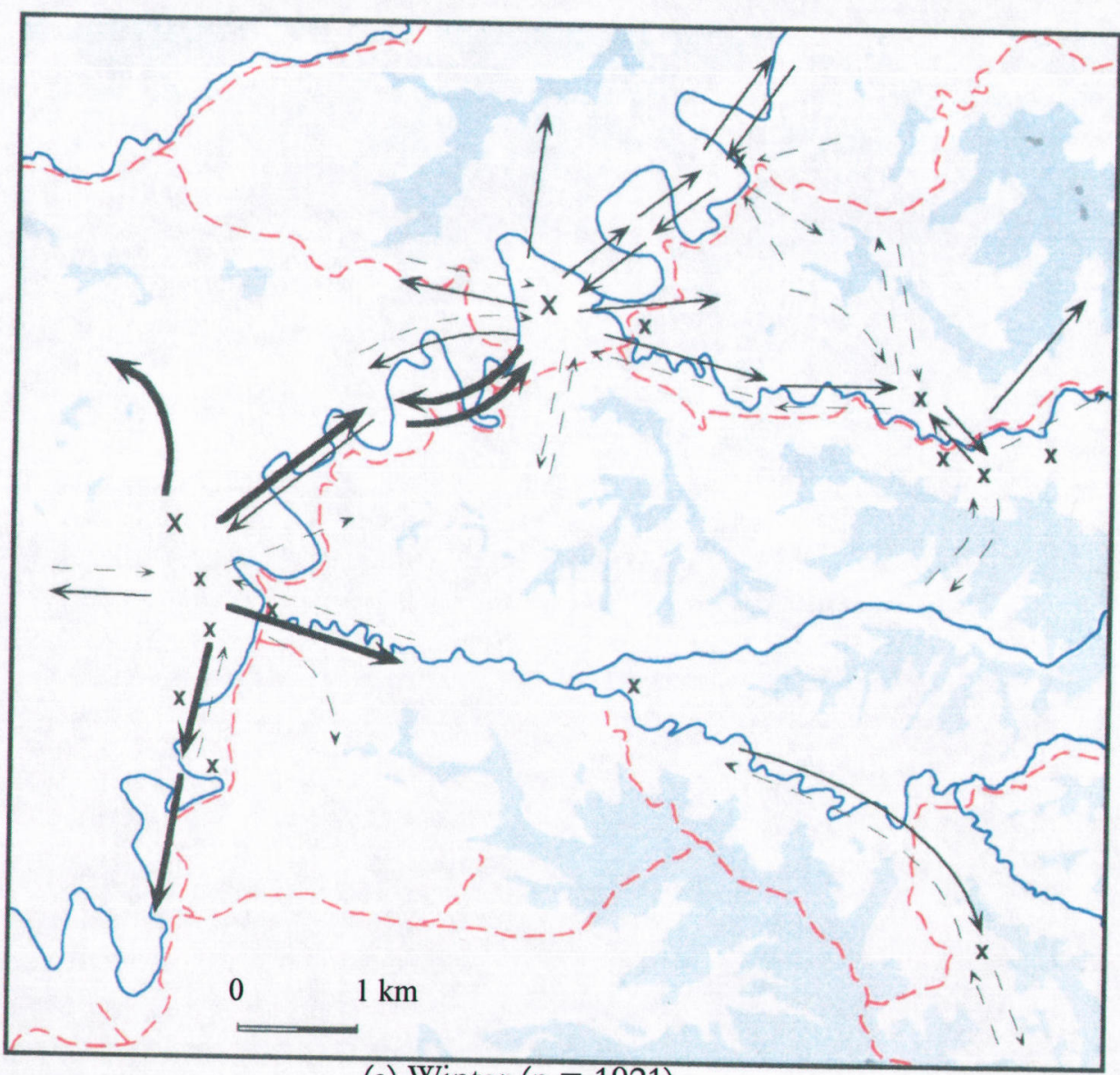

(a) Winter $(\mathrm{n}=1921)$

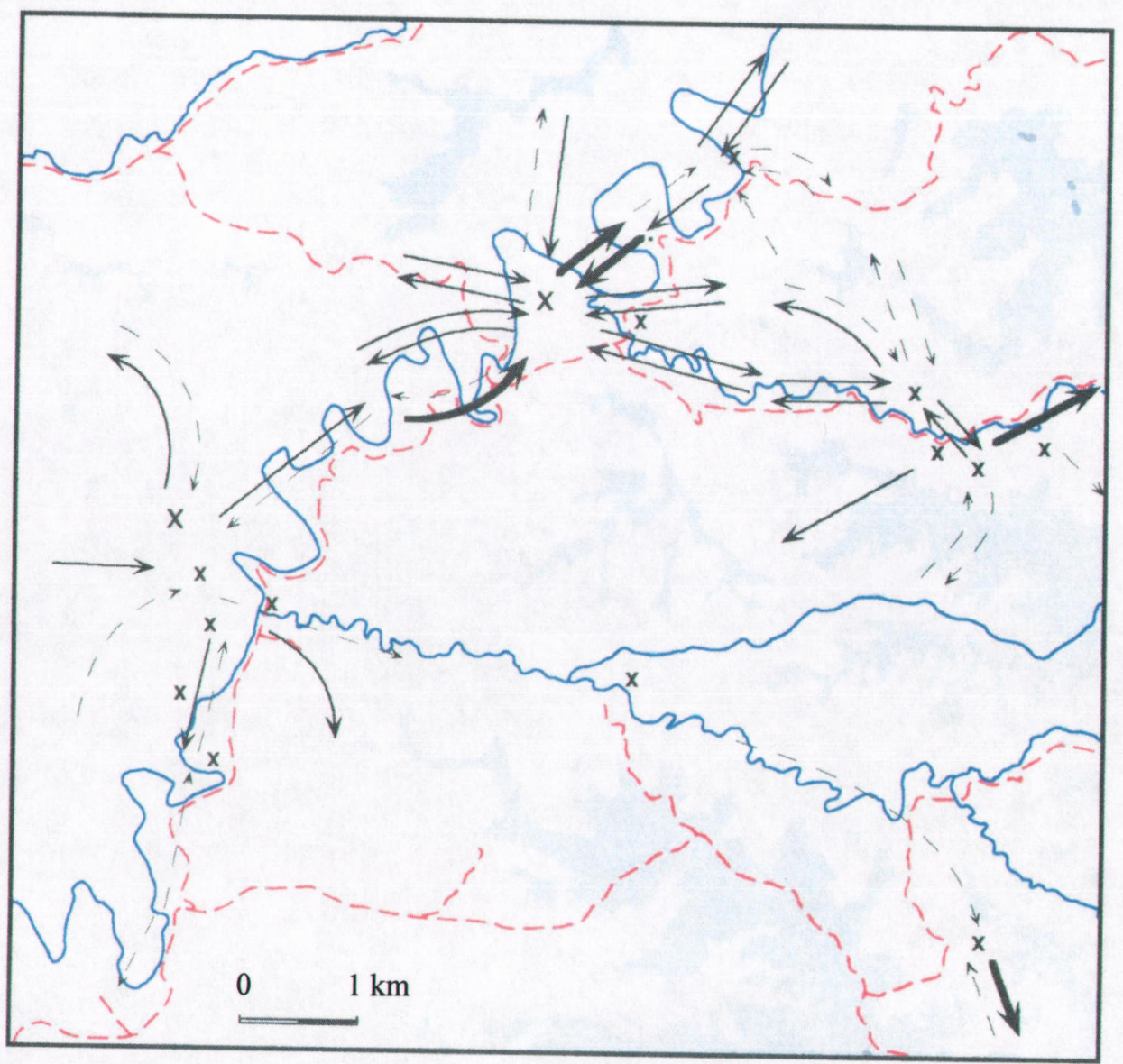

(b) Late morning $(\mathrm{n}=734)$ 


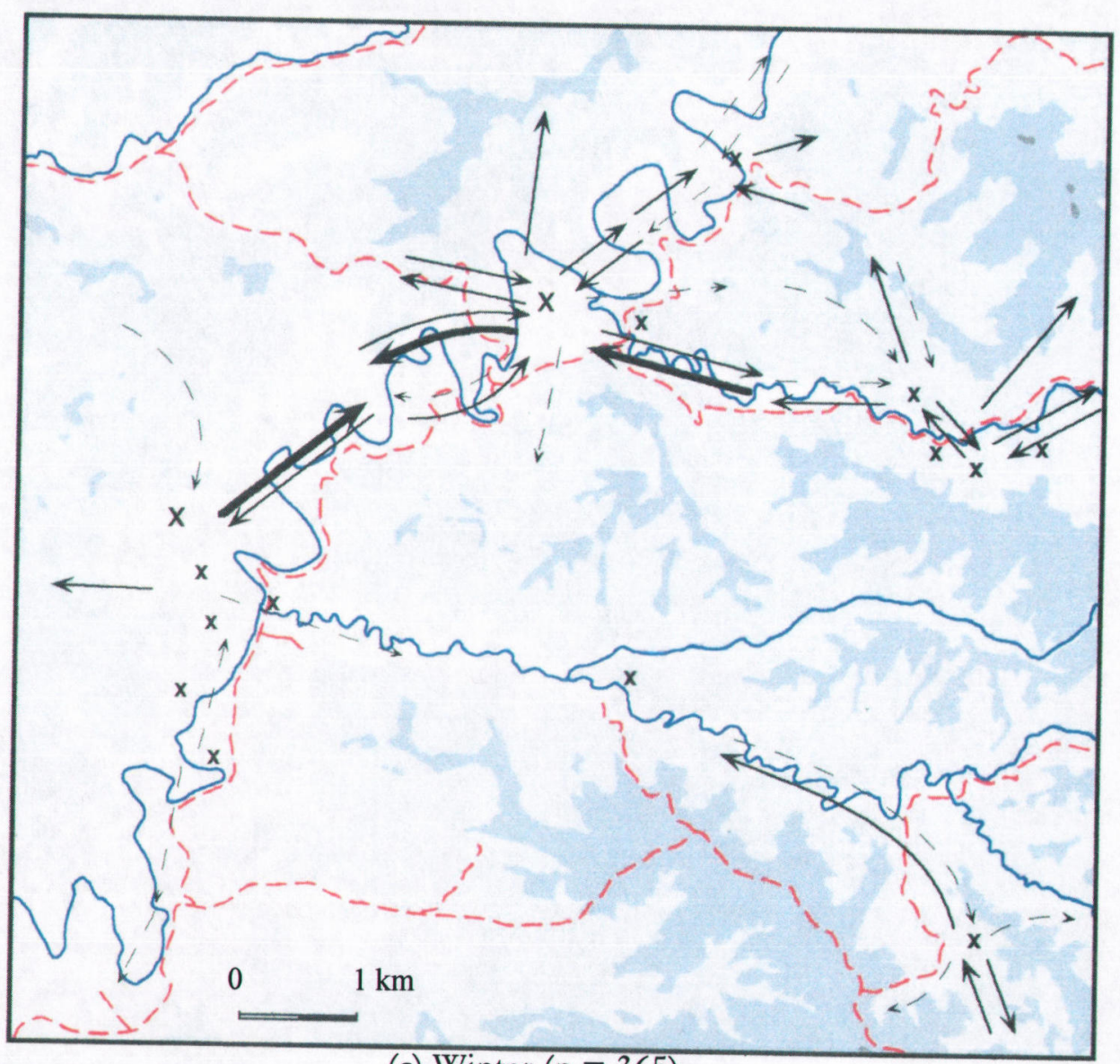

(c) Winter $(\mathrm{n}=365)$

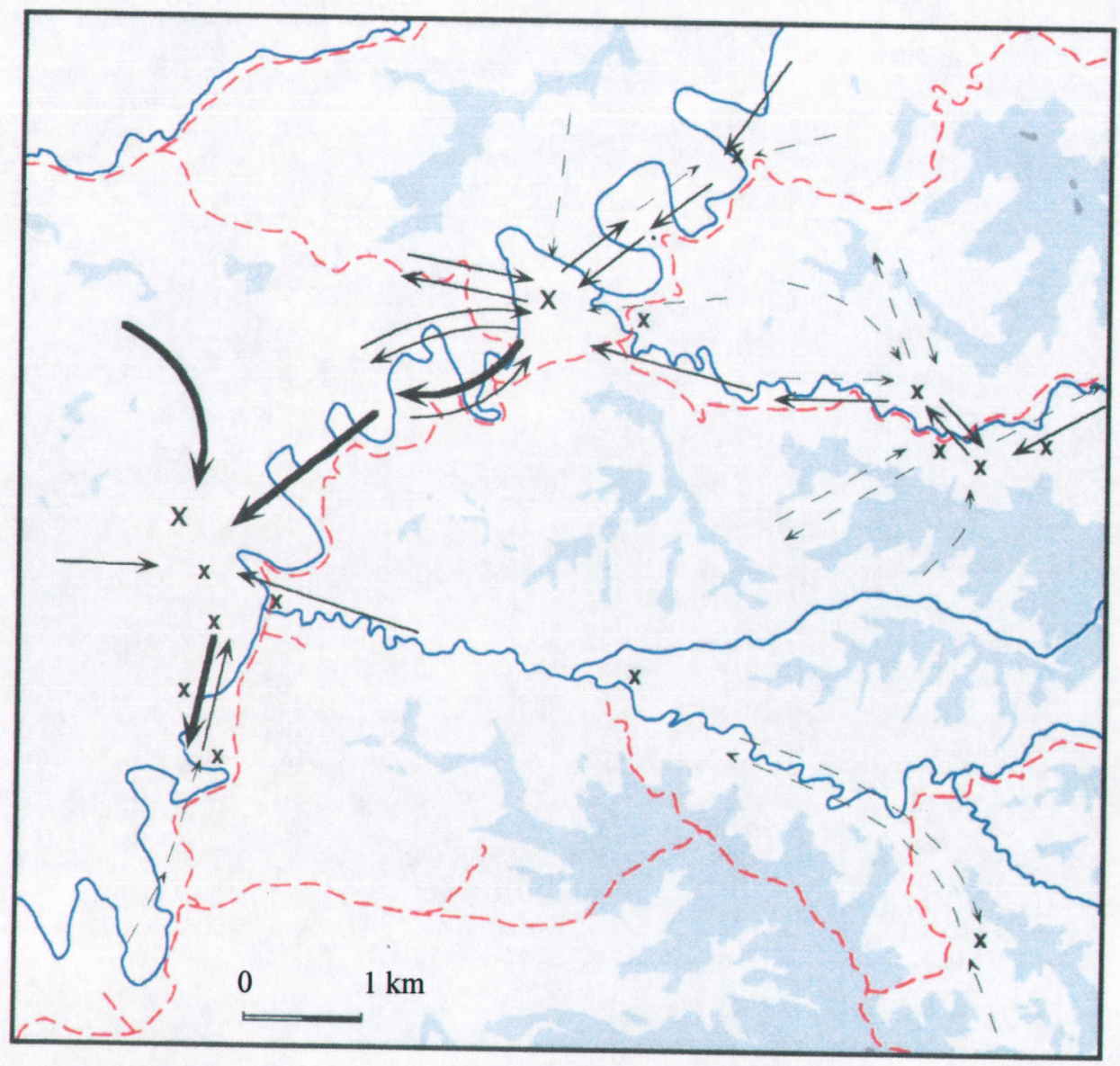

(d) Mid-afternoon $(\mathrm{n}=802)$ 


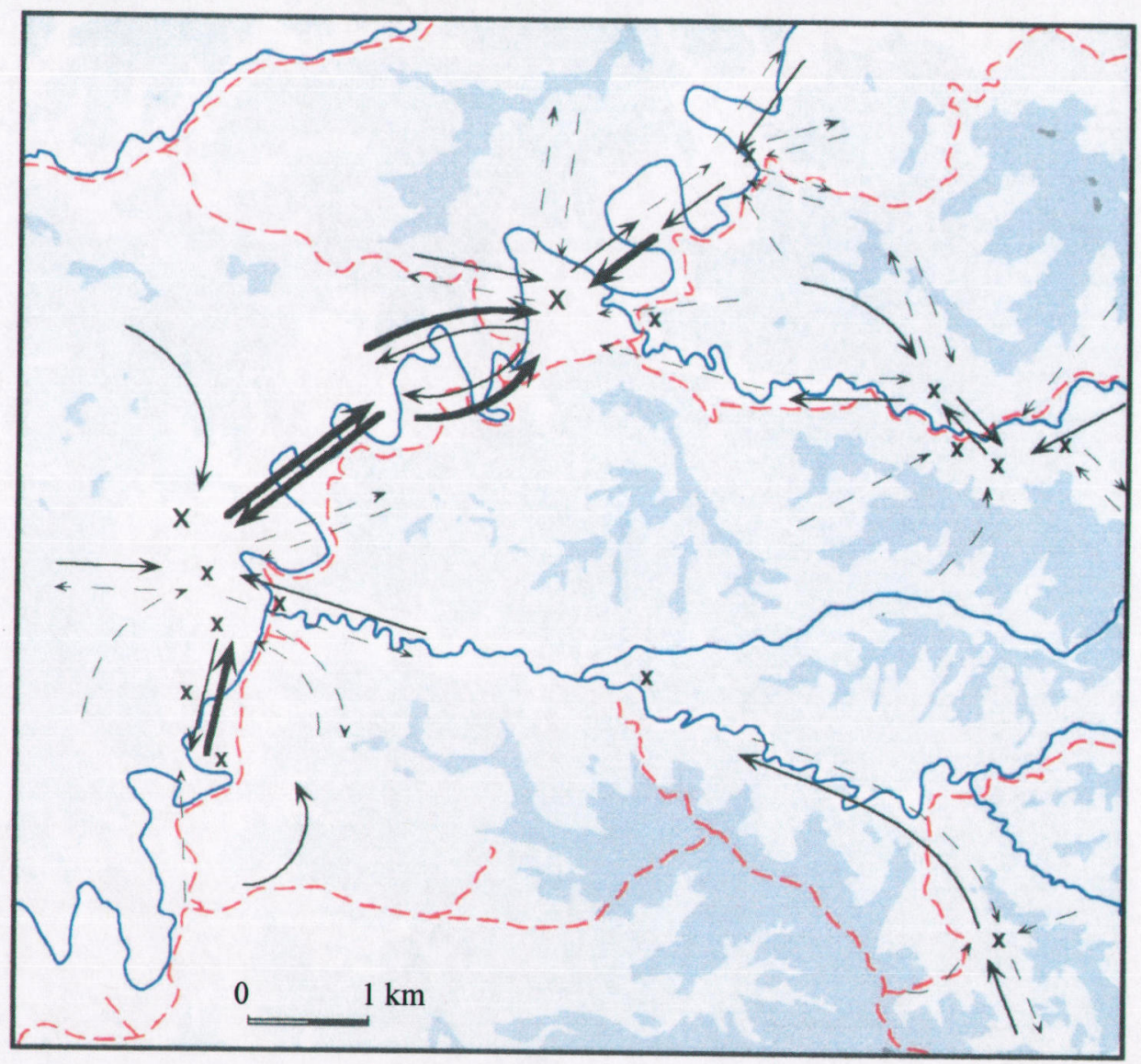

(e) Late afternoon $(n=2465)$ 
There was little seasonal variation in the direction of movement, most of the variation was related to the numbers moving in a particular direction (Figure 3.10a-e). The increase in abundance of $C$. galerita during autumn and winter was reflected in an increase in the number of birds moving along the Turakina River (77.6 and $69.9 \%$ of flock movements in autumn and winter respectively) (Figure 3.10c-d). In summer and early spring, foraging groups dispersed more evenly throughout their daytime range, with only $44.8-40.3 \%$ of movement along the Turakina River (Figure 3.10b,e).

\subsubsection{Cacatua galerita foraging distances}

Total foraging distances could not be determined as daily foraging trips by groups of $C$. galerita frequently took them outside the study area. For some groups this meant a daily foraging range in excess of 8 kilometres from their roost. Foraging distances did show some seasonal variation. The most detailed information was gathered on distance of foraging flights from the Sutherland's roost. During the breeding season (spring-summer) between 12 and $65 \%($ mean $=43 \%$, s.d. $=18.4, \mathrm{n}=6)$ of flights by C. galerita were within 1 kilometre of the roost, while in the non-breeding season (autumn-winter) 0 to $48 \%$ (mean $=26.9 \%$, s.d. $=$ $16.1, \mathrm{n}=7$ ) of foraging trips were within 1 kilometre (Table 3.6). The difference between these two periods was not statistically significant $(t=-1.684$, d.f. $=11, P=0.12)$. 
Altitude (m asl)

$$
\begin{aligned}
& >300 \\
& 200-300 \\
& 100-200 \\
& 0-100
\end{aligned}
$$

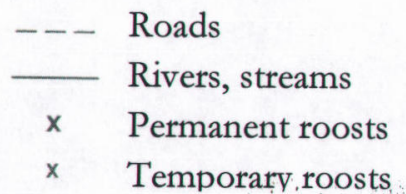

Percent of birds

$\longrightarrow<1 \%$

$\longrightarrow 1-5 \%$

$x$ Temporary roosts

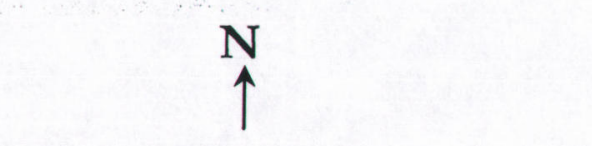

Scale $(\mathrm{km})$

\begin{tabular}{lll}
$0 \quad 1 \quad 2 \quad 3$ \\
\hline
\end{tabular}

Figure 3.10. Seasonal variation in the use of flight paths by Cacatua galerita in the Turakina Valley between November 1992 and October 1993. Arrows indicate percent of birds and direction moved. 


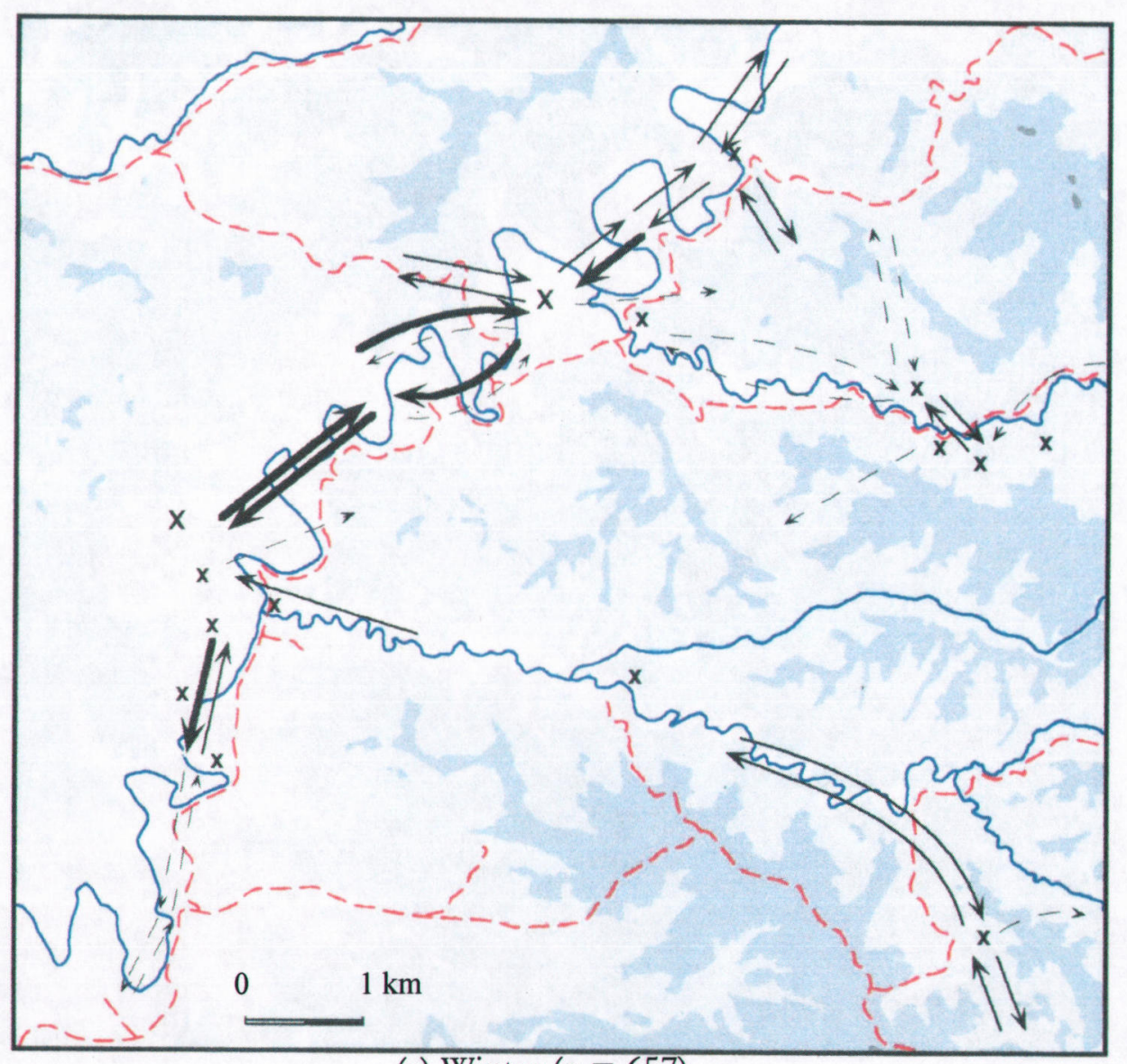

(a) Winter $(\mathrm{n}=657)$

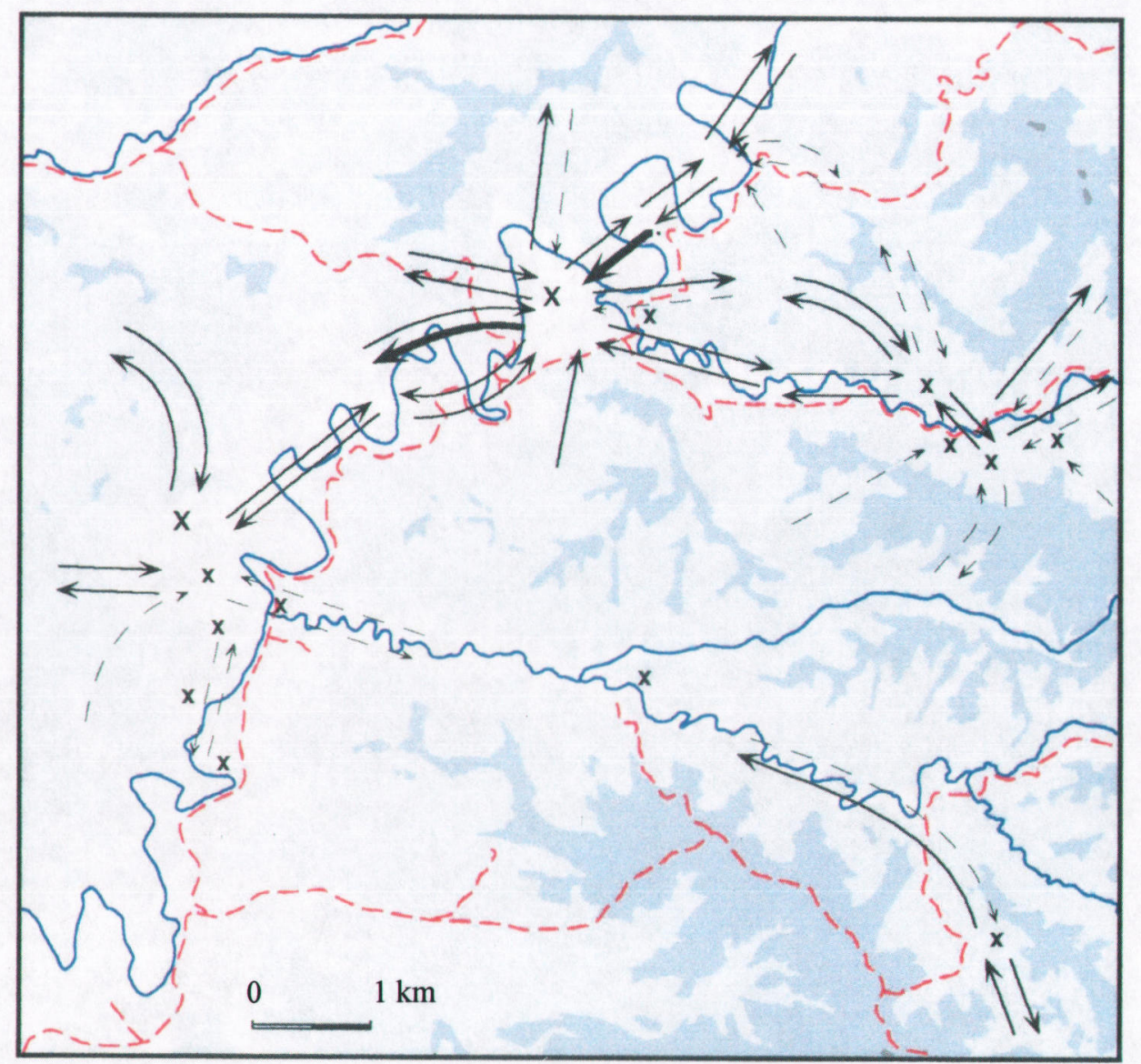

(b) Summer $(\mathrm{n}=920)$ 


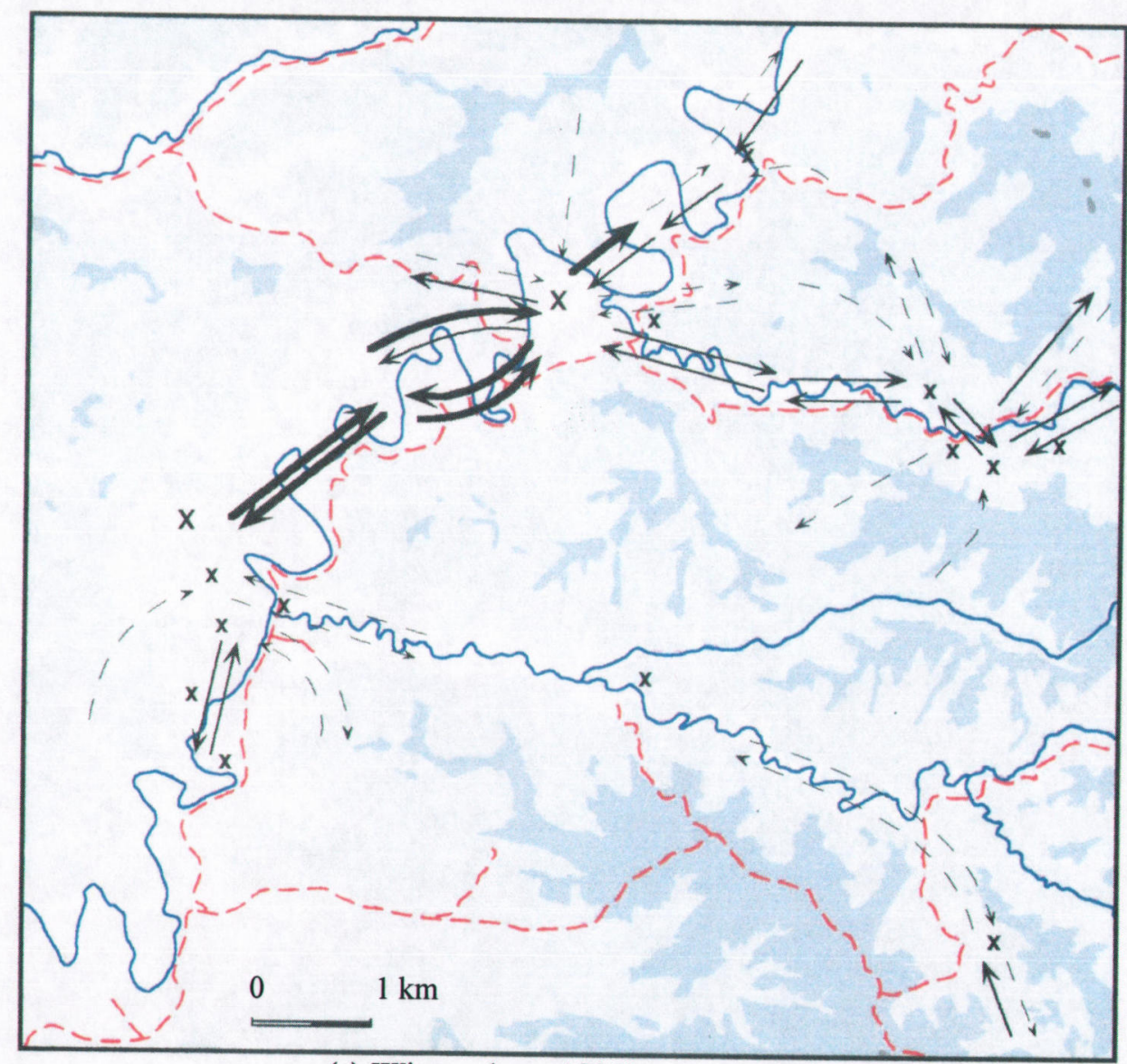

(c) Winter $(\mathrm{n}=1092)$

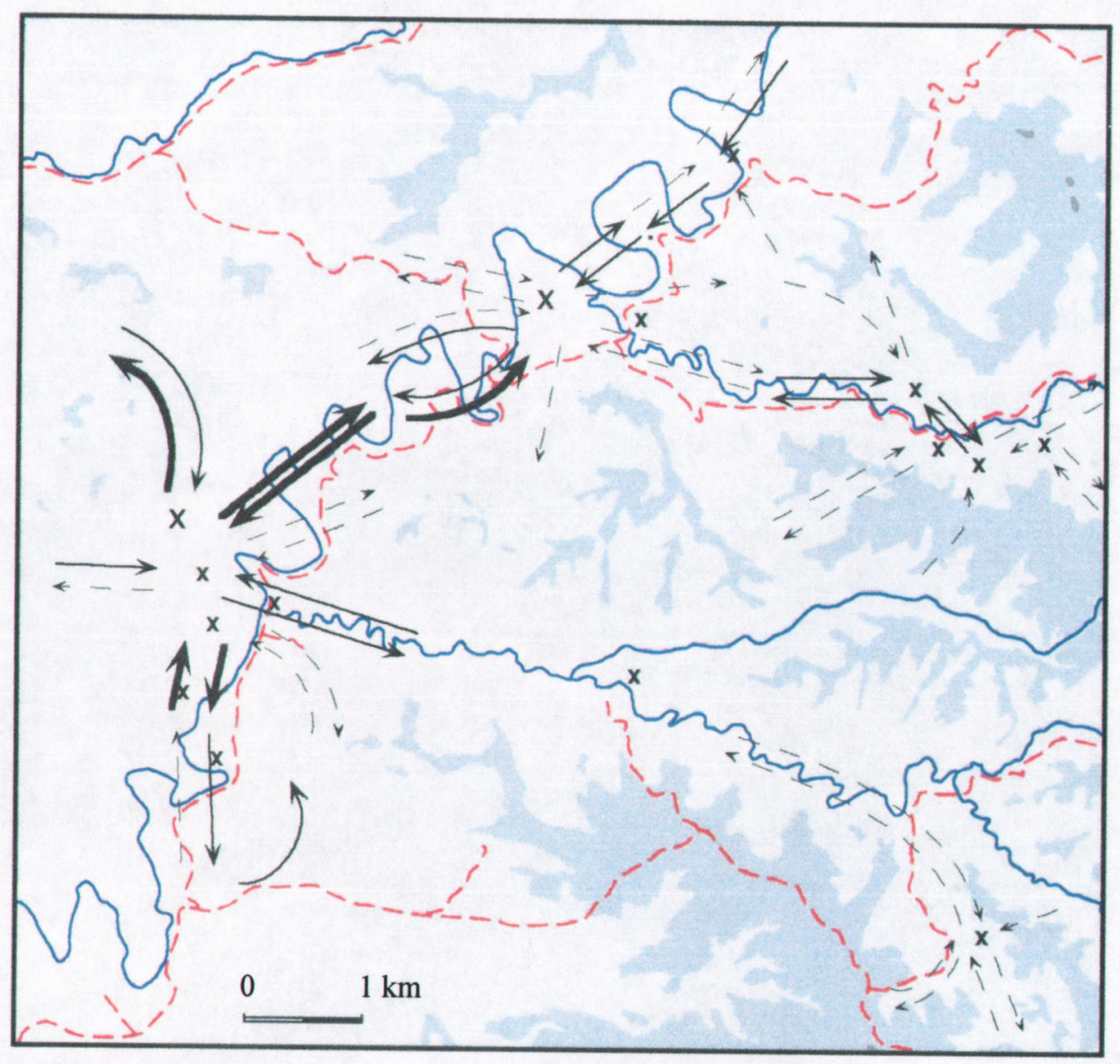

(d) Winter $(\mathrm{n}=3169)$ 


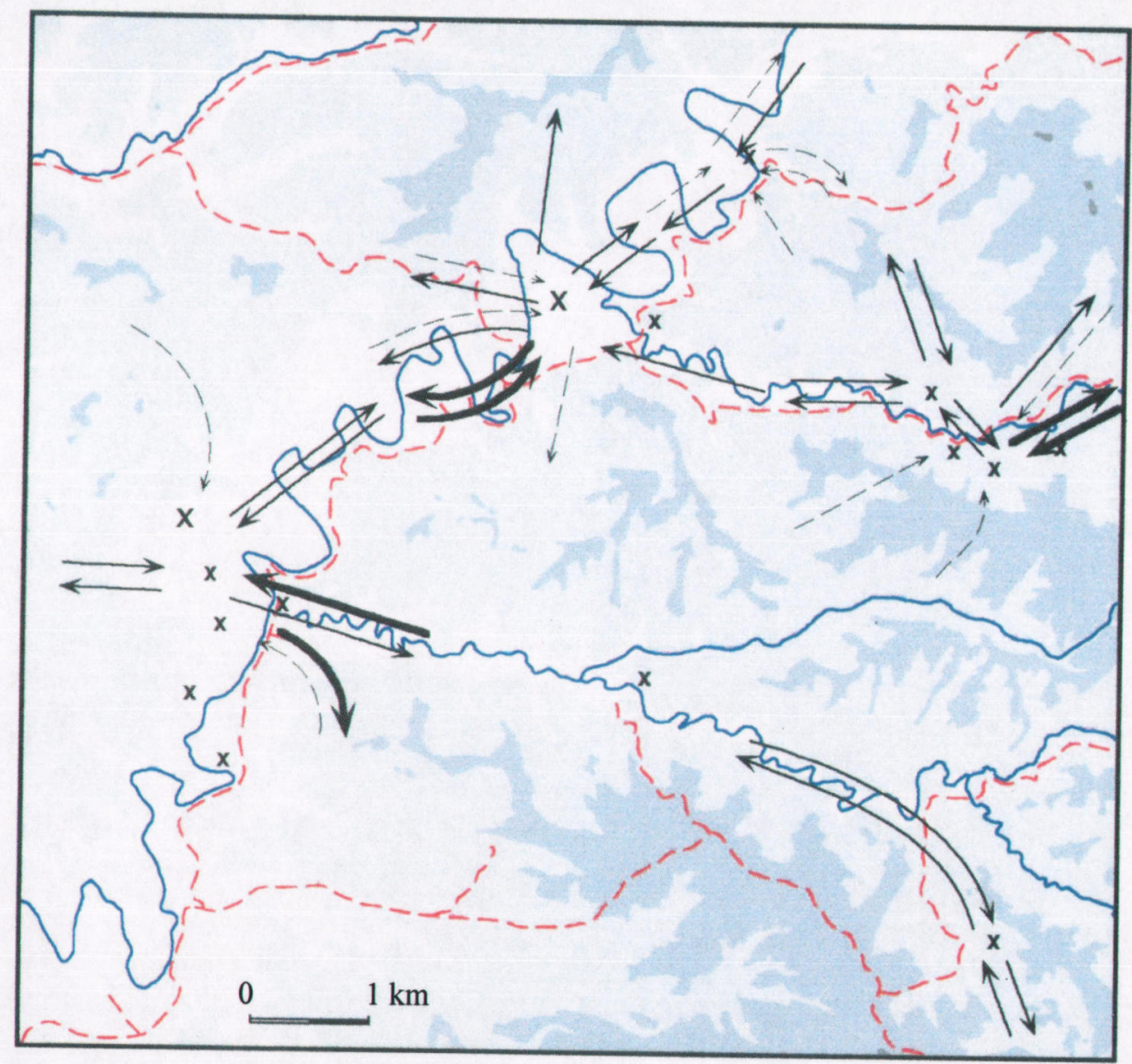

(e) Late spring $(\mathrm{n}=439)$ 
Table 3.6. Monthly record of the number of Cacatua galerita entering and leaving Sutherland's Bush Roost and the surrounding Sutherland's observation area.

\begin{tabular}{lrrrr}
\hline Survey (month) & $\begin{array}{c}\text { Number leaving } \\
\text { reserve }\end{array}$ & $\begin{array}{c}\text { Number leaving } \\
\text { area }\end{array}$ & $\begin{array}{c}\text { Number } \\
\text { entering } \\
\text { reserve }\end{array}$ & $\begin{array}{c}\text { Number } \\
\text { entering } \\
\text { area }\end{array}$ \\
\hline November & 218 & 133 & 219 & 130 \\
December & 101 & 90 & 66 & 57 \\
January & 142 & 94 & 145 & 89 \\
February & 120 & 43 & 121 & 41 \\
March & 159 & 122 & 155 & 118 \\
April & 183 & 110 & 147 & 72 \\
May & 144 & 83 & 102 & 92 \\
June 1 & 124 & 95 & 125 & 93 \\
June 2 & 132 & 135 & 123 & 126 \\
July & 83 & 68 & 85 & 68 \\
August & 110 & 54 & 114 & 58 \\
September & 138 & 69 & 128 & 59 \\
October & 34 & 16 & 34 & 16 \\
\hline
\end{tabular}

\subsubsection{Cacatua galerita flock size at foraging sites}

\subsubsection{Diurnal variation in size of foraging flocks}

Flock size decreased early in the day, from a mean of 8.0 (s.d. $=16.9, \mathrm{n}=614$ ) in early morning to 6.4 (s.d. $=12.8, \mathrm{n}=527$ ) in late morning (Figure 3.11), as flocks broke up into smaller units, although the difference was not significant $(t=1.779$, d.f. $=1139, \mathrm{P}=0.075)$. Mean flock size increased significantly $(\mathrm{t}=-3.232$, d.f. $=781, \mathrm{P}=0.001)$ from mid-morning to mid-day $($ mean $=10.1$, s.d. $=18.8, \mathrm{n}=256)$ then remained relatively constant from midday to late afternoon (mid-afternoon: mean $=11.1$, s.d. $=22.1, \mathrm{n}=314$; late afternoon: mean $=11.0$, s.d. $=22.1, \mathrm{n}=550)(\mathrm{t}$ tests, d.f. $=568-862, \mathrm{P}$ 's $=0.566-0.949)($ Figure 3.11) . 

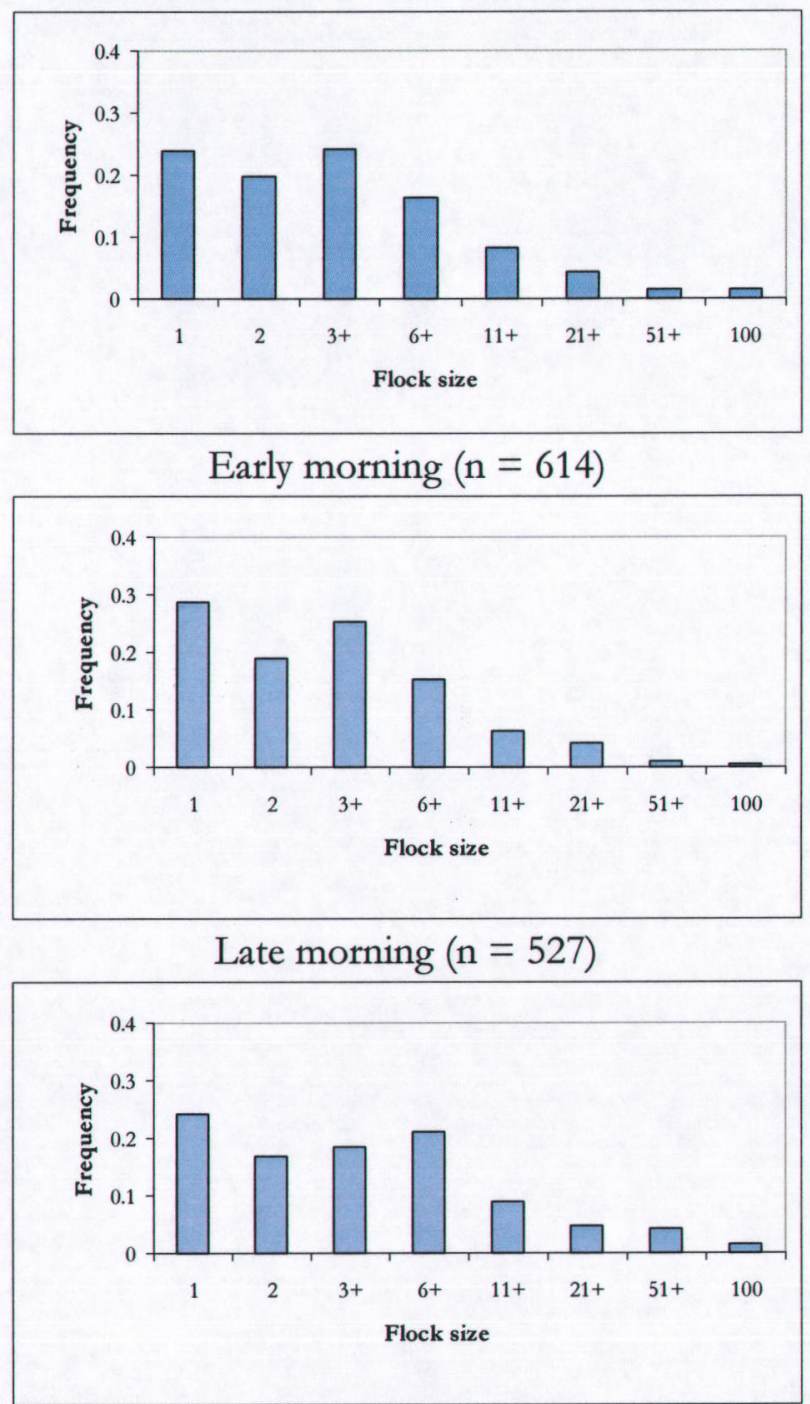

Mid-day $(n=256)$

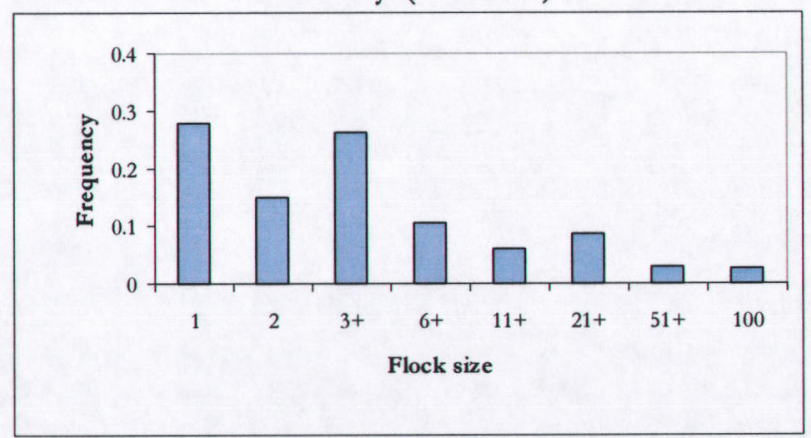

Mid afternoon $(\mathrm{n}=314)$

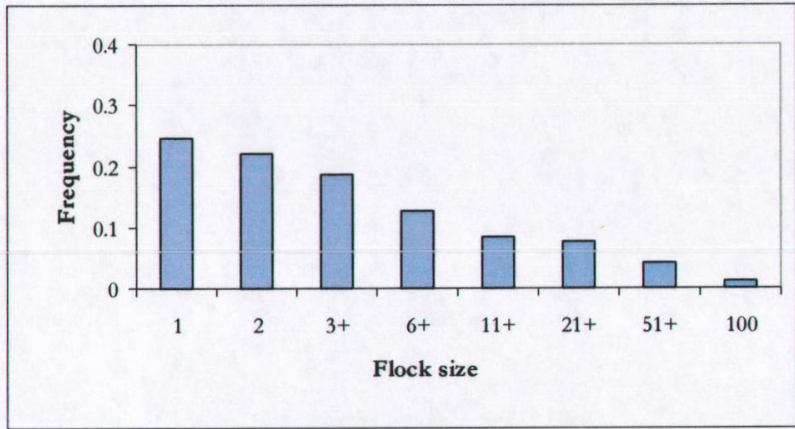

Late afternoon $(n=550)$

Figure 3.11. Diurnal variation in the number of Cacatua galerita seen foraging together. Values represent frequency of the various flock sizes recorded during each season. 


\subsubsection{Seasonal variation in C. galerita foraging flock size}

Aggregations of foraging C. galerita tended to be small, most groups (67.8\%) consisted of 1 to 5 birds (median flock size $=3$ ) (Figure 3.12). Largest flock sizes were recorded in winter $($ mean $=16.3$, s.d. $=27.3$, range 1-178) when the population in the study area was greatest. Lowest mean flock sizes were recorded in summer $($ mean $=4.1$, s.d. $=4.2$, range 1-29) and early spring $($ mean $=3.4$, s.d. $=4.1$, range $1-34)$ when the population was at its lowest (Figure 3.12). Mean flock size each month was significantly correlated to population size (based on dusk population counts for each month) $(\mathrm{r}=0.9409$, d.f. $=13, \mathrm{P}<0.0001)$.

Table 3.7. Frequency of the various Cacatua galerita flock sizes observed in the Turakina Valley ordered according to habitat type in which the birds were recorded.

\begin{tabular}{|c|c|c|c|c|c|c|c|c|c|}
\hline \multirow[t]{2}{*}{ Habitat type } & \multicolumn{8}{|c|}{ Flock size categories } & \multirow{2}{*}{$\begin{array}{l}\text { Number } \\
\text { of flocks }\end{array}$} \\
\hline & 1 & 2 & $3+$ & $6+$ & $11+$ & $21+$ & $51+$ & $100+$ & \\
\hline Tall native & 370 & 292 & 305 & 189 & 84 & 54 & 26 & 13 & 1333 \\
\hline Low native & 23 & 20 & 19 & 12 & 5 & 2 & 0 & 0 & 81 \\
\hline Cupressus & 39 & 21 & 50 & 40 & 17 & 16 & 1 & 0 & 184 \\
\hline macrocarpa & & & & & & & & & \\
\hline Pinus spp. & 31 & 20 & 33 & 12 & 9 & 6 & 0 & 0 & 111 \\
\hline Non-pine exotic & 31 & 26 & 30 & 25 & 13 & 4 & 1 & 0 & 130 \\
\hline Grassland & 16 & 13 & 36 & 26 & 26 & 26 & 10 & 6 & 159 \\
\hline Crop & 4 & 1 & 3 & 6 & 6 & 17 & 16 & 11 & 64 \\
\hline
\end{tabular}

\subsubsection{Variation in C. galerita foraging flock size in association with babitat}

Size of foraging flocks differed with habitat type (Table 3.7). The average size of flocks of $C$. galerita foraging on crops $($ mean $=53.2$, s.d. $=45.1$, range $1-178)$ and grassland $($ mean $=19.2$, s.d. $=26.3$, range 1-123) were significantly larger than flocks foraging in tree habitats $(\mathrm{t}=$ 4.189 , d.f. $=2060, \mathrm{P}<0.001)$. Some large flocks were recorded in tall native forest (mean = 7.4 , s.d. $=15.9$, range 1-127), but overall mean flock sizes in tree habitats tended to be small (mean flock size ranging from 4.3 (s.d. $=5.0$ ) in low native forest to 7.7 (s.d. $=9.8$ ) in Cupressus macrocarpa). Most of this difference resulted from the larger number of 


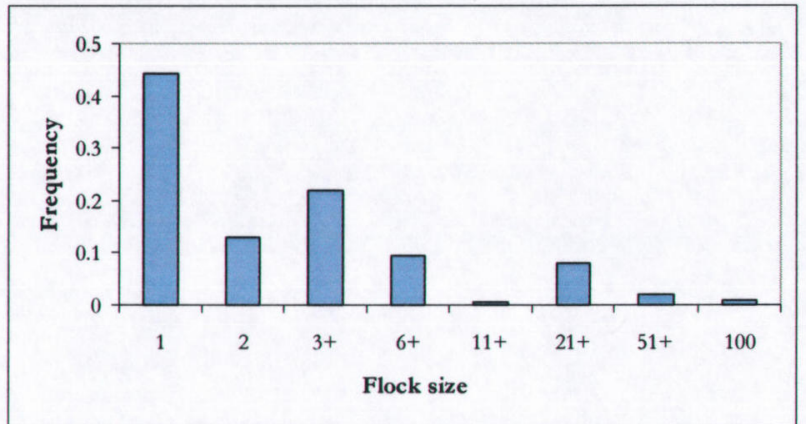

Late spring $(\mathrm{n}=201)$

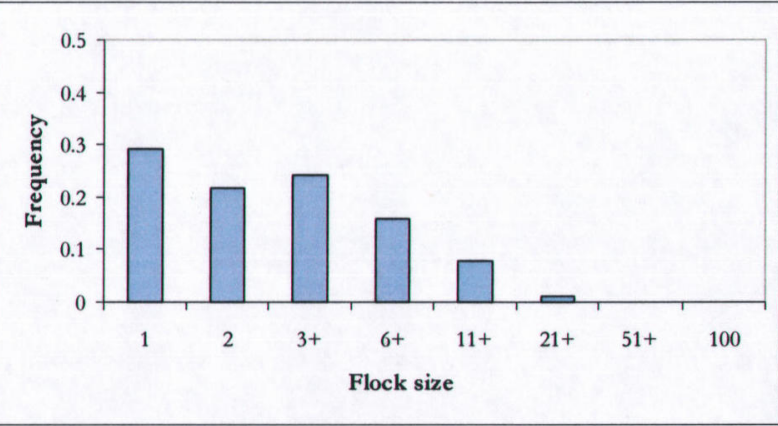

Summer $(\mathrm{n}=571)$

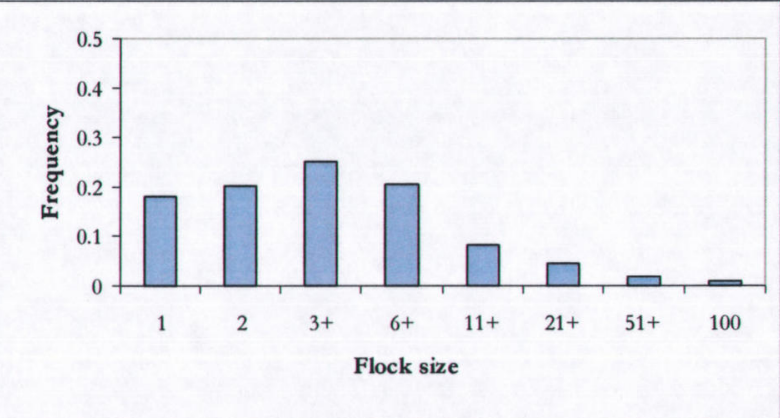

Autumn $(\mathrm{n}=517)$

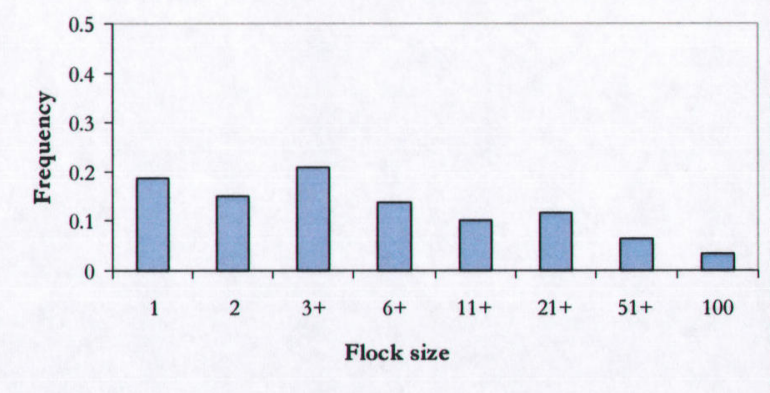

Winter $(n=689)$

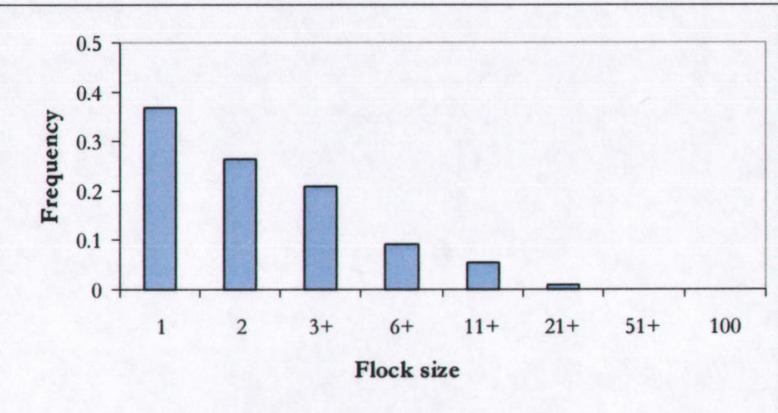

Early spring $(\mathrm{n}=283)$

Figure 3.12. Seasonal variation in the number of Cacatua galerita seen foraging together. Values represent frequency of the various flock sizes recorded during each season. 
small flocks $(71.2 \%$ of flocks were of five or fewer birds) seen using tree habitats compared to $12.3-40.9 \%$ of flocks being of five or fewer birds in crop and grassland habitats respectively (Table 3.7). Some caution must be taken in interpreting these results because the difficulty in observing birds in trees meant that flock sizes for these habitats might be greatly underestimated.

\subsubsection{Flock size in relation to different behavioural activities}

Flocks of C. galerita were dynamic, frequently changing in size as groups, or individuals, joined or left the main flock. The average number of birds seen feeding together (mean = 10.7 , s.d. -21.0$)$ was significantly larger ( $t$ tests, d.f. $=1067-2395$, P's $<0.001)$ than the average number of birds seen resting (including resting, resting alert, climbing, autopreening, rain-bathing, allopreening, display, fighting and nest attendance) (mean $=6.7$, s.d. $=14.4)$ and flying $($ mean $=4.7$, s.d. $=10.1)$. The average number of birds seen resting together was significantly greater $(t=2.23$, d.f. $=1886, P=0.026)$ than the average number of birds seen flying together. Seasonally, the mean sizes of flocks were consistently larger when the birds were feeding than when birds were resting ( $t$ tests, d.f. $=194-804$, P's $\leq 0.007$ ) (Figure 3.13). Feeding flocks were also larger than flying flocks in late spring $(t=2.309$, d.f. $=100, P=$ $0.023)$, summer $(t=2.328$, d.f. $=313, \mathrm{P}=0.021)$ and winter $(t=2.657$, d.f. $=313, \mathrm{P}=$ $0.008)$, but were not significantly different in autumn $(t=1.476$, d.f. $=253, P=0.144)$ and early spring $(t=0.578$, d.f. $=80, P=0.565)$. Mean sizes of flocks seen resting were larger than mean sizes of flying flocks in late spring and winter, but were smaller than flying flocks at other times of the year, although the differences were not significant ( $t$ tests, d.f. $=140$ 617, P's $=0.111-0.814)$ (Figure 3.13). 


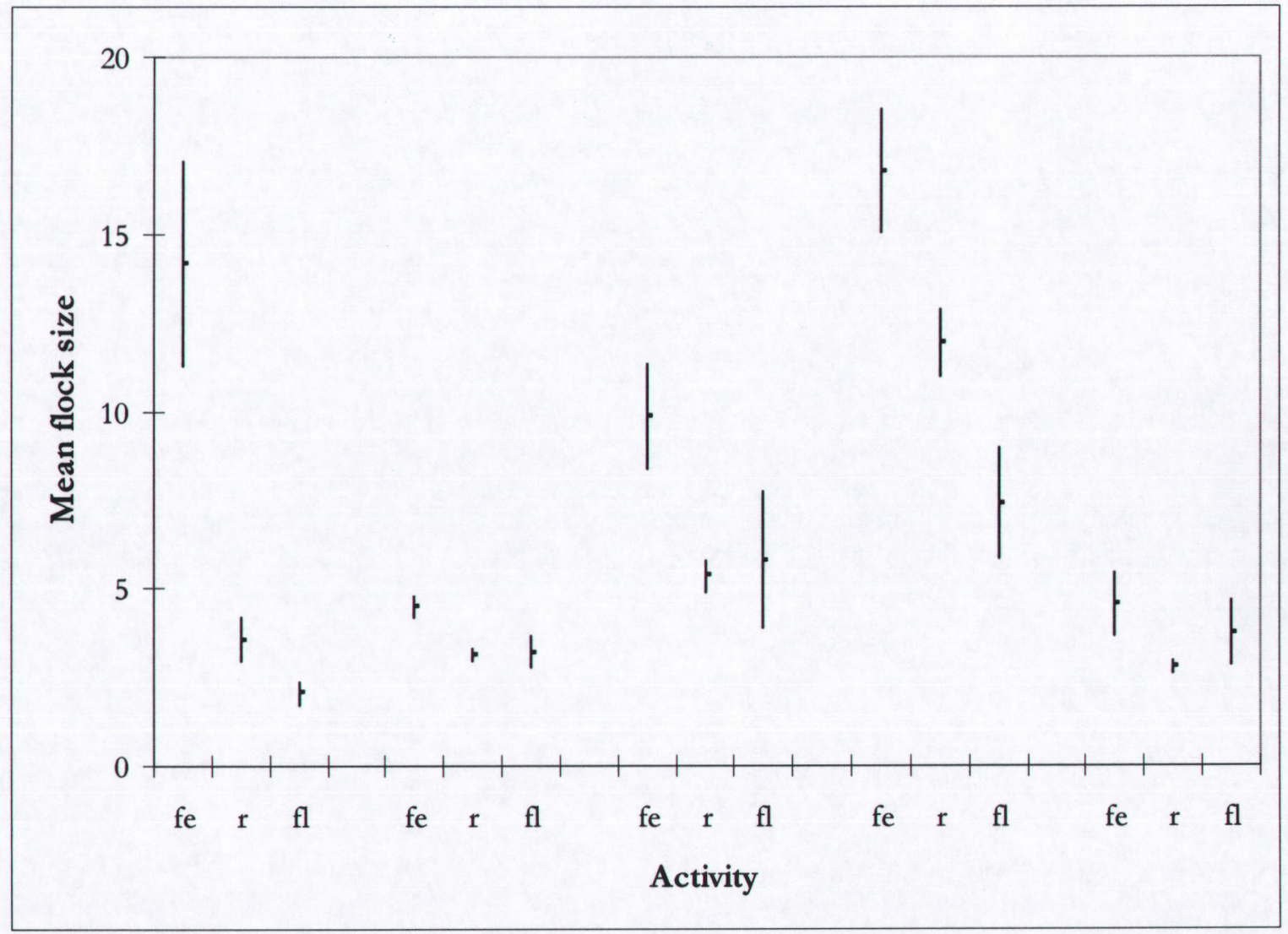

Figure 3.13. Variation in the size of flocks seen feeding $(\mathrm{fe})(\mathrm{n}=789)$, resting $(\mathrm{r})(\mathrm{n}=1608)$ and flying $(\mathrm{fl})(\mathrm{n}=280)$ in each season from November 1992 to October 1993. Bars represent mean \pm one standard error. 


\subsubsection{The time-activity budget of $C$. galerita}

\subsubsection{Variation in C. galerita behaviour}

Aggregations of $C$. galerita, observed during foraging activity, consisted of 1-178 birds (mean $=9.02$, s.d. $=18.6, \mathrm{n}=2261)$. Over half $(55.1 \%, \mathrm{n}=689)$ of all records were obtained in winter reflecting the increased number of birds in the study area then. There was also considerable variation in habitat preference. Most records came from tall native forest $(50.8 \%, \mathrm{n}=1333)$ and open ground habitats $(33.3 \%, \mathrm{n}=223)$, while least observations were obtained from low native vegetation $(1.8 \%, \mathrm{n}=81)$ (Figure 3.14). Resting and feeding were the most frequently recorded behaviours (together making up $89.1 \%$ of total daily activity), and their occurrence tended to be inversely related to each other (Table 3.7). Again, caution must be taken in interpreting these data because flock observations were heavily biased towards open habitats so no attempt was made to test for significance of the data.

\subsubsection{Diurnal variation in C. galerita behaviour}

Cacatua galerita activity varied considerably during the course of the day, and the diurnal activity pattern showed seasonal variation. The overall pattern of activity (Table 3.8 ) shows two peaks in feeding, the first early in the morning and the second late in the afternoon, while resting was the most frequent activity throughout the middle of the day. The recorded incidences of flying (Table 3.8) were generally greater early in the morning and late in the afternoon, coinciding with the observed increase in movement of birds between foraging sites and roosts at these times (Figure 3.9). There was little variation in the amount of time spent in feather maintenance behaviour between diurnal periods, except in the late afternoon when the occurrence of this behaviour decreased (Table 3.8). Two incidences of rainbathing, recorded in late morning and mid-day, occurred during heavy showers of rain and were not an indication of daily patterns of activity.

There was some seasonal variation in the diurnal patterns of the various activities (Figure 3.15). Activity patterns of C. galerita in late spring, autumn and winter activities were most similar to the overall pattern of diurnal activity. 


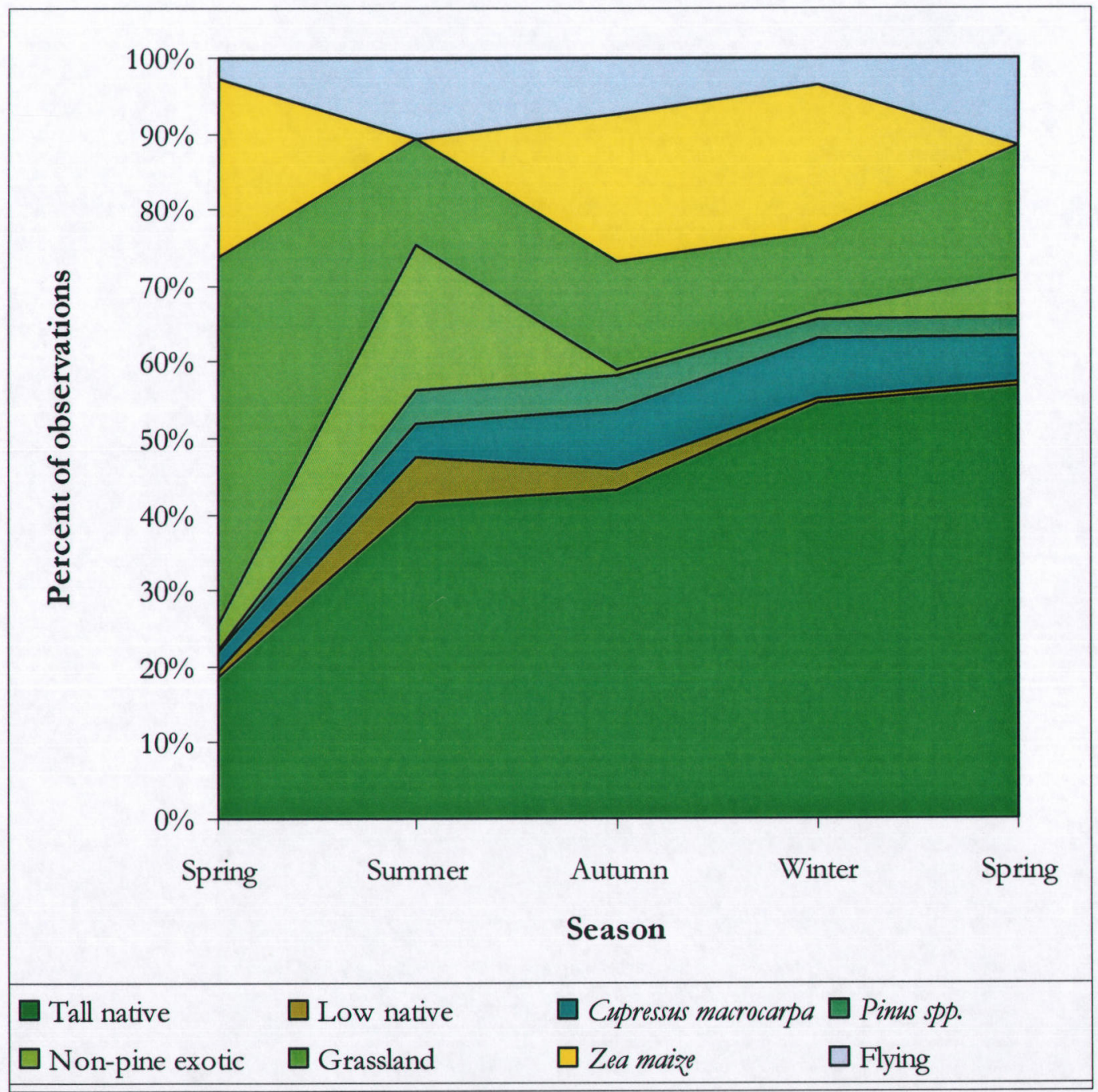

Figure 3.14. Seasonal variation in the habitats used by Cacatua galerita in the turakina Valley. Values represent data gathered between November 1992 and October 1993. 


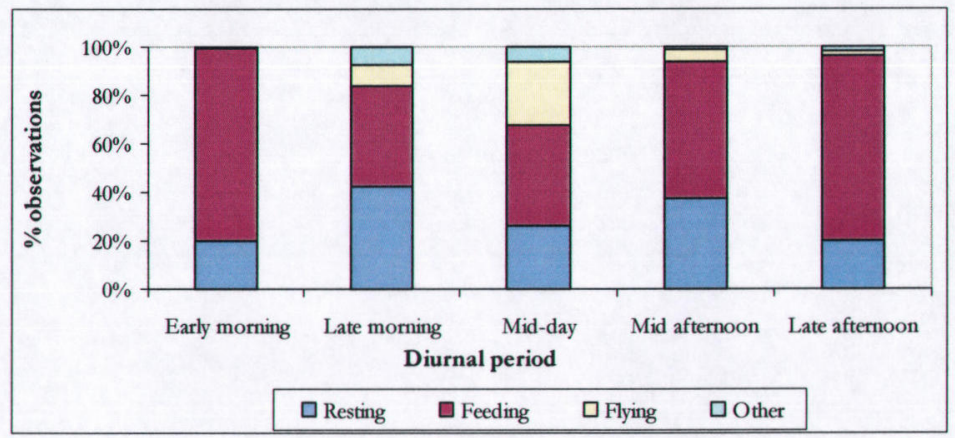

Late spring $(n=201)$

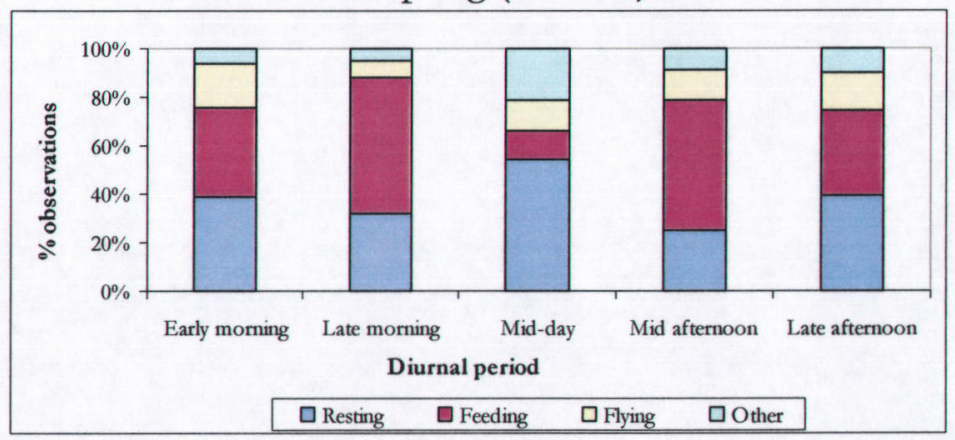

Summer $(\mathrm{n}=571)$

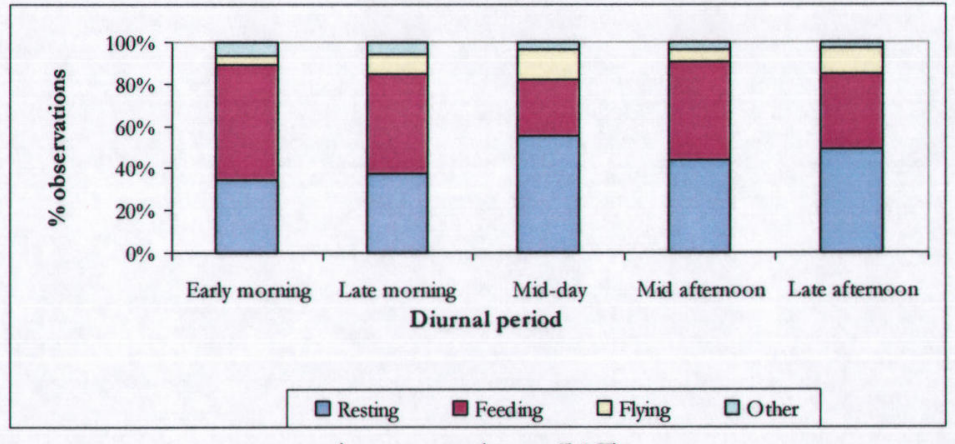

Autumn $(\mathrm{n}=517)$

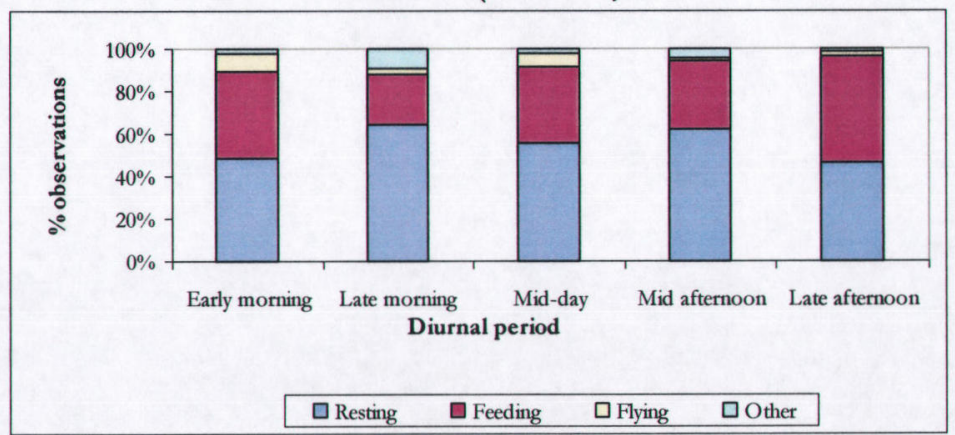

Winter $(n=689)$

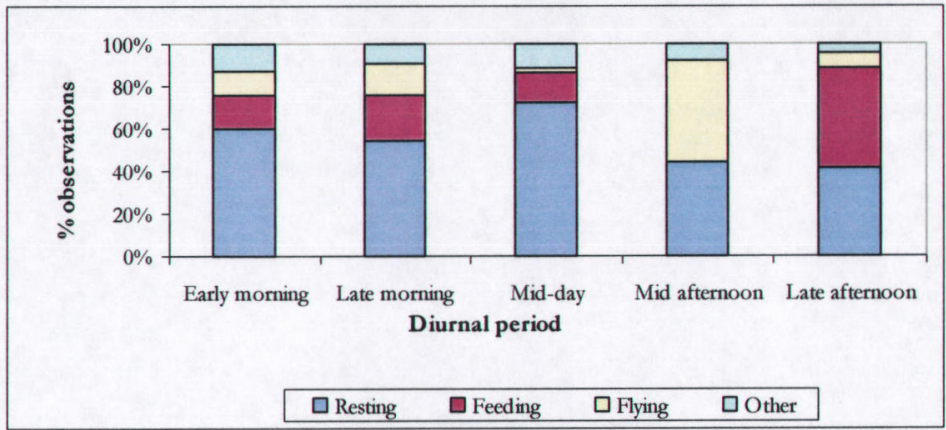

Early spring $(n=283)$

Figure 3.15. Seasonal variation in the diurnal activity of Cacatua galerita in the Turakina Valley. Values represent data gathered between November 1992 and October 1993. 
Table 3.8. Frequency of Cacatua galerita activities recorded in each of five diurnal periods.

Data represent combined records from all seasons.

\begin{tabular}{|c|c|c|c|c|c|}
\hline \multirow[t]{2}{*}{ Activity } & \multicolumn{5}{|c|}{ Diurnal period } \\
\hline & $\begin{array}{c}\text { Early } \\
\text { morning }\end{array}$ & $\begin{array}{l}\text { Late } \\
\text { morning }\end{array}$ & Mid-day & $\begin{array}{c}\text { Mid- } \\
\text { afternoon }\end{array}$ & $\begin{array}{c}\text { Late } \\
\text { afternoon }\end{array}$ \\
\hline Resting & 2047 & 1761 & 1472 & 1927 & 2602 \\
\hline Feeding & 2208 & 1142 & 845 & 1301 & 2915 \\
\hline Flying & 427 & 190 & 200 & 120 & 384 \\
\hline Climbing & 20 & 20 & 8 & 7 & 13 \\
\hline Autopreening & 108 & 68 & 65 & 72 & 61 \\
\hline Rain-bathing & & 120 & 7 & & \\
\hline Allopreening & 44 & 28 & 10 & 42 & 34 \\
\hline Display & 31 & 22 & 10 & 15 & 51 \\
\hline Fighting & 10 & 4 & 2 & 5 & 4 \\
\hline Nest attendance & 12 & 4 & 8 & 10 & 3 \\
\hline Number of flocks & 614 & 527 & 256 & 314 & 550 \\
\hline
\end{tabular}

\subsubsection{Seasonal variation in C. galerita behaviour}

Overall, most of the day was spent resting (day resting and night roosting). Proportion of the day these birds spent resting increased from a minimum in late spring (53\%) to a maximum in winter (81\%) (Table 3.9). Time spent feeding decreased from $43.8 \%$ of daily activity in late spring to $15.7 \%$ in winter, and just $13 \%$ in early spring (Table 3.9). Summer and autumn were intermediate between these two periods.

Cacatua galerita spent, on average, $4.4 \%$ of their day flying, although the proportion of time spent on this activity varied considerably from season to season (Table 3.9). The least amount of time spent flying was in late spring $(2 \%)$ and winter $(1.8 \%)$, the most time spent flying was in summer $(7.9 \%)$ and early spring (6.2\%) (Table 3.9$)$. Autumn $(4.2 \%$ of time spent flying) was again intermediate between these two periods.

There was also considerable seasonal variation in the time spent in feather maintenance (autopreening and rain-bathing) and social activities (allopreening, display, fighting and nest attendance), decreasing from a combined total of $4.8 \%$ of activity in summer to $1.5 \%$ in 
winter. During winter, almost half of the total observations of feather maintenance were recorded on a single day when a flock of $C$. galerita rain-bathed during a brief period of heavy rain.

Table 3.9. Frequency of Cacatua galerita activities recorded in each season from November 1992 to October 1993.

\begin{tabular}{|c|c|c|c|c|c|}
\hline \multirow[t]{2}{*}{ Activity } & \multicolumn{5}{|c|}{ Diurnal period } \\
\hline & Late spring & Summer & Autumn & Winter & $\begin{array}{l}\text { Early } \\
\text { spring }\end{array}$ \\
\hline Resting & 390 & 869 & 1841 & 6183 & 526 \\
\hline Feeding & 1104 & 979 & 1882 & 4212 & 234 \\
\hline Flying & 50 & 315 & 371 & 473 & 112 \\
\hline Climbing & 4 & 22 & 19 & 23 & 0 \\
\hline Autopreening & 10 & 97 & 92 & 134 & 41 \\
\hline Rain-bathing & 0 & 0 & 0 & 120 & 7 \\
\hline Allopreening & 6 & 26 & 28 & 86 & 12 \\
\hline Display & 5 & 30 & 45 & 32 & 17 \\
\hline Fighting & 2 & 8 & 13 & 2 & 0 \\
\hline Nest attendance & 4 & 9 & 0 & 12 & 12 \\
\hline Number of flocks & 201 & 571 & 517 & 689 & 283 \\
\hline $\begin{array}{l}\text { Mean length of } \\
\text { active day (minutes) }\end{array}$ & 900 & 846.3 & 692.3 & 605 & 770 \\
\hline
\end{tabular}

Fights between C. galerita were infrequent $(<0.1 \%$ of total daily activity) (Table 3.9$)$. The incidence of fighting was greatest in summer and continued to be recorded frequently in autumn (Table 3.9). Only two observations of fighting between individuals were recorded during winter and spring. 
Table 3.10. Frequency of Cacatua galerita activities recorded in each of seven habitat types in the Turakina Valley. Data represent combined records from all seasons.

\begin{tabular}{|c|c|c|c|c|c|c|c|}
\hline \multirow[t]{2}{*}{ Activity } & \multicolumn{7}{|c|}{ Habitat type } \\
\hline & $\begin{array}{l}\text { Tall } \\
\text { native }\end{array}$ & $\begin{array}{l}\text { Low } \\
\text { native }\end{array}$ & $\begin{array}{l}\text { Cupressus } \\
\text { macrocarpa }\end{array}$ & $\begin{array}{l}\text { Pinus } \\
\text { spp. }\end{array}$ & $\begin{array}{l}\text { Non- } \\
\text { pine } \\
\text { exotic }\end{array}$ & Grassland & Crop \\
\hline Resting & 7633 & 214 & 676 & 379 & 217 & 551 & 139 \\
\hline Feeding & 1228 & 108 & 710 & 192 & 469 & 2480 & 3224 \\
\hline Flying & 148 & 4 & 6 & 3 & 9 & 3 & 43 \\
\hline Climbing & 62 & 3 & 2 & 0 & 1 & 0 & 0 \\
\hline Autopreening & 337 & 9 & 7 & 17 & 0 & 4 & 0 \\
\hline Rain-bathing & 127 & 0 & 0 & 0 & 0 & 0 & 0 \\
\hline Allopreening & 142 & 2 & 4 & 4 & 0 & 6 & 0 \\
\hline Display & 102 & 11 & 4 & 4 & 8 & 0 & 0 \\
\hline Fighting & 14 & 4 & 0 & 3 & 2 & 2 & 0 \\
\hline $\begin{array}{l}\text { Nest } \\
\text { attendance }\end{array}$ & 37 & 0 & 0 & 0 & 0 & 0 & 0 \\
\hline $\begin{array}{l}\text { Number of } \\
\text { flocks }\end{array}$ & 1333 & 81 & 184 & 111 & 130 & 159 & 64 \\
\hline
\end{tabular}

\subsubsection{Behaviours associated with babitat types}

Some C. galerita behaviours were restricted to, or were most common in, particular habitat types (Table 3.10). Most (89.5\%) observations of feather maintenance and social activities were obtained from tall native forest. Rain-bathing and nesting activity was exclusive to this habitat type. Resting was also most commonly observed in tall native forest $(77.8 \%$ of all records of resting), including extended periods of resting (birds resting continuously for half an hour or more). Cacatua galerita infrequently rested for extended periods in grassland, and when it was observed it was generally associated with flocks feeding on nearby grassland or maize. When foraging in crops, resting was restricted to very brief intervals between bouts of feeding. Most of their time in ground habitats was spent feeding (81.4-94.7\% of observations from grassland and crop respectively) (Table 3.10). Feeding was also the most commonly recorded behaviour in non-pine exotics $(66.3 \%)$ and C. macrocarpa $(50.4 \%)$. 


\subsubsection{Seasonal variation in energetic costs of activities of $C$. galerita.}

There was considerable seasonal variation on the energy expended on different activities. Flying, despite being a minor part of daytime activity, was a major cost to these birds, dominating energy expenditure in summer and early spring (Table 3.11). The lowest mean daily energy expenditure occurred in winter resulting from a greater proportion of time spent resting and a reduction in costs of flying, feeding and on feather maintenance and social activity (Table 3.11); however, much of the reduced cost of expenditure in winter would be offset by increased costs of thermoregulation at this time.

Table 3.11. The energetic costs of behaviours for Cacatua galerita. Values represent average daily energetic costs of behaviour. Active day was determined from Figure 3.4.

\begin{tabular}{|c|c|c|c|c|c|}
\hline \multirow[t]{2}{*}{ Behaviour } & \multicolumn{5}{|c|}{ Energetic expenditure (kcal) } \\
\hline & Late spring & Summer & Autumn & Winter & $\begin{array}{l}\text { Early } \\
\text { spring }\end{array}$ \\
\hline Resting & 261.2 & 366.0 & 348.1 & 388.8 & 493.9 \\
\hline Feeding & 1381.6 & 770.5 & 665.0 & 494.9 & 410.6 \\
\hline Flying & 400.0 & 1584.8 & 838.0 & 355.3 & 1256.4 \\
\hline Climbing & 6.4 & 22.1 & 8.6 & 3.5 & 0 \\
\hline Autopreening & 12.5 & 76.0 & 32.4 & 15.7 & 71.6 \\
\hline Rain-bathing & 0.0 & 0.0 & 0.0 & 14.0 & 12.2 \\
\hline Allopreening & 7.5 & 20.4 & 9.8 & 10.1 & 21.0 \\
\hline Display & 6.2 & 23.5 & 15.8 & 3.7 & 29.7 \\
\hline Fighting & 16.0 & 40.2 & 29.4 & 1.5 & 0 \\
\hline Nest Attendance & 5.0 & 7.1 & 0.0 & 1.4 & 21.1 \\
\hline Night roosting & 540.0 & 593.7 & 747.7 & 835 & 670 \\
\hline $\begin{array}{l}\text { Daily energy } \\
\text { expenditure (kcal) }\end{array}$ & 2636.3 & 3504.3 & 2694.7 & 2123.8 & 2986.5 \\
\hline
\end{tabular}




\subsubsection{Habitat use by $C$. galerita}

\subsubsection{Habitat availability and variation in babitat use by C. galerita}

Improved grassland was the dominant land surface cover, comprising between $74.9 \%$ and $76.2 \%$ of the total surface cover of the six observation areas (Table 3.12). Other common vegetation types were tall native forest $(11.2 \%$ of surface area), crop ( $4.3 \%$ and $5.7 \%$ of surface area in 1992 and 1993 respectively) and low native forest (3.8\%). Pinus spp., C. macrocarpa and non-pine exotics each made up considerably less than $2 \%$ of surface area. Cupressus macrocarpa was the least abundant habitat type $(0.8 \%$ surface area), but was widespread, generally occurring in small stands (average stand size was 0.4 ha, s.d. $=0.3, \mathrm{n}=$ 36).

Cacatua galerita were recorded in all habitat types, although their use was not in proportion to their occurrence within the study area. Tall native forest, C. macrocarpa, Pinus spp., non-pine exotics and crops were used proportionally more than their occurrence, while fewer observations were obtained from low native forest and grassland $\left(\chi^{2}\right.$, d.f. $\left.=6, \mathrm{P}<0.0001\right)$. Despite the very low P-value, these results should only be taken as an indication of the extent of use of these habitats as the number of birds recorded in tree habitats was likely to have been underestimated compared with numbers using ground habitats where birds were more visible.

Native forest remnants (tall native forest) were the most commonly used habitat type by $C$. galerita in all seasons except late spring when activity was concentrated on grassland and crops (Figure 3.14). Use of other habitats varied considerably according to season. For example, C. galerita made extensive use of non-pine exotics, particularly poplars (Populus spp.), during summer $(63.3 \%$ of total observations from this habitat type). Use of crops also varied considerably reflecting the seasonal availability of suitable foods from this habitat type. 


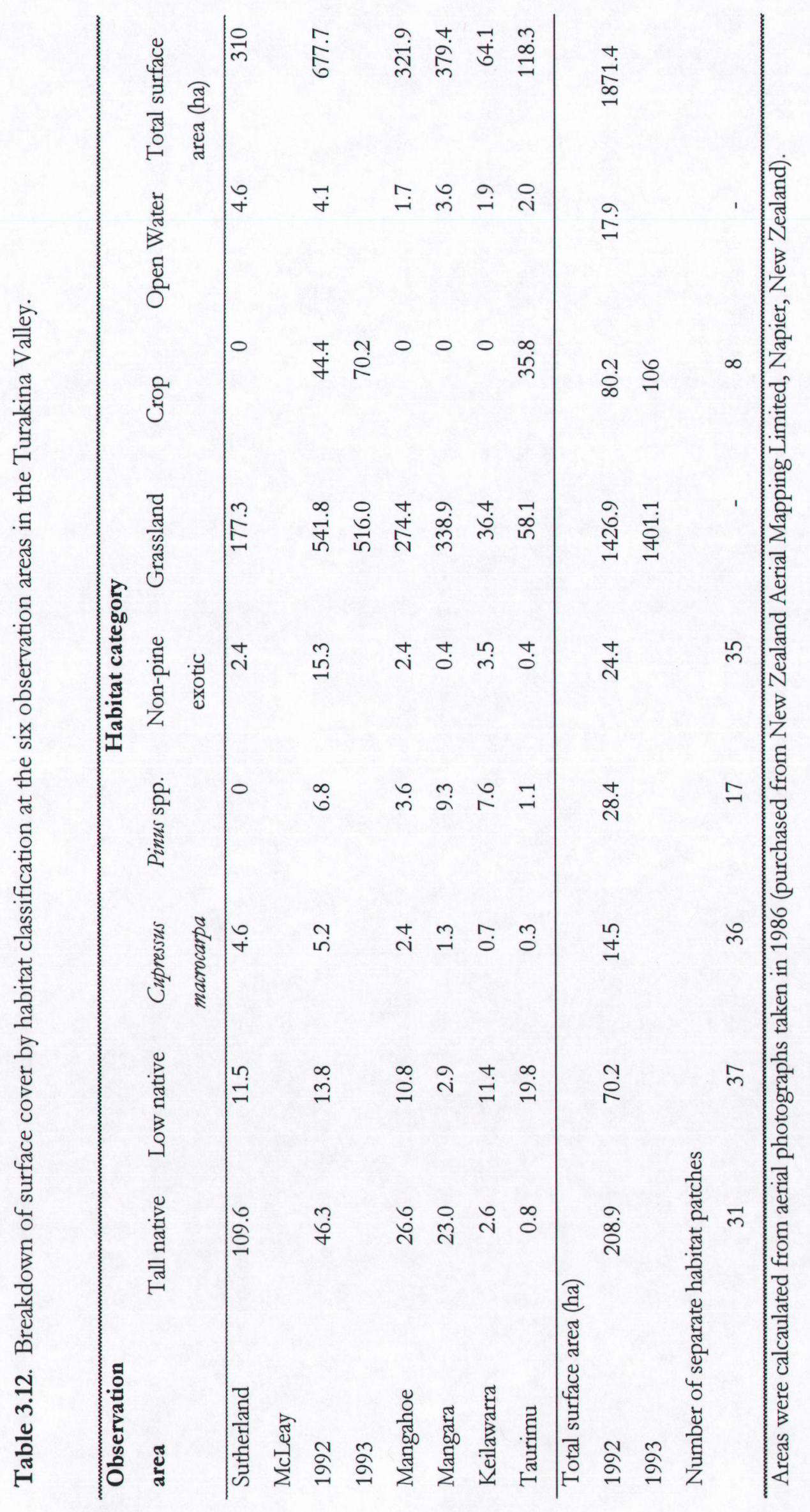




\subsubsection{Habitat patch use by C. galerita}

There was little seasonal variation in the areas where $C$. galerita were recorded. Most of the variation observed was related to the number of birds sighted in a particular stand of trees or a field (Figure 3.16a-e). In summer (Figure 3.16b), foraging groups were more evenly spread throughout the study area, whereas in winter (Figure 3.16d) numbers of C. galerita were greatest along the Turakina River, especially towards the south of the study area. Autumn (Figure $3.16 \mathrm{c}$ ) and spring $(3.16 \mathrm{a}, \mathrm{e})$ were intermediate between these two periods.

The greatest diversity of vegetation types was along the valley floors. This is also where the majority of observations of C. galerita were obtained (Figure 3.16a-e). Of the habitat available, the most intensively used patches were in and around roost sites $(77.6 \%$ of records of C. galerita were obtained within 1 kilometre of a roost, including $92.4 \%$ of birds observed foraging on grassland) and along frequently used flight paths.

Foraging C. galerita tended to use stands of larger and senescent trees more frequently than small, young trees. This was most noticeable for Pinus spp. and U. bollandica, which were present in stands of widely varying ages. Approximately $84 \%$ of C. galerita recorded in Pinus spp. were in mature or senescent trees, $16 \%$ were in trees between 10-15 years old, and no birds were observed in trees less than 10 years of age.

\subsubsection{Breeding behaviour}

There were 18 known nesting pairs within the study site, but not all attempted breeding at the same time. Nest attendance began as early as June, with occasional visits to old nest holes. Peak activity at known nest holes was recorded between July and September, and again in December (1992/93 season only). In the 1992/93 breeding season heavy rain in September was reported to have destroyed early nesting attempts (G. Butters personal communication). Some pairs started again later in the season, possibly giving rise to the two peaks in nesting activity seen; however, nesting birds were very secretive and so actual nest visiting rates might have been quite different to observed rates. Nesting activity (birds entering nest holes) ended in January (1991/92 season) and December (1992/93 season). 


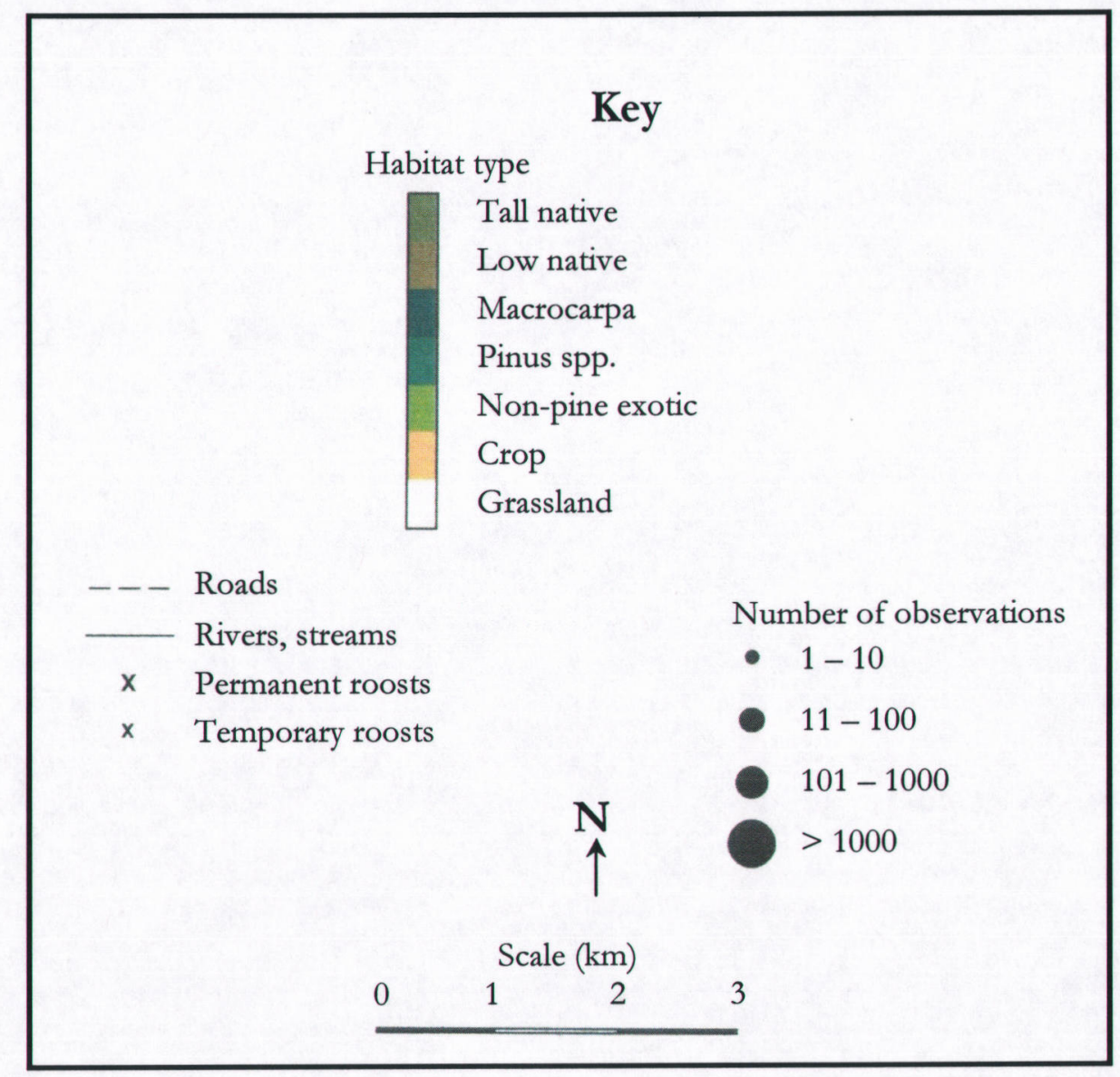

Figure 3.16. Patches of habitat used by foraging groups of Cacatua galerita between

November 1992 and October 1993. Circle size indicates the number of birds recorded using that patch for that season. 


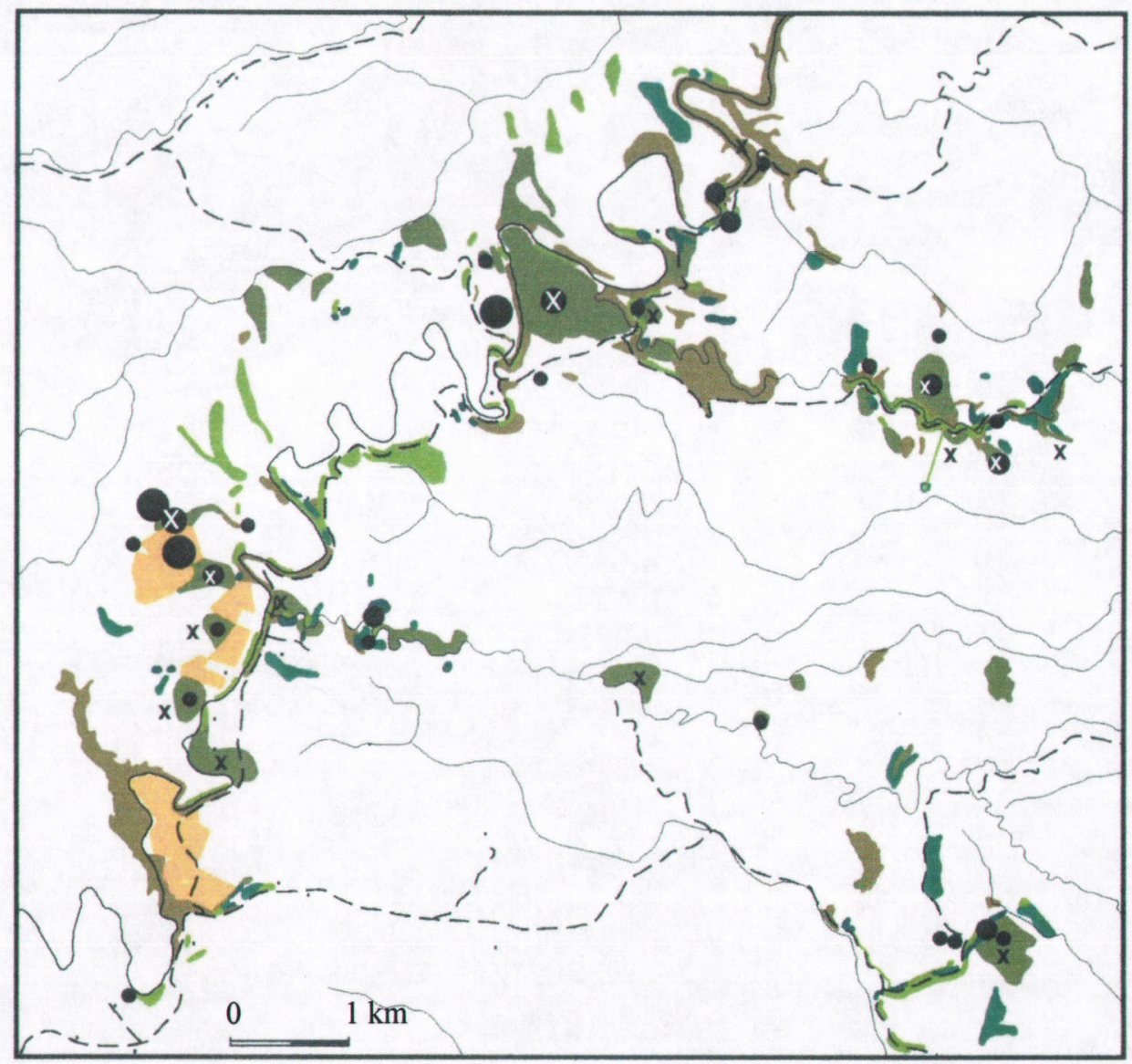

(a) Winter $(n=1532)$

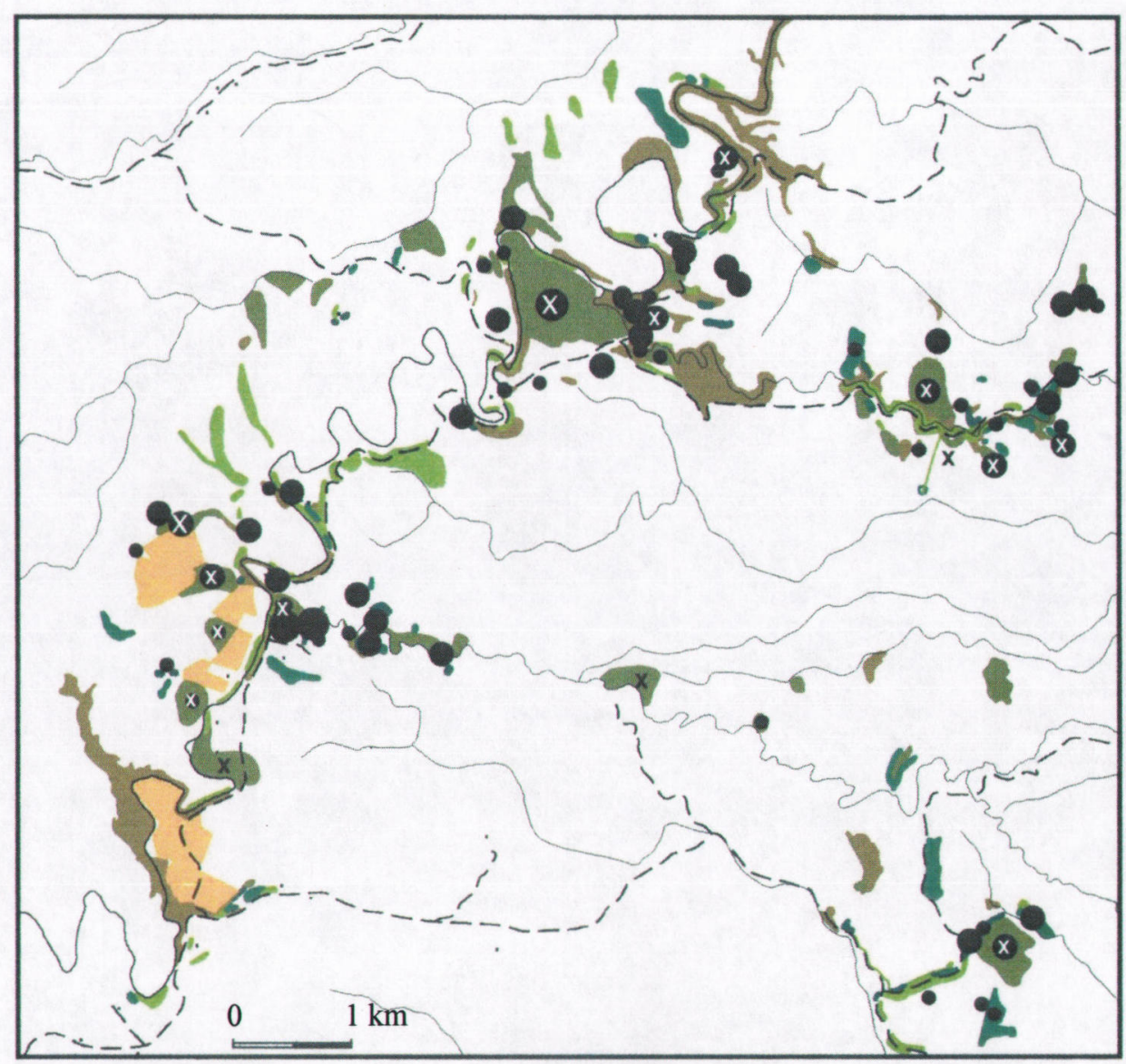

(b) Summer $(\mathrm{n}=2107)$ 


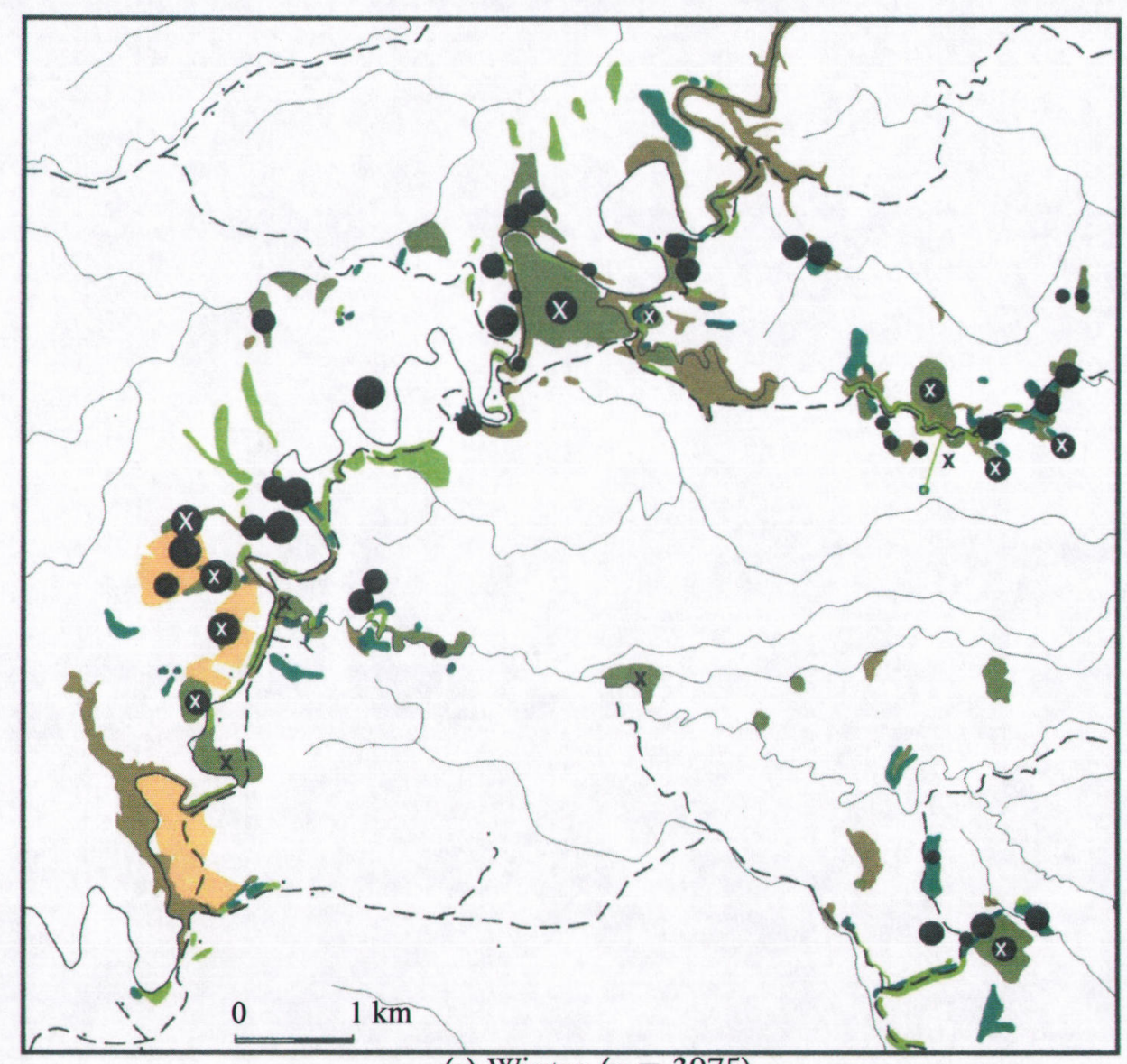

(c) Winter $(\mathrm{n}=3975)$

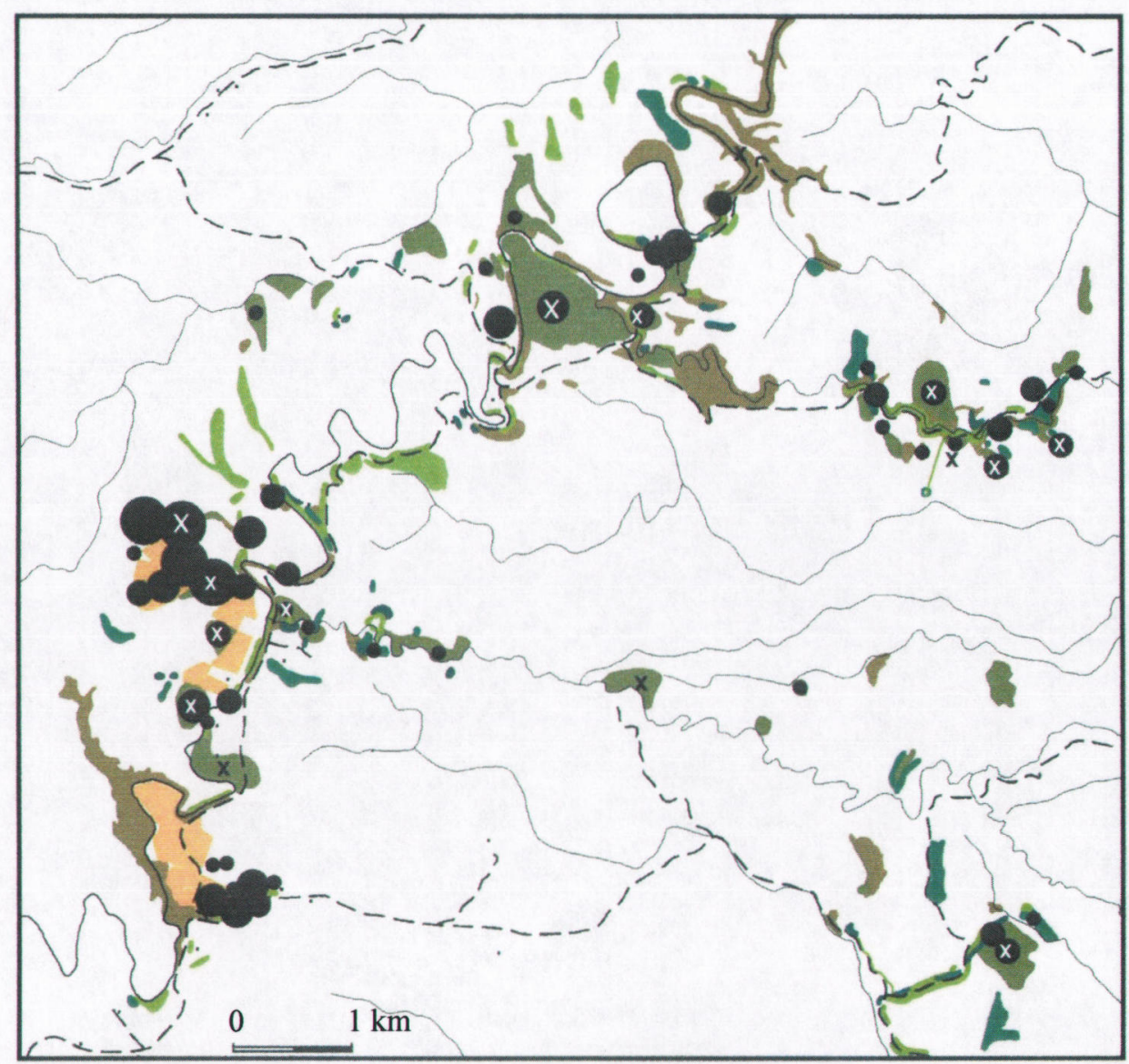

(d) Winter $(n=10888)$ 


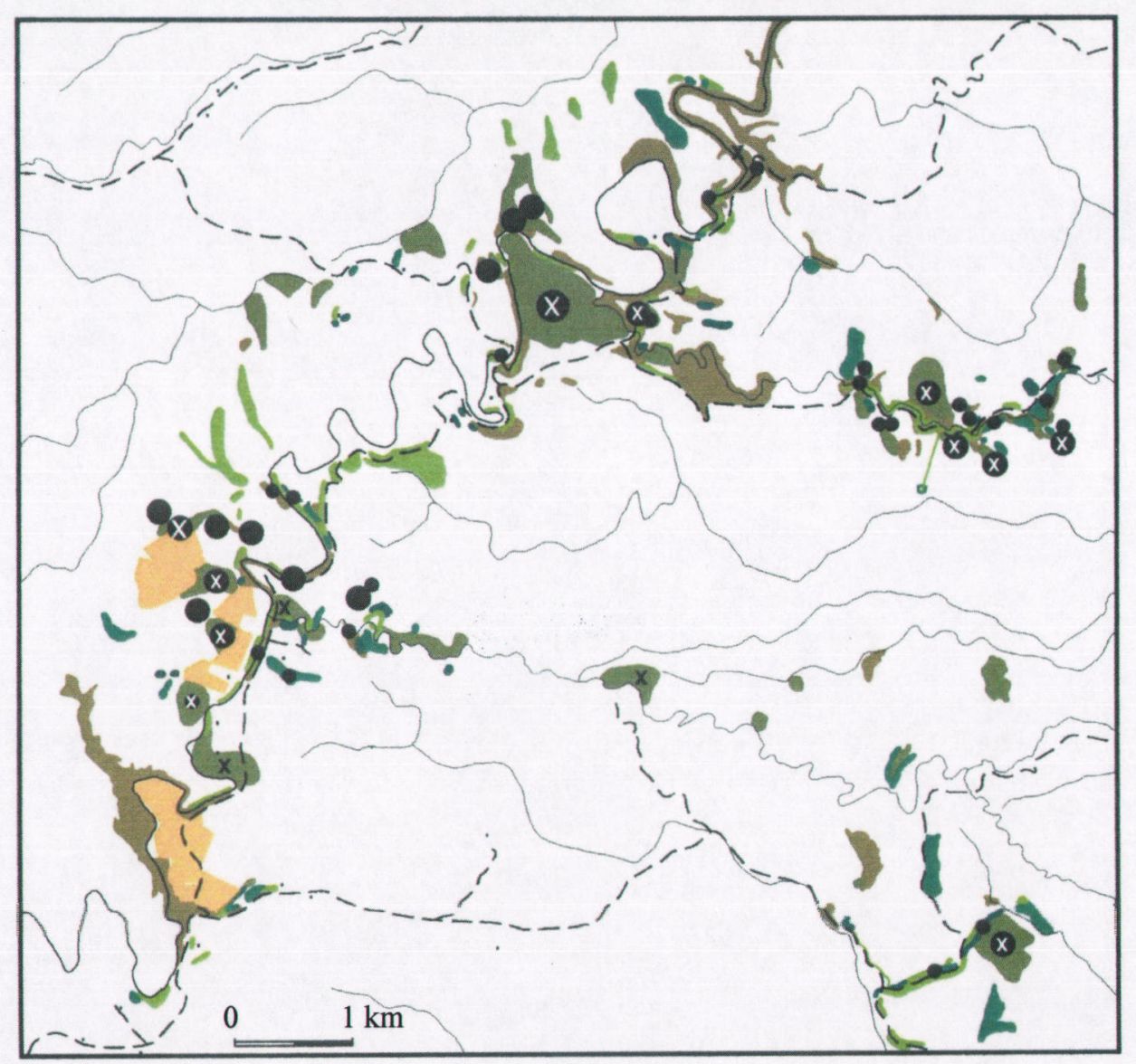

(e) Early spring $(\mathrm{n}=852)$ 
The nest sites used by C. galerita in the Turakina Valley were all in tall emergent podocarps, both dead and living (Table 3.13). Dead trees were favoured sites for nests (50\%), probably because they offered greater opportunities for birds to excavate suitable holes. Although heights of individual nests were not always recorded, the lowest was above $18 \mathrm{~m}$ and the highest known nest was recorded at $37.5 \mathrm{~m}$. Cacatua galerita exhibited considerable fidelity to nest trees, the same nest tree, and often the same cavity being used in consecutive seasons. Nests were abandoned when the tree or branch fell over. Inspection of an abandoned nest in a $D$. dacrydioides revealed water had leaked into the nest cavity.

An average of 1.63 eggs were laid per nest (Table 3.14), while nest production to hatching averaged just 1.47 (neither of the 3 egg clutches survived to hatching). An Australasian harrier (Circus approximans) reportedly took the eggs/chicks from one nest (developmental stage unknown), and all remaining chicks were taken from nests by humans so no estimate of fledging success was possible.

Table 3.13. Nest sites of Cacatua galerita in the Turakina valley.

\begin{tabular}{llcc:}
\hline Nest tree (species) & Nest site & In use & Abandoned \\
\hline Dacrycarpus dacrydioides & Trunk & 1 & 1 \\
& Branch & 1 & 1 \\
Dacrydium cupressinum & Trunk & 1 & \\
Podocarpus totara & Branch & 1 & \\
Unknown (dead) & Trunk & & \\
& Branch & 1 & \\
Total & Trunk & 5 & 2 \\
\hline
\end{tabular}


Table 3.14. Egg production by Cacatua galerita in the Turakina and Pohangina Valleys, Manawatu-Wanganui during the 1991/92 and 1992/93 breeding seasons.

\begin{tabular}{llccc}
\hline Nesting season & Location & 1 & Clutch size & \\
& & 2 & 3 & 1 \\
\hline $1991 / 92$ & Pohangina & 3 & 1 & \\
& Turakina & 4 & 4 & 1 \\
$1992 / 93$ & Turakina & & & \\
\multirow{2}{*}{ Total } & & 9 & 8 & 2 \\
\hline
\end{tabular}

\subsubsection{Diurnal variation in C. galerita babitat use}

Cacatua galerita were observed in tall native forest more than in each of the other habitats at all times of the day, though fewer observations were recorded in early morning and late afternoon when they occurred most frequently on grassland and crops (Figure 3.17). Use of trees was greatest from late morning to mid afternoon. This pattern of diurnal activity was consistent throughout the year, but the proportion of time C. galerita were observed in trees varied according to the availability of crops. When crops were not available the proportion of birds recorded in trees was considerably greater throughout the day than when crops were available.

Diurnal variation in the number of $C$. galerita that were observed feeding in the seven habitat types (Figure 3.18) was similar to the overall pattern of habitat use (Figure 3.17). Foraging $C$. galerita concentrated their activities at ground habitats (grassland and crops) early in the morning (74.8\% of observations) and at mid- (59.1\%) and late afternoon (92.5\%), moving to forage in trees at mid-morning (81.1\%) and mid-day (56\%) (Figure 3.18). 


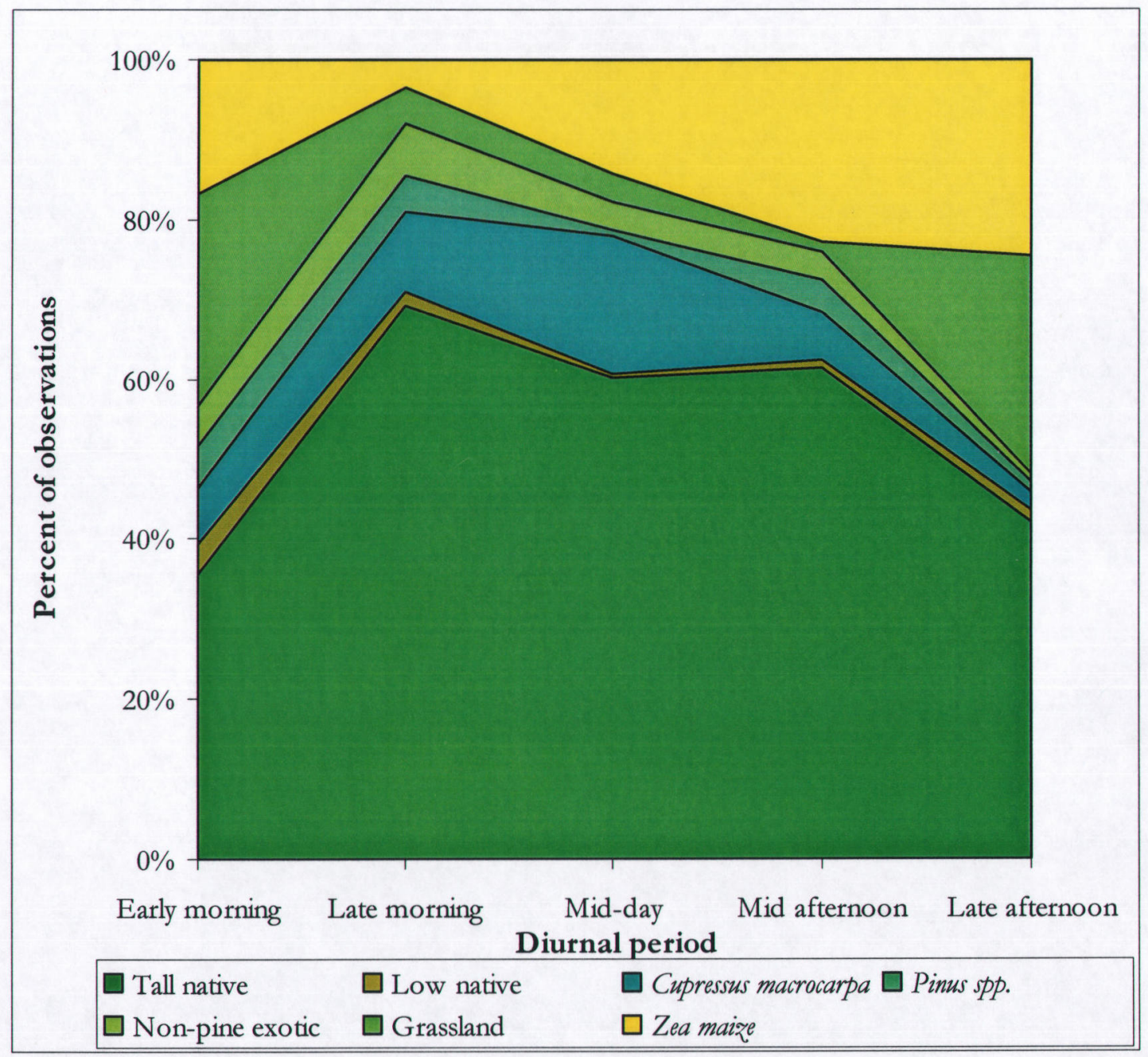

Figure 3.17. Diurnal variation in the habitat used by Cacatua galerita in the Turakina Valley. Values represent the combined observations from November 1992 to October 1993. 


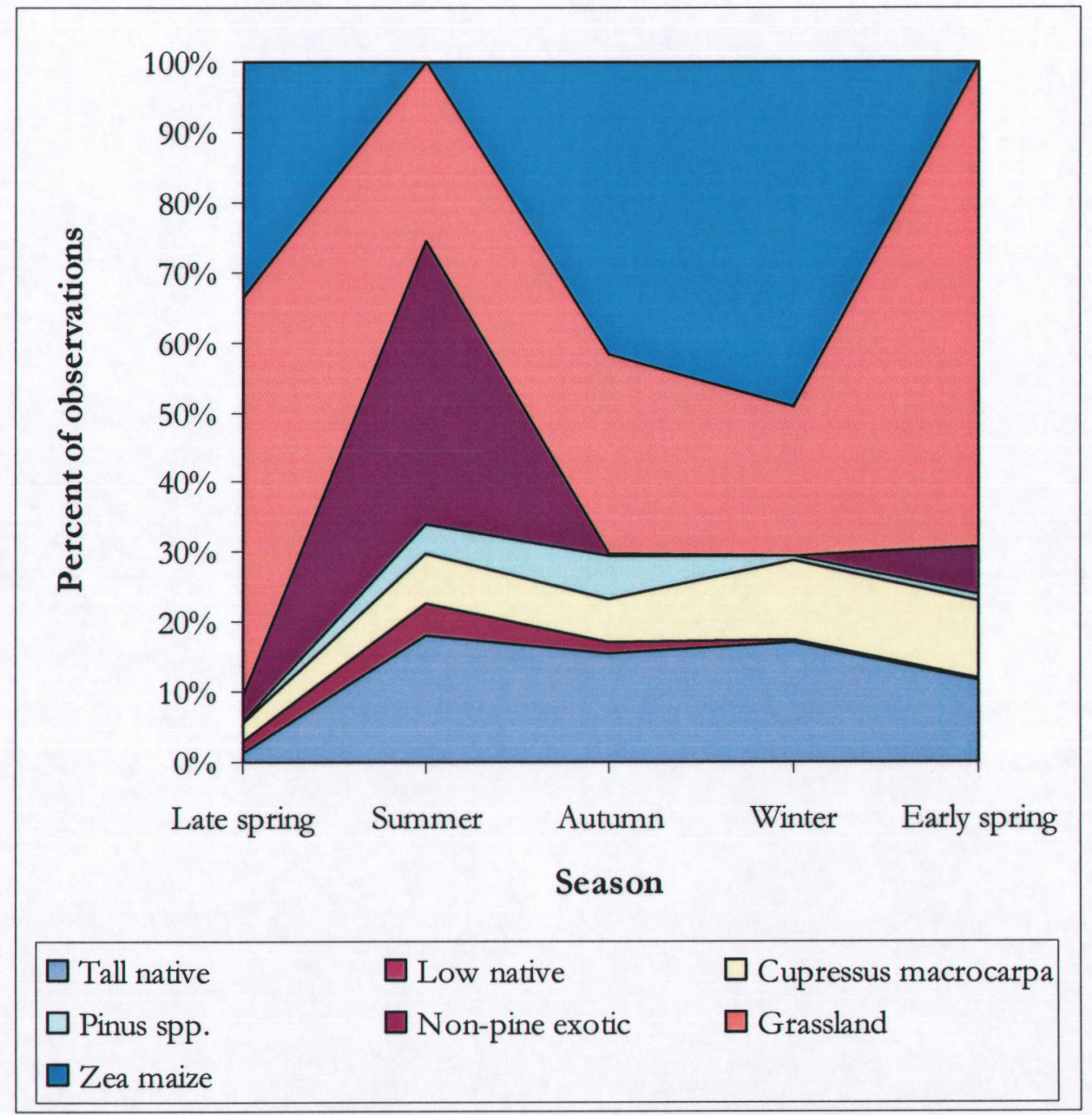

Figure 3.18. Diurnal variation in the distribution of feeding observations of Cacatua galerita. Values represent the combined observations from November 1992 to October 1993. 


\subsubsection{Foraging ecology of C. galerita}

\subsubsection{Food availability}

Grass seed was available throughout the year, though it became much less abundant during winter and early spring (Figure 3.19). By June grass seeds had gone from plants on the lower river terraces, but persisted in pockets along streams and road verges, and on lightly grazed slopes.

Between November 1992 and October 1993 maize was available to C. galerita in the Turakina Valley for a short period after sowing (November), on standing plants from April (when the plants set seed) until late June (when the last plants were harvested), and in stubbles from early June to July (Figure 3.19).

Most native and exotic tree species used by C. galerita in the Turakina Valley produce flowers and develop leaf buds in spring (Figure 3.19). Summer and autumn were the seasons of greatest abundance and variety in seed and fruit availability. Introduced conifers, such as Pinus spp. and C. macrocarpa, produce their seed cones in autumn and winter, but mature seed cones may be present on trees throughout the year.

Larvae of common pasture-dwelling invertebrates, for example, grass grub (Costelytra zealandica: Coleoptera) and porina moth (Wiseana spp.: Lepidoptera), are closer to the surface in autumn and winter, when the surface layers are wetter (Langer 1973; Purchas 1973), while adults are active in spring and summer. These species can build up to great numbers, $C$. zealandica in free-draining alluvial and pumice soils and Wiseana spp. larvae in wet soil, although C. zealandica tend to be patchy in distribution (Langer 1973). The larvae of woodboring insects with a one-year life cycle are most active in autumn and winter, while larvae of insects with a longer life cycle are available throughout the year.

\subsubsection{Cacatua galerita feeding behaviour in maize}

Cacatua galerita showed a preference for some fields of maize over others. Crops suffering most predation were most distant from human activity and were bordered closely by trees or high ground, such as a hill face. Cacatua galerita did not visit crops bordering farmers' residences and sheds. 


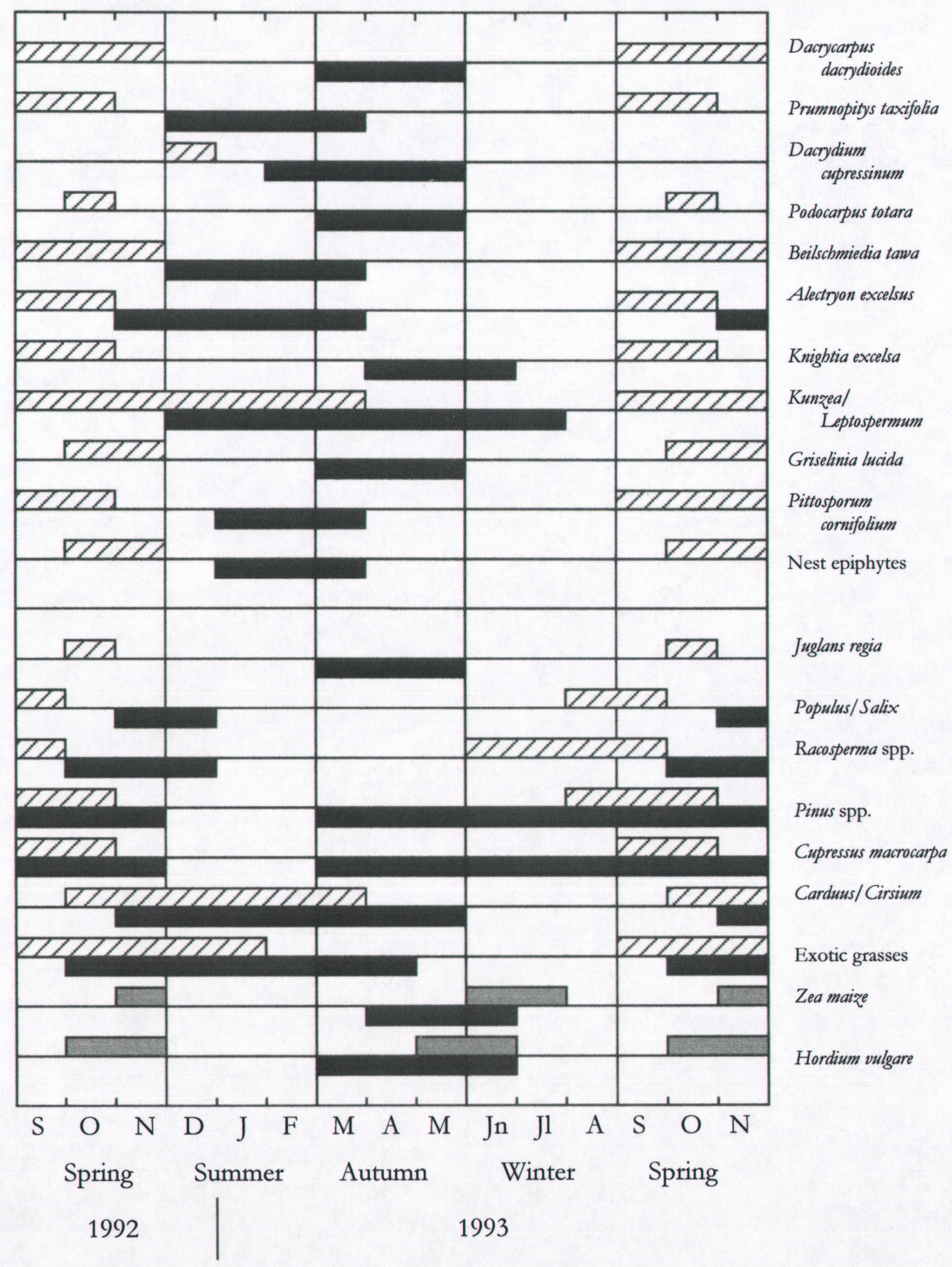

$\square Z$ Period of main abundance of flowers

Period of main abundance of fruit and seeds

$\square$ Crop seed available in stubbles or sown grain

Figure 3.19. Flowering and fruiting times of plant species exploited by Cacatua galerita in the Turakina Valley between November 1992 and October 1993. Data sourced from Allan (1961), Webb et al. (1988) and personal observations. 
Cacatua galerita feeding on a crop usually approached via a refuge, such as a tree or group of trees, directly adjacent to the crop. Initially, individual birds and small groups moved from the refuge to the fence bordering the crop before moving into the crop itself. Once a feeding flock had become established, further flocks of C. galerita moving into the area entered directly into the crop, joining birds already feeding, rather than approaching from the refuge. At times large flocks of $C$. galerita congregated on maize crops to feed. After feeding, groups of birds moved to nearby pasture or refuges to rest.

To get access to the seed head on standing maize C. galerita perched on the stalk or cut the plant down by biting the stem. The husk surrounding the seed head was bitten through and a section peeled away. Most birds removed the seed head and moved away to open ground, a fence or tree taking the seed head with them. Once harvesting began $C$. galerita fed on spilt grain and no further feeding was recorded on standing plants, even though they were available.

In 1992 the maize harvest was delayed by wet weather and was finally completed in September. Considerable damage was caused to the outermost 2 to 6 rows, where the majority of seed heads had been removed and a large proportion of the plants bitten off close to the ground. The number of plants damaged decreased further into the crop. Where trees bordered, or were located within the crop, plants were damaged up to 24 rows into the crop. In areas of poor germination, creating open patches, the intensity of damage radiated out from the open area, with least damage occurring furthest from the centre. Possums (Trichosurus vulpecula), ducks (mostly Anas platyrbynchos and Tadorna variegata), introduced passerines, pheasants (Phasianus colchicus), rodents (Rattus spp.) and fungal infection also caused considerable damage to this crop and so losses could not be attributed entirely to any one causal factor.

In 1993 the maize crops were harvested in June and the impact of $C$. galerita on the crops was much less severe. Generally damage was restricted to the outermost 2 to 3 rows in two fields of maize where they bordered forest, and the fenceline most distant from the farmers' house.

\subsubsection{Diet of C. galerita}

Cacatua galerita foraged from a range of native and foreign plant species (Table 3.15). The main foods of C. galerita varied seasonally. Some species were only available and/or exploited for a limited time, while others were exploited throughout the year, although their 
contribution to the diet varied seasonally. Approximately $84 \%$ of feeding observations were recorded from introduced vegetation, almost $70 \%$ from grassland and crop habitats. Of these, the single most important species was maize $(38.1 \%, n=2558)$. Other crops grown in the area include barley (Hordeum vulgare), which they did exploit, but was not monitored, and choumollier (Brassica oleracea), which was not visited by these birds.

Grassland contributed $57.1 \%$ of feeding observations in late spring, and $70 \%$ in early spring (Table 3.15). Most feeding occurred in short, heavily grazed pastures. Of 3046 observations only four were recorded from long grass. When grass seed was abundant, between spring and autumn, C. galerita were observed stripping seeds from the seeding heads. These birds may also have obtained water from grass; they were frequently observed sliding their bills along stems and leaf blades early in the morning when these were laden with dew.

Cacatua galerita feeding on grassland in autumn and winter, when most grass seed was in the buried seed bank and larvae of common pasture invertebrates (such as C. zealandica and Wiseana spp.) were most common, were frequently observed probing beneath the surface of the pasture, and several groups were observed digging into the mud around drying pools in early spring. Also, they were seen overturning cow dung and foraging among clumps of vegetation on open bare surfaces, such as slip-faces. The food items taken were not identified. Cacatua galerita fed extensively on the seed heads of thistles (Carduss spp. and Cirsium spp.) in summer (5.5\% of observations) and autumn (15.1\%) (Table 3.15). Seeds of other pasture weeds, such as inkweed ( $P$. octandra), were taken from fallow land around maize crops in summer and winter, and from disturbed surfaces, such as slip-faces, in summer and autumn.

Cacatua galerita were observed eating the seeds from the cones and seed heads of many of the exotic tree species present in the valley, but may also have been eating flowers and leaf buds of these plants. There was significant seasonal variation in the species that they were seen feeding on. For example, Pinus spp. was most important in autumn and C. macrocarpa was most important in winter (Table 3.15). Eighty four percent of feeding observations from non-pine exotics were obtained in summer, including $86.4 \%$ of observations of feeding in $U$. bollandica, and all observations in $M$. domestica, Eucalyptus spp. and Racosperma spp. (Table 3.15). 
Table 3.15. Plant species and species associations in which Cacatua galerita were observed feeding in the Turakina Valley between November 1992 and October 1993. Values represent number of feeding records from each species. Actual food items are listed (for example, $\mathrm{s}=$ seed and/or fruit, $\mathrm{f}=$ flowers) if they could be determined.

\begin{tabular}{lccccc} 
Species & $\begin{array}{c}\text { Late } \\
\text { spring }\end{array}$ & Summer & Autumn & Winter & $\begin{array}{c}\text { Early } \\
\text { spring }\end{array}$ \\
\hline
\end{tabular}

Maize (Zea maize)

Newly sown maizes 371

Standing crops

Stubbles

Ploughed field

\section{Grassland}

Bare ground

Cage traps 3

Juncus sp. ${ }^{\mathrm{s}}$

2

Pasture

632

166

295

Pasture weeds ${ }^{s}$

Slip-face

Thistless (Carduus

spp., Cirsium spp.)

Trifolium sp.

\section{Exotic conifers}

Cupressus macrocarpas

Pinus spp. ${ }^{\mathrm{s}}$

\section{Non-pine exotic}

\section{Eucalyptus spp.}

Malus domesticas

Racosperma spp. ${ }^{\mathrm{f}}$

Salix spp.

Populus spp.

\section{Native forest}

Alectryon excelsus

Astelia solandri and

Collospermum hastatum

\begin{tabular}{|c|c|}
\hline Beilschmiedia tawas & \\
\hline Cordyline australis & \\
\hline Dacrycarpus dacrydioides & 8 \\
\hline
\end{tabular}




\begin{tabular}{|c|c|c|c|c|c|}
\hline Dacrydium cupressinum & 2 & 120 & 7 & 28 & 7 \\
\hline Dead tree & 4 & 19 & 18 & 21 & 8 \\
\hline Griselinia lucida & & & & & 1 \\
\hline Knightia excelsa & 1 & 2 & 1 & & \\
\hline $\begin{array}{l}\text { Leaf litter under } \\
\text { native forest cover }\end{array}$ & & 6 & & & \\
\hline $\begin{array}{l}\text { Leptospermum scoparium } \\
\text { and Kunzea ericoides }\end{array}$ & 11 & 11 & 28 & 99 & \\
\hline Melicytus ramiflorus & & & 4 & & \\
\hline Podocarpus totara & 4 & & 10 & 108 & \\
\hline $\begin{array}{l}\text { Small leaved } \\
\text { divaricates }^{1}\end{array}$ & & & 1 & & \\
\hline Total & 1106 & 1134 & 2100 & 4218 & 237 \\
\hline
\end{tabular}

Flocks seen feeding in $D$. dacrydioides, the most common emergent species in the Turakina Valley, dominated observations of $C$. galerita foraging in native forest habitats $(62.2 \%)$ (Figure 3.19). As for exotic tree species, there were significant seasonal differences in the use of native tree species by $C$. galerita. Dacrydium cupressinum was exploited significantly more in summer $\left(\chi^{2}=302\right.$, d.f. $\left.=4, P<0.001\right), D$. dacrydioides more often in autumn and winter $\left(\chi^{2}=\right.$ 1080, d.f. $=4, \mathrm{P}<0.001)$ and totara (Podocarpus totara) more in winter $\left(\chi^{2}=360.8\right.$, d.f. $=4, \mathrm{P}$ $<0.001)$ than at other times of the year. Most feeding occurred when berries were present, but $C$. galerita also chipped off bark of living $D$. dacrydioides and chewed rotten timber of dead and living trees throughout the year, possibly to extract invertebrates, but also perhaps to excavate nest holes.

Most $C$. galerita seen feeding in native forest habitats were in the canopy and emergent layers, but some were seen foraging on the ground in very open B. tawa and titoki (Alectryon excelsus) forest, and some groups were seen foraging on the ground beneath $D$. dacrydioides growing in the open. Cacatua galerita were also observed foraging in low growing native shrubs and small tree species along the margins of forest patches, streams and in small scrub remnants in pasture, though this was uncommon. Most observations of foraging in native tree species were obtained in summer, except for $K$. ericoides and $L$. scoparium, which C. galerita exploited $\operatorname{most}\left(\chi^{2}=214.3\right.$, d.f. $\left.=4, \mathrm{P}<0.001\right)$ in winter (Table 3.15). 
Generally, use of plant species by $C$. galerita coincided with when these plants were fruiting, and they showed an overall preference for the most abundant seed-producing species at any particular time.

Table 3.16. Estimated seasonal averages for daily energy intake by Cacatua galerita. Values are: $\mathrm{n}=$ number of foraging observations from each plant group; and $\mathrm{kcal}=$ contribution to daily energy intake.

\begin{tabular}{lllllllllll}
\hline Species & Late spring & & Summer & \multicolumn{2}{c}{ Autumn } & & Winter & \multicolumn{2}{c}{ Early spring } \\
& $\mathrm{n}$ & $\mathrm{kcal}$ & $\mathrm{n}$ & $\mathrm{kcal}$ & $\mathrm{n}$ & $\mathrm{kcal}$ & $\mathrm{n}$ & $\mathrm{kcal}$ & $\mathrm{n}$ & $\mathrm{kcal}$ \\
\hline
\end{tabular}

Thistles

\section{Introduced annual}

and perennial herbs

$\begin{array}{llllllll}225 & 1.006 & 43 & 0.104 & 17 & 0.020 & 9 & 0.193\end{array}$

\section{Bare ground}

$\begin{array}{llllll}5 & 0.021 & 749 & 1.683 & 22 & 0.438\end{array}$

Pasture

$\begin{array}{llllllllll}632 & 2.613 & 166 & 0.669 & 295 & 0.642 & 812 & 0.880 & 133 & 2.566\end{array}$

Zea maize

$\begin{array}{llllllll}371 & 1.448 & 120 & 0.247 & 2070 & 2.119 & 2 & 0.036\end{array}$

\section{Introduced deciduous}

and evergreen trees

$\begin{array}{llllllllll}38 & 0.174 & 333 & 1.489 & 7 & 0.017 & 4 & 0.005 & 14 & 0.300\end{array}$

Introduced conifers

$\begin{array}{llllllllll}35 & 0.193 & 111 & 0.597 & 243 & 0.706 & 500 & 0.723 & 28 & 0.721\end{array}$

Native evergreen trees

$\begin{array}{llllllllll}12 & 0.055 & 51 & 0.228 & 35 & 0.085 & 99 & 0.119 & 3 & 0.064\end{array}$

Native conifers

$\begin{array}{llllllllll}14 & 0.077 & 162 & 0.871 & 272 & 0.790 & 619 & 0.895 & 18 & 0.463\end{array}$

Dead tree invertebrates

$\begin{array}{llllllllll}4 & 0.018 & 19 & 0.084 & 18 & 0.043 & 21 & 0.025 & 8 & 0.168\end{array}$

Mean daily

4.579

5.260

5.131

4.883

4.950

intake 


\subsubsection{Caloric counts of foods eaten by C. galerita}

Seasonal averages of daily intake, based on caloric values for the food items consumed by $C$. galerita and frequency of foraging observations from various plant groups, were used to provide a rough estimate of the daily intake of calories by these birds (Table 3.16). Seeds of grasses, which included maize, had the lowest caloric values of the foods eaten by C. galerita, but constituted most of the energy intake by these birds in winter and spring. Despite this, there was not a great difference in the calory intake by $C$. galerita between seasons (Table 3.16). Seed from native and exotic conifers contributed substantially to energy intake in all seasons except late spring, with the greatest contribution occurring in winter $(33.1 \%)$.

\subsection{DISCUSSION}

\subsubsection{Population size}

Cacatua galerita resident in the Turakina Valley study area were part of a wider population. The resident population fluctuated between 52 to 151 birds (November-March and AugustOctober 1993). This number was made up of a maximum of 18 breeding pairs and a varying number of apparently non-breeding birds. The number of $C$. galerita residing in the study area was greatest in winter, with an observed peak of 310 individuals in July, approximately six times as many birds as were present in the following spring.

Build up in the number of C. galerita over winter in north-eastern New South Wales, Australia was considered to have resulted from aggregation of nomadic birds (non-breeding adults and juveniles) within the "permanent home range" of the sedentary population, made up of breeding and non-breeding adults (Noske 1980). In the present study the number of nesting birds remained constant or decreased during spring-summer so most of the variation in population size at this time of year was made up of non-breeding birds. Some of these nonbreeding birds were resident while others were obviously nomadic, resulting in daily changes in the number of birds at some roosts of 26-35 individuals, and monthly variation in the local population of 13-54 individuals. The increase in winter resulted from the aggregation of these nomadic birds, and probably breeding birds and non-breeding adults that are normally resident in adjacent valleys or other sections of the Turakina Valley. If so, the winter population may represent a considerable proportion of the resident population from the near reaches of the Turakina, Whangaehu and possibly Rangitikei River catchments, an area encompassing several hundred square kilometres. 


\subsubsection{Factors affecting flock forming behaviour of $C$. galerita}

My data suppor hypothesis 3.1, that flock forming behaviour is an adaptation to feeding on temporally available and localised food sources.

The smaller flock sizes seen in spring and summer coincided with when these birds were actively nesting and when most of their food was obtained from widespread, but not very abundant food sources (such as provided by pasture). Large flock sizes were seen in late spring, autumn and winter, and were associated with greater population density and with the formation of large feeding aggregations on maize. In both 1992 and 1993, after maize seed had germinated, crops had been harvested and the stubble had been ploughed, both population density and flock size decreased rapidly.

Cannon (1984) and Emison and Nicholls (1992) related variation in flock size to the flock building behaviour of birds. Large feeding aggregations seen by Emison and Nicholls (1992) resulted from small flocks of individuals flying to join others seen feeding at a suitable food source. Evidence of this flock forming behaviour was seen when C. galerita were feeding on maize, and may also explain the significantly larger size of feeding flocks compared to flying flocks recorded in this study. The large size of resting flocks is related to the gregarious nature of the species, occupying communal roosts and sharing day rest sites. This type of behaviour is considered to be an adaptation to feeding on transient and localised food sources, allowing improved survival of young birds over their first winter (Wilson 1973; Feare et al. 1974; Saunders 1974, 1980; Noske 1980; Cannon 1984; Westcott and Cockburn 1988; Delestrade 1994).

Flock forming behaviour has also been attributed to predation avoidance (Westcott and Cockburn 1988), aridity of the climate (Smith and Moore 1992), territorial behaviour (Wilson 1973) and changes in level of agonistic behaviour (Pigeon 1970). New Zealand has fewer avian predators, in both number and variety, compared to the native range of the species in Australia. Humans are likely to be the greatest threat to the species in New Zealand, from shooting and by capturing chicks and adults for the pet trade. The habit of C. galerita clustering in one part of a crop, generally furthest from areas of human activity and close to refuges, may well be in response to the threat of human predation, but did not discourage these birds from congregating on this crop. Intraspecific aggression is unlikely to have contributed significantly to the changes in population density seen: territorial behaviour has 
not been reported for this species (Higgins 1999), and agonistic behaviour was rarely observed during this study and was greatest in summer and autumn prior to population increase. Furthermore, there was no observed increase in agonistic behaviour in winter or spring prior to population dispersal. Rainfall in the Turakina and neighbouring valleys was relatively constant during the year, so change in aridity is also unlikely to have contributed to the changes in density of the population.

Variation in the number of C. galerita present in the Turakina Valley did not show significant correlation with trends in annual variation of flock sizes seen through the rest of the country. Factors relating to changes in population size may be specific to each area. Dominant grassland species are the same over much of the species' range in New Zealand, and predominant tree species in native and exotic forests are similar throughout. Site specific factors, such as availability (or lack of availability) of crop seed may be most important in determining population size and its seasonal variation. The large flocks seen in the western Waikato in winter were in areas where maize and possibly other crops are grown; however, the relation between such factors cannot be confirmed without similar surveys being undertaken in these areas.

\subsubsection{Seasonal effects on behaviour of $C$. galerita}

Three strategies used by birds to cope with increased thermoregulatory costs of winter are (1) to increase the proportion of time dedicated to resting; (2) to increase the proportion of time dedicated to feeding; or (3) switch to a more energy rich and/or abundant food source (Magrath and Lill 1983; Westcott and Cockburn 1988; Robbins 1993).

Prediction 3 (Hypothesis 3.2) was not supported by my data. Cacatua galerita in the Turakina Valley did not increase time spent feeding in winter, instead they reduced feeding effort and increased time spent resting, which supports prediction 3. Most of the energy conservation by these birds in winter was achieved by reducing the amount of energy expended on flying. This was achieved by moving to the roost in the McLeay's observation area that was located immediately adjacent to their main source of food at this time (maize). Time spent in other activities was also reduced in winter, although these did not provide as great a saving in energy expenditure as reduction in flying.

My data also supports prediction 2. The main part of C. galerita diet in winter was maize, which had the lowest metaboliseable energy contents of the foods exploited; however, seeds 
from this crop occur at much greater abundance than all other foods exploited by these birds and were available immediately adjacent to their roost. Seeds of introduced conifers $(C$. macrocarpa and Pinus spp.) were important components of C. galerita diet in winter, but also require more effort to obtain (occurring in small widely distributed patches and having seeds embedded in woody cones).

Crimson rosellas (Platycercus elegans), red-rumped parrots (Psephotus baematonotus) and galah (C. roseicapilla) were also found to reduce time spent foraging, and on feather maintenance and social behaviour in winter, instead increasing the amount of time spent resting (Magrath and Lill 1983; Westcott and Cockburn 1988). Resting is a less energetically expensive activity than foraging and is therefore the best way to spend time saved through a reduction in foraging (Magrath and Lill 1988).

A study of rooks (Corvus frugilegus) in Scotland concluded that the availability of oat stacks during winter allowed birds to obtain food when it may otherwise have been difficult to locate resulting in increased density of birds in winter, but also resulted in an increase in the proportion of time birds spent resting because their was limited access (due to social hierarchies within C. frugilegus populations) to the food (Feare et al. 1974). Cacatua galerita are not known to have social hierarchies (Higgins 1999), and they had unrestricted access to maize seed that could not be defended easily by individuals, so social structure is unlikely to have caused the increased time spent resting.

In early spring, when $C$. galerita are likely to still face high costs of thermoregulation and must also expend energy in breeding activity, the birds in the Turakina Valley increased the time (and the associated energy costs) flying, while reducing time spent feeding. The energy content of foods exploited at this time (mostly grass seeds) are also relatively low in caloric content. The reason for this greater activity, while facing high costs of thermoregulation and consuming low energy food items, is not known. It is possible that many of the birds present at this time are incubating eggs and so are not spending much time in extended bouts of feeding. In late spring they spent a much greater amount of time foraging (and little time on feather maintenance and social activity) and it is possible that they are feeding chicks then.

When feeding chicks, yellow-billed magpies (Pica nuttalli) reduced time spent in feather maintenance to allow more time to find food. Feathers were maintained by a greater incidence of rain-bathing, a short bath making up for a greater amount of time needed to preen (Verbeek 1972). Rain-bathing by C. galerita was only recorded in winter and early 
spring, although considering only two incidences of this behaviour were seen, the opportunity for $C$. galerita to rain-bathe may reflect chance rather than any seasonal trend.

\subsubsection{Habitat use}

In this study I observed habitat use by $C$. galerita within a $72 \mathrm{~km}^{2}$ area constituting pastoral and agricultural land use, and exotic and native forest. As predicted in Hypothesis 3.3, cereal grain (particularly maize) and grassland contributed greatly to the $\operatorname{diet}$ of $C$. galerita, though to a much less extent than was observed in Australia by Noske (1980). Exotic and native tree species were an important source of food for C. galerita, dominating feeding observations in some months. As was found in the previous study of C. galerita in the Turakina Valley by Speirs (1989), this species made extensive use of native forest remnants.

Bennett (1978, in Noske 1980) considered C. galerita displayed an "edge effect", which for this species is where grassland (or farmland) is adjacent to the preferred, or natural, habitat of the species. The natural habitat provides many of the species resource requirements, such as shelter and breeding sites, and grassland (or agriculture) provides additional food supplies. Noske (1980) suggests that prior to clearing of forest and introduction of cereal crops in Australia, C. galerita were more arboreal. Although seed in native and exotic grasslands was abundant in spring and summer (Noske 1980), limited availability in autumn and winter means that other sources of food would have to be found, which, prior to the introduction of cereal crops, would have been provided by trees.

An edge effect, as described in Noske (1980), also best described the situation found in the Turakina Valley. Tall native forest provided most of the resource requirements of $C$. galerita there ( $48 \%$ of all daytime observations of $C$. galerita came from tall native forest, including most records of resting, self-maintenance and social behaviour), despite only constituting $11.2 \%$ of the land surface area, while feeding mostly occurred in the surrounding farmland. Native forest also acted as the focal point for the dispersal and aggregation of foraging flocks, most of the frequently used flight paths linking stands of tall native forest. Native forest remnants in the Turakina Valley appear to fulfil the same function for C. galerita as native forest habitat in Australia.

The more arboreal nature of $C$. galerita in the Turakina Valley may be attributed to the lesser extent of cropping in this area. Only two cereal species were grown in the Turakina Valley (maize and $H$. vulgare) and seed from these crops was only available in spring (newly sown 
seed) and in autumn-winter (ripe seed on plants and in stubbles). In comparison, the diet of C. galerita studied by Noske (1980) consisted mostly of seeds of cereals. In Noskes' study sites five cereal crop species were grown (H. vilgare, oats Avena sativa, Sorghum sp., sunflower Helianthus annuus and wheat Triticum aestivum), and crop seed was available throughout the year. Seeds of grasses and grassland weeds, such as thistles, were important in spring, when crop seed was least available, trees providing little food for these cockatoos.

Increased local planting of Pinus spp. in New Zealand (including the tributaries of the Turakina River) may provide an alternative highly abundant food source for C. galerita in the future, though this may take several years as cockatoos in the Turakina Valley and in Australia (Saunders 1974) showed a strong preference for older trees, which produce a greater abundance of cones. Ultimately, increased availability of Pinus spp. may not cause an increase in population size as its' seed cones are utilised at the same time as maize. Cacatua galerita may however feed on seed cones of Pinus spp. after maize has been harvested and so a greater number of birds could remain in the area during late winter and spring.

\subsubsection{Breeding activity}

There were up to 18 breeding pairs in the study site (approximately 1 nest for every $4 \mathrm{~km}^{2}$ ) and an unknown number just outside the area monitored. Prior to the build up in numbers in autumn there were approximately 109 birds (dusk counts: range 88-151) resident within the study site (1992/93 breeding season). This means just $33 \%$ of birds from the resident population were involved in breeding then. Although fewer birds were resident in October 1993 there were also fewer nesting attempts by the remaining birds. Noske (1980) estimated that $40 \%$ of the population were actively breeding, the remaining birds were considered to be juveniles and non-breeding adults.

As mentioned above, all nest activity occurred in native forest remnants, and all nests were located in large emergent podocarp trees within these remnants. Whether $C$. galerita require large podocarps for successful breeding is unknown, but their distribution might be limited by the availability of small native forest remnants and/or old established plantings of exotics. Reduction in bird distributions has often been related to a reduction in tree cover Noske 1980; Clark et al. 1986; Gibbons et al. 1994). Clearing land, particularly of large diameter old trees, reduces the availability of nest cavities required by large hole nesting species, such as cockatoos, and may also lead to increased competition for remining holes with other species, 
including possums (Trichosurus vulpecula) and starlings (Sturnus vulgaris) (Noske 1980; Green 1983).

\subsubsection{Conclusion}

Cacatua galerita formed a large winter aggregation in the Turakina Valley. This aggregation probably included most or all of the birds from within a range of several hundred square kilometres. Flock sizes seen throughout the year were significantly related to the number of birds residing within the study area. The benefit to individual birds in aggregating in the Turakina Valley was to reduce the time spent flying (the most energetically costly activity for birds) to obtain food because they roosted alongside their main food source (maize) at this time. The number of $C$. galerita occupying the winter roost increased rapidly in two brief periods (April and June), suggesting location and exploitation of the maize crop was not random. If location of the maize crop was based on experience, juvenile or first year birds would benefit from accompanying experienced individuals, providing a further benefit of flock forming behaviour.

Cacatua galerita in the Turakina Valley did not exploit more calorically rich foods in winter, instead eating a relatively calorically poor source of food (maize) compared to other times of year. Despite this they decreased time spent feeding. Maize seed is very abundant, so despite spending less time feeding, foraging efficiency was likely to have been much greater for birds feeding on this crop than other foods available. Other methods used by C. galerita in the Turakina Valley to meet increased costs of thermoregulation in winter were by decreasing the amount of time spent flying and by a reduction in the time spent on feather maintenance and social behaviour. Time saved in this way was spent resting.

Although C. galerita spent most of their active day foraging in highly modified habitats (farmland), they also utilised native forest remnants, spending close to $51 \%$ of their active day in this habitat. Cultivated farmland provided the main source of food, allowing maintenance of a large number of $C$. galerita, especially in winter. Native forest provided most of the nonfood resource requirements of these birds, including night roosts, daytime refuges and nest sites, but was also used for minor feeding throughout the year and more intensive feeding in autumn.

Up to $33 \%$ of the resident population were involved in breeding. Nests were all located in large podocarps, and availability of these trees (or equivalent large old exotic trees) might be a 
limiting factor in C. galerita distribution. Between 1 and 3 eggs were laid (average 1.63), but fledging success could not be determined because the chicks from these nests were taken by humans prior to fledging.

Decrease in proportion of time spent feeding in early spring (when nest attendance increased) was attributed to these birds incubating eggs. Increased time spent feeding, and decrease in feather maintenance and social activity, in late spring may be related to demands of feeding chicks. 


\section{Chapter 4}

\section{The impact of sulphur-crested cockatoos (Cacatua galerita) on native bird and forest communities in the Turakina Valley}

\subsection{INTRODUCTION}

Herbivores are important components of forest ecosystems and can shape plant species composition by influencing competitive interactions between plants, and by regulating ecosystem structure (Mattson and Addy 1975; McNaughton 1983; Marquis 1984; Risley and Crossley 1988; Lennartsson et al. 1998; Strauss and Agrawal 1998). The overall impact of herbivores is to accelerate the removal of nutrients from plants, in most cases acting to the detriment of individual plants by reducing plant growth, reproductive capacity and/or survival, but they may also confer a nutritional advantage on a plant community by mobilising nutrients trapped within senescent vegetation (Mattson and Addy 1975; Marquis 1984; Crawley 1985; Lamb 1985; Hendrix 1988; Meijden et al. 1988; Lennartsson 1998). Even minor levels of herbivory $(5-10 \%)$ have been shown to have an effect on the demography of trees (Marquis 1984; Cowan et al. 1985; Crawley 1985; Cowan and Waddington 1990, 1991). Herbivores may also promote successional development by accelerating the decline of some age classes or entire species (Mattson and Addy 1975; Schowalter 1981; Meijden et al. 1988). Additionally, through competition for resources (food, space, nesting sites), species acting on community structure, such as predators, dispersers, pollinators and browsers, may be displaced (Diamond and Veitch 1981; Green 1983; Leathwick et al. 1983; Moyle and Light 1996; Williams and Karl 1996; Greene 1998b; Holway 1998).

New Zealand's indigenous forests are the remnants of a vast forest covering much of both islands, the most extensive remaining tracts now being confined to mountainous areas and the west coast of the South Island (Kirkpatrick 1999). Most of the lower elevation forests have been cleared and replaced by exotic species and the remaining native vegetation is largely fragmented. At the same time extinction of native fauna and introduction of exotic species has led to an alteration in the selection pressures exerted on New Zealand plants (Atkinson and Greenwood 1989; Clout and Hay 1989; Holdaway 1989). There is increasing evidence that introduced browsers, seed eaters and predators, through impoverishment of 
native habitats or competition, displace native species, though most studies in this area refer to introduced mammalian herbivores (Diamond and Veitch 1981; Leathwick et al. 1983; Atkinson and Greenwood 1989; Clout and Hay 1989; Mark 1989).

Cacatua galerita were introduced to New Zealand in the early 1900's and have become regular visitors to native forest remnants in some areas (Oliver 1930; Martin 1962; Martin and Bartlett 1963; Speirs 1989; CSN 1976, 1977, 1984, 1987, 1988, 1990, 1992). Cacatua galerita are large predominantly granivorous birds that forage along the forest edge and in open grassland in preference to closed forest in Australia (Emison and Porter 1978; Noske 1980; Homberger 1992). Studies of habitat use and diet of C. galerita in Australia indicate that this species requires grassland to provide sufficient food sources to maintain presence, and that they probably can not find sufficient food to sustain themselves solely from native forest (Emison and Porter 1978; Noske 1980; Emison and Nicholls 1992; Higgins 1999).

Published records of C. galerita feeding in New Zealand are restricted to a few casual observations (mainly CSN) and a short study by Speirs (1989). In Sutherland's Bush Reserve, Turakina Valley, Manawatu-Wanganui. Speirs (1989) identified fallen green twigs of three podocarp species (kahikatea Dacrycarpus dacrydioides, rimu Dacrydium cupressinum and matai Prumnopitys taxifolia: family Podocarpaceae) between February and April 1989, which she attributed to the feeding activities of C. galerita. On average $6.5 \%$ of trees were damaged, with peak damage to D. cupressinum recorded in February, and to D. dacrydioides and P. taxifolia in March. Greatest damage was recorded for D. cupressinum (5.1 branches $/ \mathrm{m}^{2}$ ) (Speirs 1989). No damage was recorded for other plant species in the reserve, though $C$. galerita have been observed feeding in manuka (Leptospermum scoparium) (CSN 1976, 1977, 1987) and on the cones of kauri (Agathis australis) (CSN 1976; S. Chapman personal communication).

Speirs' (1989) observations of feeding heights used by bird species in Sutherland's Bush Reserve indicated that $C$. galerita foraged above 15 metres, overlapping the preferred foraging height of New Zealand pigeon (Hemiphaga novaeseelandiae) and G. tibicen. Such evidence of damage to native trees has led some to believe that C. galerita are having a significant deleterious effect on native forest remnants, and could potentially displace native birds and even bats within these fragments.

The few grassland species that existed prior to human colonisation, such as New Zealand quail (Coturnix novaeseelandiae) and moa, are extinct, and these differed greatly in size and probably foraging habit from $C$. galerita. The nearest ecological equivalents to $C$. galerita in the 
native land bird fauna of New Zealand are the parrots kaka (Nestor meridionalis), kea (N. notabilis), kakapo (Strigops babroptilus) and kakariki (Cyanoramphus spp.). These species are restricted to large forest tracts and offshore islands, and most only occur in large numbers where predators are absent or where intensive predator control is undertaken. The exception is $N$. notabilis, which is largely alpine in distribution.

Some of the ecologically important native forest birds still present in many of the fragmented forest remnants where C. galerita are present are Hemiphaga novaeseelandiae, tui Prosthemadera novaeseelandiae) and bellbirds (Anthornis melanura) (Heather and Robertson 1996). These species play a major role in the dispersal and pollination of many forest tree and shrub species, both because of their foraging activities and because they occur in reasonable numbers over a wide area (McEwen 1978; Clout and Hay 1989). The diet of these species (recorded in McEwen 1978; Clout and Hay 1989; O’Donell and Dilks 1994) are quite different from that recorded for C. galerita (Higgins 1999) and so direct competition for food items might not be common. However, introduced birds are often more aggressive than native species, and combined with a gregarious nature, they may exclude native species from food sources (Greene 1988b).

In this chapter I shall examine the impact of $C$. galerita on native forest ecosystems in New Zealand, as measured by their overlap in resource use with three native bird species (tui Prosthemadera novaeseelandiae, bellbird Anthornis melanura and New Zealand pigeon Hemiphaga novaeseelandiae), and the nature and extent of their impact on native tree and shrub species in forest remnants in the Turakina Valley. The impact of $C$. galerita is addressed by the following hypotheses.

\section{Hypothesis 4.1}

The food requirements of $C$. galerita are obtained from introduced plants located on farmland.

\section{- Prediction 1}

- Cacatua galerita diet will consist of seed from arable crops and pasture plants (grasses and introduced pasture weeds, such as thistles). 
- Prediction 2

- Because most of their food is obtained from modified (non-native) environments and mostly from the ground, C. galerita will not compete with native forest birds for food and/or foraging sites.

Hypothesis 4.2

Cacatua galerita do not significantly impact on native forest tree and shrub species.

- Prediction 1

- Impact on native tree species will be restricted to emergent podocarp trees greater than $15 \mathrm{~m}$ in height.

- Prediction 2

- The impact of C. galerita will not be sufficient to affect survival of individual trees or forest structure.

\subsection{METHODS}

Every four weeks, from July 1991 to October 1993, I made field trips of three to nine days, of which I spent two to three days measuring greenfall (Risley and Crossley 1988) in Sutherland's Bush Reserve. The other six days were spent observing C. galerita behaviour at six locations within a $72 \mathrm{~km}^{2}$ area surrounding Sutherland's Bush Reserve (see Figure 3.3). Feeding records were collected concurrently with these data.

\subsubsection{Study area}

The study site was the same as that described in Chapter 3, Figure 3.3 (this study). Sutherland's Bush Reserve ( 53.7 ha: $39^{\circ} 55^{\prime} \mathrm{S}, 175^{\circ} 20^{\prime} \mathrm{E}$ ) in the north of the study site is the largest remaining stand of native forest in the area. Logging has only lightly modified the forest within the reserve. Although possums (Trichosurus vulpecula) and ship rats (Rattus rattus) are common, larger browsers, such as domestic livestock, are mostly prevented from entering the reserve by a boundary fence and by the Turakina River. The adjacent forest has been clear-felled and made accessible to large mammalian herbivores leaving only a thin and 
discontinuous riparian strip, with small pockets of secondary growth, all of which are highly modified by introduced mammalian browsers.

\subsubsection{Niche measures}

Within the study area, whenever $A$. melanura, $H$. novaeseelandiae, $P$. novaeseelandiae and $C$. galerita were seen feeding, details of their feeding station was recorded. For the native birds, only details of the first observation of feeding for each individual was recorded. For C. galerita, details of feeding stations were collected while travelling through the study area and when measuring greenfall between July 1991 and October 1993, and were also collected during time-budget analysis (Chapter 3) from November 1992 to October 1993. Except for timebudget analysis data, only details of the first observation of feeding for each individual was recorded, similarly to collection of foraging observations for the native birds. Because $C$. galerita were being monitored so closely during time-budget analysis it was not possible to extract 'first feeding' observations of these birds so all feeding records of C. galerita obtained during time-budget analysis were used. Using this data could potentially bias observations of feeding by C. galerita towards species they utilised most extensively (long feeding bouts), and so species that are not utilised often, or only for short periods may be under-represented. Furthermore, no attempt was made to control for differences in the conspicuousness of birds in different vegetation types; therefore, feeding details are biased towards open habitats where birds were more obvious.

Table 4.1. Habitat variables used to describe the foraging dimensions of Cacatua galerita, Prosthemadera novaeseelandiae, Anthornis melanura and Hemiphaga novaeseelandiae in the Turakina Valley.

\begin{tabular}{ll} 
Variable & Interpretation \\
\hline Plant species & $\begin{array}{l}\text { Mostly species or species groups, but including some non-vegetated sites, } \\
\text { such as drains and bare ground. }\end{array}$ \\
Height & $\begin{array}{l}\text { Estimated height in the vegetation profile where birds were seen feeding. } \\
\text { The six categories were: } 0 \mathrm{~m} ; 0-5 \mathrm{~m} ; 5-10 \mathrm{~m} ; 10-15 \mathrm{~m} ; 15-20 \mathrm{~m} \text {; and }>20 \mathrm{~m} .\end{array}$ \\
Substrate & $\begin{array}{l}\text { Surface on which birds were feeding. The four categories were: ground } \\
\text { (ground level vegetation, bare surfaces and open water); trunk; large } \\
\text { branches; and foliage (leaves and small branches). }\end{array}$
\end{tabular}


A bird was considered to be feeding if it was pecking, drinking, or if it was walking or standing and looking at the surface for part of the time, even if no food was taken or no pecks made (following Feare et al. 1974). Drinking was included with feeding because it was not always possible to determine if birds were taking food or water when foraging. One bird feeding on one type of food constituted one feeding record (following Magrath and Lill 1983). It was often impossible to see exactly what birds were eating due to the distance from which they were observed. If it could be determined, actual food items were recorded, though for analysis only the species on which they were feeding, as well as the height and substrate were used, descriptions of which are given in Table 4.1.

Niche breadth (B) was calculated from Levins (1968):

$$
\mathrm{B}=\left(\sum \mathrm{P}_{\mathrm{i}}^{2}\right)^{-1}
$$

where $\mathrm{P}_{i}=$ proportion of $i^{\text {th }}$ prey in the diet.

Niche breadth was used to calculate a standardised niche breadth $\left(B_{s}\right)$ (Hespenheide 1975):

$$
\mathrm{B}_{\mathrm{s}}=(\mathrm{B}-1) /(\mathrm{n}-1)
$$

where $\mathrm{n}=$ number of prey types identified. $\mathrm{B}_{\mathrm{s}}$ increases as food habits become more generalised, and reaches unity when all foods are exploited equally.

Competition coefficients $\left(\alpha_{i j}\right)$ were calculated from Levins (1968):

$$
\alpha_{i j}=\left(\sum P_{i} \times P_{j}\right) /\left(\sum P_{i}^{2}\right)
$$

where $\alpha_{i j}$ is the effect of species $j$ on species $i$, and $P_{i}$ and $P_{j}$ are the proportions of each food type in the diet of species $i$ and $j$ respectively. This equation was used to estimate the degree of overlap for the three foraging dimensions (plant species, height and substrate) between $C$. galerita, $P$. novaeseelandiae, $A$. melanura and $H$. novaeselandiae. 


\subsubsection{Greenfall}

One hundred plots were placed (during June 1991) in Sutherland's Bush Reserve, comprising 17 rows at $37.5 \mathrm{~m}$ intervals (Figure 4.1 ). The first plot in each row was sited approximately 10 metres in from the forest margin on the southern boundary and each successive plot was spaced at $75 \mathrm{~m}$ intervals until reaching the northern boundary of the reserve. The centre of each plot was marked by an individually numbered white plastic tag, each plot measuring 2.5 $\mathrm{m}$ radius from the centre tag (total area of each plot $=19.6 \mathrm{~m}^{2}$ ).

Greenfall from each collection date represented a four week accumulation in the plots. On each date all green leaves, discernible fragments of green leaves and green branches of podocarps up to $600 \mathrm{~mm}$ length (greenfall) were counted and removed from plots. Greenfall was sorted into plant species, the presence of fruit or cones was noted. For analysis, a sample of each species contributing to greenfall was collected and oven-dried at $70^{\circ} \mathrm{C}$ to constant weight. From April 1992 to October 1993 the number of leaves and small branches of each species discernibly resulting from C. galerita foraging activity was recorded. "Cockatoocaused" greenfall was identified after inspecting leaves and branches dropped by C. galerita feeding in podocarps and epiphytes. Leaves and small branches placed in the cockatoocaused category were characterised by a clean biting off of the petiole, stem, or occasionally the leaf blade, while larger branches $(150-600 \mathrm{~mm})$ were bitten partly through then the remaining section of the stem was torn off. Other browsers in the reserve, notably $H$. novaeseelandiae and possums (T. vulpecula), are not known to bite off branches of podocarps. Hemiphaga novaeseelandiae pick off and swallow entire leaves and fruit, whereas T. vulpecula and insects chew off branches and leaves, often leaving distinctive bite marks (Payton et al. 1999).

The greenfall plots were used as the basis for a survey of plant species composition in the reserve. Abundance was recorded for all 'species' (species and species groups) out to a $5 \mathrm{~m}$ radius from the plot marker. Lianas, epiphytes and trees with stem diameter at breast height greater than $100 \mathrm{~mm}$ were recorded out to $10 \mathrm{~m}$ radius from the centre of the plot - this was intended to include all plants that may have contributed to the greenfall collected in the plot. Aspect, slope and height of the canopy (and emergents if present) at each plot were also recorded. Sample site data were entered into the software program DECODA (Database for Ecological Community Data) (Minchin 1990). Analysis of presence/absence data from the DECODA file was undertaken using the software program TWINSPAN (Hill 1979). 


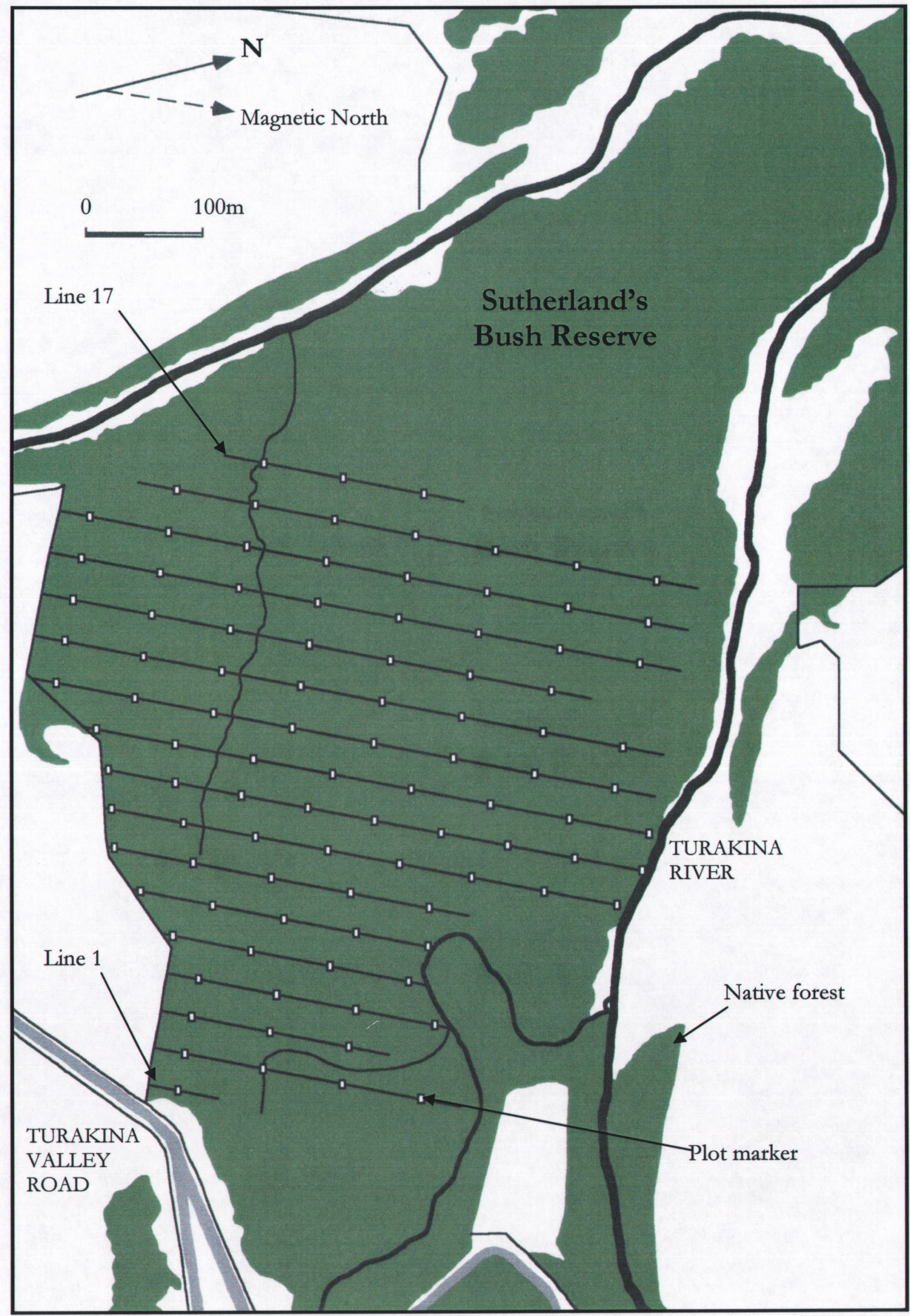

Figure 4.1. Approximate layout of vegetation survey lines and plot markers in Sutherland's Bush Reserve, Turakina Valley. 
Roost flock size, number of bird hours and number of feeding observations of C. galerita in Sutherland's Bush Reserve were obtained during collection of behavioural observations of these birds in the Sutherland's observation area (see methods: Chapter 3). These records were used to represent the monthly activity of C. galerita in the reserve.

\subsection{RESULTS}

\subsubsection{Habitat segregation of bird species in the Turakina Valley}

\subsubsection{Use of plant species}

Modified open ground habitats (grassland, arable) dominated the land surface area $(81.5 \%$ surface cover) of the Turakina Valley study site (Table 3.10, Chapter 3). The remainder of the surface area is occupied by native forest $(14.9 \%$ ), exotic conifers (mostly Cupressus macrocarpa and Pinus spp.) (2.3\%) and exotic angiosperm tree species (mostly Populus spp. and Salix spp.) (1.3\%). There were substantial differences in the use of these vegetation types by C. galerita, $P$. novaeselandiae, $A$. melanura and $H$. novaeselandiae. The native birds were mostly ( $89 \%$ of combined observations) seen foraging in native vegetation, the remainder of observations coming from exotic angiosperm trees and vines (Table 4.2). Cacatua galerita were mostly (66.6\% of observations) seen foraging in open ground habitats, only $15.5 \%$ of foraging observations coming from native vegetation, and $3.9 \%$ from exotic angiosperms (Table 4.2).

The five most common foraging species (substrates, species or species groups) of $P$. novaeseelandiae, A. melanura, $H$. novaeseelandiae and C. galerita contributed 74.7, 68.4, 67.9 and $63.9 \%$ of feeding observations respectively (Table 4.2 ). Seasonally, birds varied significantly in the plant species they were seen foraging in $\left(\chi^{2}\right.$, d.f. $=12-29$, P's $\left.<0.001\right)$. Differences arose from variations in frequency of use of a particular species in one season relative to other times of the year.

Prosthemadera novaeseelandiae were seen feeding on the widest range of native plant species (21) and had the greatest frequency of feeding records from native vegetation (97.7\%) (Table 4.2). Dacrycarpus dacrydioides appeared to be the most important species, providing a large number of foraging opportunities throughout the year. These birds were also frequently seen foraging in P. taxifolia, D. cupressinum and totara (Podocarpus totara), which together contributed 
$31.8 \%$ of feeding observations in summer and $29 \%$ in autumn. In winter $P$. novaeselandiae were more often $(37.1 \%)$ seen foraging in kanuka (Kunzea ericoides) than any other plant species, while kowhai (Sophora tetraptera) and flax (Phormium tenax) dominated feeding observations in spring (66.1\%) and summer (27.3\%). Prosthemadera novaeseelandiae were seen foraging more often in exotic species in winter $(8.6 \%)$ than during any other season (range for spring-autumn $=0-3 \%$ ), P. nigra accounting for most of these records (Table 4.2).

Kunzea ericoides was the most frequently recorded foraging site for $A$. melanura, contributing most foraging observations in summer $(54.2 \%)$ and winter (44\%), but was also important in autumn and spring (Table 4.2). Dacrycarpus dacrydioides, P. totara and S. tetraptera appeared to be of secondary importance, the podocarp species providing an important source of food in autumn (46.9\%), while $S$. tetraptera dominated feeding observations in spring $(32.3 \%)$. Of the native bird species, $A$. melanura were observed more often ( $24 \%$ of observations) foraging in exotic trees (Table 4.2).

Hemiphaga novaeselandiae were seen feeding more often in tawa (Beilschmiedia tawa) than any other species, especially in summer when $71.4 \%$ of birds seen were feeding in these plants (Table 4.2). As with the other native bird species, podocarps, particularly $D$. dacrydioides, dominated feeding records in autumn $(36.8 \%)$. In winter $H$. novaeseelandiae were seen feeding on a considerably wider range of plants (13) than used in other seasons (range 8-9 species) and did not appear to concentrate their foraging efforts on one or two favoured species as seen at other times of the year. Greatest use of exotic species by $H$. novaeseelandiae occurred in winter $(21.9 \%)$ and spring (62.1\%). Overall, most observations were of birds feeding in Salix spp., though tree lucerne (Calicotome palmensis) dominated feeding observations in winter. 


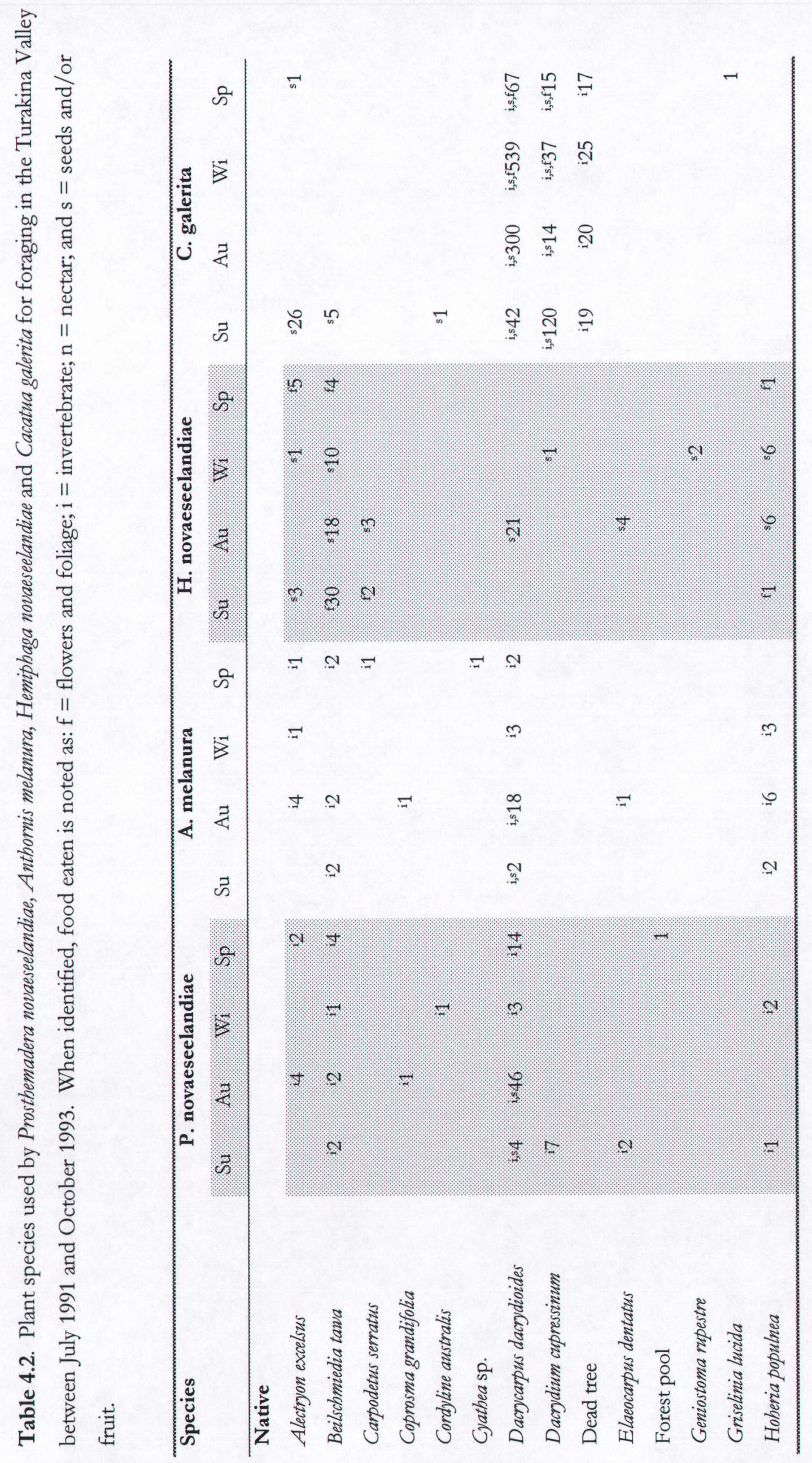




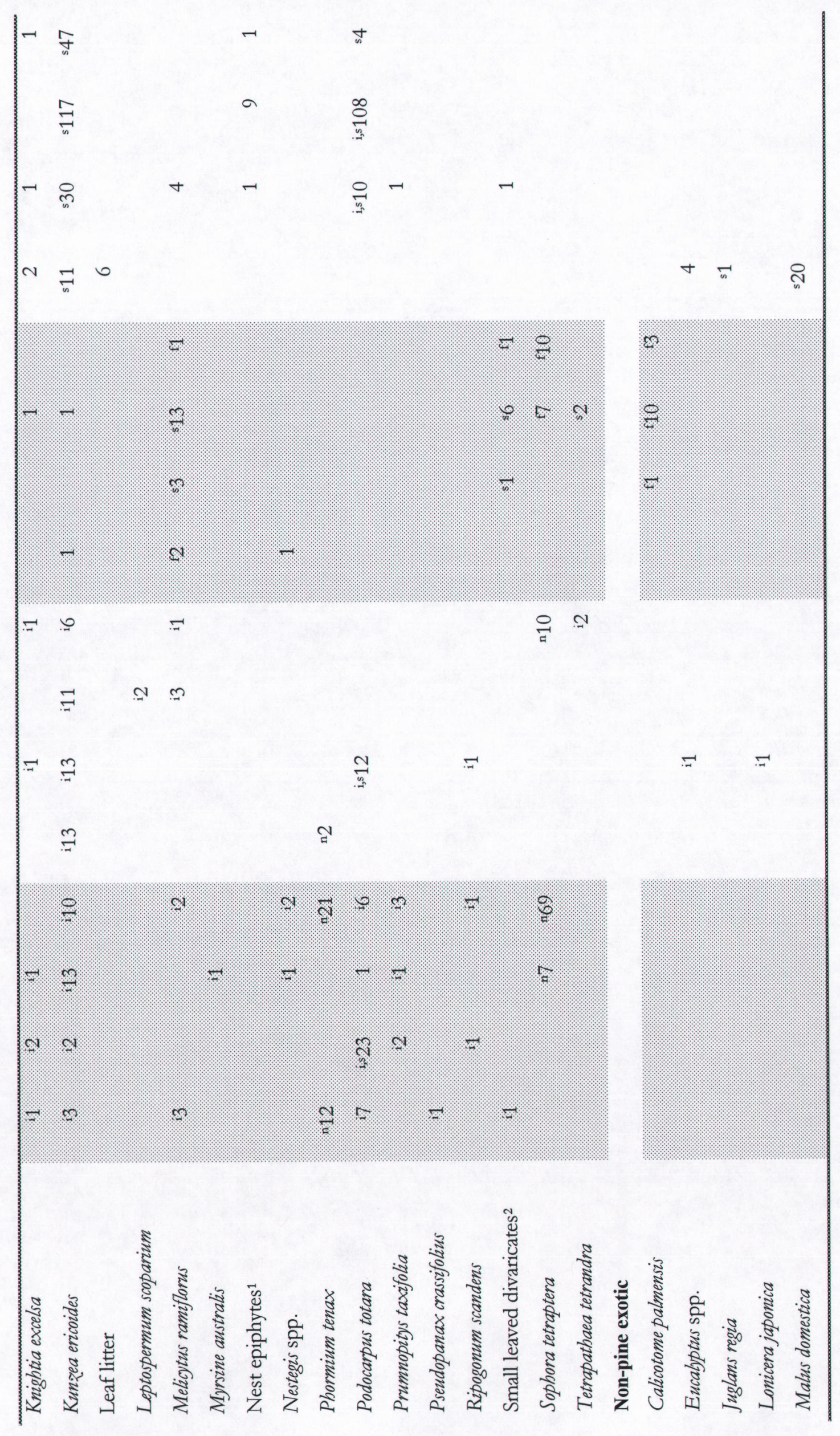




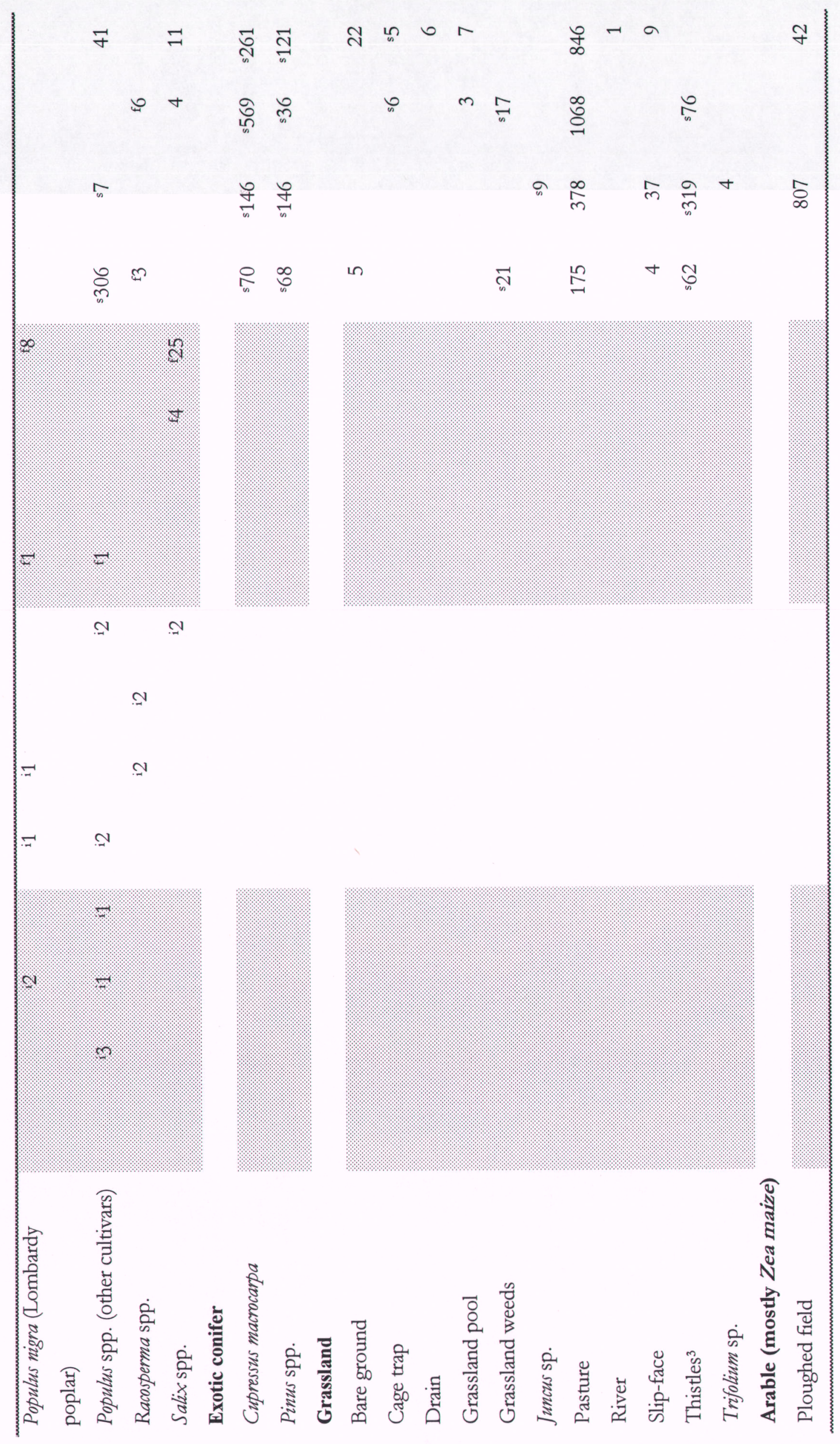




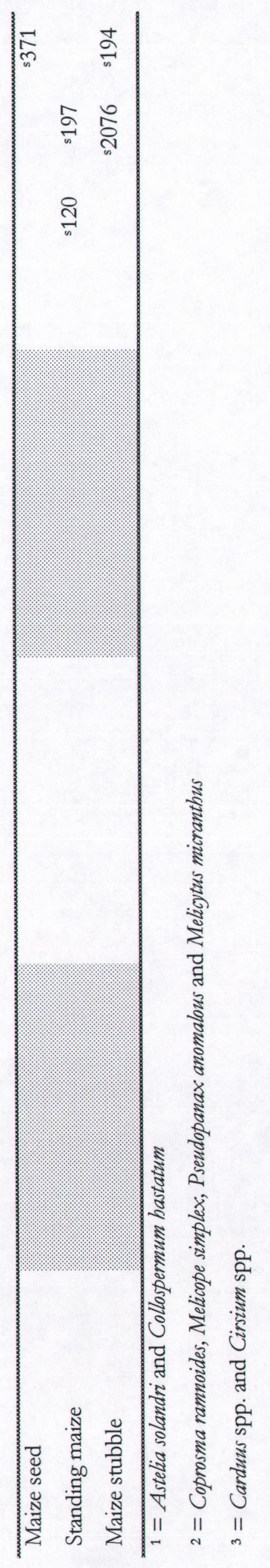

흔 
Cacatua galerita were recorded foraging on the widest variety of plant species (38), including 23 exotic and 15 native (Table 4.2). Pasture was an important food source for C. galerita throughout the year, especially in spring (40.5\%), though maize (Zea maize) was the single most important food species of these birds (contributing $28.6 \%$ of total feeding observations). Trees provided the most important source of food for C. galerita in summer ( $72 \%$ of feeding observations), with $U$. hollandica dominating feeding observations at this time $(31.5 \%)$, though emergent podocarps were also important $(16.7 \%)$. Between autumn and spring C. galerita were seen foraging more in open ground habitats $(69.9-71.9 \%$ of observations). Most feeding occurred in ploughed fields in autumn, maize in winter and pasture in spring (Table 4.2). Exotic conifers were also important sources of food for $C$. galerita. Two species, C. macrocarpa and $P$. radiata, contributed $14.4 \%$ of total foraging records, similar to the frequency of feeding observations from the more species rich native forests. Cacatua galerita were the only species that were seen foraging on exotic conifers and were mostly feeding on seed cones of older trees. These birds also showed a strong preference for only a few of the native plant species available. The most important were emergent podocarps, which contributed $75.3 \%$ of foraging observations from native forest, including Dacrycarpus dacrydioides, which comprised $48.5 \%$ of all feeding records from native vegetation (7.8\% of total foraging observations) (Table 4.2 ).

There were significant interspecific differences in the plants used by the different bird species $\left(\chi^{2}\right.$, d.f. $\left.=45-49, \mathrm{P}^{\prime} \mathrm{s}<0.0001\right)$. Cacatua galerita foraged in $11-12$ species used by the native birds, though five of the seven species contributing greater than $5 \%$ of feeding records for $C$. galerita were from habitats that were not shared with these native birds (exotic conifer, grassland and arable) (Table 4.2). Although there was considerable overlap in the species preferred by $P$. novaeseelandiae, $A$. melanura and $H$. novaeseelandiae (14 species shared between each species pair) the order of preference varied (Table 4.2). With the exception of $P$. novaeseelandiae and $A$. melanura in winter $\left(\chi^{2}\right.$, d.f. $\left.=16, \mathrm{P}>0.05\right)$, there were also significant seasonal differences in species preferences between native birds $\left(\chi^{2}\right.$, d.f. $=13-30, \mathrm{P}^{\prime} \mathrm{s}<$ 0.005). Cacatua galerita differed most $\left(\chi^{2}\right.$, d.f. $\left.=20-30, P^{\prime} s<0.0001\right)$, but the difference was least in summer when C. galerita were seen foraging more frequently ( $72.5 \%$ of observations) in trees than in open ground habitats.

\subsubsection{Foraging beights}

All four bird species foraged throughout the vegetation profile except the ground, which the native birds (apart from a single $P$. novaeseelandiae) were not seen to use. These birds showed 
preferences for particular vegetation strata, and there was also significant seasonal variation $\left(\chi^{2}\right.$, d.f. $\left.=4.5, \mathrm{P}^{\prime} \mathrm{s}<0.001\right)$ in height range where birds were seen foraging (Figure 4.2). Prosthemadera novaeseelandiae, $A$. melanura and $H$. novaeseelandiae were mostly $(77-81 \%$ of observations) seen foraging between 0 and 15 metres, though they were seen frequently in the emergent and canopy layers (above $20 \mathrm{~m}$ ) in autumn (Figure 4.2). Cacatua galerita foraged mostly at $0 \mathrm{~m}(66.9 \%$ of observations) and above $10 \mathrm{~m}(31 \%)$. A greater proportion of $C$. galerita were seen feeding higher in the vegetation profile $(>15 \mathrm{~m})$ in summer $(56.2 \%)$ than during the remainder of the year (15.3-19.3\%) (Figure 4.2).

Prosthemadera novaeseelandiae and $A$. melanura showed considerable overlap in their preferred foraging heights $\left(\chi^{2}\right.$, d.f. $\left.=5, P>0.05\right)$, both species differing slightly from $H$. novaeseelandiae $\left(\chi^{2}\right.$, d.f. $=4-5$, P's $\left.<0.05\right)$. All of the native birds showed highly significant differences in preferred heights from $C$. galerita $\left(\chi^{2}\right.$, d.f. $=5$, P's $\left.<0.0001\right)$. Seasonally, despite greater frequency of feeding in trees by $C$. galerita during summer, differences in height used compared with the native birds were again highly significant $\left(\chi^{2}\right.$, d.f. $=5$, P's $\left.<0.0001\right)$.

\subsubsection{Substrate}

Foliage was the most important foraging substrate for P. novaeseelandiae (90.4\%), A. melanura $(91 \%)$ and $H$. novaeseelandiae $(97.3 \%)$, the remainder of observations coming from bark on large branches (Figure 4.3). There was little variation between seasons in the substrates that the native birds were seen foraging on $\left(\chi^{2}\right.$, d.f. $\left.=1-2, \mathrm{P}^{\prime} \mathrm{s}>0.1\right)$. Ground was the most frequently recorded foraging substrate for C. galerita ( $66.7 \%$ of observations), followed by foliage $(31.4 \%$ ) (Figure 4.3$)$. Dead trees and the bark on the trunk and large branches of live trees accounted for the remaining foraging records for $C$. galerita. As with foraging height, $C$. galerita showed highly significant changes in foraging substrates between seasons $\left(\chi^{2}\right.$, d.f. $=2$ 3 , P's $<0.0001)$ associated with their seasonal changes in forage species. 

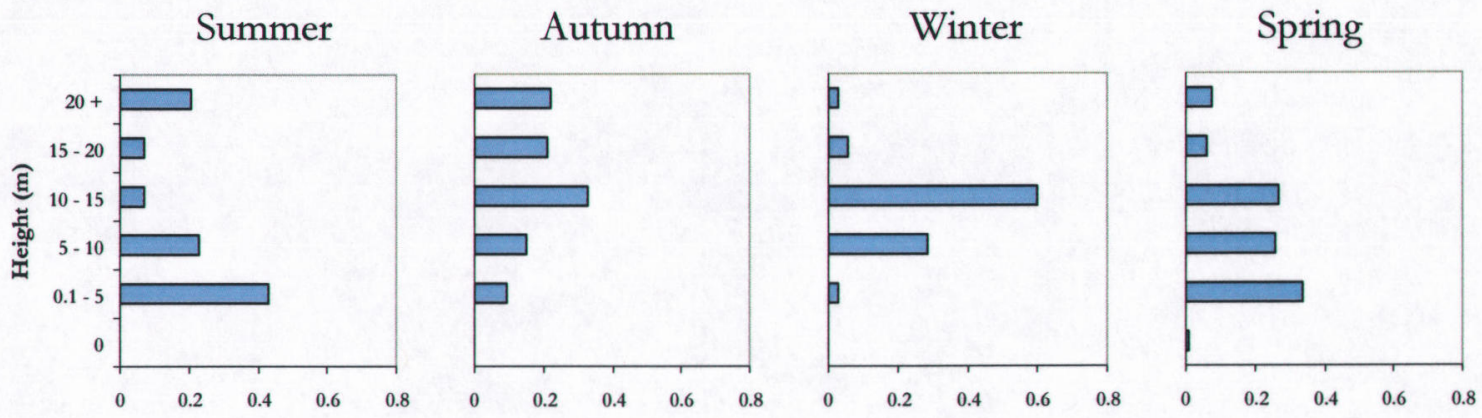

Tui (Prosthemadera novaeseelandiae) $(\mathrm{n}=301)$
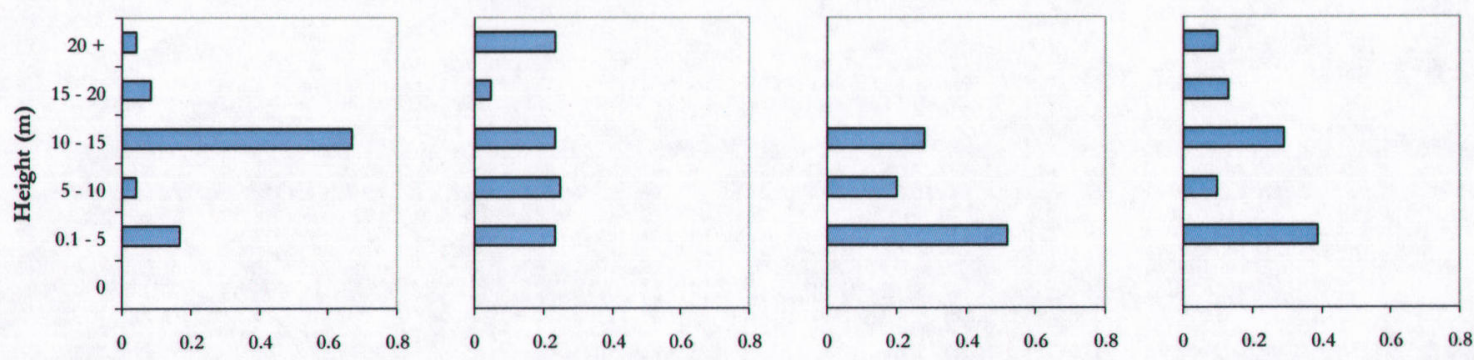

Bellbird (Anthornis melanura) $(\mathrm{n}=144)$
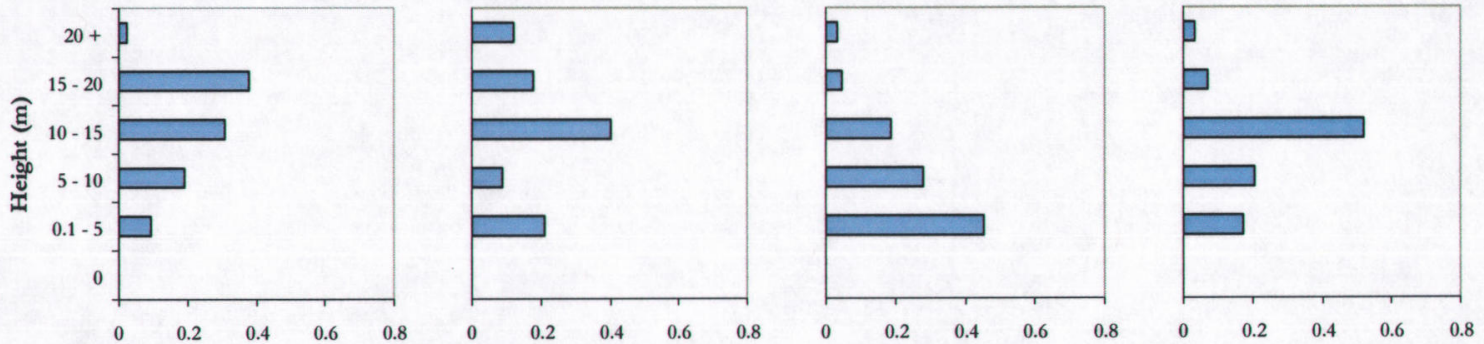

New Zealand pigeon (Hemiphaga novaeseelandiae) $(\mathrm{n}=221)$
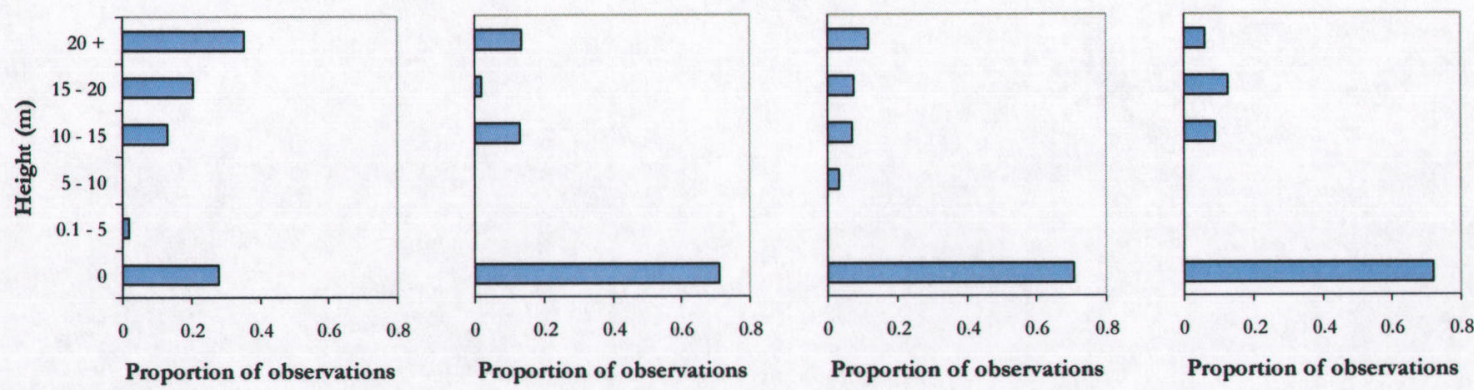

Sulphur-crested cockatoo (Cacatua galerita) $(\mathrm{n}=10328)$

Figure 4.2. Foraging height distribution of four bird species in the Turakina Valley between July 1991 and October 1993. 

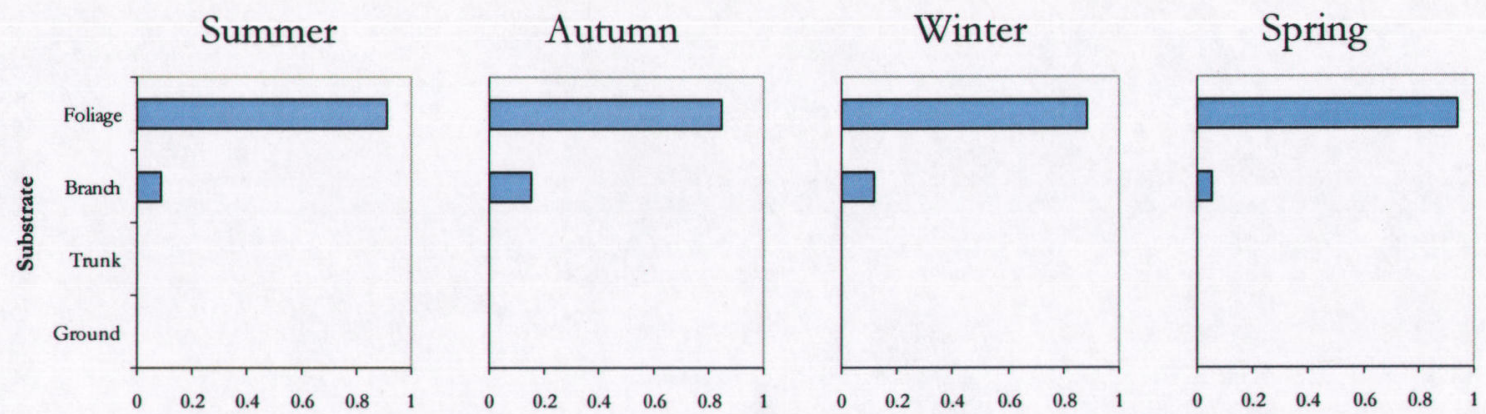

Tui (Prosthemadera novaeseelandiae) $(\mathrm{n}=301)$
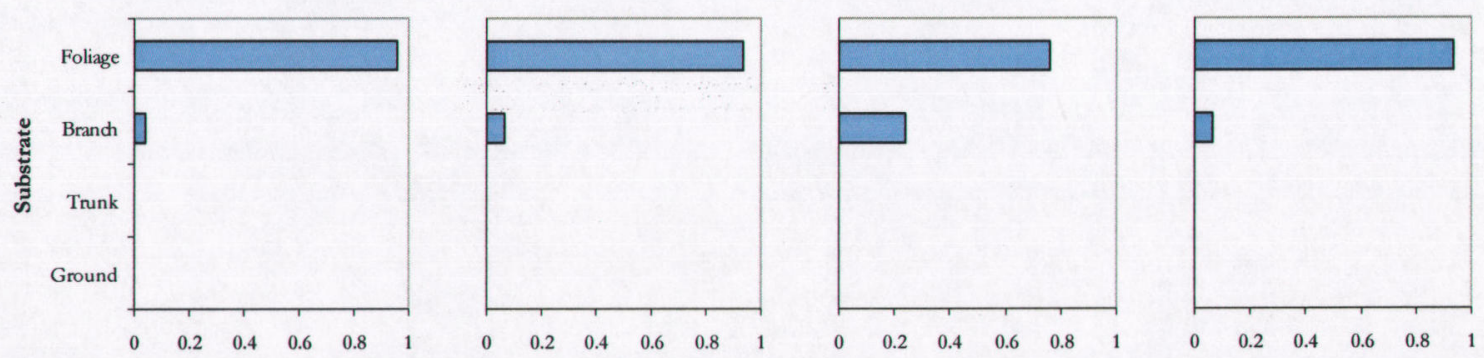

Bellbird (Anthornis melanura) $(\mathrm{n}=144)$
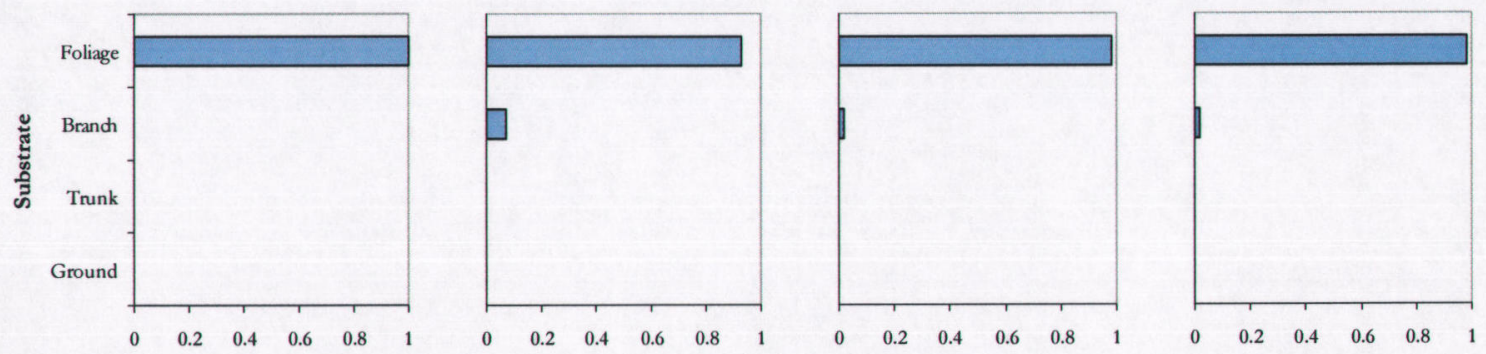

New Zealand pigeon (Hemiphaga novaeseelandiae) $(\mathrm{n}=221)$
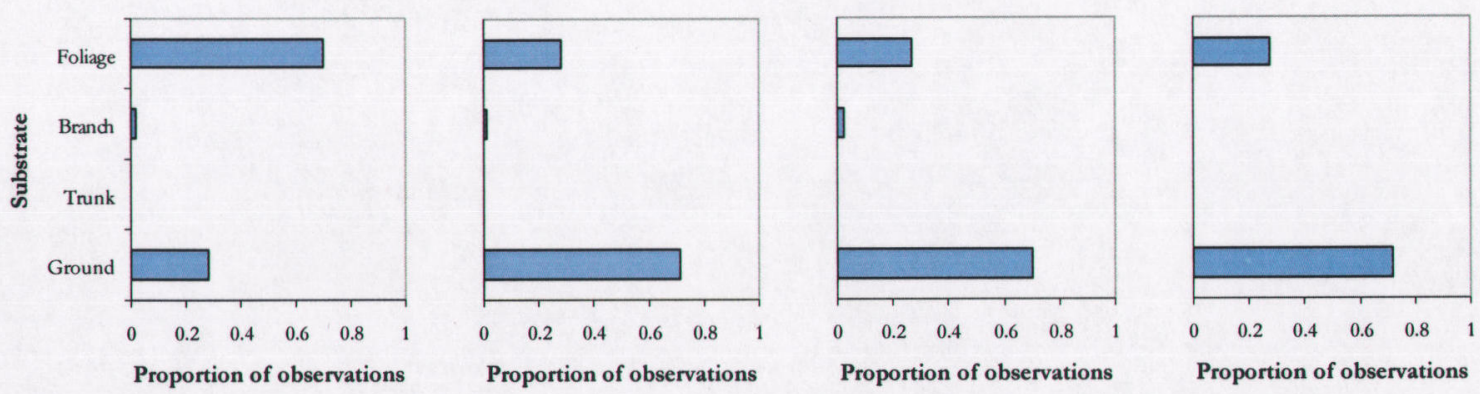

Sulphur-crested cockatoo (Cacatua galerita) $(\mathrm{n}=10328)$

Figure 4.3. Foraging substrates used by four species of bird in the Turakina Valley between July 1991 and October 1993. 
With the exception of $A$. melanura and $H$. novaeseelandiae in winter $\left(\chi^{2}=9.585\right.$, d.f. $=1, \mathrm{P}=$ $0.002)$ and $P$. novaeseelandiae and $H$. novaeseelandiae in spring $\left(\chi^{2}=10.839\right.$, d.f. $\left.=2, P=0.004\right)$, differences between native species in use of foraging substrates were not significant $\left(\chi^{2}\right.$, d.f. $=$ $1-2$, P's $\geq 0.1)$. In contrast, $C$. galerita varied significantly from the native bird species in the use of foraging substrates in all seasons, though least variation occurred in summer $\left(\chi^{2}\right.$, d.f. $=$ 2 , P's $\leq 0.008$ ) when $C$. galerita were foraging more in foliage. Greater variation occurred in autumn, winter and spring $\left(\chi^{2}\right.$, d.f. $=2-3$, P's $\left.<0.0001\right)$ when $C$. galerita foraged mostly on the ground.

Table 4.3. Calculations of niche breadth (B) (Levins 1968) and standardised niche breadth $\left(B_{s}\right)(H e s p e n h e i d e ~ 1975)$ for four bird species resident in the Turakina Valley between July 1991 and October 1993.

\begin{tabular}{lccccc}
\hline $\begin{array}{l}\text { Foraging } \\
\text { resource }\end{array}$ & & P. novaeselandiae & A. melanura & H. novaeselandiae & C. galerita \\
\hline Plant species & $\mathrm{B}$ & 6.56 & 6.94 & 7.57 & 7.22 \\
& $\mathrm{~B}_{\mathrm{s}}$ & 0.25 & 0.27 & 0.37 & 0.17 \\
Foraging height & $\mathrm{B}$ & 4.46 & 3.98 & 4.01 & 2.08 \\
& $\mathrm{~B}_{\mathrm{s}}$ & 0.69 & 0.60 & 0.60 & 0.22 \\
Substrate & $\mathrm{B}$ & 2.14 & 1.68 & 1.91 & 1.99 \\
& $\mathrm{~B}_{\mathrm{s}}$ & 0.28 & 0.17 & 0.23 & 0.25 \\
All data combined & $\mathrm{B}$ & 24.24 & 19.90 & 26.97 & 8.12 \\
& $\mathrm{~B}_{\mathrm{s}}$ & 0.34 & 0.36 & 0.42 & 0.08 \\
\hline
\end{tabular}

\subsubsection{Niche breadth and overlap}

Although foraging over the most diverse range of plant species, height and substrate, $C$. galerita preferentially used a restricted variety of foraging sites and had the narrowest niche breadth (Table 4.3). The native bird species had considerably broader niche breadths than $C$. galerita. Hemiphaga novaeseelandiae, which foraged over the narrowest range of plant species, height and substrate utilised their resources most equally and had the broadest niche breadth (Table 4.3). 
Competition coefficients were determined for each species pair (Table 4.4). The greatest overlap in resource use was between $P$. novaeseelandiae and $A$. melanura $\left(\alpha_{\mathrm{tb}}=0.54, \alpha_{\mathrm{bt}}=0.44\right)$ and least overlap between $H$. novaeseelandiae and $C$. galerita $\left(\alpha_{\mathrm{pc}}=0.05, \boldsymbol{\alpha}_{\mathrm{cp}}=0.02\right)$. Overall, $C$. galerita overlapped less with native bird species (range $=0.02-0.18$ ) than the native species overlapped with each other (range 0.21-0.54) (Table 4.4).

Table 4.4. Competition coefficients $\left(\alpha_{i j}\right)$ (Levins 1968) for four bird species resident in the Turakina Valley between July 1991 and October 1993.

\begin{tabular}{lccccc}
\hline \begin{tabular}{l} 
Species being affected \\
\multicolumn{1}{c}{ (i) }
\end{tabular} & P. novaeselandiae & A. melanura & H. novaeselandiae & C.galerita \\
\hline $\begin{array}{l}\text { P. novaeselandiae } \\
\text { A. melanura }\end{array}$ & - & 0.54 & 0.23 & 0.12 \\
H. novaeselandiae & 0.44 & - & 0.21 & 0.18 \\
C. galerita & 0.25 & 0.28 & - & 0.05 \\
\hline
\end{tabular}

Overlap in the use of foraging dimensions was greatest in autumn and lowest in winter (Table 4.5). Seasonally, the pattern of resource overlap between all species was autumn $>$ spring $\geq$ summer $>$ winter, while the pattern of overlap in resource use between $C$. galerita and the native birds was autumn $>$ summer $>$ winter $=$ spring. Cacatua galerita had a greater competitive affect on all of the native species than they on C. galerita. Seasonally, C. galerita had a greater (or equal) affect on the native species in autumn, winter and spring, but the native species had a greater competitive affect on $C$. galerita in summer.

\subsubsection{Impact on native plant species}

\subsubsection{Vegetation}

The detailed results of the vegetation survey of Sutherland's Bush Reserve are listed in Appendix 3. Dacrycarpus dacrydioides was the dominant emergent species $(63.6 \%$ of trees with diameter at breast height $(\mathrm{dbh})>500 \mathrm{~mm}$ ) occurring in $83 \%$ of plots, though $P$. taxifolia and $D$. cupressinum occur throughout and $P$. totara are common in well drained areas. Beilschmiedia tawa, titoki (Alectryon excelsus) and $K$. ericoides dominate the dense canopy (together comprising $79.5 \%$ of canopy trees with $\mathrm{dbh}>100 \mathrm{~mm}$ ), while the understorey is comprised of a wide 
range of dicotyledon shrubs, cabbage trees (Cordyline australis), tree ferns (Cyathea dealbata and C. smithii) and Nikau (Rhopalostylas sapida). Lianas and epiphytes are common throughout, with supplejack (Ripogonum scandens) occurring in $90 \%$ of plots and nest epiphytes (Astelia solandri and Collospermum hastatum) in $73 \%$.

Table 4.5. Competition coefficients $\left(\alpha_{i j}\right)$ (Levins 1968) determined for seasonal overlap in resource use by four bird species resident in the Turakina Valley between July 1991 and October 1993. Prosthemadera novaeseelandiae (tui) $=\mathrm{t} ;$ Anthornis melanura $($ bellbird $)=\mathrm{b}$; Hemiphaga novaeseelandiae $($ New Zealand pigeon $)=\mathrm{p}$; and Cacatua galerita $=\mathrm{c}$. For example, $\alpha_{\mathrm{tb}}$ is the affect of bellbirds on tui.

\begin{tabular}{lllll}
\hline & Summer & Autumn & Winter & Spring \\
\hline $\boldsymbol{\alpha}_{\mathrm{tb}}$ & 0.40 & 0.72 & 0.31 & 0.41 \\
$\boldsymbol{\alpha}_{\mathrm{bt}}$ & 0.15 & 0.54 & 0.44 & 0.54 \\
$\boldsymbol{\alpha}_{\mathrm{tp}}$ & 0.08 & 0.43 & 0.12 & 0.18 \\
$\boldsymbol{\alpha}_{\mathrm{pt}}$ & 0.06 & 0.43 & 0.21 & 0.13 \\
$\boldsymbol{\alpha}_{\mathrm{tc}}$ & 0.10 & 0.22 & 0.04 & 0.02 \\
$\boldsymbol{\alpha}_{\mathrm{ct}}$ & 0.12 & 0.07 & 0.02 & 0.01 \\
$\boldsymbol{\alpha}_{\mathrm{bp}}$ & 0.07 & 0.35 & 0.06 & 0.29 \\
$\boldsymbol{\alpha}_{\mathrm{pb}}$ & 0.15 & 0.46 & 0.07 & 0.16 \\
$\boldsymbol{\alpha}_{\mathrm{bc}}$ & 0.05 & 0.23 & 0.02 & 0.04 \\
$\boldsymbol{\alpha}_{\mathrm{cb}}$ & 0.17 & 0.11 & 0.01 & 0.01 \\
$\boldsymbol{\alpha}_{\mathrm{pc}}$ & 0.03 & 0.16 & 0.01 & 0.01 \\
$\boldsymbol{\alpha}_{\mathrm{cp}}$ & 0.05 & 0.06 & 0.00 & 0.01 \\
\hline
\end{tabular}

Separation of plots by vegetation composition using TWINSPAN produced low eigen-values ( 0.131 for the first division), reflecting the considerable homogeneity of the understorey flora. Despite this, there were two broad types of vegetation in the reserve. The first was a mixture of large podocarps ( $\mathrm{dbh}>500 \mathrm{~mm}$ ), varying in height from 25-35 metres, emergent over a canopy of B. tawa and $A$. excelsus $(12-24 \mathrm{~m})$. The second type of vegetation had a canopy dominated by $K$. ericoides, and mostly lacked large podocarps. Examination of the two groups of vegetation plots produced by TWINSPAN revealed the vegetation had been divided closely along the lines of these two types of vegetation and so, despite the low eigen-value, 
the results of the TWINSPAN analysis have been used here. The areas of large podocarp/B. tawa/ $A$. excelsus forest is referred to as type 1 vegetation and the $K$. ericoides forest is referred to as type 2 vegetation (Figure 4.4).

\subsubsection{Intensity of greenfall}

Forty one 'species' (species or species groups) of trees, shrubs lianas and epiphytes were represented in the greenfall (Table 4.6). Six species (D. dacrydioides, D. cupressinum, B. tawa, Melicytus ramiflorus, Tetrapathaea tetrandra and 'nest epiphytes') together contributed $75.5 \%$ of greenfall (grams dry weight), of which D. cupressinum $(28.7 \%)$ was the greatest contributor (Table 4.7). The annual dry weight of greenfall for a particular species was not significantly correlated with the number of those plants recorded (or present in a particular size category) in the vegetation survey.

Greenfall averaged $0.21 \mathrm{~kg} /$ plot (s.d. $=0.29 \mathrm{~kg}$, range $=0.01-2.58 \mathrm{~kg}$ ) and was significantly greater $(\mathrm{t}=2.179$, d.f. $=98, \mathrm{P}<0.05)$ at plots with type 1 vegetation than type 2 vegetation (Figure 4.5). Marked peaks of greenfall in 1991 and 1993 (Figure 4.6) resulted from a large fall of $M$. ramiflorus leaves (August-December 1991) and branch stripping of emergent $D$. cupressinum by C. galerita (February-March 1993). No relation was found to occur between greenfall and rainfall (Ferriby Station data) $(r=0.042$, d.f. $=28, P=0.8287)$. 


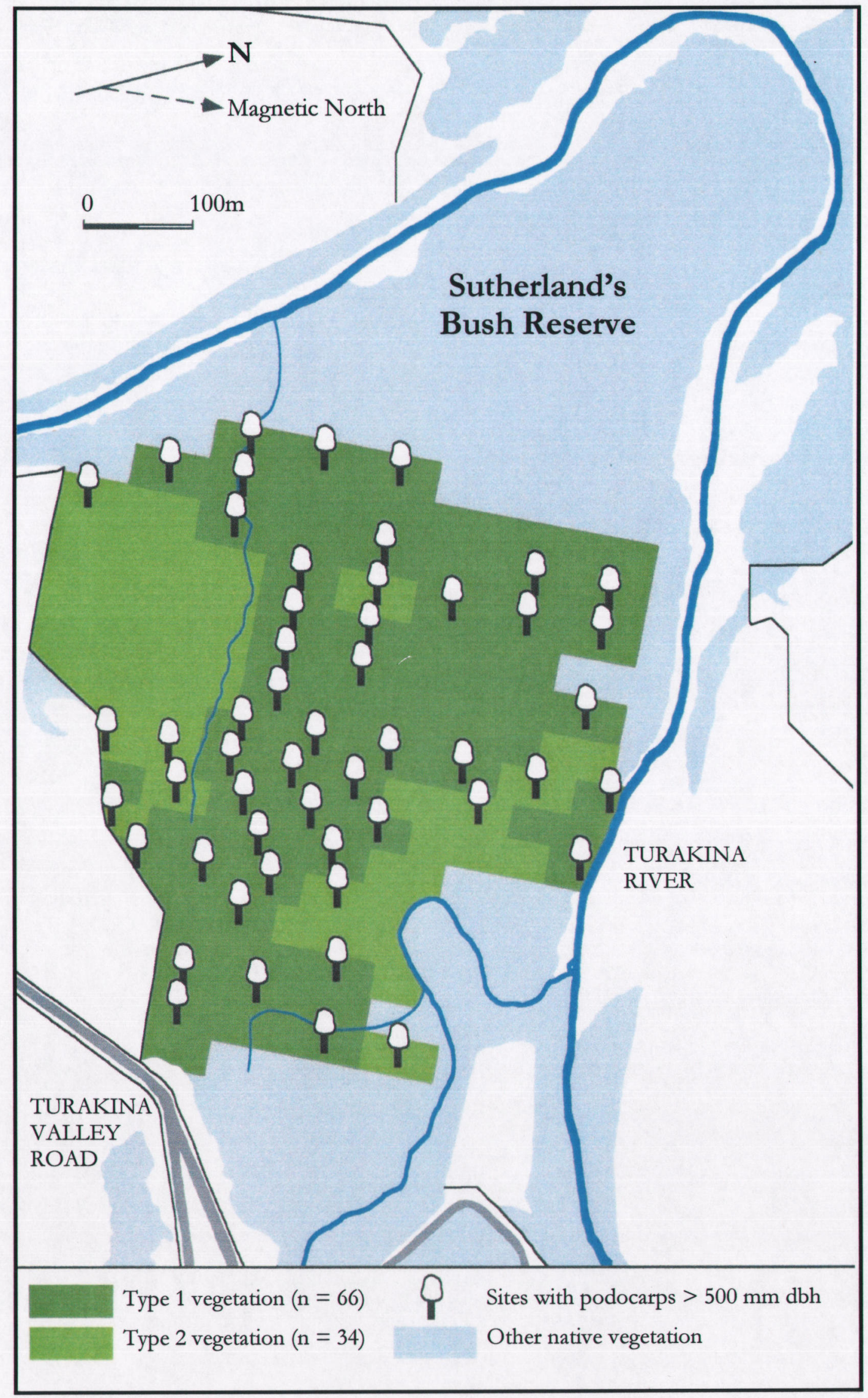

Figure 4.4. Distribution of large podocarp trees $(>500 \mathrm{~mm} \mathrm{dhb})$ and different vegetation categories, determined using TWINSPAN (Hill 1979), along transects within Sutherland's Bush Reserve, Turakina Valley. 
Monthly totals of greenfall were combined according to season, and means of monthly greenfall for each season were compared. There was no detectable variation ( $t$ tests, d.f. $=$ 11-13, P's $>0.1$ ) in the quantity of greenfallen litter between seasons (Figure 4.6). Furthermore, seasonal comparison of greenfall of the six species that contributed $5 \%$ or more to total greenfall showed that, except for an increase in the amount of $D$. dacrydioides in greenfall between summer and autumn $(t=-3.083$, d.f. $=11, P=0.01)$, there were no differences in dry weight biomass of greenfall between seasons ( $t$ tests, d.f. $=11-13$, P's > $0.05)$.

Table 4.6. Average leaf weights of species contributing to greenfall in Sutherland's Bush Reserve, Turakina Valley.

\begin{tabular}{|c|c|c|c|c|}
\hline Species & $\begin{array}{l}\text { Size class } \\
(\mathrm{mm})\end{array}$ & $\begin{array}{c}\text { Number of } \\
\text { leaves/branches } \\
\text { sampled }\end{array}$ & $\begin{array}{l}\text { Mean leaf } \\
\text { weight (g) }\end{array}$ & $\begin{array}{l}\text { Standard } \\
\text { deviation }\end{array}$ \\
\hline \multicolumn{5}{|l|}{ Podocarpaceae } \\
\hline \multirow[t]{7}{*}{ Dacrycarpus dacrydioides } & $0-50$ & 40 & 0.0536 & 0.0532 \\
\hline & $51-100$ & 48 & 0.4386 & 0.2336 \\
\hline & $101-150$ & 45 & 1.0753 & 0.5593 \\
\hline & $151-200$ & 13 & 2.0103 & 0.7890 \\
\hline & $201-300$ & 9 & 3.6045 & 2.3477 \\
\hline & $301-400$ & 6 & 9.5774 & 4.6926 \\
\hline & $401-600$ & 3 & 13.3160 & 7.1476 \\
\hline \multirow[t]{7}{*}{ Dacrydium cupressinum } & $0-50$ & 48 & 0.1325 & 0.0829 \\
\hline & $51-100$ & 38 & 0.3107 & 0.2816 \\
\hline & $101-150$ & 44 & 0.7902 & 0.5803 \\
\hline & $151-200$ & 37 & 2.0537 & 1.4860 \\
\hline & $201-300$ & 17 & 5.5089 & 6.4054 \\
\hline & $301-400$ & 12 & 11.1115 & 6.5592 \\
\hline & $401-600$ & 6 & 14.6303 & 9.5596 \\
\hline \multirow[t]{6}{*}{ Podocarpus totara } & $0-50$ & 50 & 0.0895 & 0.1267 \\
\hline & $51-100$ & 33 & 0.4437 & 0.2856 \\
\hline & $101-150$ & 11 & 1.9531 & 0.7375 \\
\hline & $151-200$ & 6 & 5.4201 & 2.9865 \\
\hline & $201-300$ & 6 & 10.0478 & 4.3468 \\
\hline & $301-400$ & 1 & 25.0388 & - \\
\hline
\end{tabular}




\begin{tabular}{|c|c|c|c|c|}
\hline & $401-600$ & 2 & 38.0551 & 0.6605 \\
\hline \multirow[t]{7}{*}{ Prumnopitys taxifolia } & $0-50$ & 57 & 0.0466 & 0.0208 \\
\hline & $51-100$ & 58 & 0.3443 & 0.2393 \\
\hline & $101-150$ & 30 & 0.7599 & 0.5133 \\
\hline & $151-200$ & 18 & 1.3752 & 1.0734 \\
\hline & $201-300$ & 6 & 3.2727 & 1.2712 \\
\hline & $301-400$ & 5 & 8.2489 & 4.8325 \\
\hline & $401-600$ & 6 & 11.5269 & 7.1116 \\
\hline \multicolumn{5}{|c|}{ Lianes, epiphytes and dicotyledonous shrubs and trees } \\
\hline Alectryon excelsus & & 42 & 0.1597 & 0.1285 \\
\hline Aristotelia serrata & & 27 & 0.3172 & 0.1317 \\
\hline Astelia solandri, Collospermum & & 21 & 3.0747 & 3.9547 \\
\hline \multicolumn{5}{|l|}{ bastatum } \\
\hline Beilschmiedia tawa & & 64 & 0.1289 & 0.0981 \\
\hline Brachiglottis repanda & & 47 & 0.5345 & 0.1394 \\
\hline Carpodetus serratus & & 43 & 0.0168 & 0.0084 \\
\hline Coprosma grandifolia & & 40 & 0.2731 & 0.1502 \\
\hline Coprosma ramnoides, Melicope & & 52 & 0.0068 & 0.0028 \\
\hline \multicolumn{5}{|l|}{ simplex, Pseudopanax anomalous, } \\
\hline \multicolumn{5}{|l|}{ Melicytus micranthus } \\
\hline Cordyline australis & & 25 & 2.2379 & 2.5255 \\
\hline Corynocarpus laevigatus & & 40 & 0.4170 & 0.2101 \\
\hline Earina autumnalis, E. & & 27 & 0.2909 & 0.2621 \\
\hline \multicolumn{5}{|l|}{ mucronatus } \\
\hline Elaeocarpus dentatus & & 47 & 0.1616 & 0.0747 \\
\hline Elaeocarpus bookerianus & & 19 & 0.0752 & 0.0349 \\
\hline Geniostoma mpestre & & 42 & 0.0606 & 0.0312 \\
\hline Griselinia lucida & & 45 & 0.6247 & 0.8585 \\
\hline Hedycaria arborea & & 39 & 0.0978 & 0.0306 \\
\hline Hoheria populnea & & 34 & 0.2906 & 0.0871 \\
\hline Knightia excelsa & & 39 & 0.6836 & 0.3206 \\
\hline Kunzea ericoides & & 49 & 0.1010 & 0.1094 \\
\hline Luarelia novae-zelandiae & & 24 & 0.1429 & 0.0316 \\
\hline Lonicera japonica & & 50 & 0.0573 & 0.0453 \\
\hline Lophomyrtus bullata & & 44 & 0.0634 & 0.0279 \\
\hline Macropiper excelsum & & 48 & 0.1714 & 0.0756 \\
\hline Melicytus ramiflorus & & 47 & 0.2141 & 0.1177 \\
\hline Metrosideros colensoi, $M$. diffusa & & 57 & 0.0078 & 0.0030 \\
\hline Myrsine australis, Pittosporum & & 59 & 0.0546 & 0.0435 \\
\hline
\end{tabular}




$\begin{array}{llll}\text { tennifolium } & & & \\ \text { Nestegis cunninghamii, N. } & 64 & 0.1729 & 0.1270 \\ \text { Lanceolata } & & & \\ \text { Olearia rani } & 39 & 0.2994 & 0.1443 \\ \text { Parsonsia heterophylla } & 30 & 0.0595 & 0.0354 \\ \text { Pennantia corymbosa } & 45 & 0.0323 & 0.0255 \\ \text { Pittosporum cornifolium } & 29 & 0.0762 & 0.0529 \\ \text { Pittosporum eugenioides } & 42 & 0.1637 & 0.0800 \\ \text { Pseudopanax crassifolius } & 44 & 0.5834 & 0.2596 \\ \text { Ripogonum scandens } & 48 & 0.3491 & 0.1917 \\ \text { Rubus australis } & 31 & 0.2036 & 0.0988 \\ \text { Schefflera digitata } & 48 & 0.2480 & 0.1118 \\ \text { Tetrapathaea tetrandra } & 54 & 0.1688 & 0.1006 \\ \text { m. }\end{array}$

\subsubsection{Intensity of cockatoo-caused greenfall}

Cockatoo-caused greenfall was recorded during every survey from April 1992 to October 1993 (Table 4.8). Occurrence of cockatoo-caused greenfall was localised and irregular. Sixty percent of cockatoo-caused greenfall was recorded from just five plots, including $31 \%$ from plot 29, while no cockatoo-caused greenfall was recorded from 39 plots (Figure 4.7). Cockatoo-caused greenfall contributed a significantly greater proportion $\left(\chi^{2}=1104.9\right.$, d.f. $=$ $1, \mathrm{P}<0.0001)$ of total greenfall found in plots with type 1 vegetation compared to plots with type 2 vegetation. 


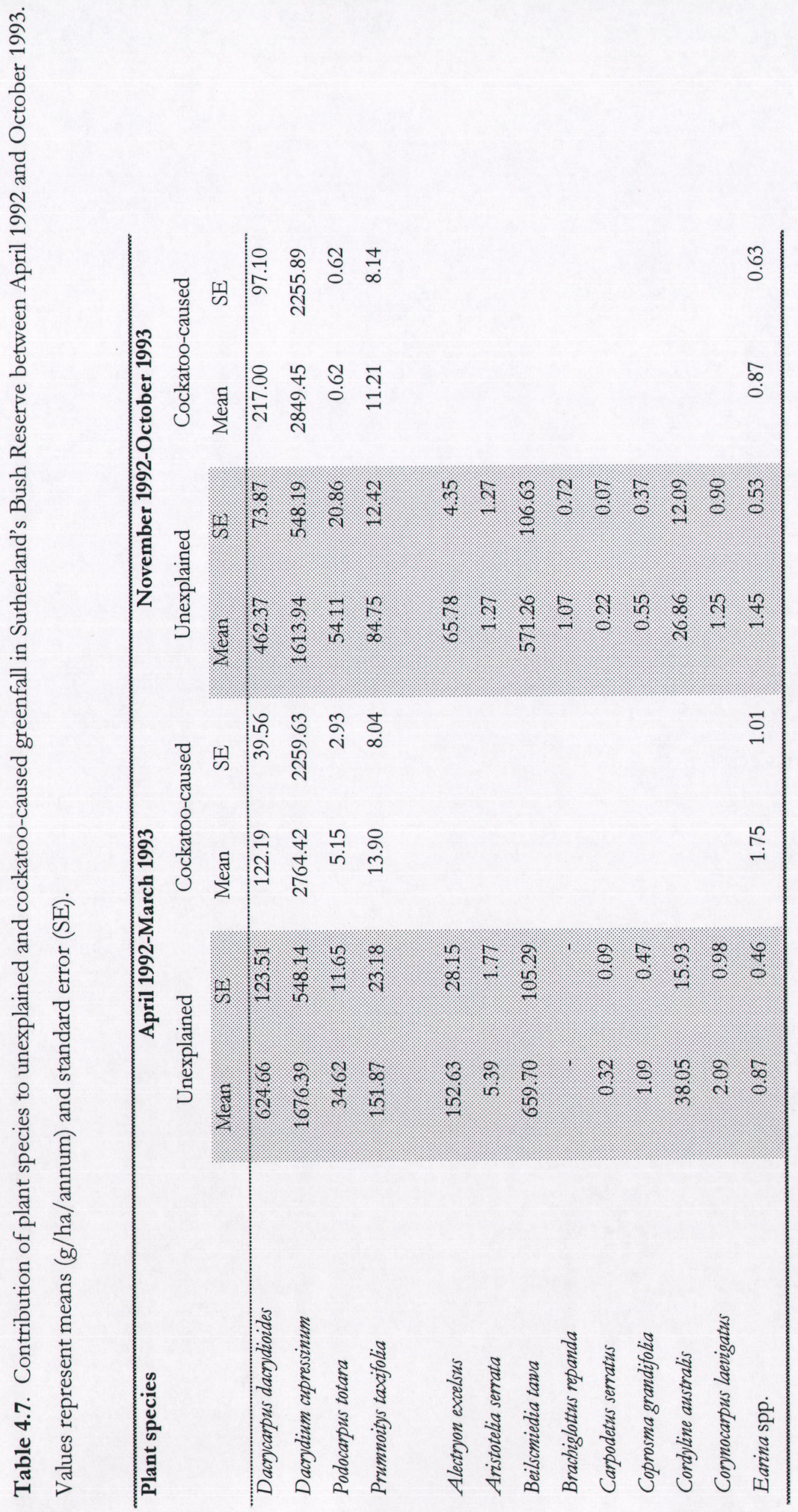




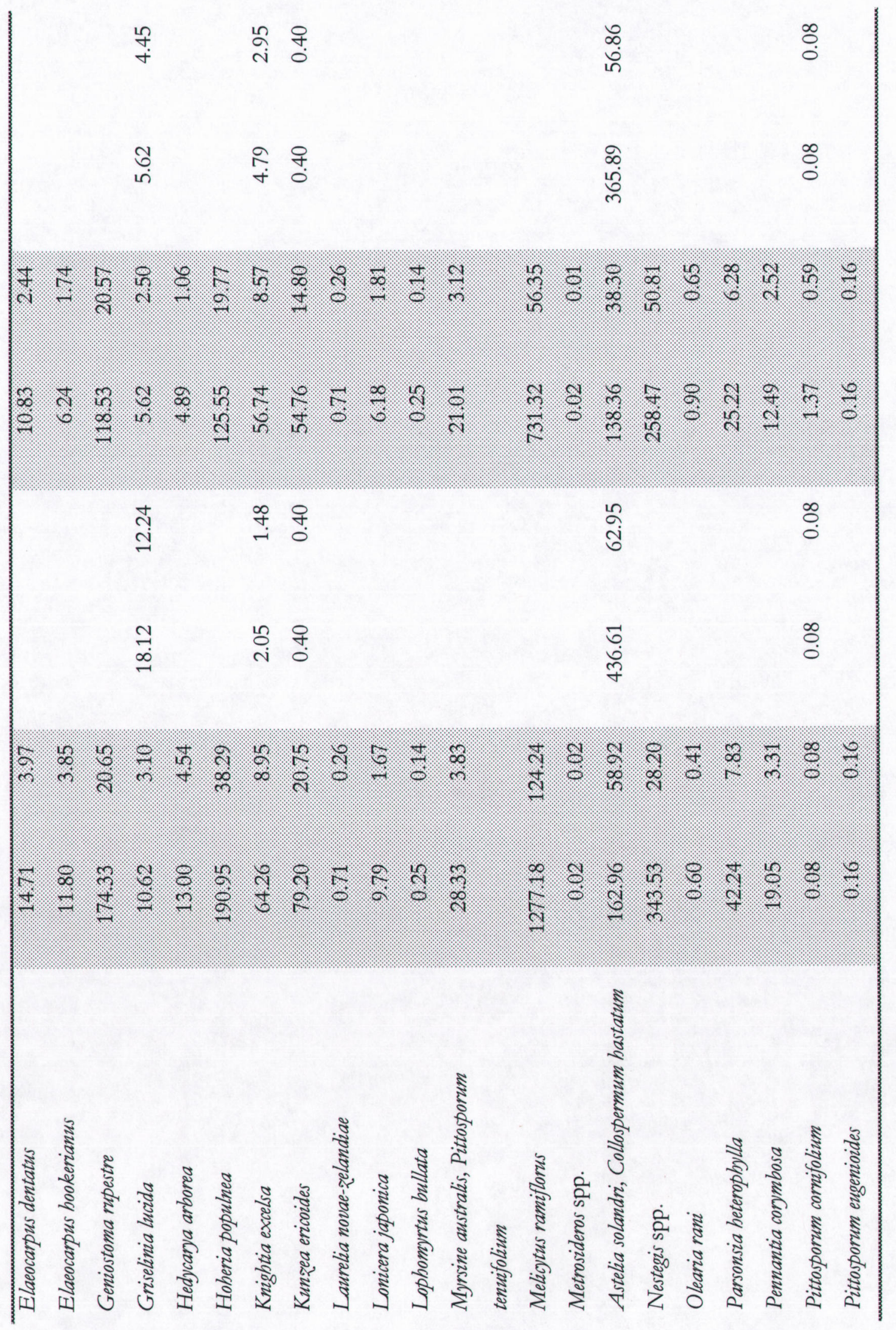




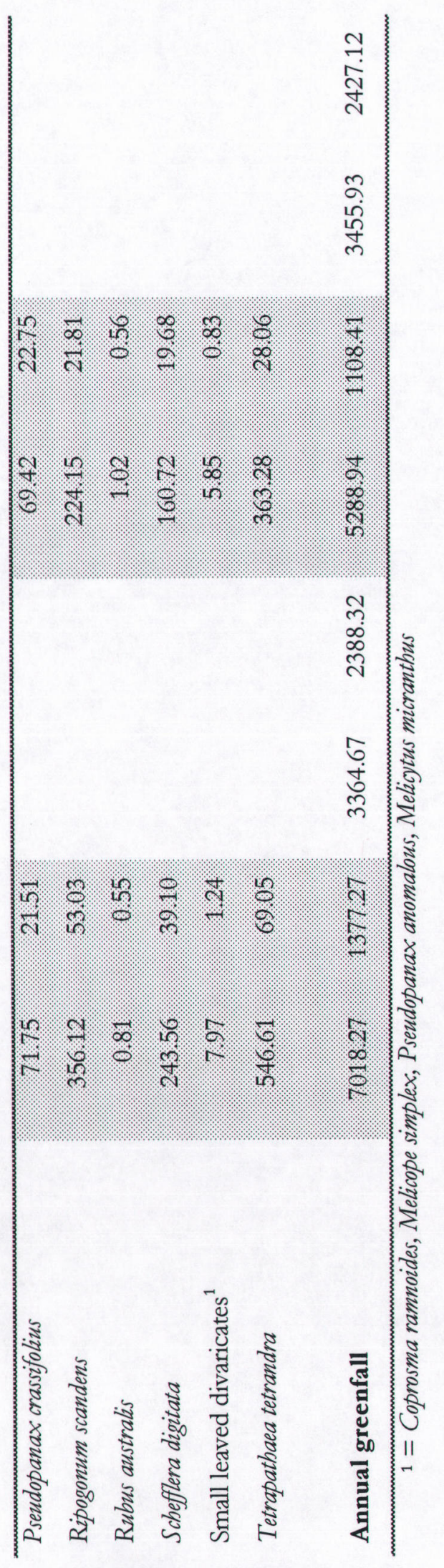




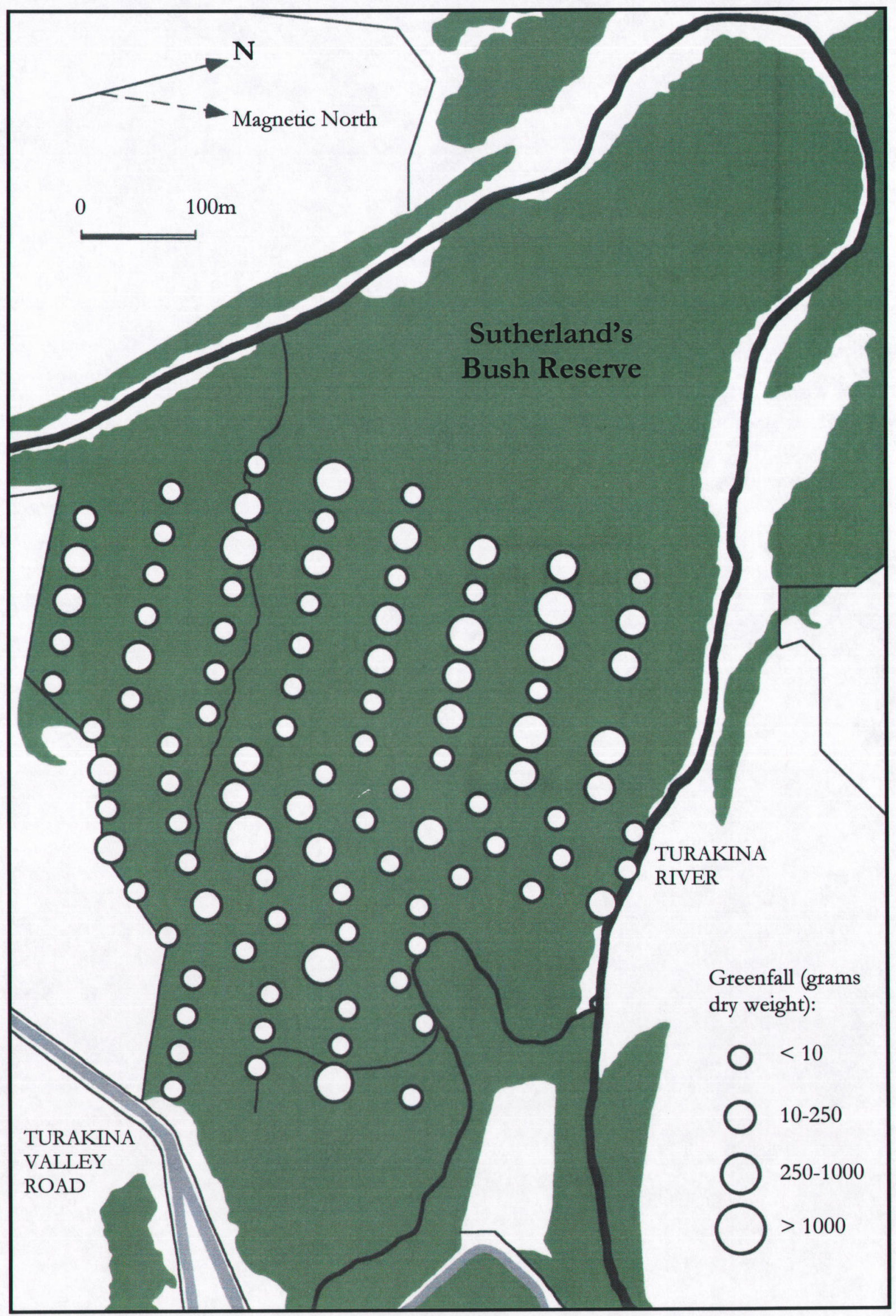

Figure 4.5. Distribution of greenfall at 100 vegetation sampling plots within Sutherland's Bush Reserve between August 1991 and October 1993. 


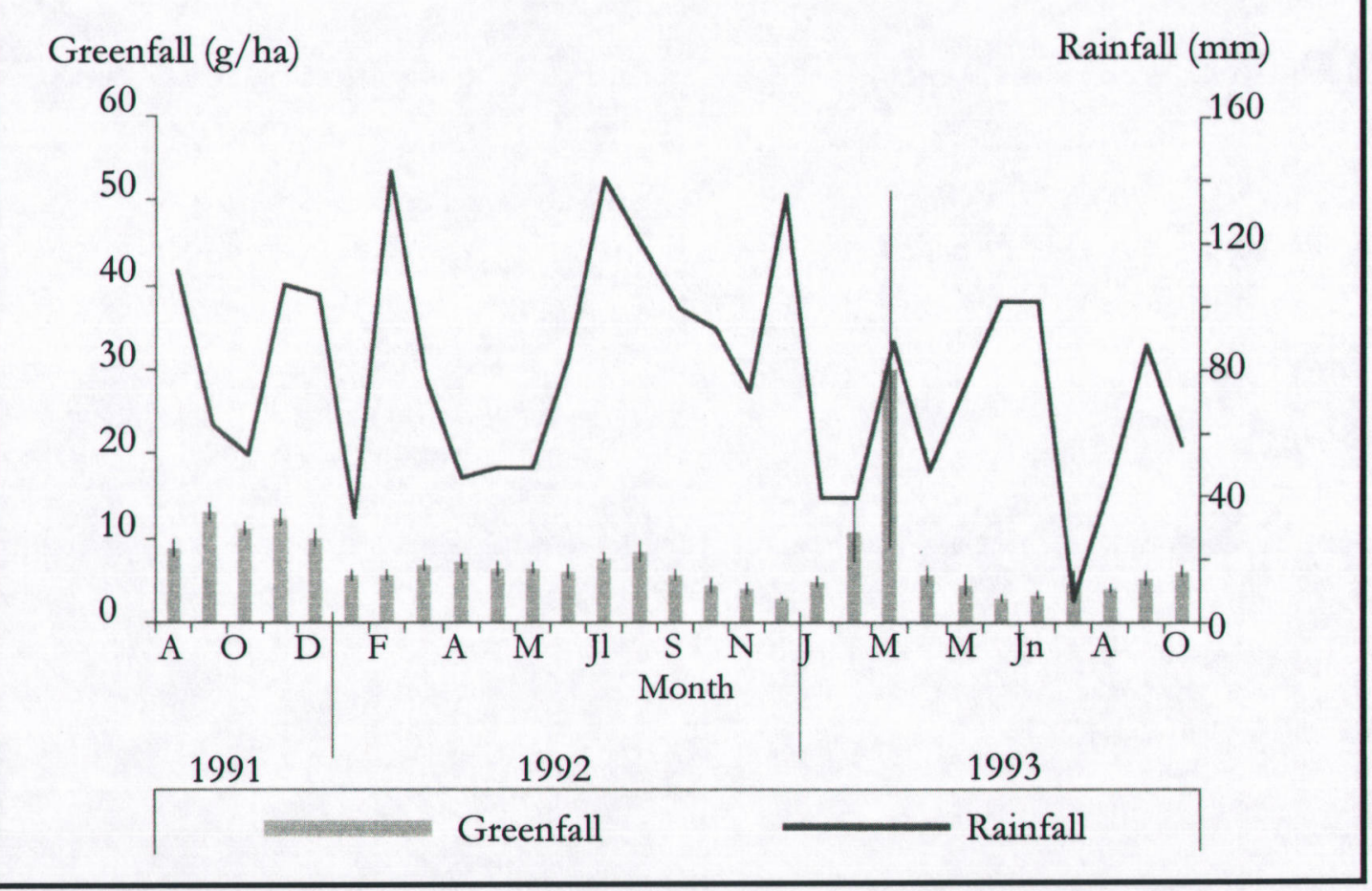

Figure 4.6. Mean and standard error of monthly dry weight of greenfall, for 100 plots in Sutherland's Bush Reserve, and total monthly rainfall (from Ferriby Station, Mangahoe Valley) from August 1991 to October 1993.

For each collection date, mean biomass (mean dry weight greenfall per plot) of cockatoocaused greenfall and of unexplained greenfall was compared ( $\mathrm{t}$ tests, alpha $=0.01, \mathrm{n}=100$ ). In 17 paired comparisons unexplained greenfall contributed significantly greater inputs to the forest floor than cockatoo-caused greenfall (Table 4.8). In only one of the 21 paired comparisons did cockatoo-caused greenfall contribute more to total greenfall than unexplained, though this difference was not significant $(t=-0.88$, d.f. $=198, P=0.38)$. On this occasion (indicated by the large peak during March 1993: Figure 4.6) heavy defoliation by C. galerita of two large D. cupressinum (at plot 29 and plot 81 ) contributed $76.8 \%$ of total greenfall ( $95.4 \%$ of cockatoo-caused greenfall for this month).

No relationship was found between monthly biomass of cockatoo-caused greenfall in Sutherland's Bush Reserve and the number of C. galerita roosting in the reserve, number of bird hours spent in the reserve or number of feeding observations (P's > 0.1) (Table 4.9). There was also no correlation ( $\mathrm{P}$ 's $>0.1$ ) between the frequency of $C$. galerita seen feeding on 
D. dacrydioides and D. cupressinum each month (Table 4.2) and the abundance of cockatoocaused greenfall of these species.

Only 10 of the 41 'species' represented in the total greenfall also contributed to cockatoocaused greenfall (Table 4.7). All four podocarp species and all four species of epiphytic angiosperms recorded as present in the vegetation survey were also recorded in the cockatoocaused greenfall. No epiphytic Pteridophytes were recorded in the greenfall found in the plots, but fronds of the epiphytic fern Lycopodium varium showing evidence of having been bitten off by $C$. galerita were observed just outside of a survey plot on one occasion.

Cacatua galerita contributed more than $25 \%$ of the total greenfall recorded for five species $(D$. dacrydioides, D. cupressinum, Griselinia lucida, Earina spp. and nest epiphytes) (Table 4.7). Note: the $75 \%$ of nest epiphyte greenfall attributed to C. galerita is likely to be an overestimate due to initial confusion in distinguishing $C$. galerita-related damage from T. vulpecula-related damage. Monthly records of cockatoo-caused greenfall from April 1992 to October 1993 were combined into seasons and these seasonal data were compared. There was no discernible difference in the amount of cockatoo-caused greenfall found ( $t$ tests, d.f. $=6-11$, P's > 0.1). 


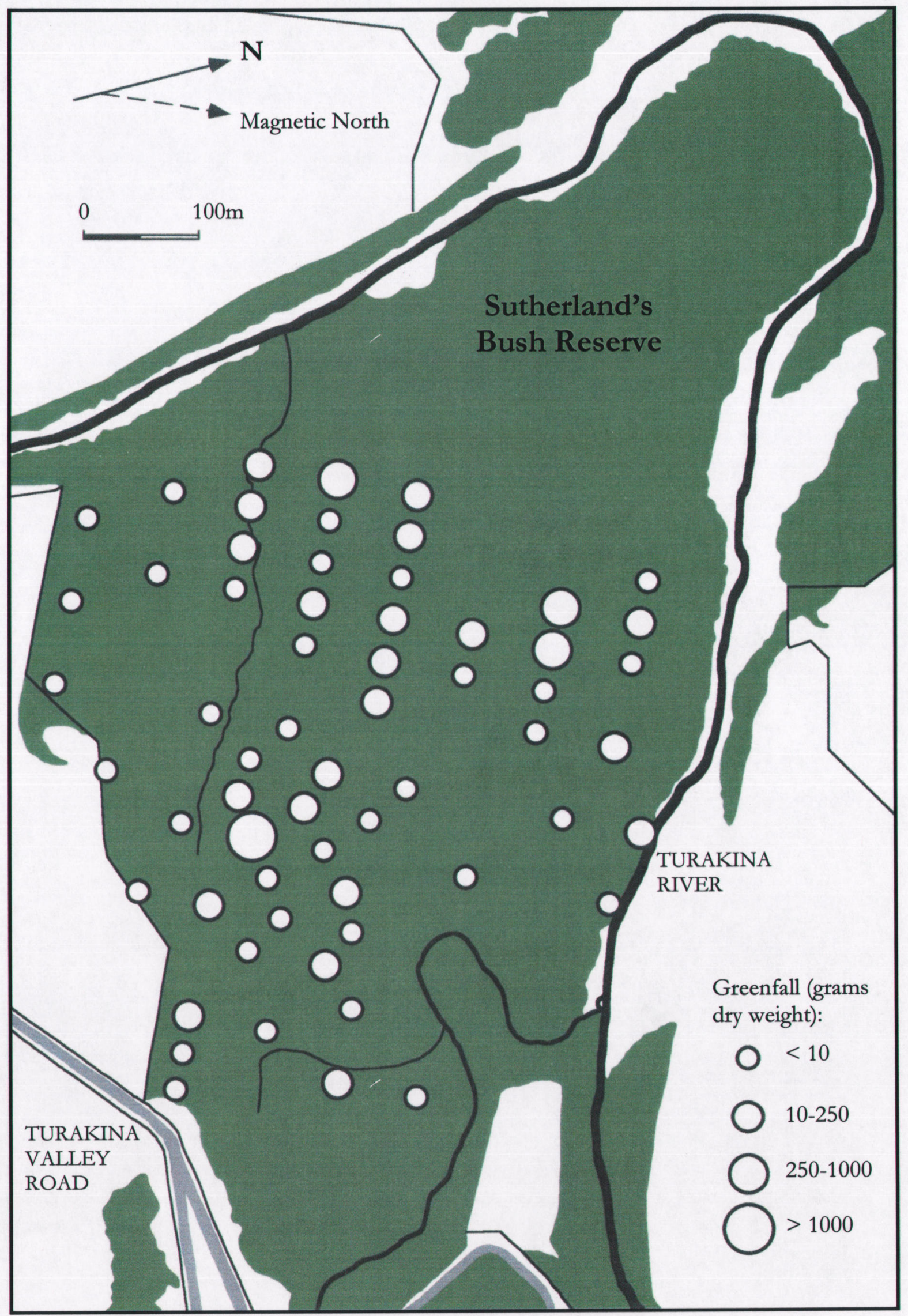

Figure 4.7. Distribution of cockatoo-caused greenfall at 100 vegetation sampling plots within Sutherland's Bush Reserve between April 1992 and October 1993. 
Table 4.8. Comparison of mean monthly unexplained and cockatoo-caused greenfall from Sutherland's Bush Reserve between April 1992 and October 1993.

\begin{tabular}{|c|c|c|c|c|c|c|}
\hline \multirow[t]{2}{*}{$\begin{array}{l}\text { Survey } \\
\text { (month) }\end{array}$} & \multicolumn{2}{|c|}{ Unexplained greenfall } & \multicolumn{2}{|c|}{$\begin{array}{c}\text { Cockatoo-caused } \\
\text { greenfall }\end{array}$} & \multirow[t]{2}{*}{$\begin{array}{c}\text { t-value } \\
(\text { d.f. }=198)\end{array}$} & \multirow[t]{2}{*}{ P-value } \\
\hline & mean & std & mean & std & & \\
\hline April & 5.73 & 4.88 & 1.35 & 4.30 & 6.73 & $<0.001$ \\
\hline May & 4.98 & 4.93 & 1.20 & 5.43 & 5.15 & $<0.001$ \\
\hline May & 5.56 & 4.55 & 0.94 & 3.93 & 7.68 & $<0.001$ \\
\hline June & 5.41 & 6.00 & 0.61 & 3.62 & 6.85 & $<0.001$ \\
\hline July & 7.16 & 6.11 & 0.52 & 1.82 & 10.42 & $<0.001$ \\
\hline August & 6.90 & 8.24 & 1.22 & 4.58 & 6.03 & $<0.001$ \\
\hline September & 4.66 & 4.64 & 1.05 & 4.07 & 5.85 & $<0.001$ \\
\hline October & 3.53 & 3.94 & 0.92 & 4.54 & 4.34 & $<0.001$ \\
\hline November & 3.55 & 4.57 & 0.39 & 1.52 & 6.56 & $<0.001$ \\
\hline December & 2.42 & 2.16 & 0.20 & 1.02 & 9.29 & $<0.001$ \\
\hline January & 4.04 & 4.40 & 0.84 & 2.94 & 6.05 & $<0.001$ \\
\hline February & 9.52 & 31.46 & 1.16 & 6.53 & 2.60 & 0.010 \\
\hline March & 6.68 & 27.30 & 23.24 & 186.14 & -0.88 & 0.380 \\
\hline April & 3.65 & 4.47 & 1.99 & 7.33 & 1.93 & 0.055 \\
\hline May & 2.75 & 3.88 & 1.57 & 8.28 & 1.29 & 0.198 \\
\hline June & 2.55 & 2.36 & 0.23 & 1.18 & 8.79 & $<0.001$ \\
\hline June & 2.92 & 3.37 & 0.38 & 1.90 & 6.57 & $<0.001$ \\
\hline July & 3.03 & 3.43 & 1.74 & 10.40 & 1.18 & 0.240 \\
\hline August & 3.23 & 2.82 & 0.62 & 2.26 & 7.22 & $<0.001$ \\
\hline September & 3.62 & 4.85 & 1.45 & 5.68 & 2.91 & 0.004 \\
\hline October & 5.00 & 5.66 & 0.75 & 2.25 & 6.98 & $<0.001$ \\
\hline
\end{tabular}

Table 4.9. Measures of Cacatua galerita use of Sutherland's Bush Reserve from April 1992 to October 1993. Test statistic used was Pearson's product-moment correlation.

\begin{tabular}{lcccccc}
$\begin{array}{l}\text { Survey } \\
\text { (month) }\end{array}$ & $\begin{array}{c}\text { Evening } \\
\text { roost size }{ }^{1}\end{array}$ & $\begin{array}{c}\text { Bird hours } \\
\text { in reserve }\end{array}$ & $\begin{array}{c}\text { No. of } \\
\text { feeding } \\
\text { observations }\end{array}$ & $\begin{array}{c}\text { Feeding obs. } \\
\text { in } \boldsymbol{D} .\end{array}$ & $\begin{array}{c}\text { Feeding obs. } \\
\text { dacrydioides }^{3}\end{array}$ & $\begin{array}{c}\text { in } \boldsymbol{D} . \\
\text { cupressinum }^{3}\end{array}$ \\
\hline April & 44 & 200.00 & - & - & - \\
May & 16 & 151.00 & - & - & - \\
May & 0 & 64.00 & - & - & -
\end{tabular}




\begin{tabular}{|c|c|c|c|c|c|}
\hline June & 10 & 146.00 & - & - & - \\
\hline July & 25 & 156.25 & 12 & - & - \\
\hline August & 24 & 161.50 & 20 & - & - \\
\hline September & 14 & 666.50 & 26 & - & - \\
\hline October & 37 & 170.25 & 18 & - & - \\
\hline November & 119 & 316.50 & 3 & 1 & 1 \\
\hline December & 38 & 367.75 & 3 & 0 & 0 \\
\hline January & 46 & 315.50 & 64 & 13 & 47 \\
\hline February & 61 & 552.50 & 31 & 2 & 29 \\
\hline March & 51 & 273.00 & 12 & 9 & 2 \\
\hline April & 74 & 698.25 & 68 & 58 & 4 \\
\hline May & 36 & 129.50 & 3 & 3 & 0 \\
\hline June & 13 & 220.25 & 10 & 10 & 0 \\
\hline June & 25 & 281.25 & 15 & 14 & 1 \\
\hline July & 8 & 163.75 & 19 & 15 & 4 \\
\hline August & 45 & 211.00 & 10 & 6 & 2 \\
\hline September & 36 & 325.25 & 4 & 3 & 0 \\
\hline October & 14 & 76.50 & 3 & 0 & 1 \\
\hline $\mathrm{r}$ & 0.1371 & 0.0282 & -0.0483 & 0.3330 & -0.0894 \\
\hline P-value & 0.5534 & 0.9033 & 0.8539 & 0.2662 & 0.7716 \\
\hline
\end{tabular}

$1=$ number of $C$. galerita roosting in the reserve in the evening following the monthly population survey.

$2=$ calculated from number of birds present in the reserve through the day and day length.

$3=$ frequency of feeding observations in $D$. dacrydioides and $D$. cupressinum were compared with amount of greenfall of these species found in survey plots.

With the exception of Earina spp. $(r=-0.015$, d.f. $=100, P=0.883)$, there was a significant correlation (P's $=0.026-0.00004$, d.f. $=100$ ) between the annual dry weight of cockatoocaused greenfall for a particular species recorded at a plot and the number of these plants present (or for podocarps, trees with $\mathrm{dbh}>500 \mathrm{~mm}$ ) (Table 4.10). There was also a significant and positive correlation between the biomass of $D$. cupressinum in the cockatoocaused greenfall and abundance of branches of this species found lying on the ground that were bearing fruit $(r=0.919$, d.f. $=21, \mathrm{P}<0.001)$. No similar relationship was seen for the other three podocarp species occurring in the reserve (d.f. $=21$, P's $>0.05$ ). No relationship was found between the number of juvenile $D$. dacrydioides $(r=-0.0635$, d.f. $=100, P=0.53$ ) 
and D. cupressinum $(\mathrm{r}=0.1732$, d.f. $=100, \mathrm{P}=0.08)$ trees $(\mathrm{dbh}<100 \mathrm{~mm})$ and the abundance of cockatoo-caused greenfall for these species.

Cacatua galerita bit off significantly more larger branches of podocarps than were recorded in the unexplained greenfall $\left(\chi^{2}=2991.9\right.$, d.f. $\left.=6, \mathrm{P}<0.0001\right)$, ranging from $5.9 \%$ of branches $0-100 \mathrm{~mm}$ in length to $100 \%$ of branches $400-600 \mathrm{~mm}$ in length (Table 4.11 ).

Table 4.10. Correlations between cockatoo-caused greenfall and abundance of plant species occurring in vegetation survey plots in Sutherland's Bush Reserve between April 1992 and October 1993. Test statistic used was Pearson's product-moment correlation. Degrees of freedom $=100$.

\begin{tabular}{|c|c|c|c|}
\hline Species & $\begin{array}{l}\text { Plant size category } \\
\text { (dbh } \mathrm{mm} \text { ) }\end{array}$ & Correlation coefficient & $\mathbf{P}$ \\
\hline \multicolumn{4}{|l|}{ Podocarpaceae } \\
\hline \multirow[t]{3}{*}{ Dacrycarpus dacrydioides } & $0-100$ & -0.0739 & 0.4304 \\
\hline & $100-500$ & 0.1650 & 0.0767 \\
\hline & $500+$ & 0.4888 & 0.0000 \\
\hline \multirow[t]{3}{*}{ Dacrydium cupressinum } & $0-100$ & 0.2618 & 0.0045 \\
\hline & $100-500$ & 0.2661 & 0.0039 \\
\hline & $500+$ & 0.3194 & 0.0005 \\
\hline \multirow[t]{3}{*}{ Podocarpus totara } & $0-100$ & 0.5424 & 0.0000 \\
\hline & $100-500$ & 0.4756 & 0.0000 \\
\hline & $500+$ & 0.5034 & 0.0000 \\
\hline \multirow[t]{3}{*}{ Prumnopitys taxifolia } & $0-100$ & 0.1378 & 0.1402 \\
\hline & $100-500$ & 0.4747 & 0.0000 \\
\hline & $500+$ & 0.3633 & 0.0001 \\
\hline \multicolumn{4}{|c|}{ Lianes, epiphytes and dicotyledonous shrubs and trees } \\
\hline \multirow[t]{2}{*}{ Alectryon excelsus } & $0-100$ & 0.0474 & 0.6132 \\
\hline & $100+$ & 0.5834 & 0.0000 \\
\hline \multirow[t]{2}{*}{ Aristotelia serrata } & $0-100$ & 1.0000 & 0.0000 \\
\hline & $100+$ & 1.0000 & 0.0000 \\
\hline Astelia solandri, & - & 0.4548 & 0.0000 \\
\hline \multicolumn{4}{|l|}{ Collospermum bastatum } \\
\hline \multirow[t]{2}{*}{ Beilschmiedia tawa } & $0-100$ & 0.6223 & 0.0000 \\
\hline & $100+$ & 0.6743 & 0.0000 \\
\hline
\end{tabular}




\begin{tabular}{|c|c|c|c|}
\hline Brachiglottis repanda & $0-100$ & 0.5154 & 0.0000 \\
\hline \multirow[t]{2}{*}{ Carpodetus serratus } & $0-100$ & 0.4713 & 0.0000 \\
\hline & $100+$ & 0.0422 & 0.6532 \\
\hline Coprosma grandifolia & $0-100$ & 0.4812 & 0.0000 \\
\hline \multirow[t]{2}{*}{ Cordyline australis } & $0-100$ & 0.7537 & 0.0000 \\
\hline & $100+$ & 0.8058 & 0.0000 \\
\hline Corynocarpus laevigatus & $0-100$ & 0.9369 & 0.0000 \\
\hline Earina spp. & - & -0.0224 & 0.8118 \\
\hline \multirow[t]{2}{*}{ Elaeocarpus dentatus } & $0-100$ & 0.5603 & 0.0000 \\
\hline & $100+$ & 0.6917 & 0.0000 \\
\hline Elaeocarpus hookerianus & $100+$ & 0.5485 & 0.0000 \\
\hline \multirow[t]{2}{*}{ Genisotoma mpestre } & $0-100$ & 0.5996 & 0.0000 \\
\hline & $100+$ & -0.0050 & 0.9572 \\
\hline Griselinia lucida & - & 0.6616 & 0.0000 \\
\hline \multirow[t]{2}{*}{ Hedycarya arborea } & $0-100$ & 0.6856 & 0.0000 \\
\hline & $100+$ & 0.1691 & 0.0695 \\
\hline \multirow[t]{2}{*}{ Hoberia populnea } & $0-100$ & 0.4722 & 0.0000 \\
\hline & $100+$ & 0.3057 & 0.0008 \\
\hline \multirow[t]{2}{*}{ Kniahtigexcelon=0 } & 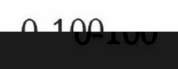 & م2300 & - \\
\hline & $100+$ & 0.5536 & 0.0000 \\
\hline \multirow[t]{2}{*}{ Kunzea ericoides } & $0-100$ & 0.6317 & 0.0000 \\
\hline & $100+$ & 0.6522 & 0.0000 \\
\hline \multirow[t]{2}{*}{ Laurelia novae-zelandiae } & $0-100$ & 0.5289 & 0.0000 \\
\hline & $100+$ & 0.8525 & 0.0000 \\
\hline Lonicera japonica & - & 0.7540 & 0.0000 \\
\hline Lophomyrtus bullata & $0-100$ & 0.5722 & 0.0000 \\
\hline \multirow[t]{2}{*}{ Macropiper excelsum } & $0-100$ & 0.9766 & 0.0000 \\
\hline & $100+$ & 1.0000 & 0.0000 \\
\hline \multirow[t]{2}{*}{ Meligytus ramiflorus } & $0-100$ & -0.0441 & 0.6382 \\
\hline & $100+$ & 0.3436 & 0.0002 \\
\hline Metrosideros spp. & - & 0.0876 & 0.3496 \\
\hline Myrsine austrates, & $0-100$ & 0.2198 & 0.0178 \\
\hline \multicolumn{4}{|l|}{ Pittosporum tenvifolium } \\
\hline & $100+$ & 0.5695 & 0.0000 \\
\hline \multirow[t]{2}{*}{ Nestegis spp. } & $0-100$ & 0.2798 & 0.0024 \\
\hline & $100+$ & 0.5149 & 0.0000 \\
\hline \multirow[t]{2}{*}{ Olearia rani } & $0-100$ & 0.6943 & 0.0000 \\
\hline & $100+$ & 0.4005 & 0.0000 \\
\hline Parsonsia beteropbylla & - & 0.0550 & 0.5580 \\
\hline
\end{tabular}




\begin{tabular}{lccc} 
Pennantia corymbosa & $0-100$ & 0.2652 & 0.0040 \\
& $100+$ & 0.2401 & 0.0094 \\
Pittosporum cornifolium & - & 0.0355 & 0.7056 \\
Pittosporum eugenioides & $0-100$ & 0.7040 & 0.0000 \\
& $100+$ & -0.0087 & 0.9262 \\
Pseudopanax crassifolius & $0-100$ & 0.0337 & 0.7192 \\
& $100+$ & -0.0009 & 0.9922 \\
Ripogonum scandens & - & 0.2720 & 0.0031 \\
Rubus australis & - & 0.0911 & 0.3307 \\
Schefflera digitata & $0-100$ & 0.8230 & 0.0000 \\
& $100+$ & 0.7481 & 0.0000 \\
Small leaved divaricates ${ }^{1}$ & $0-100$ & 0.4560 & 0.0000 \\
& $100+$ & 0.0647 & 0.4902 \\
Tetrapathaea tetrandra & - & 0.6538 & 0.0000 \\
\hline
\end{tabular}

1 = Coprosma ramnoides, Melicope simplex, Pseudopanax anomalous, Melicytus micrantbus.

Table 4.11. Frequency of various branch sizes of podocarps contributing to the unexplained and cockatoo-caused components of greenfall in Sutherland's Bush Reserve between April 1992 and October 1993.

\begin{tabular}{|c|c|c|c|c|c|c|c|c|}
\hline \multirow{2}{*}{$\begin{array}{c}\begin{array}{c}\text { Branch size } \\
(\mathbf{m m})\end{array} \\
0-50\end{array}$} & \multicolumn{2}{|c|}{$\begin{array}{l}\text { Dacrycarpus } \\
\text { dacrydioides }\end{array}$} & \multicolumn{2}{|c|}{$\begin{array}{l}\text { Dacrydium } \\
\text { cupressinum }\end{array}$} & \multicolumn{2}{|c|}{$\begin{array}{c}\text { Podocarpus } \\
\text { totara }\end{array}$} & \multicolumn{2}{|c|}{$\begin{array}{c}\text { Prumnopitys } \\
\text { taxifolia }\end{array}$} \\
\hline & 1123 & 131 & 2175 & 101 & 246 & 4 & 824 & 39 \\
\hline $51-100$ & 1015 & 86 & 1807 & 101 & 51 & 2 & 282 & 8 \\
\hline $101-150$ & 232 & 69 & 661 & 153 & 5 & 2 & 43 & 2 \\
\hline $151-200$ & 67 & 46 & 217 & 273 & 3 & 0 & 10 & 1 \\
\hline $201-300$ & 21 & 21 & 54 & 257 & 0 & 0 & 4 & 0 \\
\hline $301-400$ & 1 & 5 & 8 & 79 & 0 & 0 & 1 & 2 \\
\hline $401-600$ & 0 & 0 & 0 & 9 & 0 & 0 & 0 & 0 \\
\hline Total & 2459 & 358 & 4922 & 973 & 305 & 8 & 1164 & 52 \\
\hline
\end{tabular}




\subsection{DISCUSSION}

\subsubsection{Competition}

\subsubsection{Foraging segregation of $C$. galerita, $P$. novaeseelandiae, $A$. melanura and $H$. novaeseelandiae}

The number of records of $P$. novaeseelandiae, $A$. melanura, $H$. novaeseelandiae and $C$. galerita in no way indicates their population sizes. Instead, numbers reflect the conspicuousness of the species. Cacatua galerita were seen and recorded most often as they were more obvious (large, white and feeding in the open and in flocks) and because they were the main focus of this study. Anthornis melanura were not recorded very often due to their small size, cryptic colouration and because of their preference for foraging in dense, low growing shrubs and small trees.

The four species of bird studied exhibited varying degrees of sequential specialisation in their diets as they switched between specific food sources from season to season. Cacatua galerita appeared to use the largest range of plant species, height, substrate and also foraging techniques, including gleaning, probing beneath the surface of pasture and ripping bark and rotten wood (A. Styche personal observation), though this is possibly because more foraging observations of this species were obtained compared to the native species.

Cacatua galerita obtained most of their food from farmland. However, prediction 1 of hypothesis 4.1 was not supported by my data. While agricultural land, crops and pasture, was important, in some months dominating observations of feeding, C. galerita also spent significant effort foraging in exotic (mostly, but not exclusively conifers) and native trees. Foraging observations from $A$. melanura, $H$. novaeseelandiae and $P$. novaeseelandiae came mostly from native forest tree species, with exotic angiosperm trees being the only other plant group utilised.

There are limitations on how much can be read into these results. For example, seasonal changes in the importance of particular plant species, substrate or height ranges are difficult to interpret, and could indicate changes in food quantity and/or quality, the weather conditions at the time of sampling, or may simply reflect sampling effort. A more intensive sampling effort might show a broader range of plant species and foraging stations used by these birds (for example, McEwen (1978) recorded 95 species eaten by $H$. novaeseelandiae). Another potential source of bias could arise through variation in the spread of the sampling 
effort. Although there were repeated sampling bouts (every four weeks between August 1991 and October 1993), few birds (except C. galerita) were seen in any season in any one year. Apparent preference for a particular plant species may, therefore, reflect chance (more likely when sample size is low), patchiness of preferred foods in the environment (more likely to have an effect if birds are more obvious in some vegetation types compared to others), or annual and/or seasonal variability in flower and fruit production and invertebrate populations.

The actual food items observed being consumed by birds in this study were not always identified and can not be determined on the basis of the evidence presented here. However, since many of the plants used here are the same as those that these species were seen to use in other studies (summarised in Heather and Robertson 1996; Higgins 1999) their diets might also be expected to be the same or similar. Of the native bird species, $H$. novaeseelandiae has the greatest dietary specialisation, feeding mostly on fruit and foliage, while $P$. novaeseelandiae and $A$. melanura have broad omnivorous diets, feeding on a combination of invertebrates, nectar and fruit (McEwen 1978; Robertson 1985; Clout and Hay 1989; Rowley et al. 1989; Marchant and Higgins 1990; Baker 1992; O’Donnell and Dilks 1994; Heather and Robertson 1996; Williams and Karl 1996; Castro and Robertson 1997). Cacatua galerita feed mostly on seeds, but also eat fruit, foliage and other nutritious plant parts, and invertebrates (Frith 1977; Noske 1980; Lepschi 1993; Higgins 1999). Considering these differences in diet, the overlap in resource use between all species is likely to be greatly overestimated. Despite this, competition for feeding opportunities and/or space (for example, $P$. novaeseelandiae defending favourite food trees from other birds) can increase the overlap between species.

The four species studied differed from each other in the plant species used, their preferred feeding heights and for the most part their diet. Prosthemadera novaeseelandiae and $A$. melanura had the greatest overlap in foraging dimensions, which is expected given they are closely related (family Meliphagidae), are of similar size, and have a similar dietary range, though competition between similar or closely related bird species in native forests in New Zealand is considered to be rare (McLay 1974). While C. galerita in this study spent a greater effort foraging in trees than observed in Australia (Noske 1980), this did not result in significant overlap in foraging dimensions with the native species. Overall, the native species overlapped more with each other than with C. galerita. These findings support prediction 2 of hypothesis 4.1. Cacatua galerita are unlikely to directly affect (through competition) the foraging opportunities of $A$. melanura, $H$. novaeseelandiae and $P$. novaeseelandiae. 
With the possible exception of extremely monocultural areas, agricultural landscapes offer a wide range of habitats in which birds can find food and breeding sites (Clark et al. 1986). Food is often concentrated and abundant in agricultural areas, therefore, granivorous birds obtain food there more efficiently than in natural habitats. Maize seed was a very important food for C. galerita in this study, though other vegetation types provided an important source of food when this crop was not available and as a supplement when maize was present. In the absence of cereal crops C. galerita would have to rely on food provided by grassland and/or trees, including native species, which may, therefore, bring them into greater competition with native bird species. Studies of $C$. galerita living in areas where crops are not grown are needed to determine what $C$. galerita use as an alternative to cereals, especially in winter.

\subsubsection{Potential overlap between C. galerita and other native bird species in New Zealand}

Maps of C. galerita distribution in New Zealand (Chapter 2, this study) show the current range of this species overlaps the ranges of many native land bird species, though the list of potential competitors is small (Turbott 1990; Heather and Robertson 1996). Approximately $81 \%$ of C. galerita foraging records were obtained from open ground and exotic conifer vegetation, which is not used by many native land bird species. Cacatua galerita did forage extensively in emergent podocarps and were recorded foraging in native hardwood species (B. tawa, A. excelsus and $K$ ericoides) in this study, and have been recorded in similar habitats in other parts of the country (Oliver 1930; Martin 1962; Martin and Bartlett 1963; CSN 1976, $1977,1984,1987,1988,1990,1992)$. Although podocarps tend to produce abundant fruit so mitigating any competition, it is at this time of year that native forest birds may face strongest competition from C. galerita for food and/or foraging opportunities.

Further competitive interactions between $C$. galerita and native forest birds may arise during nesting. The decline of parrot species in Tasmania is believed to be a consequence of nesting-hole competition with the more aggressive starling (Sturnus vulgaris) (Green 1983). Many native forest birds, and bats nest and/or roost in cavities in trees. Cacatua galerita, galah (C. roseicapilla), rosellas (Platycercus elegans and P. eximius) and rainbow lorikeets (Trichoglossus baematodus) also nest in cavities in trees and competition for suitable nest sites by these more aggressive adventive birds is seen to be a potential threat to native species (Greene 1998b). Overlap in the site selection and dimension of tree holes used by $C$. galerita with native species is an area that needs further investigation. 
Greatest competition for C. galerita, particularly when feeding on cereal stubbles and spilt grain, may come from native ducks (Tadorna variegata, Anas gracilis and $A$. superciliosa) and the suite of introduced birds and mammals introduced by Europeans. For example, C. galerita were seen feeding alongside $T$. variegata, mallard ducks ( $A$. platyrbynchos), ring-necked pheasants (Phasianus colchicus), and numerous introduced finches on spilt grain in maize stubble during July 1993 (personal observation). In native forests, ship rats (Rattus rattus) may consume the entire seed crop from native podocarp and hardwood trees (Daniel 1973), while T. vulpecula, goats (Capra bircus) and deer (mostly Cervus spp. and Dama dama), can reduce flower and fruit production, and even the overall abundance of some food plants (Leathwick et al. 1983; Cowan et al. 1985; Mark 1989; Cowan and Waddington 1990, 1991).

\subsubsection{Impact on native vegetation}

\subsubsection{The nature and extent of damage to native tree and shrub species by C. galerita}

Cacatua galerita foraging in native forest were mostly seen in emergent podocarps and this was reflected in the substantial contribution of podocarp foliage to cockatoo-caused greenfall. Leaves and branches of epiphytes from within these podocarps were also recorded frequently in cockatoo-caused greenfall and were seen at other times discarded on the forest floor. Cockatoo-caused greenfall of other species was very rarely recorded (less than $0.1 \%$ ) and was difficult to distinguish from the impacts of other browsers in the forest, such as T. vulpecula and invertebrates. These data support prediction 1 , hypothesis 4.2 , though a more correct interpretation is that the impact of C. galerita in Sutherland's Bush Reserve is almost exclusively to emergent podocarp trees greater than 25 metres in height and their associated epiphytic flora.

Composition of greenfall did not relate closely to the frequency with which these birds were seen feeding in particular podocarp species. For example, C. galerita were seen feeding mostly in $D$. dacrydioides, but $D$. cupressinum branches comprised the greatest single component of cockatoo-caused greenfall. Such differences in observed feeding rates and dropping rates of branches may result from variation in C. galerita activities when in different trees (for example, these birds may prefer chewing the branches of $D$. cupressinum). Alternatively, composition of the greenfall found in this survey may be heavily influenced by chance events. Most cockatoo-caused greenfall of D. cupressinum was recorded in March 1993, resulting from the partial defoliation of two large rimu trees (102 and 459 rimu branches were dropped in two vegetation sampling plots by $C$. galerita, compared to an average of 5.2 branches and/or 
leaves (s.d. = 26.5, $\mathrm{n}=$ 321) between April 1992 and October 1993 (unpublished data)). Almost all of the branches and leaves dropped in these two survey plots were of $D$. cupressinum, just two items were leaves from epiphytes attached to these trees. Such heavy defoliation of trees by $C$. galerita was not frequent, and was seen on only two other occasions, neither near survey plots. On each occasion the litter was dominated by a single species $(D$. cupressinum), and heavy defoliation was seen only once at each site.

Several species of cockatoo have been recorded biting off green twigs. For example, Boehm (1959) noted that $C$. roseicapilla had a habit of biting the bark of trunks and limbs of nesting trees and also bit off green twigs, "often littering the ground beneath the tree with pieces of foliage". During a study of white-tailed black cockatoos (Calyptorbynchus baudinii) in Pinus plantations in Western Australia, Saunders (1974) found a positive correlation between the number of chewed green twigs and the number of cones eaten.

Two possible explanations for the heavy defoliation of vegetation by $C$. galerita are considered below. First, damage may be a direct by-product of feeding activity. Second, C. galerita defoliated favoured perching and/or nesting trees during activities that were not associated with feeding.

Some damage to native trees by $C$. galerita was associated with feeding activity by these birds. For example, a significant and positive correlation was found between the abundance of cockatoo-caused greenfall and the number of fallen branches of $D$. cupressinum bearing ripe fruit. However, the majority of branches of podocarps, and no branches of other species, dropped by these birds showed evidence of bearing fruit. This was particularly so for the $D$. cupressinum trees most heavily defoliated by $C$. glaerita. Cockatoos, including C. galerita, are known to bite branches off while feeding, either when walking between food bearing branches or biting off a branch and holding it with a foot while extracting food (Saunders 1974; A. Styche personal observation). Although ripe fruit would normally be present on $D$. cupressinum in March, these trees did not produce, or produced very few, ripe fruit in 1993 (A. Styche personal observation). No fruit were seen on the particular D. cupressinum trees defoliated by $C$. galerita, and none of the branches bitten off these trees had fruit, so defoliation was not considered to have been associated with feeding (at least on fruit or seeds).

An increase in the frequency of $C$. galerita observed foraging in $D$. dacrydioides in winter was associated with large numbers of these birds coming to feed on adjacent maize crops. 
During similar "minor feeding" events in New South Wales (Noske 1980), C. galerita took little or no food, but were possibly looking for particular items, such as invertebrates. Commonly diets of herbivores are comprised of a large component from few species and small amounts from several species that are being sampled or have very limited availability (Robbins 1993). Important nutrients may be being sought from these small dietary components that are not available in the major food items, or there may be other advantages in consuming a variety of foods, such as more efficient utilisation of nutrients and carbohydrates from food when items are combined. For example, northern bobwhite quail (Colinus virginianus) maintained their body weight when fed a diet of mixtures of seeds that when offered individually could not provide sufficient energy for these birds to survive (Madison and Robel 2001). Leaf fall in the forest patches bordering maize was not monitored so the affect of increased feeding in $D$. dacrydioides in reserves bordering maize is not known. However, increased feeding in $D$. dacrydioides in forest bordering maize does not explain the greater fall of $D$. cupressinum in Sutherland's Bush Reserve.

Cockatoo-caused greenfall was patchy in distribution. Cacatua galerita congregated and rested in sparsely foliaged and sometimes dead emergent native trees, and cockatoo-caused greenfall tended to be more frequent and more intense around these trees. Whether C. galerita were responsible for defoliating these trees or whether they occupied trees that already had an open canopy is not known, but the habit of these birds of biting branches could well serve to retain an open canopy and may cause the death of particular emergents and the epiphytes they contain.

\subsubsection{Comparison of cockatoo-caused greenfall with other studies of litter-fall in New Zealand}

Total annual greenfall in Sutherland's Bush Reserve equated to only $0.2 \%$ (and cockatoocaused greenfall just $0.08 \%$ ) of the average annual litter-fall (mean $=5297.541 \mathrm{~kg} / \mathrm{ha}$ dry weight, s.d. $=585.29, \mathrm{n}=17$, range $=3357.4-7810 \mathrm{~kg} / \mathrm{ha}$ ) recorded in podocarp-broadleaf forests in the lower North Island, New Zealand (Daniel 1975; Cowan et al. 1985; Cowan and Waddington 1991); however, the cockatoo-caused fall of $D$. cupressinum branches equaled more than $5 \%$ of the total litter-fall biomass of this species recorded in Cowan et al. (1985). Greenfall found in this study was also significantly less $\left(\chi^{2}=53.69\right.$, d.f. $\left.=1, \mathrm{P}<0.001\right)$ than the contribution of greenfall (mean $=51.75 \mathrm{~kg} / \mathrm{ha}$, s.d. $=20.789, \mathrm{n}=4)$ to total litter-fall $($ mean $=3871.425 \mathrm{~kg} / \mathrm{ha}$, s.d. $=585.29, \mathrm{n}=4)$ recorded in a northern temperate deciduous forest by Risley and Crossley (1988). 
It is difficult to estimate the impact this level of defoliation has on individual trees and forest structure as a whole. Insufficient information has been provided here to answer prediction 2, hypothesis 4.2. The long-term effect on the individual trees being defoliated by C. galerita (that is, whether it causes mortality of the tree or not) can not be determined by such a shortterm study. Unless trees are stressed, such as by disease, age or climate, they have been shown to recover from extensive loss of foliage (up to $40 \%$ ), with little or no loss of primary production, and limited defoliation may even stimulate vegetative and reproductive growth (Mattson and Addy 1975; McNaughton 1983; Marquis 1984; Lennartsson et al. 1998; Strauss and Agrawal 1998). The ability of plants to tolerate defoliation varies significantly between individuals and species, and can also be affected by timing (for example, whether early or late in the growing season) and nature (whether from biting or sucking herbivores) of the herbivory, and by variation in light, water and nutrient availability (Mattson and Addy 1975; McNaughton 1983; Marquis 1984; Meijden 1988; Lennartsson et al. 1998; Strauss and Agrawal 1998).

Crawley (1985) found that plant compensation is not fully effective against low-density herbivore populations and slight differences in the level of defoliation between plants may cause important differences in plant fitness. Browsing by T. unpecula, deer and C. bircus has been shown to significantly alter species composition as excessive browsing kills more palatable species (Leathwick et al. 1983; Cowan et al. 1985; Mark 1989; Cowan and Waddington 1990). Such effects can result in a loss of plant diversity within isolated forest communities, and may potentially lead to reduction in the numbers of native birds and invertebrates that rely on these species (Diamond and Veitch 1981; Leathwick et al. 1983).

If the extent of defoliation by C. galerita that was recorded is sufficient to cause the death of some plants then their preference for particular species (mainly D. cupressinum and some epiphytes), combined with the fragmented nature of forested areas in the Turakina Valley, may result in local declines in the abundance, and possibly the extinction of these species. Cacatua galerita may also be having a similar impact in forest patches throughout their range, though differences in the abundance of $C$. galerita, forest composition and in the abundance of food available on adjacent farmland suggest that such effects will vary from place to place.

Alternatively, where there is a considerable understorey vegetation layer, defoliation of the oversorey may even result in an increase in primary production and in plant biomass, as the understorey vegetation compensates with increased growth rates resulting from the increase in light and nutrients available to these plants (Mattson and Addy 1975; Lamb 1985). Such a 
change in forest structure could benefit some native bird species, including $H$. novaeseelandiae and $A$. melanura, which foraged in hardwood trees and shrubs that grew lower in the vegetation profile (which would benefit most from removal or thinning of the emergent layer). However, removing large diameter canopy and emergent trees may have a disproportionately large negative effect on some bird populations (O'Donnell and Dilks 1994). The fruit of $D$. dacrydioides and $D$. cupressinum was an important food source for $P$. novaeseelandiae, $A$. melanura and $H$. novaeseelandiae (this study), and has been shown to be important for successful breeding of $N$. meridionalis, $N$. notabilis and Cyanoramphus spp. (O’Donnell and Dilks 1994). Some populations of these species may be particularly affected if large numbers of $C$. galerita penetrate into areas where they occur.

Diamond and Veitch (1981) and Holdaway (1990) showed diversity of native forest birds decreased with increasing modification of the environment. Furthermore, the diversity and abundance of introduced birds was shown to increase with increasing modification of the flora. The presence of exotic bird species and some recently self-introduced species (for example, silvereyes, Zosterops lateralis) has been associated with the introduction into forest fragments of invasive plant species, particularly those with bird dispersed fruit (Williams and Karl 1996). Factors, such as defoliation of emergent trees by $C$. galerita, that reduce the structural integrity of native forest remnants could provide more suitable habitat for introduced birds that are in turn more likely to introduce weeds that could decrease the quality of the habitat further for native birds and other native fauna.

\subsubsection{Conclusion}

Cacatua galerita did obtain most of their food from introduced vegetation, particularly from cultivated land, pasture (and pasture weeds) and introduced conifers; however, seeds of native trees and shrubs also contributed to the diet of these birds, particularly in autumn.

Cacatua galerita exhibited little direct overlap in resource use with the native forest birds studied here, and are unlikely to affect these species through direct competition for food resources owing to significant differences in their preferred diet. Furthermore, these birds occur at low abundances. Cacatua galerita, the most abundant species, ocurred at less than 2.1 birds $/ \mathrm{km}^{2}$ during autumn, when they exhibited greatest overlap in resource use with native birds, and were unlikely to exploit all of the available resources. 
Impact on native forest patches is predominantly to emergent podocarps (greater than 25 metres in height), in particular D. cupressinum, and their associated epiphytes. As a worst case scenario, the extent of defoliation recorded could result in the death of these plants and their decline, and possible extinction, in forest patches within the range of these birds. Despite this, $D$. cupressinum and many of the epiphytes affected constituted a minor component of vegetation in the reserves in the Turakina Valley, most of which are dominated by the structurally equivalent $D$. dacrydioides and therefore are unlikely to lose much structural integrity.

By creating light gaps, C. galerita could potentially contribute to changes in plant species composition in forest patches by promoting abundance and density of understorey plants, and may also increase the chance of invasion by weeds. However, given their low abundance and lack of significant damage to native trees, C. galerita are unlikely to be a significant modifying force in these forests. This is particularly so given the presence of introduced mammalian browsers and seed predators that, by their size, feeding habits and/or numbers, are significant modifying forces in most if not all forest remnants on farmland throughout the country. 


\section{Chapter 5}

\section{General summary and conclusions}

\subsection{SUMMARY}

This thesis represents the first substantive study of Cacatua galerita in New Zealand. This study was planned to interpret a range of aspects of C. galerita biology in New Zealand, extending research from an initial intensive population study in a New Zealand stronghold (Turakina Valley) to examination of its overall distribution. Analysis of C. galerita distribution in relation to a range of environmental variables, and the characteristics of habitat use, food, movements and social organisation underlying its relationship was undertaken to determine the pattern of invasion of this species in New Zealand. The possible consequences of this invasion were examined in relation to their impacts on agricultural production, native flora and fauna.

Since the species became established in the early 1900's the New Zealand population has gradually expanded. Initially colonies were probably entirely a result of new invasions (stemming from the release or escape of cage birds), but the origin of further populations over more recent years is uncertain. Lack of research on C. galerita in New Zealand means their preferred habitats and potential impact on native biota and agriculture has, until now, been little known. Cacatua galerita in Australia are responsible for considerable, though localised, damage to crops and have successfully adapted to human-induced changes to the environment, especially clearance of forests and planting cereal crops, resulting from the spread of agriculture (Noske 1980). Concerns about the impact of this species on native forest communities and on agriculture in New Zealand prompted this study.

\subsubsection{The role of climate in defining the range of $C$. galerita}

Visual inspection of the mapped distribution of $C$. galerita in New Zealand suggests their range is limited by altitude, or more likely environmental factors that are a function of altitude. For example, direct relationships have been shown to occur between altitude and temperature, rainfall and vegetation (Wardle 1981; Lonsdale 1988). Typically, as altitude increases so too does rainfall, while both temperature and vegetation height decreases. 
A widely accepted hypothesis in biological literature is that species' geographic ranges are limited by climatic factors, and similarly that invading species have a greater chance of success if they are introduced to an area with a climate that matches that in their native range (Caughley et al. 1987; Root 1988b; Walker 1990; Lodge 1993a; Moyle and Light 1996; Holway 1998; Duncan et al. 2001). Within the area of climatic suitability species ranges are affected further by the availability of suitable habitat, such as particular plant species, and for birds the availability of nest sites (Pigeon 1970; Clark et al. 1986; Root 1988a; Gentilli 1992; Brown and Stillman 1993; Gibbons et al. 1994). I tested this hypothesis using the distribution of $C$. galerita as an example. The current distribution of this species in Australia and in New Zealand was matched against a range of environmental factors, including measures of temperature, rainfall, altitude, characteristics of vegetation and intensity of human landuse.

In this study I found that temperature, while a significant factor, was not the only factor influencing the distribution of this species, instead their distribution was defined by a combination of temperature, presence of cultivated land and particular characteristics of vegetation. Some of these variables are likely to be causal, while others are probably correlates of these or of other factors that were not considered in this study.

\subsubsection{Effects of temperature on distribution}

Species ranges are often defined by their upper and lower critical temperature limits (Robbins 1993). Outside these limits, an animals' energetic demands increase due to the energy demanding processes needed to dissipate heat or to maintain a stable body temperature in the face of cooling ambient temperatures.

My data agree with prediction 1 of hypothesis 2.1. In New Zealand C. galerita have not been recorded in areas where the extremes of temperature are outside the limits experienced by this species in Australia.

While the climate in Australia tests the upper limit of tolerance to temperature for $C . g$. galerita, the climate in New Zealand appears to test their lower limit of tolerance, this species not being seen in areas where extreme minimum temperature was below $-9^{\circ} \mathrm{C}$, despite the extensive area available. Within this preferred temperature range C. galerita distribution was further affected by the availability of cultivated land, open woodland (in New Zealand) and of avoidance of areas with low scrub and heath vegetation (Australia). 


\subsubsection{Effects of cultivating land}

The presence of cultivated habitat is important for some species, particularly seed-eating birds and rodents. Seed eating animals are able to find food more easily in these habitats, seeds from arable crops often constituting the bulk of their diet (Pigeon 1970; Noske 1980; Clark et al. 1986; Temby and Emison 1986; Emison and Nicholls 1992; Anderson 1996; Robinson et al. 2001).

The data presented here do support prediction 2 of hypothesis 2.1. Seeds of maize, grasses and introduced pasture weeds constituted the bulk of the diet of C. galerita (together contributing almost $75 \%$ of feeding observations of these birds), including most of their energy intake in winter. Availability of crop seed, particularly in winter, may allow the continued presence of $C$. galerita populations in areas that cooler ambient temperatures in winter might normally prevent them occupying.

While the presence of $C$. galerita in New Zealand (and Australia) did not show a significant response to the presence of exotic forestry (mostly monocultures of Pinus radiata), seeds of both native and exotic conifers are an energy rich source of food and formed a major component of $C$. galerita diet in this study. Exotic conifers are likely to become increasingly important to these birds as more of what is currently grassland is converted to forestry (mostly $P$. radiata).

Absolute abundance and spatial distribution of resources essential for breeding have also been shown to have major impacts on bird populations (Clark et al. 1986; Robinson 2001). An important limiting factor of C. galerita distribution in Australia and New Zealand may be shortage of nest sites. Most nest records from Australia and New Zealand are from hollows in large trees (Higgins 1999). In Australia, height of nest hollows in trees averaged 10-12.7 metres (Higgins 1999). In this study height of nest hollows were above 18 metres, and all nests were in large ( $>20$ metres height) native podocarp trees. Shortage of large trees offering potential nest holes in scrub and heath vegetation and cleared farmland, along with competition for nest holes, for example, with possums (Noske 1980) and other hole nesting species (Green 1983; Greene 1998b), may limit breeding and consequently the establishment of the species in some areas. However, the effect of such characteristics of vegetation and agriculture on the distribution of $C$. galerita may be more complex, for in both New Zealand and Australia post-breeding birds moved to crop growing areas where they concentrated and damaged crops. 


\subsubsection{Gaps in the distribution of C. galerita in New Zealand and Australia}

Hypothesis 2.2 was not supported by my data. Cacatua galerita in New Zealand and C. g. galerita in Australia were not present in all areas that logistic modelling of their distribution predicted would be suitable.

Between 17 and 18 environmental variables (for New Zealand and Australia respectively) were used to model distribution of C. galerita in this study. Many variables were not included, which left approximately $35 \%$ of the variation in distribution of C. g. galerita in Australia and $70 \%$ of variation in the distribution of C. galerita in New Zealand that could not be explained by the best models I produced.

Several reasons were put forward to explain the gaps in distribution that were seen. The arid zone of central Australia and presence of a closely related and possibly functionally equivalent species, C. g. fitzroyii, in northern Australia may have blocked the dispersal of C. g. galerita to areas that might be suitable. In New Zealand, invasion history (where the birds were released) may have played a more important role in determining distribution of $C$. galerita than suitability of the environment. Distinguishing between these hypotheses is not possible on the basis of the evidence presented here.

\subsubsection{Factors of $C$. galerita ecology affecting their distribution}

\subsubsection{Advantages of flock forming behaviour for C. galerita}

Gregariousness in birds has been largely related to the distribution of resources, particularly food (Cannon 1984; Emison and Nicholls 1992). Cacatua galerita is a gregarious species (Higgins 1999), with flocks containing hundreds of individuals being recorded, including in New Zealand. Greatest flock sizes of three species of cockatoos (C. galerita, C. roseicapilla and C. tenuirostris) recorded by Noske (1908) and Emison and Nicholls (1992) were observed when these species were feeding on very concentrated, but transitory cereal and sunflower crops. Smallest flock sizes coincided with when they were feeding on widely distributed and less transitory foods and with when they were breeding. I tested the hypothesis that flock forming behaviour in C. galerita is an adaptation to feeding on temporally available and localised food sources. 
Concentration of food was found to have the greatest effect on flock size, with largest flocks recorded when C. galerita were feeding on maize (very concentrated, but transitory) and smallest mean flock size recorded when they were feeding on less dense and dispersed sources of food. Dispersal to breeding sites, once the concentrated food source available in maize stubbles was removed, contributed towards decreased flock size in spring and summer. Social interaction, for example greater intraspecific aggression, did not appear to have any noticeable effect on flock size.

Aggregation of $C$. galerita from several hundred square kilometres into a single communal roost alongside maize crops in winter reflects its importance to this population. By moving to roost alongside this crop, individual C. galerita reduced the amount of time (especially flying time) needed to forage for food. Time saved in this way was spent resting, the least energy expensive activity.

The gregarious nature of C. galerita is likely to be an important factor in their continued presence in the Turakina Valley, and may have contributed to their successful establishment in New Zealand. Delestrade (1994) found gregarious behaviour in the Alpine chough (Pyrrbocorax graculus) contributed to greater survival of juvenile birds because of the presence in these flocks of experienced adult birds. During winter, adult birds returned to reliable and abundant sources of food, which juveniles accompanying these birds were also able to exploit. The increase in abundance of $C$. galerita in the Turakina Valley study area during autumn was unlikely to have resulted from chance encounters with the maize crop or to an increase in social behaviour that coincided with availability of this crop. Increase in abundance occurred in two influxes just as maize seed was ripening, while there was no increase in social behaviour (instead there was an observed decrease in this activity). The increase in abundance over winter probably reflects the experience of birds within this population, returning to an area (and at a time) where an abundant source of food was available in past years. Juvenile birds accompanying these experienced adults would benefit from their experience, a significant advantage of gregarious behaviour.

\subsubsection{Use of native vegetation by C. galerita}

In Australia, C. galerita prefer the edges of forest alongside grassland and reach greatest abundances where there is a mosaic of woodland and grassland or arable habitats (Emison and Porter 1978; Noske 1980). In such habitats, the forest provides most of their non-food 
resource requirements (such as daytime refuges and night roosts), while most of their food is obtained from the grasses and cereal crops on the adjacent farmland.

In this study I investigated the hypothesis that most resource requirements would be provided by modified (non-native) environments, and that being largely granivorous, $C$. galerita would obtain most food from these environments.

While C. galerita did use native forest remnants in the Turakina Valley, the findings from this research strongly suggest that in New Zealand C. galerita are restricted to areas dominated by exotic grassland and cultivated habitats. The abundance and variety of seed producing plants, providing a year round source of food, were the major reasons for $C$. galerita making greatest use of these habitats. For example, the availability of maize seed in winter was an important factor in allowing these birds to meet the greater energetic demands then. Native forest remnants were found to provide a similar role to forest in Australia, providing day-time refuges, night roosts and nest sites.

\subsubsection{Impact on native forest ecosystems}

The landscape of New Zealand has undergone severe transformations in the last approximately 800 years of human colonisation, from predominantly continuous forest to predominantly grassland, and changes continue to occur. In most areas the remaining native vegetation is being modified (the result of fragmentation and an invasive alien flora and fauna) or cleared completely, while large areas of pasture are converted to exotic plantation forests, or are left to regenerate into scrub and native forest. At the same time many native birds, lizards and insects that were once important in shaping these native habitats have become rare or extinct. Against this background of change it is a formidable task to ascertain the impact that any single mechanism (such as a single species) has made on this environment.

In chapter 4, I examined the impact of $C$. galerita on native habitats in New Zealand, testing the hypotheses that the food requirements of C. galerita are obtained from farmland; and that this species does not significantly impact on native tree and shrub species. This information was obtained from observations of $C$. galerita in the Turakina Valley, where this species has been present for over 70 years. 
As stated previously, most of the food requirements of $C$. galerita were obtained from highly modified farmland habitats. While cereal crops and pasture were very important to this population, these birds foraged more in trees than C. galerita observed by Noske (1980) in Australia, probably reflecting the geater availability of cereal and other seed crops to the Australian population. Not all feeding occurred in exotic vegetation, these birds also exploiting large podocarp trees in native forest remnants, particularly during autumn when these trees were fruiting. Cacatua galerita foraging was characteristic of a sequential specialist, concentrating feeding on the most abundant seed producing species available at the time.

The observed foraging segregation between C. galerita and Anthornis melanura, Hemiphaga novaeseelandiae and Prosthemadera novaeseelandiae is likely to be the result of the largely terrestrial, seed-eating habit of $C$. galerita. Despite this, C. galerita may have an indirect impact on native species through the impact their browsing has on particular trees. Cacatua galerita occasionally heavily defoliated emergent trees in forest remnants, particularly Dacrydium cupressinum and their associated epiphytes, potentially resulting in the removal of some species from these forests. However, the impact $C$. galerita browsing has on these trees and on forest structure is beyond the scope of this study to determine. Cacatua galerita, though relatively large (approximately 895g: Higgins 1999), are uncommon (numbers ranged from 0.7-4.3 birds $/ \mathrm{km}^{2}$ ) and are unlikely to have an immediate broad-scale influence on their environment.

Determining the impact of defoliation of trees by C. galerita on forest remnants is important, although measuring the consequence of this impact could be problematical. Many of the species most severaly affected (such as Dacrydium cupressinum) may live for many hundreds of years over which time the physical appearance of the tree may change as a result of chance events, local environmental factors, or in response to the changing life history of the tree. Proving cause and effect between C. galerita browsing and the altered appearance or death of the tree is therefore not easy. Management of forest remnants (control of invasive plant and animal pests) to promote greater survival and recruitment of juvenile trees to the canopy could easily compensate for any gradual decline of emergent trees resulting from the activity of $C$. galerita and would ensure that the current structure of these forest remnants is maintained. 


\subsection{RECOMMENDATIONS}

\subsubsection{Limitations and achievements of the present study}

During this study (aspects of which have spanned 12-28 months) quantitative behavioural data from a large number of individuals were obtained. I have identified the broad-scaled factors important in defining the distribution of C. galerita, and identified characters of these broad-scaled factors that $C$. galerita use on an everyday basis. As a result of this work we now have a greater understanding of the food and movements of this species that underly its habitat use and abundance. Cacatua galerita in the Turakina Valley demonstrated similar gross temporal changes in social organisation, behaviour and habitat use to populations in Australia (Noske 1980). They are mobile in response to changing availability of food sources and exhibited a complex feeding strategy, displaying evidence of sequential specialisation (O’Donell and Dilks 1994).

There are extensive areas of New Zealand with a climate that matches that of the native range of this species; however, the history of extensive closed forest may not have been suitable for this species. Cacatua galerita (and C. roseicapilla) represent an avian feeding guild (Atkinson and Millener 1991) that is new to New Zealand. Cacatua galerita are an edge species, obtaining most of their non-food resource requirements from forests and their food requirements from adjacent grassland (and more recently from arable crops on farmland). Their presence here has probably only become possible following the clearing of forests and introduction of abundant seed producing grassland species (including cereal crops).

Changes in agricultural landuse practices in New Zealand have important implications for these birds. Recent conversion of large areas of pasture to exotic plantation forests and changes in the area and variety of crops grown are likely to contribute to the increase in size and distribution of C. galerita populations here. Much of the pastoral land converted to forestry (mostly Pinus radiata), or allowed to regenerate into native forest, is in areas where farming is marginal, such as on erosion prone hillsides (Kirkpatrick 1999). Most C. galerita seen feeding on pasture were on highly productive river flats that are unlikely to be converted to forestry or be allowed to revert into native forest. Therefore, planting of these hillsides in exotic conifer forests would provide an additional food source rather than replacing one currently exploited by C. galerita. 


\subsubsection{Recommendations for future research}

\subsubsection{Breeding biology}

Demographic studies of C. galerita would clarify whether:

- $\quad$ populations are increasing; and

- which populations are contributing to this increase.

Information related to breeding biology, such as the size dimensions of nest hollows, could also be used to predict the potential for overlap with native hole nesting and/or roosting species, including kaka (Nestor meridionalis), kakariki (Cyanoramphus spp.) and native bats (Chalinolobus tuberculatus and Mystacina tuberculata).

\subsubsection{Banding studies}

Whether the appearance of new colonies of C. galerita, for example on the east coast of the North Island, are the result of new invasions or of dispersal is uncertain. Little is known of the home ranges of C. galerita, or if juveniles disperse away from their natal area, and if so how far they move. An extensive banding study of $C$. galerita would clarify whether these birds are dispersing and if so to what extent dispersal might be contributing to their apparent increase in range. A banding programme could also provide information on the local movement of $C$. galerita, on the relationships between individual birds and on causes and extent of mortality.

\subsubsection{Genetic analysis}

Relatedness between individuals within and between populations can be determined from studies of their DNA, and I recommend such studies be undertaken on C. galerita. While banding studies may show the current patterns of dispersal of this species, historic relationships between flocks, and individuals within flocks, can only be shown through analysis of DNA. This information would provide further evidence of the pattern and rate of dispersal (if it is occurring) of C. galerita in New Zealand. 


\subsubsection{Basal metabolic rate}

Non-passerine birds with a weight approximate to C. galerita have been found to have a lower critical temperature limit (when inactive/resting) of $2.43^{\circ} \mathrm{C}$ (Robbins 1993). This temperature limit is silmilar to the lower mean daily temperature range $\left(3^{\circ} \mathrm{C}\right.$ mean daily minimum temperature) of $C$. galerita in New Zealand, but is well above the extreme minimum recorded temperature range $\left(-9^{\circ} \mathrm{C}\right)$ experienced by these birds. Root $(1988 \mathrm{~b})$ found that winter ranges of 14 bird species in North America are restricted to areas where the energy needed to compensate for a colder environment is not greater than approximately 2.5 times their basal metabolic rate (BMR). Measurement of the BMR of C. galerita could clarify the situation in New Zealand.

\subsubsection{Foraging/ diet studies}

More foraging studies of C. galerita are needed in areas of contrasting cropping regimes, and where cereal crops are not grown. Such research would confirm the importance of cereal crops in influencing local abundances of this species. In such studies, observations of $C$. galerita feeding should be collected in a way that will allow better comparison with recent and/or ongoing feeding studies of native birds that have a similar feeding habit. Evidence of feeding on native invertebrates; which species they are preying on, and their importance to the diet of $C$. galerita, should also be considered in any such feeding study.

Two suggested methods for recording diet of C. galerita are; following individualy marked birds, and analysing stomach contents. Both these methods have drawbacks when applied to this species. Cacatua galerita in the Turakina Valley were highly mobile when foraging and were extremely wary, often fleeing when approached to within a distance where food items could be accurately identified. Furthermore, they foraged in different habitats on a daily and seasonal basis, with some foods constituting a small component of their diet, so large sample sizes of diet and/or foraging records would be required.

- Following individually marked birds

- Before any attempt is made to follow banded birds researchers should determine whether the potential study population is able to be acclimatised to their presence.

- If they cannot be acclimatised to observers then it is unlikely that accurate feeding records will be obtained from all habitats, particularly when they are foraging in dense stands of trees where the observer has to approach close to identify the items being eaten. 
- Analysing stomach contents

- Samples should be taken from many individuals from different diurnal periods throughout the year.

- Obtaining sufficient samples to provide a significant dataset could prove prohibitive.

- There are few populations where this sort of harvest is sustainable.

- These birds are also difficult to shoot and/or trap so large sample sizes will be difficult to obtain.

- Cacatua galerita are valued as part of the local wildlife, or at least as a financial resource, by some individuals. I recommend that prior to undertaking any such sampling consultation be undertaken with the local community. 


\section{Chapter 6}

\section{Options for the management of cockatoos in New Zealand}

\subsection{POTENTIAL IMPACTS OF COCKATOOS IN NEW ZEALAND}

Cockatoos have the potential to be serious pests of cereal and fruit crops, and severe financial losses may be caused in some years (Pigeon 1970; Noske 1980; Long 1985; Halse 1986). Cockatoos also damage fruit and nut trees planted in gardens for local food production or ornamentation, but are more of a nuisance value in these situations. Analyses of parrot damage to crops in Australia showed that the area of crop damaged on each property did not tend to vary greatly in size (Noske 1980; Long 1985; Halse 1986). Smaller crops were more likely to be severely effected. There was also considerable variation in the impact of different species. Cacatua roseicapilla tend to move through an area in small family groups causing widespread, but not intensive damage (Pigeon 1970; Higgins 1999). In Noske (1980) and in the present study, C. galerita formed large aggregations in a localised area causing extensive damage to crops in that area (Pigeon 1970; Noske 1980).

Less is known about the current or potential impact of cockatoos on native biodiversity in New Zealand. In the Turakina Valley C. galerita caused significant impacts on indivudual trees. Browsing by $C$. galerita could lead to declines in the abundance and potentially to localised extinction of some species (for example, Dacrydium cupressinum and Griselinia lucida). Furthermore, by creating light gaps, C. galerita could potentially contribute to changes in plant species composition in these forest patches by promoting abundance and density of understorey plants, and may also increase the chance of invasion by weeds.

Although no significant overlap in resource use was found between C. galerita and native forest birds in this study, modification of forest fragments could cause an indirect effect on these forest bird communities. There are also other species (such as kaka Nestor meridionalis) on which their potential impact is not known. While C. galerita have not been recorded on any of the offshore islands or large forest tracts of the central North Island, another introduced parrot, eastern rosellas (Platycercus eximius), which occupy a similar native range to this species, are encroaching on these areas (Wright and Clout 2001). Offshore islands and large forest tracts act as important refugia for a number of threatened species, including kaka 
(Nestor meridionalis), kakariki (Cyanorampbus spp.) and native short-tailed bats (Mystacina tuberculata), that may be at risk from competition for foraging resources and nest sites with these more aggressive introduced parrots. More detailed research is required to determine if C. galerita can maintain a presence in the central North Island (and the small offshore islands), and whether there is overlap in nest site selection between this species and native hole nesting birds and bats.

\subsection{ISSUES RELATED TO COCKATOO MANAGEMENT}

\subsubsection{The legal status of cockatoos in New Zealand}

Cacatua galerita and C. roseicapilla are considered to have been introduced by humans and so are not given the protection afforded native species. Both are listed in the Fifth Schedule of the Wildlife Act 1953 and are declared unprotected throughout New Zealand (Section 7). As a consequence these birds may be legally captured or killed by any person, although this is subject to other provisions in the Wildlife Act and other factors, such as access to land. Furthermore, the methods used to capture or kill cockatoos must comply with the provisions in the Animal Welfare Act 1999; and if using toxins, the Agricultural Chemicals and Veterinary Medicines and Hazardous Substances and New Organisms Acts.

There is currently confusion amongst landowners regarding the legal status of cockatoos, particularly C. galerita, many considering them to have some form of legal protection (personal obervation). The first step in managing cockatoos should be informing the public of the legal status of these birds, for example through Regional (Animal) Pest Management Strategies. This will empower landowners to deal with most problems that arise from the impact of cockatoos without the need for further input from external agencies.

\subsubsection{Population responses to control}

A widely accepted hypothesis in ecology is that species (or population) ranges are positively related to abundance (Gaston 1996; Gaston and Curnutt 1998). If abundance is reduced then the species range should also be reduced. In the Turakina Valley, C. galerita gathered on one property in winter, and this aggregation may have included all or most of the birds from an area encompassing several hundred square kilometres. A reduction of this flock is likely to reduce the range of this population, potentially affecting presence over hundreds of square 
kilometres. Cacatua roseicapilla are also known to be highly mobile and often congregate in one area. As a consequence control of this species at a particular site might also be expected to affect the population over a much wider area. Some populations could be lost as a result of this control. Cockatoos generally rely on a high adult survival rate to maintain presence (Halse 1986; Higgins 1999). Their habit of travelling in family groups (Higgins 1999) means that birds shot when feeding on crops could be breeding adults. For small populations, loss of these breeding birds could eventually result in extinction.

Although population abundance and range size relationships are generally positive, the response of populations to reduction in range or abundance can be dependent on aspects of the species ecology and behaviour, such as their response to persecution. For example, rooks (Corvus frugilegus) disperse in response to persecution, so may occupy a greater range despite reduced abundance (Purchas 1973; Environment Waikato 1996). Research is required into the response of cockatoos to persecution, and this should be undertaken before management decisions are made.

\subsubsection{Public ownership of a highly mobile and valuable species}

Despite occasional conflicts with individual landowners, C. galerita are generally regarded as part of the community in the Turakina Valley. These birds are also popular for financial reasons. A small industry has arisen around C. galerita, with some farmers leasing access to nests, receiving between $\$ 100$ and $\$ 200$ for every chick taken from their properties. A similar price is paid for adult birds captured on these farms. The number of $C$. galerita removed from the Turakina population each year is unknown, but is unlikely to exceed 20-30 birds, but occasionally this harvest is much greater. In 1994 an extra 74 birds were removed (all from one property), in addition to the usual number taken (P. Corliss personal communication). Large numbers have been captured prior to this, generally by different individuals, but there are no written records of when this has occurred, or of the numbers taken.

Although some level of harvest is accepted by most landowners, excessive harvesting has often resulted in conflict with the local farming community. The attitudes of landowners to these birds could be interpreted as a form of collective ownership. Intense harvesting threatens the production of chicks (and the associated income) on other properties and is viewed by some as threatening the survival of the Turakina population, and this is where conflict with the local community arises. For example, an attempt by the Rangitikei Branch of the Royal Forest and Bird Protection Society to encourage trapping of C. galerita in their 
reserves in the Turakina Valley was brought to a halt by local farmers because it was seen to threaten this population (H. Stewart personal communication). Similarly the individual who took most of the birds in 1994 was eventually stopped and asked to leave, and is no longer welcome on some properties.

Pest managers will face similar problems if they attempt to control C. galerita populations. Often the damage caused by $C$. galerita is localised, affecting a small number of properties (Noske 1980; Long 1985; Halse 1986; this study). Reducing the impact of C. galerita on the affected properties by reducing abundance will almost certainly affect the abundance of birds on neighbouring properties. As a consequence, efforts to control these birds, particularly if the intention is to greatly reduce the numbers of or to eradicate significant populations, would require acceptance from the wider community.

\subsection{MANAGEMENT APPROACH}

\subsubsection{Options for the management of cockatoos}

Cockatoos are introduced species and are almost certainly having a detrimental impact on agricultural production, exotic forestry, and probably individual trees and possibly some species in native habitats throughout their range. Having said this, the financial and biodiversity losses from this impact are localised and unlikely to outweigh the cost of control. Furthermore, cockatoos are popular cage birds, which have successfully established following escapes from captivity in the past and could well do so again if the captive population remains. The benefits from eradicating birds from captivity are also unlikely to outweigh the value owners of these birds place on their pets. Despite this, control of cockatoo populations may be considered where their impact is causing significant financial losses to some individuals, or where they threaten populations of native species. The advantages and disadvantages of three options available for managing the impacts of cockatoos are considered below.

1. Do nothing

2. Site management

- Manage numbers to minimise impacts on sites of importance, such as cereal crops, native forest remnants, or native species. 
3. Species management

- Eradicate populations and/or species from New Zealand.

\subsubsection{Do notbing}

In the do nothing approach control of $C$. galerita (and C. roseicapilla) is left to the individual landowner. This management approach assumes there will be little change, in terms of abundance or impact of these species, and is the management option currently in place.

\section{Advantages:}

- Individual landowners can determine what the acceptable level of impact is and undertake control if and when this level is reached.

- The community retains ownership in their management.

- Options for controlling these birds are more varied and may be more acceptable to local residents than the methods available or acceptable to external agencies. For example, control can be used to provide an income by selling trapped birds.

\section{Disadvantages:}

- Cockatoos are wary, and often difficult to approach, so shooting may not be effective at removing large numbers of individuals. Bird scaring devices are also generally ineffective as birds rapidly adapt to them (Noske 1980; Halse 1986; A. Styche personal observation).

- While individual landowners can act against cockatoos on their own properties, they cannot address the problem if the nuisance animals are arising from a neighbouring property where the owners do not undertake control.

- The abundance of cockatoos that is acceptable to individual landowners might be detrimental to other resources, for example conservation values in native habitats.

- Control carried out by individual landowners could act to disperse these birds.

\subsubsection{Site management}

If the current effort invested in capturing cockatoos for the pet trade (a significant if not the main factor affecting cockatoo abundance in New Zealand) declines, for example, as a result of reduction in the prices paid for cage birds, abundance of some cockatoo populations are likely to increase significantly above the numbers recorded at present. In this scenario, management of cockatoo populations by professional pest managers would have to be 
considered. Management might also be considered where impacts are occurring beyond the effort of individual landowners to control. For example, where large numbers of cockatoos congregate on particular crops and/or important reserves.

\section{Advantages:}

- Professional pest managers have access to a range of control options not available to the general public and are more likely to achieve a greater reduction in the cockatoo population than individual landowners.

- Effort can be concentrated at selected sites minimising the impact on the rest of the population.

- The effort put into control is likely to be more consistent and maintained for a longer term than that of individual landowners.

\section{Disadvantages:}

- Cost of control is likely to exceed financial losses currently being caused by these birds.

- Communities that have aesthetic reasons for retaining cockatoos and/or that benefit financially from the trade in wild caught cockatoos are likely to be resistant to the control efforts of external agencies.

\subsubsection{Species management}

Despite the current lack of significant impact, eradication of at least some populations of cockatoos might be considered and is technically achievable for at least two of the three distinct populations of cockatoos in New Zealand (C. galerita in the South Island and $C$. roseicapilla in the North Island). These populations are localised, the only known population of C. roseicapilla is confined to the South Auckland area, while C. galerita in the South Island are restricted to Banks Peninsula and the Catlins (Southland-Otago). In the North Island, though not common, C. galerita are widespread. The effort involved to eradicate this population (as well as being publicly unacceptable) would far outweigh the financial losses this species is causing, or their risk to biodiversity, although removal of particular colonies might be considered. 


\subsubsection{Methods of control}

A variety of methods have been used to minimise the impact of pest birds on crops. Many of these options involve frightening birds away from a particular crop or area and may not be effective if there is not a suitable alternative food source, or if the birds then move on to damage crops on another property. These methods can be summarised as follows:

\subsubsection{Shooting}

Shooting is a popular method for controlling pest populations of birds. Although shooting may not appreciably reduce numbers of some populations, it can considerably reduce the amount of time they spend feeding in a particular crop (Halse 1986). Shooting is especially effective if dealing with a small number of individuals, particularly if these do not respond to alternative methods (such as scaring devices), or are not able to be trapped.

\subsubsection{Scaring devices}

Scaring devices (such as scare guns) are used to deter birds from recently planted and/or germinating crops that are only vulnerable to damage from these species for a short period. Scaring devices have a limited effectiveness because birds generally become habituated to them, and unless they are combined with occasional shooting (Noske 1980) they are ineffective at deterring birds over a longer period (Noske 1980; personal observation).

\subsubsection{Farm management}

Noske (1980) reviewed several methods used by farmers to reduce the impact of birds (including $C$. galerita) on crops. These methods take advantage of the behaviour of these birds to redirect their impact to less valuable crops or to avoid having ripe seed present in winter when their energy demands are greatest and local abundance increases. Most of these methods require cooperation between individual farmers because these birds range over many properties, so reducing impact on one property could result in increased impacts on another. A brief detail of these methods is given below.

- Timing of crop planting to avoid greater local abundance of cockatoos in winter

- Seed-eating birds that cause damage to cereal crops tend to form large aggregations in winter. By planting crops early they can be harvested before these large flocks form. 
- If maize matured earlier in the year, it is less likely to be damaged by C. galerita because alternative abundant and energy rich foods were available to these birds then, and because they had not yet congregated into the single large flock.

- Decoy crops

- Decoy crops can be planted in areas favoured by birds (for example, in the open and with good allround visibility, and along frequently used flight paths) to distract them from more valuable crops.

- Noske (1980) also suggests decoy crops should be planted earlier than the main crop so that feeding begins there before the main crop ripens.

- Retaining stubble

- In this study C. galerita showed a strong preference for feeding on spilt grain and stubble over seeds on standing plants.

- By harvesting part of a crop early and retaining the stubble (and restricting access to stock), damage to the remaining crop would be minimised.

\subsubsection{Poisons}

Toxins available for bird control in New Zealand are alpha-chloralose and DRC 1339. Most formulations of these poisons are unavailable for use by the general public. Regulations governing the use of toxins in New Zealand further restrict the applications for these chemicals.

- DRC 1339 is a poison that is only registered for use on starlings (Sturnus vulgaris), rooks (Corrus frugilegus) and other corvids so can not be used on cockatoos.

- Alpha-chloralose is a narcotisizing agent that is commercially available in wheat, barley, pea and bird paste baits. No license is required to use baits with a toxin concentration less than $2.5 \%$, but there are potential problems with this product.

- Baits with alpha-chloralose concentration $<2.5 \%$ have not been found to be effective on large birds, such as cockatoos.

- Recent changes to the Acts governing the use of pesticides means that in future bait formulations containing this toxin will have to be registered separately for every target species. At present this toxin has not been registered for either cockatoo species. 


\subsubsection{Traps}

Traps (mostly cage traps, with or without call birds) are the main method used to capture cockatoos for the pet trade. Live-trapping, using cages and calling birds, has also been used successfully for controlling magpies (Gymnorbina tibicen) (P. Russell personal communication) and rainbow lorikeets (Trichoglossus haematodus) (Younger 1999).

Using live-trapping a large number of birds can be captured from a single population, without risking scaring birds and moving them on to other properties. There are also many designs of cage trap available, including the commercially available Larsen trap. This method is also selective, minimising impacts on non-target species, and can be used by the general public in urban and rural areas; however, there are some disadvantages of trapping. For example, the trapper is left with the task of disposing of the live birds. Some birds may also be neophobic and will not be caught in traps. To overcome this, trapping may be combined with other methods, such as shooting. 


\section{References}

ALLAN, H. H. 1961. Flora of New Zealand Volume 1. Indigenous Trachophytes, Psilopsida, Lycopsida, Filicopsida, Gymnosperms, Dicotyledons. Government Printers, Wellington, New Zealand.

ALTMANN, J. 1974. Observational study of behaviour: sampling methods. Behaviour, Volume 49: 227-267.

ANDERSON, A. G. 1977. New Zealand in maps. Holmes and Meier Publishers Incorporated, New York.

ANDERSON, I. 1996. Crops and cockatoos upset a delicate balance. New Scientist, Volume 150 (2036): 10.

ANON 1990. Vegetation. Atlas of Australian Resources Volume 3. Australian Surveying and Land Information Group, Canberra.

ANON 1998. Philip's New Zealand world atlas. Reed Publishing Limited, New Zealand.

ATKINSON, I. A. E. and Greenwood, R. M. 1989. Relationships between moas and plants. Supplement to the New Zealand Journal of Ecology, Volume 12: 67-96.

ATKINSON, I. A. E. and Millener, P. R. 1991. An ornithological glimpse into New Zealand's pre-human past. In: Acta XX Congressus Internationalis Ornithologici. Bell, B. D. (Editor). Pages 129-192.

AUGUSTIN, N. H., Cummins, R. P. and French, D. D. 2001. Exploring spatial vegetation dynamics using logistic regression and a multinomial logit model. Journal of Applied Ecology, Volume 38 (5): 991-1006.

AUSTRALIAN BUREAU OF METEOROLOGY (no date). Climate averages, [Online]. Available: http://www.bom.gov.au/climate/averages/ [2000, May 12].

BAKER, A. R. 1992. Foods of the Bellbird, Tui and New Zealand Pigeon. Notornis, Volume 39 (4): 261-262. 
BELL, B. D. 1991. Recent avifaunal changes and the history of ornithology in New Zealand. In: Acta XX Congressus Internationalis Ornithologici. Bell, B. D. (Editor). Pages 195-230.

BENNETT, M. T. 1978. Sunflower cropping and the bird pest problem - a general appraisal: the status, distribution and abundance of birds involved. In: Aspects of the behaviour and ecology of the White Cockatoo (Cacatua galerita) and Galah (C. roseicapilla) in croplands in north-east New South Wales. Noske, S. 1980. Unpublished Masters Thesis, University of New England, Armidale, New South Wales.

BEN-SHAHAR, R. and Skinner, J. D. 1988. Habitat preferences of African ungulates derived by uni- and multivariate analyses. Ecology, Volume 69 (5): 1479-1485.

BLAKERS, M., Davies, S. J. J. F. and Reilly, P. N. 1984. The atlas of Australian birds. Melbuorne University Press, Australia.

BOEHM, E. F. 1959. Parrots and cockatoos of the Mount Mary Plains, South Australia. Emu, Volume 59: 83-87.

BOON, W. M., Kearvell, J. C., Daugherty, C. H. and Chambers, G. K. 2000. Molecular systematics and conservation of kakariki (Cyanoramphus spp.). Science for Conservation, submitted.

BOWERMAN, B. L., O'Connell, R. T. and Dickey, D. A. 1986. Linear statistical models an applied approach. Duxbury Press, Boston.

BROWN, A. F. and Stillman, R. A. 1993. Bird-habitat associations in the eastern Highlands of Scotland. Journal of Applied Ecology, Volume 30: 31-42.

BUCKINGHAM, R. 1989. Wildlife of the Catlins Region. Unpublished Report, Department of Conservation, Invercargill, New Zealand.

BUCKLAND, S. T. and Elston, D. A. 1993. Empirical models for the spatial distribution of wildlife. Journal of Applied Ecology, Volume 30: 478-495. 
BULL, P. C., Gaze, P. D. and Robertson, C. J. R. 1985. The atlas of bird distribution in New Zealand. Ornithological Society of New Zealand, Wellington, New Zealand.

BULL, P. C. and Whitaker, A. H. 1975. The amphibians, reptiles, birds and mammals. In: Biogeography and ecology in New Zealand. Kuschel, G. (Editor). Dr W. Junk, B. V. Publishers, The Hague.

CANNON, C. E. 1984. Flock size of feeding eastern and pale-headed rosellas (Aves: Psittaciformes). Australian Wildlife Research, Volume 11: 349-355.

CAREY, J. R. 1996a. The incipient Mediterranean fruit fly population in California: implications for invasion biology. Ecology, Volume 77 (6): 1690-1697.

CAREY, J. R. 1996b. The future of the Mediterranean fruit fly Ceratitis capitata invasion of California: a predictive framework. Biological Conservation, Volume 78: 35-50.

CASTRO, I and Robertson, A. W. 1997. Honeyeaters and the New Zealand forest flora: the utilisation and profitability of small flowers. New Zealand Journal of Ecology, Volume 21 (2): 169-179.

CAUGHLEY, G., Short, J., Grigg, G. C. and Nix, H. 1987. Kangaroos and Climate: an analysis of distribution. Journal of Animal Ecology, Volume 56: 751-761.

CHRISTENSEN, R. 1997. Log-linear models and logistic regression. Second Edition. Springer-Verlag, New York.

CLARK, R. G., Titman, R. D., Bider, J. R. and Greenwood, H. $1986 . \quad$ Influence of agricultural land-use practices on bird damage and control. Proceedings of the International Ornithological Congress 19, Volume 1: 464-473.

CLOUT, M. N. and Hay, J. R. 1989. The importance of birds as browsers, pollinators and seed dispersers in New Zealand forests. Supplement to New Zealand Journal of Ecology, Volume 12: 27-33.

COLEMAN, J. D. 1977. The foods and feeding of starlings in Canterbury. Proceedings of the New Zealand Ecological Society, Volume 24: 94-105. 
COWAN, P. E., Waddington, D. C., Daniel, M. J. and Bell, B. D. 1985. Aspects of litter production in a New Zealand lowland podocarp/broadleaf forest. New Zealand Journal of Botany, Volume 23: 191-199.

COWAN, P. E. and Waddington, D. C. 1990. Suppression of fruit production of the endemic forest tree, Elaeocarpus dentatus, by introduced marsupial brushtail possums, Trichosurus mipecula. New Zealand Journal of Botany, Volume 28: 217-224.

COWAN, P. E. and Waddington, D. C. 1991. Litterfall under hinau, Elacocapus dentatus, in lowland podocarp/mixed hardwood forest, and the impact of brushtail possums, Trichosurus vulpecula. New Zealand Journal of Botany, Volume 29: 385-394.

CRAWLEY, M. J. 1985. Reduction of oak fecundity by low-density herbivore populations. Nature, Volume 314: 163-164.

CRIST, T. O. 1998. The spatial distribution of termites in shortgrass steppe: a geostatistical approach. Oecologia, Volume 114: 410-416.

DANIEL, M. J. 1973. Seasonal diet of the ship rat (Rattus r. rattus) in lowland forest in New Zealand. New Zealand Ecological Society, Volume 20: 21-30.

DANIEL, M. J. 1975. Preliminary account of litter production in a New Zealand lowland podocarp-rata-broadleaf forest. New Zealand Journal of Botany, Volume 13: 173-187.

DAUGHERTY, C. H., Gibbs, G. W. and Hitchmough, R. A. 1993. Mega-island or microcontinent? New Zealand and its fauna. TREE, Volume 8 (12): 437-442.

DELESTRADE, A. 1994. Factors affecting flock size in the alpine chough Pyrrbocorax graculus. Ibis, Volume 136: 91-96.

DEVARENNE, C. 1997. SigmaStat statistical software, version 2.03. SPSS software products, SPSS Inc., USA.

DIAMOND, J. M. and Veitch, C. R. 1981. Extinctions and introductions in the New Zealand avifauna: cause and effect? Science, Volume 211: 499-501. 
DUNCAN, R. P. 1997. The role of competition and introduction effort in the success of passeriform birds introduced to New Zealand. American Naturalist, Volume 149: 903-915.

DUNCAN, R. P., Blackburn, T. M. and Veltman, C. J. 1999. Determinants of geographical range sizes: a test using introduced New Zealand birds. Journal of Animal Ecology, Volume 68: $963-975$.

DUNCAN, R. P., Bomford, M., Forsyth, D. M. and Conibear, L. 2001. High predictability in introduction outcomes and the geographical range size of introduced Australian birds: a role for climate. Journal of Animal Ecology, Volume 70 (4): 621-632.

EMISON, W. B. and Nicholls, D. G. 1992. Notes on the feeding patterns of the long billed corella, sulphur-crested cockatoo and galah in southeastern Australia. South Australian Ornithologist, Volume 31: 117-121.

EMISON, W. B. and Porter, J. W. 1978. Summer surveys of birds in the Mt Cobberas Snowy River area of Victoria, Australia. Emu, Volume 78: 126-136.

ENVIRONMENT WAIKATO 1996. Regional Pest Management Strategy: operative 19962001. Environment Waikato Regional Council, Hamilton.

FALLA, R. A. 1953. The Australian element in the avifauna of New Zealand. Emu, Volume 53: 36-46.

FEARE, C. J., Dunnet, G. M. and Patterson, I. J. 1974. Ecological studies of the rook (Corvus frugilegus L.) in north-east Scotland: food intake and feeding behaviour. Journal of Applied Ecology, Volume 11: 867-896.

FLEMING, C. A. 1962. History of the New Zealand land bird fauna. Notornis, Volume 9 (8): $270-274$.

FORSHAW, J. M. 1989. Parrots of the world. Third (revised) Edition. Lansdowne Editions, Melbourne. 
FORSTER, R. R. 1975. The spiders and harvestmen. In: Biogeography and ecology in New Zealand. Kuschel, G. (Editor). Dr W. Junk, B. V. Publishers, The Hague.

FORSYTH, M. D. and Duncan, R. P. 2001. Propagule size and the relative success of exotic ungulate and bird introductions to New Zealand. The American Naturalist, Volume 157 (6): 583-595.

FRIEND, G. R. 1982. Bird populations in exotic pine plantations and indigenous eucalypt forests in Gippsland, Victoria. Emu, Volume 82: 80-91.

FRITH, H. J. (Consultant editor) 1977. Readers Digest complete book of Australian Birds. Readers Digest Services Party Limited, Sydney.

GASTON, K. J. 1996. The multiple forms of the interspecific abundance-distribution relationship. Oikos, Volume 76: 211-220.

GASTON, K. J. and Curnutt, J. L. 1998. The dynamics of abundance-range size relationships. Oikos, Volume 81: 38-44.

GATES, S., Gibbons, D. W., Lack, P. C. and Fuller, R. J. 1994. Declining farmland bird species: modelling geographical patterns of abundance in Britain. In: Large scale ecology and conservation biology. Edwards, P. J., May, R. M. and Webb, N. (Editors). 35 ${ }^{\text {th }}$ Symposium of the British Ecological Society. Blackwell Scientific Publications, Oxford.

GENTILLI, J. 1992. Numerical clines and escarpments in the geographical occurrence of avian species; and a search for relevant environmental factors. Emu, Volume 92: 129-140.

GIBBONS, D., Gates, S., Green, R. E., Fuller, R. J. and Fuller, R. M. 1995. Buzzards Buteo buteo and ravens Corvus corax in the uplands of Britain: limits to distribution and abundance. Ibis, Volume 137: S75-S84.

GILL, B. and Martinson, P. 1991. New Zealand's extinct birds. Random Century, Auckland.

GODLEY, E. J. 1975. Flora and vegetation. In: Biogeography and ecology in New Zealand. Kuschel, G. (Editor). Dr W. Junk, B. V. Publishers, The Hague. 
GOLLEY, F. B. 1961. Energy values of ecological materials. Ecology, Volume 42: 581584.

GREEN, R. E. 1997. The influence of numbers released on the outcome of attempts to introduce exotic bird species to New Zealand. Journal of Animal Ecology, Volume 66: 2535.

GREEN, R. H. 1983. The decline of the eastern rosella and other Psittaciformes in Tasmania concomitant with the establishment of the introduced European starling. Records of the Queen Victoria Museum, Number 82: 1-4.

GREENE, T.C. 1998a. Foraging ecology of the red-crowned parakeet (Cyanoramphus novaezelandiae novaezelandiae) and yellow-crowned parakeet (C. auriceps auriceps) on Little Barrier Island, Hauraki Gulf, New Zealand. New Zealand Journal of Ecology, Volume 22 (2): 161171.

GREENE, T. C. 1998b. Potential impact of rainbow lorikeets released in suburban North Shore, Auckland. Unpublished Environmental Impact Report, Department of Conservation, New Zealand.

GREENWOOD, J. J. D. 1995. Unwelcome immigrants? TREE, Volume 10 (10): 395-396.

HALSE, S. A. 1986. Parrot damage in apple orchards in south-western Australia: a review. Technical Report, Western Australia Department of Conservation and Land Management, Series Number 8 .

HEALY, A. J. and Edgar, E. 1980. Flora of New Zealand Volume 3. Adventive cyperaceous, petalous and spathaceous monocotyledons. R. E. Owen, Government Printer, Wellington, New Zealand.

HEATHER, B. D. and Robertson, H. A. 1996. The field guide to the birds of New Zealand. Viking, Auckland, New Zealand. 
HENDRIX, S. D. 1988. Herbivory and its impact on plant reproduction. In: Plant reproduction ecology: patterns and strategies. Lovett Doust, J. and Lovett Doust, L. (Editors). Oxford University Press, New York. Pages 246-263.

HERBOLD, B. and Moyle, P. B. 1986. Introduced species and vacant niches. The American Naturalist, Volume 128 (5): 751-760.

HESPENHEIDE, H. A. 1975. Prey characteristics and predator niche width. In: Ecology and evolution of communities. Cody, M. L. and Diamond, J. R. (Editors). Harvard University Press, Cambridge, Massachusetts.

HEWITT, G. M. 1989. The subdivision of species by hybrid zones. In: Speciation and its consequences. Otte, D. and Endler, J. A. (Editors). Sinauer Associates Incorporated, Sunderland, Massachusetts.

HIGGINS, P. J. (Senior Editor) 1999. Handbook of Australian, New Zealand, and Antarctic birds, volume 4: parrots to dollarbird. Oxford University Press, Melbourne. Pages: 163176.

HILL, M. O. 1979. TWINSPAN: a FORTRAN program for arranging multivariate data in an ordered two-way table by classification of the individuals and attributes. Ithaca, New York: Cornell University.

HOLDAWAY, R. N. 1989. New Zealand's pre-human avifauna and its vulnerability. Supplement to the New Zealand Journal of Ecology, Volume 12: 11-25.

HOLDAWAY, R. N. 1990. Changes in the diversity of New Zealand forest birds. New Zealand Journal of Zoology, Volume 17: 309-321.

HOLWAY, D. A. 1998. Factors governing rate of invasion: a natural experiment using Argentine ants. Oecologia, Volume 115: 206-212.

HOMBERGER, D. 1991. The evolutionary history of parrots and cockatoos: a model for evolution in the Australian avifauna. In: Acta XX Congressus Internationalis Ornithologici. Bell, B. D. (Editor). Pages 398-403. 
HOSMER, Jr, D. W., and Lemeshow, S. 1989. Applied Logistic Regression. John Wiley \& Sons Inc., USA.

HUBBARD, C. E. 1954. Grasses. Penguin Books, Bungay, Suffolk.

HUTTON, Captain F. W. 1872. The geographical relations of the New Zealand fauna. Transactions of the New Zealand Institute, Volume 5: 1-28.

KENDEIGH, S. C. and West, G. C. 1965. Caloric values of plant seeds eaten by birds. Ecology, Volume 46: 553-555.

KING, C. M. 1984. Immigrant killers. Oxford University Press, Auckland, New Zealand.

KING, C. M. 1990. The handbook of New Zealand mammals. Oxford University Press, Auckland, New Zealand.

KIRKPATRICK, R. 1999. Bateman contemporary atlas New Zealand. David Bateman Ltd, Auckland, New Zealand.

LAMB, D. 1985. The influence of insects on nutrient cycling in eucalypt forests: a beneficial role? Australian Journal of Ecology, Volume 10: 1-5.

LAMBRECHTSEN, N. C. 1992. What grass is that? New Zealand Department of Science and Industrial Research. Fourth Edition. Information Series Number 87. G. P. Publications Ltd.

LANGER, R. H. M. 1973. Pastures and pasture plants. Second Edition. A. H. and A. W. Reed, Wellington, New Zealand.

LEATHWICK, J. R., Hay, J. R. and Fitzgerald, A. E. 1983. The influence of browsing by introduced mammals on the decline of North Island kokako. New Zealand Journal of Ecology, Volume 6: 55-70.

LEGENDRE, S., Clobert, J., Moller, A. P. and Sorci, G. 1999. Demographic stochasticity and social mating system in the process of extinction of small populations: the case of passerines introduced to New Zealand. American Naturalist, Volume 153: 449-463. 
LENNARTSSON, T., Wilsson, P. and Tuomi, J. 1998. Induction of overcompensation in the field gentian Gentianella campestris. Ecology, Volume 79 (3): 1061-1072.

LEPSCHI, B. J. 1993. Food of some birds in eastern New South Wales: additions to Barker and Vestjens. Emu, Volume 93: 195-199.

LEVER, C. 1987. Naturalized birds of the world. Bath Press, Avon.

LEVINS, R. 1968. Evolution in changing environments; some theoretical explorations. Princeton University Press, Princeton, New Jersey.

LODGE, D. M. 1993a. Species invasions and deletions: community effects and responses to climate and habitat change. In: Biotic interactions and global change. Kareiva, P. M., Kingsolver, J. G. and Huey, R. B. (Editors). Sinauer Associates Inc., Sunderland, Massachusetts. Pages 367-387.

LODGE, D. M. 1993b. Biological invasions: lessons for ecology. TREE, Volume 8 (4): 133-137.

LONG, J. L. 1981. Introduced birds of the world. David and Charles, Newton Abbot, London.

LONG, J. L. 1985. Damage to cultivated fruit by parrots in the south of Western Australia. Australian Wildlife Research, Volume 12: 75-80.

LONSDALE, W. M. 1988. Predicting the amount of litterfall in forests of the world. Annals of Botany, Volume 61: 319-324.

MADISON, L. A. and Robel, R. J. 2001. Energy characteristics and consumption of several seeds recommended for northem bobwhite food plantings. Wildlife Society Bulletin, Volume 29 (4): 1219-1227.

MAGRATH, R. and Lill, A. 1983. The use of time and energy by the crimson rosella in a temperate wet forest in winter. Australian Journal of Zoology, Volume 31: 903-912. 
MARCHANT, S. and Higgins, P. J. 1990. Handbook of Australian, New Zealand and Antarctic birds; volume 1: ratites to ducks. Part B: Australian pelican to ducks. Oxford University Press, Melbourne.

MARK, A. F. 1989. Responses of indigenous vegetation to contrasting trends in utilisation by red deer in two south western New Zealand National Parks. Supplement to the New Zealand Journal of Ecology, Volume 12: 103-114.

MARQUIS, R. J. 1984. Leaf herbivores decrease fitness of a tropical plant. Science, Volume 226: 537-539.

MARTIN, J. S. 1962. Sulphur-crested Cockatoo (Kakatoe galerita) photoed near Hunterville. Notornis, Volume 10 (2): 73.

MARTIN, J. S. and Bartlett, J. 1963. Sulphur-crested Cockatoos near Hunterville. Notornis, Volume 10 (5): 241.

MATTSON, W. J. and Addy, N. D. 1975. Phytophagous insects as regulators of forest primary production. Science, Volume 190: 515-522.

MAYR, E. 1965. The nature of colonisations in birds. In: The genetics of colonising species. Baker, H. G. and Stebbins, G. L. (Editors). Academic Press, New York and London.

MCCULLAGH, P. and Nelder, J. A. 1989. Generalized Linear Models. Second Edition. Chapman and Hall, London.

MCEVEY, A. 1965. The birds of the Rutherglen District. Emu, Volume 65: 1-56.

MCEWEN, W. M. 1978. The food of the New Zealand Pigeon (Hemiphaga novaeseelandiae novaeseelandiae). New Zealand Journal of Ecology, Volume 1: 99-108.

MCKENZIE, H. R. 1979. Birds of the Hunua Ranges. Notornis, Volume 26 (1): 105-119. 
MCKLAY, C. L. 1974. The species diversity of New Zealand forest birds: some possible consequences of the modification of beech forests. New Zealand Journal of Zoology, Volume 1 (2): 179-96.

MCNAUGHTON, S. J. 1983. Compensatory plant growth as a response to herbivory. Oikos, Volume 40: 329-336.

MEIJDEN, E. V. D., Wijn, M. and Verkaar, H. J. 1988. Defense and regrowth, alternative plant strategies in the struggle against herbivores. Oikos, Volume 51: 355-363.

MINCHIN, P. R. 1990. DECODA: database for ecological community data, version 2.00 . Australian National University, Australia.

MOOREHOUSE, R. J. 1997. The diet of the North Island kaka Nestor meridionalis septentrionalis) on Kapiti Island. New Zealand Journal of Ecology, Volume 21 (2): 141-152.

MOYLE, P. B. and Light, T. 1996. Fish invasions in California: do abiotic factors determine success? Ecology, Volume 77 (6): 1666-1670.

NOSKE, S. 1980. Aspects of the behaviour and ecology of the White Cockatoo (Cacatua galerita) and Galah (C. roseicapilla) in croplands in north-east New South Wales. Unpublished Masters Thesis, University of New England, Armidale, New South Wales.

O'DONNELL, C. F. J. and Dilks, P. J. 1994. Foods and foraging of forest birds in temperate rainforest, South Westland, New Zealand. New Zealand Journal of Ecology, Volume 18 (2): 87-107.

OLIVER, W. R. B. 1930. New Zealand Birds. Fine Arts New Zealand Ltd, Wellington, New Zealand.

OLIVER, W. R. B. 1955. New Zealand Birds. Second Edition. A. H. and A. W. Reed, Wellington, New Zealand.

OSBORNE, P. E. and Tigar, B. J. 1992. Interpreting bird atlas data using logistic models: an example from Lesotho, southern Africa. Journal of Applied Ecology, Volume 29: 55-62. 
OWEN, M. and Black, J. M. 1991. Geese and their future fortune. Ibis, Volume 133: 2835.

PAYTON, I. J., Pekelharing, C. J. and Frampton, C. M. 1999. Foliar Browse Index: a method for monitoring possum (Trichosurus vulpecula) damage to plant species and forest communities. Manaaki Whenua-Landcare Research, Lincoln, New Zealand.

PEARCE, J. L., Cherry, K., Drielsma, M. Ferrier, S. and Whish, G. 2001. Incorporating expert opinion and fine-scale vegetation mapping into statistical models of faunal distribution. Journal of Applied Ecology, Volume 38: 412-424.

PERROTT, J. K. and Armstrong, D. P. 2000. Vegetation composition and phenology of Mokoia Island, and implications for the reintroduced hihi population. New Zealand Journal of Ecology, Volume 24 (1): 19-30.

PIGEON, R. W. J. 1970. The individual and social behaviour of the Galah Kakatoe roseicapilla) (Vieillot). Unpublished Masters Thesis, University of New England, Armidale, New South Wales.

PLUMB, T. 1982. Agriculture. Atlas of Australian Resources, volume 3. Division of National Mapping, Canberra.

PULLIAM, H. R. 1988. Sources, sinks, and population regulation. American Naturalist, Volume 132: 652-661.

PURCHAS, T. P. G. 1973. The feeding ecology of the rook (Corvus frugilegus frugilegus L.) in the Heretaunga Plains Hawke's Bay. Unpublished $\mathrm{PhD}$ Thesis, Victoria University of Wellington.

RIDPATH, M. G. and Moreau, R. F. 1966. The birds of Tasmania: ecology and evolution. Ibis, Volume 108: 348-393.

RISLEY, L. S. and Crossley, D. A. 1988. Herbivore-caused greenfall in the Southern Appalachians. Ecology, Volume 69 (4): 1118-1127.

ROBBINS, C. T. 1993. Wildlife feeding and nutrition. Second Edition. Academic Press, Incorporated. 
ROBERTSON, C. J. R. (Consultant editor) 1985. Readers Digest complete book of New Zealand birds. Readers Digest, Methuen, Sydney.

ROBINSON, R. A., Wilson, J. D. and Crick, H. Q. P. 2001. The importance of arable habitat for farmland birds in grassland landscapes. Journal of Applied Ecology, Volume 38 (5): 1059-1069.

ROOT, T. 1988a. Environmental factors associated with avian distributional boundaries. Journal of Biogeography, Volume 15: 489-505.

ROOT, T. 1988b. Energy constraints on avian distributions and abundances. Ecology, Volume 69 (2): 330-339.

ROWLEY, I. 1983. Mortality and dispersal of juvenile galahs, Cacatua roseicapilla, in the Western Australian wheatbelt. Australian Wildlife Research, Volume 10: 329-342.

ROWLEY, I., Russell, E. and Palmer, M. 1989. The food preferences of cockatoos: an aviary experiment. Australian Wildlife Research, Volume 16: 19-32.

SALMON, J. T. 1975. The influence of man on the biota. In: Biogeography and ecology in New Zealand. Kuschel, G. (Editor). Dr W. Junk, B. V. Publishers, The Hague.

SALMON, J. T. 1990. The native trees of New Zealand. Revised Edition. Heinemann Reed, Auckland.

SAUNDERS, D. A. 1974. The occurrence of the White-tailed Black Cockatoo, Calyptorbynchus baudinii, in Pinus plantations in Western Australia. Australian Wildlife Research, Volume 1: 45-54.

SAUNDERS, D. A. 1980. Food and movements of the short-billed form of the whitetailed black cockatoo. Australian Wildlife Research, Volume 7: 257-269.

SCHOWALTER, T. D. 1981. Insect herbivore relationship to the state of the host plant: biotic regulation of ecosystem nutrient cycling through ecological succession. Oikos, Volume 37: 126-130. 
SHIGESADA, N., Kawasaki, K. and Takeda, Y. 1995. Modelling stratified diffusion in biological invasions. American Naturalist, Volume 146: 229-251.

SMITH, G. T. and Moore, L. A. 1992. Patterns of movement in the western long billed corella Cacatua pastinator in the south-west of Western Australia. Emu, Volume 92: 19-27.

SMITH, J. N. M., Taitt, M. J., Rogers, C. M., Arcese. P., Keller, L. F., Cassidy, A. L. E. V. and Hochachka, W. M. 1996. A metapopulation approach to the population biology of the song sparrow Melospiza melodia. Ibis, Volume 138: 120-128.

SOKAL, R. R. and Rohlf, F. J. 1981. Biometry: the principles and practice of statistics in biological research. Second Edition. W. H. Freeman and Company, New York.

SORCI, G., Moller, A. P. and Clobert, J. 1998. Plumage dichromatism of birds predicts introduction success in New Zealand. Journal of Animal Ecology, Volume 67: 263-269.

SPEIRS, E. A. H. 1989. Observations of the Sulphur-crested Cockatoos, Cacatua galerita, Latham 1790 (Aves: Psittaciformes), in the Turakina Valley, Rangitikei. Unpublished Report, Royal Forest and Bird Protection Society of New Zealand Incorporated.

SPSS. 1999. SPSS Base 9.0. SPSS Inc., Chicago.

STATSOFT. 1994. STATISTICA for the Macintosh. Statsoft, USA.

STRAUSS, S. Y. and Agrawal, A. A. 1999. The ecology and evolution of plant tolerance to herbivory. TREE, Volume 14 (5): 179-185.

TEMBY, I. D. and Emison, W. B. 1986. Foods of the long-billed Corella. Australian Wildlife Research, Volume 13: 57-63.

TEMPLE, S. A. 1992. Exotic birds: a growing problem with no easy solution. The Auk, Volume 109 (2): 395-397.

THOMSON, G. M. 1922. The naturalisation of animals and plants in New Zealand. Cambridge University Press, London. 
TOWNSEND, C. R. 1991. Exotic species management and the need for a theory of invasion ecology. New Zealand Journal of Ecology, Volume 15 (1): 1-2.

TURBOTT, E. G. 1961. The interaction of native and introduced birds in New Zealand. New Zealand Ecological Society: Proceedings, Number 8: 62-66.

TURBOTT, E. G. (Convener) 1990. Checklist of the birds of New Zealand and the Ross Dependency, Antarctica. Third Edition. Random Century and Ornithological Society of New Zealand, Auckland.

VELTMAN, C. J., Nee, S. and Crawley, M. J. 1996. Correlates of introduction success in exotic New Zealand birds. American Naturalist, Volume 147: 542-557.

VERBEEK, N. A. M. 1972. Daily and annual time budget of the yellow-billed magpie. The Auk, Volume 89: 567-582.

VITOUSEK, P. M., D’Antonio., M. D, Loope, L. L., Rejmánek, M. and Westbrooks, R. 1997. Introduced species: a significant component of human-caused global change. New Zealand Journal of Ecology, Volume 21 (1): 1-16.

WALKER, P. A. 1990. Modelling wildlife distributions using a geographic information system: kangaroos in relation to climate. Journal of Biogeography, Volume 17: 279-289.

WALLER, M. A. 1959. Sulphur-crested Cockatoo at Kaipara Heads. Notornis, Volume 8 (6): 165 .

WARD, I. 1976. New Zealand atlas. Government Printer, Wellington, New Zealand.

WARDLE, P. 1981. Is the alpine timberline set by physiological tolerance, reproductive capacity, or biological interactions? Proceedings of the Ecological Society of Australia, Volume 11: 53-66.

WATT, J. C. 1975. The terrestrial insects. In: Biogeography and ecology in New Zealand. Kuschel, G. (Editor). Dr W. Junk, B. V. Publishers, The Hague. 
WEATHERS, W. W., Buttemer, W. A., Hayworth, A. M. and Nagy, K. A. 1984. An evaluation of time budget estimates of daily expenditure in birds. Auk, Volume 101: 459472.

WEBB, C. J., Sykes, W. R. and Garnock-Jones, P. J. 1988. Flora of New Zealand Volume 4. Naturalised Pteridophytes, Gymnosperms, Dicotyledons. Singapore National Printers Limited, Singapore.

WESTCOTT, D. A. and Cockburn, A. 1988. Flock size and vigilance in parrots. Australian Journal of Zoology, Volume 36: 335-349.

WILLIAMS, G. R. 1973. Birds. In: The natural history of New Zealand: an ecological survey. Williams, G. R. (Editor). A. H. \& A. W. Reed, Wellington. Pages 304-333.

WILLIAMS, M. J. (Chairman) 1983. Gamebird research in New Zealand. Wildlife Research Liaison Group, Research Review, Number 1.

WILLIAMS. P. A. and Karl, B. J. 1996. Fleshy fruits of indigenous and adventive plants in the diet of birds in forest remnants, Nelson, New Zealand. New Zealand Journal of Ecology, Volume 30 (2): 127-145.

WILSON, P. R. 1973. The ecology of the common myna (Acridotheres tristis L.) in Hawke's Bay. Unpublished $\mathrm{PhD}$ Thesis, Victoria University of Wellington, Wellington, New Zealand.

WODZICKI, K. 1965. The status of some exotic vertebrates in the ecology of New Zealand. In: The genetics of colonising species. Baker, H. G. and Stebbins, G. L. (Editors). Academic Press, New York. Pages 425-458.

WRIGHT, D. A. and Clout, M. 2001. The eastern rosella (Platycercus eximius) in New Zealand. Department of Conservation Science Internal Series 18. Department of Conservation, Wellington.

YOUNGER, P. 1999. Rainbow lorikeet action plan: compliance and law enforcement July 1999 - June 2002. Unpublished Report. Department of Conservation, Auckland. 


\section{Appendix 1}

Site records of Cacatua galerita and C. roseicapilla in New Zealand.

\begin{tabular}{|c|c|c|c|c|c|c|}
\hline \multicolumn{7}{|c|}{ Sulphur-crested cockatoo: North Island } \\
\hline \multirow{2}{*}{ Location } & \multirow{2}{*}{ Year } & \multirow{2}{*}{ Month } & \multirow{2}{*}{$\begin{array}{l}\text { No. } \\
\text { seen }\end{array}$} & \multicolumn{2}{|c|}{ Grid Ref. } & \multirow{2}{*}{ Source } \\
\hline & & & & South & East & \\
\hline Aberfeldy's & 1999 & 6 & 6 & & & Wanganui Chronicle \\
\hline Aka Aka & 1991 & 1 & 1 & 3719 & 17449 & CSN (39) 1992 \\
\hline Albany & 1989 & 3 & 1 & 3645 & 17440 & CSN (37) 1990 \\
\hline Aramoho & 1991 & 9 & 2 & 3954 & 17503 & CSN (41) 1994 \\
\hline Arataki Trail & 1986 & 4 & 1 & & & CSN (34) 1987 \\
\hline Awhitu & 1988 & 6 & 2 & 3705 & 17438 & CSN (31) 1984 \\
\hline Birkenhead & 1974 & 10 & 2 & 3649 & 17443 & CSN (22) 1975 \\
\hline Clarks Beach & 1985 & 11 & 8 & 3708 & 17442 & CSN (34) 1987 \\
\hline Clevedon & 1959 & 1 & 2 & 3700 & 17503 & CSN (8) 1959 \\
\hline Clevedon & 1960 & 10 & 1 & 3700 & 17503 & CSN (9) 1960 \\
\hline Clevedon & 1973 & 9 & 2 & 3700 & 17503 & CSN (23) 1976 \\
\hline Clevedon & 1973 & 9 & 2 & 3700 & 17503 & CSN (21) 1974 \\
\hline Clifton Grove & 1995 & 6 & 10 & 3938 & 17701 & CSN (43) 1996 \\
\hline Clive & 1991 & & 7 & 3935 & 17655 & CSN (41) 1994 \\
\hline Clive & 1992 & 8 & 2 & 3935 & 17655 & H. Rook \\
\hline Clive & $1991-96$ & & 4 & 3935 & 17655 & $\begin{array}{l}\text { W. Twydle \& C. } \\
\text { Macrae }\end{array}$ \\
\hline Days Bay & 1991 & 10 & 8 & 4116 & 17454 & CSN (41) 1994 \\
\hline Dry River & 1994 & & 2 & 4118 & 17522 & CSN (43) 1996 \\
\hline Eastbourne & 1991 & 6 & 4 & 4118 & 17454 & CSN (39) 1992 \\
\hline Eastbourne & 1995 & 5 & 13 & 4118 & 17454 & I. Flux \\
\hline Eastbourne & 1999 & & 8 & 4118 & 17454 & B. Wiles \\
\hline Fordell & 1989 & 6 & 5 & 3958 & 17512 & CSN (37) 1990 \\
\hline Fordell & 1999 & 6 & 6 & 3958 & 17512 & Wanganui Chronicle \\
\hline Glen Massey & 1986 & & 10 & 3740 & 17504 & CSN (35) 1988 \\
\hline Glen Massey & 1988 & 10 & 14 & 3740 & 17504 & CSN (37) 1990 \\
\hline Glen Massey & 1993 & 10 & 2 & 3740 & 17504 & CSN (42) 1995 \\
\hline Glen Massey & 1995 & 9 & & 3740 & 17504 & CSN (44) 1997 \\
\hline Glen Massey & 1996 & 3 & & 3740 & 17504 & CSN (44) 1997 \\
\hline Glen Massey & 1997 & 1 & 40 & 3740 & 17504 & CSN (45) 1998 \\
\hline Glen Murray & 1955 & & & 3725 & 17500 & Oliver (1955) \\
\hline Glen Murray & 1963 & & 40 & 3725 & 17500 & $\begin{array}{l}\text { OSNZ Supplement } \\
\text { (1972) }\end{array}$ \\
\hline Glen Murray & 1980 & & 10 & 3725 & 17500 & CSN (31) 1984 \\
\hline Glen Murray & 1983 & 5 & 40 & 3725 & 17500 & CSN (31) 1984 \\
\hline Glen Murray & 1990 & 1 & 1 & 3725 & 17500 & CSN (38) 1991 \\
\hline Glenbrook & 1987 & 6 & 5 & 3712 & 17445 & CSN (35) 1988 \\
\hline Hakariamata & 1996 & 1 & 1 & 3740 & 17504 & CSN (44) 1997 \\
\hline Hastings & 1989 & & 2 & 3939 & 17651 & CSN (38) 1991 \\
\hline Hastings & 1990 & & 6 & 3939 & 17651 & CSN (38) 1991 \\
\hline
\end{tabular}




\begin{tabular}{|c|c|c|c|c|c|c|}
\hline Hastings & 1991 & 6 & 2 & 3939 & 17651 & CSN (39) 1992 \\
\hline Havelock North & 1989 & 1 & 2 & 3945 & 17655 & CSN (37) 1990 \\
\hline Havelock North & 1989 & & 6 & 3945 & 17655 & CSN (38) 1991 \\
\hline Havelock North & 1990 & 10 & 5 & 3945 & 17655 & CSN (39) 1992 \\
\hline Havelock North & 1990 & & 11 & 3945 & 17655 & CSN (39) 1992 \\
\hline Havelock North & 1991 & 7 & 4 & 3945 & 17655 & CSN (41) 1994 \\
\hline Helensville & 1986 & 1 & 8 & 3641 & 17427 & CSN (34) 1987 \\
\hline Horotiu & 1995 & 4 & 55 & 3742 & 17512 & D. Emmett \\
\hline Horsham Downs & 1992 & 5 & & 3742 & 17515 & CSN (41) 1994 \\
\hline Houhora & 1971 & & 3 & 3448 & 17306 & Notornis (1971) \\
\hline Huia & 1976 & 3 & 1 & 3700 & 17434 & CSN (23) 1976 \\
\hline Hunterville & 1962 & & & 3955 & 17530 & Martin (1962) \\
\hline Hunterville & 1987 & 5 & 3 & 3955 & 17530 & CSN (35) 1988 \\
\hline Huntly & 1995 & 4 & 55 & 3734 & 17510 & CSN (43) 1996 \\
\hline Huntly & 1995 & 4 & 5 & 3734 & 17510 & CSN (43) 1996 \\
\hline Hunua & 1930 & & & 3705 & 17504 & Oliver (1930) \\
\hline Hunua hills & 1955 & & & 3705 & 17505 & Oliver (1955) \\
\hline Hunua hills & 1989 & & 2 & 3705 & 17505 & CSN (37) 1990 \\
\hline Judgeford & 1986 & 10 & 11 & 4105 & 17455 & CSN (35) 1988 \\
\hline Judgeford & 1996 & 4 & 40 & 4105 & 17455 & A. Styche \\
\hline Kaawa flats & 1972 & & 23 & 3731 & 17453 & CSN (20) 1973 \\
\hline Kai Iwi & 1998 & & & 3951 & 17456 & R. Grant \\
\hline Kai Iwi & 1999 & 6 & 20 & 3951 & 17456 & Wanganui Chronicle \\
\hline Kaiaua & 1975 & 8 & & 3707 & 17518 & CSN (23) 1976 \\
\hline Kaiaua & 1993 & 9 & 2 & 3707 & 17518 & CSN (42) 1995 \\
\hline Kaiaua hills & 1976 & & & 3706 & 17513 & CSN (24) 1977 \\
\hline Kaipara Heads & 1959 & 5 & 1 & 3626 & 17414 & Waller (1959) \\
\hline Karaka & 1987 & 5 & 30 & 3706 & 17452 & CSN (35) 1988 \\
\hline Karaka & 1988 & 8 & 2 & 3706 & 17452 & CSN (37) 1990 \\
\hline Karapiro & 1988 & 3 & 1 & 3800 & 17530 & CSN (36) 1989 \\
\hline Karioitahi & 1980 & 5 & 50 & 3716 & 17441 & CSN (28) 1981 \\
\hline Karori & 1999 & 2 & 1 & 4117 & 17444 & A. Styche \\
\hline Kawakawa Bay & 1986 & 8 & 1 & 3657 & 17509 & CSN (35) 1988 \\
\hline Korokoro & 1989 & 7 & 3 & 4113 & 17452 & R. Hichmough \\
\hline Korokoro & 1989 & 1 & 6 & 4113 & 17452 & CSN (37) 1990 \\
\hline Koromatua & 1991 & 5 & 30 & 3750 & 17512 & CSN (39) 1992 \\
\hline Kotemaori & 1989 & 1 & 1 & 3904 & 17702 & R. Brockie \\
\hline Kumeu & 1982 & 7 & 7 & 3647 & 17434 & CSN (31) 1984 \\
\hline Kumeu & 1983 & 8 & 8 & 3647 & 17434 & CSN (32) 1985 \\
\hline Kumeu & 1984 & 4 & 2 & 3647 & 17434 & CSN (32) 1985 \\
\hline Kumeu & 1987 & 5 & 10 & 3647 & 17434 & CSN (35) 1988 \\
\hline Lake Areare & 1995 & 4 & 200 & 3740 & 17512 & CSN (44) 1997 \\
\hline Lake Papaitonga & 1999 & 8 & 10 & 4039 & 17513 & C. Watts \\
\hline Lake Rotoiti & 1983 & 5 & 4 & 3800 & 17625 & CSN (31) 1984 \\
\hline Lake Rotoiti & 1995 & & & 3803 & 17626 & A. Styche \\
\hline Lake Rotokauri & 1992 & 3 & 8 & 3746 & 17512 & CSN (41) 1994 \\
\hline
\end{tabular}




\begin{tabular}{|c|c|c|c|c|c|c|}
\hline Lake Westmere & 1982 & 7 & 5 & 3954 & 17459 & CSN (31) 1984 \\
\hline Lake Westmere & 1995 & 8 & 3 & 3954 & 17459 & CSN (44) 1997 \\
\hline Lichfield & 1993 & & & 3807 & 17549 & J. Dodgson \\
\hline Limestone Downs & 1987 & 4 & 100 & 3729 & 17446 & CSN (35) 1988 \\
\hline Limestone Downs & 1987 & 5 & 11 & 3729 & 17446 & CSN (35) 1988 \\
\hline Maioro Forest & 1984 & 2 & 90 & 3722 & 17444 & CSN (32) 1985 \\
\hline Maioro Forest & 1987 & 11 & 35 & 3722 & 17444 & CSN (36) 1989 \\
\hline Maioro Forest & 1991 & 7 & 1 & 3722 & 17444 & CSN (41) 1994 \\
\hline Mangamahu & 1986 & 5 & 50 & 3949 & 17522 & CSN (34) 1987 \\
\hline Mangamahu & 1993 & & & 3949 & 17522 & R. Grant \\
\hline Mangamahu & 1999 & 6 & 50 & 3949 & 17522 & Wanganui Chronicle \\
\hline Mangatangi Road & 1992 & 4 & 5 & 3708 & 17511 & CSN (41) 1994 \\
\hline Mangatangi Road & 1994 & 5 & 18 & 3708 & 17511 & CSN (43) 1996 \\
\hline Mangatangi Road & 1995 & 5 & 22 & 3708 & 17511 & CSN (43) 1996 \\
\hline Mangatawhiri Dam & 1995 & 10 & 1 & 3705 & 17508 & CSN (44) 1997 \\
\hline Manurewa & 1982 & 2 & 1 & 3700 & 17455 & CSN (30) 1983 \\
\hline Manurewa & 1986 & 10 & 1 & 3700 & 17455 & CSN (35) 1988 \\
\hline Maraetotara & 1987 & 9 & 1 & 3938 & 17659 & CSN (36) 1989 \\
\hline Marakopa & 1995 & 9 & 2 & 3818 & 17445 & CSN (44) 1997 \\
\hline Massey University & $1993-95$ & & & 4023 & 17537 & D. Armstrong \\
\hline Masterton & 1989 & 6 & 1 & 4057 & 17539 & G. Foster \\
\hline Matira & 1982 & 10 & 4 & 3735 & 17451 & CSN (31) 1984 \\
\hline Melling & 1991 & 8 & 8 & 4112 & 17454 & CSN (41) 1994 \\
\hline Miranda & 1994 & 5 & 14 & 3711 & 17519 & CSN (42) 1995 \\
\hline Miranda & 1996 & 6 & 1 & 3711 & 17519 & CSN (44) 1997 \\
\hline Mohaka & 1989 & & 1 & 3907 & 17712 & R. Hichmough \\
\hline Mount Curl & 1958 & 4 & 10 & 3957 & 17530 & CSN (8) 1959 \\
\hline Mount Karioi & 1995 & 4 & & 3752 & 17448 & CSN (43) 1996 \\
\hline Muriwai Beach & 1963 & 9 & 1 & 3646 & 17423 & $\begin{array}{l}\text { OSNZ Supplement } \\
(1972)\end{array}$ \\
\hline Napier & 1992 & 3 & 2 & 3930 & 17654 & CSN (41) 1994 \\
\hline New Plymouth & 1982 & 5 & 1 & 3904 & 17404 & CSN (31) 1984 \\
\hline Ngaruawahia & 1996 & 4 & 22 & 3740 & 17508 & C. Annandale \\
\hline Ngataringa Bay & 1982 & 9 & 1 & 3649 & 17446 & CSN (31) 1984 \\
\hline Normandale & 1988 & 10 & 15 & 4112 & 17453 & CSN (38) 1991 \\
\hline Normandale & 1989 & & 15 & 4112 & 17453 & CSN (38) 1991 \\
\hline Normandale & 1991 & 2 & 15 & 4112 & 17453 & CSN (39) 1992 \\
\hline Normandale & 1999 & & 15 & 4112 & 17453 & M. McIntyre \\
\hline One Tree Hill & 1988 & 11 & 2 & 3654 & 17448 & CSN (37) 1990 \\
\hline Onewhero & 1955 & & & 3720 & 17455 & Oliver (1955) \\
\hline Onewhero & 1964 & 6 & 200 & 3720 & 17455 & $\begin{array}{l}\text { OSNZ Supplement } \\
(1972)\end{array}$ \\
\hline Onewhero & 1976 & & 40 & 3720 & 17455 & CSN (23) 1976 \\
\hline Onewhero & 1980 & 2 & 13 & 3720 & 17455 & CSN (28) 1981 \\
\hline Oratia & 1988 & 12 & 2 & 3655 & 17437 & CSN (37) 1990 \\
\hline Orere & 1960 & & 1 & 3659 & 17513 & CSN (9) 1961 \\
\hline Otanewainuku & 1984 & 10 & 2 & 3754 & 17612 & CSN (33) 1986 \\
\hline
\end{tabular}




\begin{tabular}{|c|c|c|c|c|c|c|}
\hline Otorahanga & 1991 & 1 & 1 & 3811 & 17513 & CSN (39) 1992 \\
\hline Paekakariki Hill & 1991 & 4 & 5 & 4106 & 17455 & CSN (39) 1992 \\
\hline Pahiatua & 1985 & 10 & 1 & 4030 & 17550 & CSN (34) 1987 \\
\hline Pahiatua & 1987 & 6 & 4 & 4030 & 17550 & CSN (35) 1988 \\
\hline Pahiatua & 1996 & 3 & 2 & 4030 & 17550 & C. Morris \\
\hline Pahongina Reserve & 1986 & & 30 & 4011 & 17548 & R. Hichmough \\
\hline Pahongina Reserve & 1986 & 8 & 3 & 4011 & 17548 & CSN (35) 1988 \\
\hline Pahongina Reserve & 1987 & 7 & 2 & 4011 & 17548 & CSN (36) 1989 \\
\hline Pahongina Reserve & $1992-96$ & & 4 & 4011 & 17548 & K. Mills \\
\hline Pakohu Reserve & $1992-96$ & & 4 & 4011 & 17548 & K. Mills \\
\hline Panganui Road & 1972 & & 6 & & & CSN (20) 1973 \\
\hline Papakura & 1972 & 11 & & 3704 & 17457 & CSN (20) 1973 \\
\hline Papakura & 1987 & 3 & 1 & 3704 & 17457 & CSN (35) 1988 \\
\hline Papakura & $1960-79$ & 7 & & 3704 & 17457 & R. Brockie \\
\hline Papamoa & 1991 & 8 & 6 & 3744 & 17618 & CSN (41) 1994 \\
\hline Parakao & 1994 & 11 & 2 & 3543 & 17357 & CSN (43) 1996 \\
\hline Paraparaumu & 1987 & 5 & 4 & 4055 & 17500 & D. Stracy \\
\hline Paraparaumu & 1989 & 11 & 1 & 4055 & 17500 & D. Stracy \\
\hline Paraparaumu & 1990 & 4 & 10 & 4055 & 17500 & CSN (38) 1991 \\
\hline Paraparaumu & 1990 & 5 & 1 & 4055 & 17500 & CSN (38) 1991 \\
\hline Paraparaumu & 1992 & 6 & 12 & 4055 & 17500 & CSN (41) 1994 \\
\hline Paraparaumu & 1992 & 12 & 1 & 4055 & 17500 & D. Stracy \\
\hline Paremoremo & 1999 & 5 & 37 & 3645 & 17439 & G. Pullam \\
\hline Parua Bay & 1986 & 11 & 1 & 3547 & 17427 & CSN (35) 1988 \\
\hline Pauatahanui & 1990 & 3 & 5 & 4106 & 17455 & CSN (39) 1992 \\
\hline Pauatahanui & 1993 & 8 & 2 & 4106 & 17455 & CSN (42) 1995 \\
\hline Pauatahanui & 1993 & 9 & 6 & 4106 & 17455 & CSN (42) 1995 \\
\hline Pauatahanui & 1998 & 4 & 5 & 4106 & 17455 & A. McLagan \\
\hline Pirongia & 1986 & 8 & 1 & 3800 & 17510 & CSN (35) 1988 \\
\hline Port Waikato & 1962 & & 2 & 3725 & 17445 & Martin (1962) \\
\hline Port Waikato & 1975 & 10 & 1 & 3725 & 17445 & CSN (23) 1976 \\
\hline Port Waikato & 1981 & 7 & 18 & 3725 & 17445 & CSN (30) 1983 \\
\hline Port Waikato & 1984 & 9 & 2 & 3725 & 17445 & CSN (33) 1986 \\
\hline Port Waikato & 1985 & & 16 & 3725 & 17445 & CSN (34) 1987 \\
\hline Pukekohe East & 1982 & 4 & 1 & 3712 & 17457 & CSN (30) 1983 \\
\hline Pukekohe East & 1987 & 5 & 40 & 3712 & 17457 & CSN (35) 1988 \\
\hline Puni-Mauku & 1985 & 6 & 18 & 3713 & 17450 & CSN (33) 1986 \\
\hline Puniu River & 1960 & & & 3801 & 17513 & CSN (9) 1961 \\
\hline Rangiuru School & 1988 & 7 & 4 & 3747 & 17622 & CSN (37) 1990 \\
\hline Rangiuru School & 1990 & 8 & 3 & 3747 & 17622 & CSN (39) 1992 \\
\hline Rangiuru School & 1991 & 5 & 4 & 3747 & 17622 & CSN (39) 1992 \\
\hline Rangiuru School & 1991 & 8 & 6 & 3747 & 17622 & CSN (41) 1994 \\
\hline Rangiuru School & 1991 & 9 & 2 & 3747 & 17622 & CSN (41) 1994 \\
\hline Rangiuru School & 1993 & 8 & 17 & 3747 & 17622 & CSN (42) 1995 \\
\hline Rangiuru School & 1995 & 5 & 11 & 3747 & 17622 & CSN (43) 1996 \\
\hline Rangiuru School & 1996 & 4 & 10 & 3747 & 17622 & CSN (44) 1997 \\
\hline
\end{tabular}




\begin{tabular}{|c|c|c|c|c|c|c|}
\hline Rangiuru School & 1997 & 5 & 12 & 3747 & 17622 & CSN (45) 1998 \\
\hline Rangiuru School & 1997 & 6 & & 3747 & 17622 & CSN (45) 1998 \\
\hline Rata & 1985 & 6 & 40 & 4000 & 17531 & CSN (33) 1986 \\
\hline Reikorangi & 1994 & 10 & 1 & 4054 & 17505 & CSN (43) 1996 \\
\hline $\begin{array}{l}\text { Rimutaka State } \\
\text { Forest Park }\end{array}$ & 1990 & 12 & 2 & 4121 & 17455 & CSN (39) 1992 \\
\hline $\begin{array}{l}\text { Rimutaka State } \\
\text { Forest Park }\end{array}$ & 1992 & 1 & 4 & 4121 & 17455 & CSN (41) 1994 \\
\hline $\begin{array}{l}\text { Rimutaka State } \\
\text { Forest Park }\end{array}$ & 1993 & 12 & 1 & 4121 & 17455 & A. Styche \\
\hline $\begin{array}{l}\text { Rimutaka State } \\
\text { Forest Park }\end{array}$ & 1996 & & 12 & 4121 & 17455 & I. Morrison \\
\hline Riverhead & 1974 & 12 & 2 & 3646 & 17436 & CSN (22) 1975 \\
\hline Rock Hills & 1996 & 1 & 5 & 4040 & 17600 & H. Stoffregen \\
\hline Seatoun & 1991 & 6 & 3 & 4119 & 17450 & CSN (39) 1992 \\
\hline Seatoun & 1996 & & 2 & 4119 & 17450 & B. Bell \\
\hline Silverhope & 1999 & 8 & 1 & 3958 & 17532 & A. Styche \\
\hline Stokes Valley & 1990 & 9 & 1 & 4111 & 17459 & CSN (39) 1992 \\
\hline Sutherland's Bush & 1955 & & & 3955 & 17522 & Oliver (1955) \\
\hline Sutherland's Bush & 1963 & & 400 & 3955 & 17522 & $\begin{array}{l}\text { Martin and Bartlett } \\
\text { (1963) }\end{array}$ \\
\hline Sutherland's Bush & 1977 & 1 & 14 & 3955 & 17522 & CSN (24) 1977 \\
\hline Sutherland's Bush & 1979 & 9 & 12 & 3955 & 17522 & D. Stracy \\
\hline Sutherland's Bush & 1981 & 3 & 4 & 3955 & 17522 & CSN (29) 1982 \\
\hline Sutherland's Bush & 1987 & 4 & 20 & 3955 & 17522 & R. Brockie \\
\hline Sutherland's Bush & 1989 & 4 & 128 & 3955 & 17522 & Speirs (1989) \\
\hline Taradale & 1989 & 9 & 2 & 3932 & 17651 & CSN (38) 1991 \\
\hline Taradale & 1990 & 6 & 4 & 3932 & 17651 & CSN (38) 1991 \\
\hline Te Awanga & 1989 & 2 & 1 & 3938 & 17659 & CSN (37) 1990 \\
\hline Te Kohanga & 1986 & 8 & 1 & 3719 & 17451 & CSN (35) 1988 \\
\hline Te Kowhai & 1992 & 4 & & 3744 & 17509 & CSN (41) 1994 \\
\hline Te Mata Peak & 1990 & & 4 & 3942 & 17655 & CSN (39) 1992 \\
\hline Te Puke & 1990 & 8 & 15 & 3747 & 17620 & CSN (39) 1992 \\
\hline Te Puke & 1991 & 2 & 8 & 3747 & 17620 & CSN (39) 1992 \\
\hline Te Puke & 1994 & 9 & 3 & 3747 & 17620 & CSN (43) 1996 \\
\hline Te Puroa & 1991 & 7 & 1 & 3742 & 17506 & L. Barea \\
\hline Totara Reserve & 1981 & 9 & 11 & 4011 & 17548 & CSN (30) 1983 \\
\hline Totara Reserve & 1996 & & 20 & 4011 & 17548 & J. Adams \\
\hline Totara Reserve & 1996 & 10 & 6 & 4011 & 17548 & CSN (45) 1998 \\
\hline Totara Reserve & 1993-95 & & & 4011 & 17548 & D. Armstrong \\
\hline Tukituki River & 1986 & 12 & 3 & 3936 & 17657 & CSN (35) 1988 \\
\hline Tukituki River & 1994 & 12 & 2 & 3936 & 17657 & CSN (43) 1996 \\
\hline Turakina & $1960-79$ & & 4 & 4003 & 17513 & R. Grant \\
\hline Turakina Valley & 1987 & 7 & 4 & 3955 & 17520 & CSN (36) 1989 \\
\hline Turakina Valley & 1987 & 12 & 14 & 3955 & 17520 & CSN (36) 1989 \\
\hline Turakina Valley & 1988 & 5 & 60 & 3955 & 17520 & D. Stracy \\
\hline Turakina Valley & 1989 & 5 & 11 & 3955 & 17520 & CSN (37) 1990 \\
\hline Turakina Valley & 1993 & 3 & 40 & 3955 & 17520 & D. Stracy \\
\hline
\end{tabular}




\begin{tabular}{|c|c|c|c|c|c|c|}
\hline Waiatarua & 1990 & 12 & 7 & 3656 & 17435 & CSN (39) 1992 \\
\hline Waikanae & 1989 & & & 4055 & 17505 & CSN (38) 1991 \\
\hline Waikanae & 1990 & 1 & 15 & 4055 & 17505 & CSN (39) 1992 \\
\hline Waikanae & 1992 & 6 & 14 & 4055 & 17505 & CSN (41) 1994 \\
\hline Waikanae & 1996 & 7 & 1 & 4055 & 17505 & CSN (45) 1998 \\
\hline Waikanae & 1997 & 4 & 10 & 4055 & 17505 & CSN (45) 1998 \\
\hline Waikaretu & 1969 & 10 & 130 & 3733 & 17450 & $\begin{array}{l}\text { OSNZ Supplement } \\
(1972)\end{array}$ \\
\hline Waimutu Stream & 1999 & & & 4001 & 17516 & A. Styche \\
\hline Waingaro & 1969 & & 5 & 3741 & 17500 & $\begin{array}{l}\text { OSNZ Supplement } \\
(1972)\end{array}$ \\
\hline Waingaro & 1984 & 9 & 7 & 3741 & 17500 & CSN (33) 1986 \\
\hline Waingaro & 1987 & 9 & 29 & 3741 & 17500 & CSN (36) 1989 \\
\hline Waingaro & 1991 & 12 & 12 & 3741 & 17500 & CSN (41) 1994 \\
\hline Waingaro & 1993 & 12 & 1 & 3741 & 17500 & CSN (42) 1995 \\
\hline Waingaro & 1996 & 1 & 1 & 3741 & 17500 & CSN (43) 1996 \\
\hline Wainuiomata & 1950 & 10 & 1 & 4115 & 17457 & CSN (4) 1951 \\
\hline Wainuiomata & 1955 & & & 4115 & 17457 & Oliver (1955) \\
\hline Wainuiomata & 1990 & 10 & 12 & 4115 & 17457 & CSN (39) 1992 \\
\hline Wainuiomata & 1990 & 12 & 2 & 4115 & 17457 & CSN (39) 1992 \\
\hline Wainuiomata & 1996 & 12 & & 4115 & 17457 & R. Hichmough \\
\hline Wairamarama & 1972 & & 7 & 3725 & 17452 & CSN (20) 1973 \\
\hline Wairamarama & 1983 & 8 & 53 & 3725 & 17452 & CSN (32) 1985 \\
\hline Wairamarama & 1984 & 2 & 40 & 3725 & 17452 & CSN (32) 1985 \\
\hline Wairamarama & 1985 & 6 & 200 & 3725 & 17452 & CSN (33) 1986 \\
\hline Wairamarama & 1985 & & 140 & 3725 & 17452 & CSN (34) 1987 \\
\hline Wairamarama & 1987 & 5 & 111 & 3725 & 17452 & CSN (35) 1988 \\
\hline Wairamarama & 1988 & 5 & 136 & 3725 & 17452 & CSN (36) 1989 \\
\hline Wairamarama & 1988 & 5 & 181 & 3725 & 17452 & CSN (36) 1989 \\
\hline Wairamarama & 1989 & 2 & 83 & 3725 & 17452 & CSN (37) 1990 \\
\hline Wairamarama & 1990 & 2 & 60 & 3725 & 17452 & CSN (38) 1991 \\
\hline Wairamarama & 1993 & 7 & 80 & 3725 & 17452 & CSN (42) 1995 \\
\hline Wairamarama & 1993 & 12 & 40 & 3725 & 17452 & CSN (42) 1995 \\
\hline Wairamarama & 1994 & 3 & 40 & 3725 & 17452 & CSN (42) 1995 \\
\hline Wairamarama & 1997 & 1 & 20 & 3725 & 17452 & CSN (45) 1998 \\
\hline Wairarapa & 1990 & 2 & 6 & & & CSN (38) 1991 \\
\hline Wairere & 1985 & 8 & 5 & 3605 & 17419 & CSN (34) 1987 \\
\hline Waitakere & 1922 & & & 3653 & 17432 & Thomson (1922) \\
\hline Waitakere & 1985 & 8 & 2 & 3653 & 17432 & CSN (34) 1987 \\
\hline Waitakere & 1986 & 9 & 2 & 3653 & 17432 & CSN (35) 1988 \\
\hline Waitakere & 1988 & 9 & 13 & 3653 & 17432 & CSN (37) 1990 \\
\hline Waitakere & 1989 & 1 & 12 & 3653 & 17432 & CSN (37) 1990 \\
\hline Waitakere & 1990 & 1 & 1 & 3653 & 17432 & CSN (37) 1990 \\
\hline Waitakere & 1996 & 9 & 4 & 3653 & 17432 & CSN (45) 1998 \\
\hline Waitakere & 1999 & & 60 & 3653 & 17432 & CSN (37) 1990 \\
\hline Waiuku State Forest & 1978 & & & 3722 & 17444 & CSN (26) 1979 \\
\hline Waiuku State Forest & 1980 & & 1 & 3722 & 17444 & CSN (29) 1982 \\
\hline
\end{tabular}




\begin{tabular}{lcccccl}
\hline Waiuku State Forest & 1982 & 5 & 2 & 3722 & 17444 & CSN (30) 1983 \\
Waiuku State Forest & 1983 & 8 & 62 & 3722 & 17444 & CSN (32) 1985 \\
Waiuku State Forest & 1986 & 11 & 27 & 3722 & 17444 & CSN (35) 1988 \\
Waiuku State Forest & 1991 & 4 & 4 & 3722 & 17444 & CSN (39) 1992 \\
Waiuku State Forest & 1993 & 12 & 1 & 3722 & 17444 & CSN (42) 1995 \\
Wanganui & 1972 & & 1 & 3956 & 17503 & OSNZ Supplement \\
Wanganui & 1991 & 12 & 4 & 3956 & 17503 & CSN (41) 1994 \\
Wanganui & 1992 & 5 & 2 & 3956 & 17503 & CSN (41) 1994 \\
Weber & 1992 & 10 & 2 & 4024 & 17619 & C. Duffy \\
Wellsford & 1930 & & & 3618 & 17431 & Oliver (1930) \\
Wellsford & 1955 & & & 3618 & 17431 & Oliver (1955) \\
Whangarei & 1977 & 8 & 1 & 3543 & 17419 & CSN (24) 1977 \\
Whatawhata & 1994 & 10 & 2 & 3748 & 17509 & CSN (43) 1996 \\
Whatawhata & 1995 & 4 & 5 & 3748 & 17509 & D. Emmett \\
& & & & & & \\
\hline
\end{tabular}

\begin{tabular}{lcccccc}
\hline & \multicolumn{5}{c}{ Sulphur-crested cockatoo: South Island } \\
Location & Year & Month & No. & \multicolumn{2}{c}{ Grid Ref. } & \\
& & & seen & South & East & Source \\
\hline Charleston & 1983 & 2 & 2 & 4155 & 17125 & CSN (31) 1984 \\
Cooptown & 1990 & 6 & 7 & 4345 & 17249 & CSN (38) 1991 \\
Cooptown & 1992 & & & 4345 & 17249 & CSN (41) 1994 \\
Cooptown & 1995 & 3 & 16 & 4345 & 17249 & CSN (43) 1996 \\
Diamond Harbour & 1950 & & 5 & 4338 & 17244 & A. and J. Cartman \\
Gorge Road & 1989 & 1 & 1 & 4630 & 16845 & CSN (37) 1990 \\
Greendale & 1985 & 8 & 6 & 4335 & 17205 & CSN (34) 1987 \\
Greymouth & 1983 & 3 & 1 & 4227 & 17112 & CSN (31) 1984 \\
Greymouth & 1984 & & 1 & 4227 & 17112 & CSN (33) 1986 \\
Inchbonnie & 1987 & 12 & 1 & 4244 & 17129 & CSN (36) 1989 \\
Kaituna Valley & 1989 & 5 & 4 & 4347 & 17239 & CSN (37) 1990 \\
Lake Forsyth & 1991 & 8 & 9 & 4348 & 17245 & CSN (41) 1994 \\
Lake Ryan & 1982 & 3 & 1 & 4243 & 17121 & CSN (30) 1983 \\
Little River & 1975 & & & 4345 & 17245 & A. and J. Cartman \\
Little River & 1985 & & & 4345 & 17245 & H. Wilson \\
Little River & 1994 & 7 & 7 & 4345 & 17245 & CSN (43) 1996 \\
Little River & 1995 & 12 & 2 & 4345 & 17245 & CSN (45) 1998 \\
Little River & 1996 & 3 & 30 & 4345 & 17245 & A. Hutt \\
Little River & 1996 & & 20 & 4345 & 17245 & H. Wilson \\
Maclennan & 1982 & & 3 & 4632 & 16928 & Buckingham (1989) \\
Okuti Valley & 1987 & 7 & 1 & 4347 & 17249 & CSN (36) 1989 \\
Port Levy & 1989 & 12 & 4 & 4339 & 17249 & CSN (38) 1991 \\
Pounawea & 1985 & 12 & 3 & 4630 & 16945 & CSN (34) 1987 \\
Pounawea & 1996 & & & 4630 & 16945 & P. Milelland \\
Prices Valley & 1993 & & 40 & 4347 & 17240 & CSN (42) 1995 \\
Prices Valley & 1994 & 7 & 14 & 4347 & 17240 & CSN (43) 1996 \\
Prices Valley & 1995 & 4 & 17 & 4347 & 17240 & CSN (43) 1996 \\
& & & & & & \\
& & & & & &
\end{tabular}




\begin{tabular}{lccccll}
\hline Prices Valley & 1996 & & 30 & 4347 & 17240 & A. Hutt \\
Rahui & 1990 & 11 & 1 & 4150 & 17150 & CSN (39) 1992 \\
Tahakopa & 1985 & 1 & 1 & 4631 & 16923 & Buckingham (1989) \\
Te Kinga & 1990 & 11 & 1 & 4236 & 17130 & CSN (39) 1992 \\
& & & & & & \\
\hline
\end{tabular}

\begin{tabular}{|c|c|c|c|c|c|c|}
\hline \multirow{3}{*}{ Location } & \multirow{3}{*}{ Year } & \multicolumn{4}{|c|}{ Galah, North and South Island } & \multirow{3}{*}{ Source } \\
\hline & & \multirow{2}{*}{ Month } & \multirow{2}{*}{$\begin{array}{l}\text { No. } \\
\text { seen }\end{array}$} & \multicolumn{2}{|c|}{ Grid Ref. } & \\
\hline & & & & South & East & \\
\hline Bombay & 1988 & 4 & 4 & 3712 & 17459 & CSN (36) 1989 \\
\hline Clevedon & 1959 & 1 & 2 & 3700 & 17503 & CSN (8) 1960 \\
\hline Clevedon & 1989 & 2 & 8 & 3700 & 17503 & CSN (37) 1990 \\
\hline Clevedon & 1993 & 7 & 2 & 3700 & 17503 & CSN (42) 1995 \\
\hline Clevedon & 1994 & 4 & 3 & 3700 & 17503 & CSN (42) 1995 \\
\hline Mangatawhiri & 1983 & 9 & 3 & 3713 & 17507 & CSN (36) 1989 \\
\hline Mangatawhiri & 1988 & 5 & 8 & 3713 & 17507 & CSN (36) 1989 \\
\hline Mangatawhiri & 1994 & 8 & 2 & 3713 & 17507 & CSN (43) 1996 \\
\hline Mangatawhiri & 1997 & 4 & 50 & 3713 & 17507 & CSN (45) 1998 \\
\hline Mangatawhiri & 1997 & 6 & 22 & 3713 & 17507 & CSN (45) 1998 \\
\hline Mangatawhiri & 1999 & 4 & 28 & 3713 & 17507 & OSNZ News (1999) \\
\hline Mangatawhiri Dam & 1995 & 7 & 16 & 3705 & 17508 & CSN (44) 1997 \\
\hline Mangatawhiri Dam & 1996 & 6 & 17 & 3705 & 17508 & CSN (44) 1997 \\
\hline Maraetai & 1993 & 8 & 5 & 3653 & 17502 & CSN (42) 1995 \\
\hline Muriwai Beach & 1975 & & 1 & 3646 & 17423 & I. Flux \\
\hline Pakihi Island & 1987 & 9 & 6 & 3655 & 17510 & CSN (36) 1989 \\
\hline Pakihi Island & 1988 & 8 & 5 & 3655 & 17510 & CSN (37) 1990 \\
\hline Ponui Island & 1988 & 1 & 13 & 3653 & 17510 & CSN (36) 1989 \\
\hline Ponui Island & 1991 & 10 & 34 & 3653 & 17510 & CSN (41) 1994 \\
\hline Ponui Island & 1994 & 9 & 16 & 3653 & 17510 & CSN (43) 1996 \\
\hline Pureora & 1999 & & 1 & 3832 & 17537 & T. Green \\
\hline Rotowaro & 1989 & 4 & 1 & 3735 & 17505 & CSN (37) 1990 \\
\hline Winchmore & 1994 & 5 & 1 & 4350 & 17145 & CSN (42) 1995 \\
\hline Woodhill & 1975 & 6 & 1 & 3646 & 17423 & CSN (22) 1975 \\
\hline
\end{tabular}




\section{Appendix 2}

Variation in the number of Cacatua galerita present in the vicinity of the Turakina Valley study area. Based on information gathered from 15 questionnaires (from 80 distributed in June 1993) returned by local residents. Numbers given represent the number of responses to each category for every question.

Question 1. Please indicate during which period(s) over the past twelve months you have been aware of cockatoos on or flying over your property.

\begin{tabular}{lcccc}
\hline & Summer & Autumn & Winter & Spring \\
\hline Central & 2 & 2 & 2 & 2 \\
North & 4 & 4 & 3 & 3 \\
South & 1 & 1 & 1 & 1 \\
Mangahoe & 1 & 2 & 1 & 2 \\
Mangara & 3 & 3 & 3 & 4 \\
West & 2 & 2 & 2 & 2
\end{tabular}

Question 2. Were cockatoos roosting at night on your property at any stage?

\begin{tabular}{lcccc}
\hline & Summer & Autumn & Winter & Spring \\
\hline Central & 1 & 1 & 1 & 2 \\
North & 1 & 1 & 1 & 1 \\
South & & & & \\
Mangahoe & & 1 & & 2 \\
Mangara & 1 & 1 & 2 & 3 \\
West & 1 & 1 & 1 & 1
\end{tabular}

Question 3. Were there noticeable differences in the number of cockatoos in your area between seasons? If so, could you please indicate for each season if cockatoo numbers increased/no change/decreased.

\begin{tabular}{|c|c|c|c|c|}
\hline \multicolumn{5}{|c|}{ Turakina Valley study area (central) } \\
\hline & Summer & Autumn & Winter & Spring \\
\hline decrease & & 1 & & 2 \\
\hline no change & 2 & & 2 & \\
\hline increase & 1 & 2 & 1 & 1 \\
\hline \multicolumn{5}{|c|}{ Turakina Valley north of study area (north) } \\
\hline & Summer & Autumn & Winter & Spring \\
\hline decrease & & & 2 & \\
\hline no change & 2 & 2 & 1 & 2 \\
\hline increase & 1 & 1 & & \\
\hline
\end{tabular}




\begin{tabular}{|c|c|c|c|c|}
\hline \multicolumn{5}{|c|}{ Turakina Valley south of study area (south) } \\
\hline & Summer & Autumn & Winter & Spring \\
\hline \multicolumn{5}{|l|}{ decrease } \\
\hline $\begin{array}{l}\text { no change } \\
\text { increase }\end{array}$ & 1 & 1 & 1 & 1 \\
\hline \multicolumn{5}{|c|}{ Mangahoe Valley east of study area (mangahoe) } \\
\hline & Summer & Autumn & Winter & Spring \\
\hline decrease & 2 & & & \\
\hline no change & & 2 & 2 & \\
\hline increase & & & & 2 \\
\hline
\end{tabular}

\begin{tabular}{lcccc}
\hline \multicolumn{4}{l}{ Mangara Stream south-east of study area (mangara) } \\
& Summer & Autumn & Winter & Spring \\
\hline decrease & & 1 & & 1 \\
no change & 3 & 2 & 4 & 2 \\
increase & & 1 & & 1 \\
& & & & \\
\hline
\end{tabular}

\begin{tabular}{lcccc}
\hline \multicolumn{2}{l}{ Whangaehu Valley west of study area (west) } & & \\
& Summer & Autumn & Winter & Spring \\
\hline decrease & 2 & 1 & 1 & \\
no change & 2 & 1 & 1 & 2 \\
increase & & & &
\end{tabular}




\section{Appendix 3}

Vegetation composition of 100 plots in Sutherland's Bush Reserve (from a vegetation survey undertaken in April 1994). Values represent number of individual plants of each species or species group.

\begin{tabular}{|c|c|c|c|c|c|c|c|c|c|c|c|}
\hline \multirow[t]{2}{*}{ Species } & \multirow{2}{*}{$\begin{array}{c}\text { Stem } \\
\text { diameter } \\
(\mathrm{mm})\end{array}$} & \multicolumn{10}{|c|}{ Plot number } \\
\hline & & 1 & 2 & 3 & 4 & 5 & 6 & 7 & 8 & 9 & 10 \\
\hline \multirow[t]{2}{*}{ Alectryon excelsus } & $0-100$ & 4 & 6 & 13 & 2 & 6 & 23 & 13 & 2 & 19 & 1 \\
\hline & $100+$ & 19 & 4 & 13 & 1 & 5 & 8 & 7 & & 1 & 3 \\
\hline \multirow[t]{2}{*}{ Aristotelia serrata } & $0-100$ & & & & & & & & & & \\
\hline & $100+$ & & & & & & & & & & \\
\hline \multirow[t]{2}{*}{ Beilschmiedia tawa } & $0-100$ & & 12 & 3 & 1 & & 1 & 7 & 7 & 7 & 7 \\
\hline & $100+$ & 2 & 19 & 2 & 2 & 3 & 9 & 10 & 10 & 13 & 3 \\
\hline Brachiglottis repanda & $0-100$ & & & & & & 1 & & & 1 & \\
\hline Carpodetus serratus & $\begin{array}{l}0-100 \\
100+\end{array}$ & & & & & & & & & & \\
\hline Climbing ferns 1 & - & & 10 & 6 & 2 & 4 & 4 & 2 & 5 & 5 & 3 \\
\hline Coprosma grandifolia & $0-100$ & & & & & & & & 2 & & \\
\hline Cordyline australis & $\begin{array}{l}0-100 \\
100+\end{array}$ & & & & & & & & & & \\
\hline Corynocarpus laevigatus & $0-100$ & 1 & & & & & & & & & \\
\hline Cyathea spp. ${ }^{2}$ & - & & & & 2 & & & & 2 & 1 & \\
\hline \multirow[t]{3}{*}{ Dacrycarpus dacrydioides } & $0-100$ & & & & & & & & 82 & 26 & 8 \\
\hline & $100-500$ & & & & & & 1 & & 3 & 6 & \\
\hline & $500+$ & & 1 & & & & 3 & 1 & & & \\
\hline \multirow[t]{3}{*}{ Dacrydium cupressinum } & $0-100$ & & & & & & & & & & \\
\hline & $100-500$ & & & & & & 1 & & & & \\
\hline & $500+$ & & & & 3 & & & & & & \\
\hline \multirow[t]{2}{*}{ Dead tree ${ }^{3}$} & $0-100$ & 1 & 1 & 2 & & 2 & & 1 & 2 & 3 & 2 \\
\hline & $100+$ & 1 & & 2 & & 3 & 2 & 1 & 7 & 2 & \\
\hline Dysoxylum spectabile & $0-100$ & & & & & & & & & & \\
\hline Earina spp. ${ }^{4}$ & - & 1 & & & 1 & & & 1 & & 1 & \\
\hline \multirow{2}{*}{ Elaeocarpus dentatus } & $0-100$ & & & & & & & & & & \\
\hline & $100+$ & & & & & & & & & & \\
\hline Elaeocarpus bookerianus & $100+$ & & & & & & & & & & \\
\hline Epiphytic ferns ${ }^{5}$ & - & & 1 & & 5 & 1 & 4 & 6 & 1 & & \\
\hline \multirow[t]{2}{*}{ Geniostoma rupestre } & $0-100$ & & 8 & 3 & 4 & 11 & 5 & 2 & 18 & 8 & 5 \\
\hline & $100+$ & & & & & & & & & & \\
\hline Griselinia lucida & $0-100$ & & & & & & & & & & \\
\hline Ground ferns ${ }^{6}$ & - & 12 & 39 & 72 & 32 & 47 & 95 & 51 & 27 & 108 & 99 \\
\hline \multirow[t]{2}{*}{ Hedycarya arborea } & $0-100$ & & & & & & & & 2 & & \\
\hline & $100+$ & & & & & & & & & & \\
\hline \multirow[t]{2}{*}{ Hoheria populnea } & $0-100$ & 1 & & 7 & & & & 2 & & 1 & 2 \\
\hline & $100+$ & & & & & & & & & 2 & 1 \\
\hline \multirow[t]{2}{*}{ Knightia excelsa } & $0-100$ & & & 8 & & & & 5 & 7 & & 3 \\
\hline & $100+$ & & & 1 & 2 & & 1 & 1 & & & 1 \\
\hline \multirow[t]{2}{*}{ Kunzea ericoides } & $0-100$ & & & & & & & & & & \\
\hline & $100+$ & & & & & 11 & & & & 1 & \\
\hline Laurelia novae-zelandiae & $0-100$ & & & & & & & & & 4 & 1 \\
\hline
\end{tabular}




\begin{tabular}{|c|c|c|c|c|c|c|c|c|c|c|c|}
\hline & $100+$ & & & & & & & & & 1 & \\
\hline Leucopogon fasciculatus & $0-100$ & & & & & & & & & & \\
\hline Lonicera japonica & - & & & & & & & & & & \\
\hline Lophomyrtus bullata & $0-100$ & & & & & & & & & & 3 \\
\hline \multirow{2}{*}{ Macropiper excelsum } & $0-100$ & & & & & & 1 & & & & \\
\hline & $100+$ & & & & & & & & & & \\
\hline \multirow[t]{2}{*}{ Melicytus ramiflorus } & $0-100$ & 57 & 18 & 6 & 5 & 35 & 10 & 14 & 2 & 49 & 21 \\
\hline & $100+$ & 2 & 4 & 5 & 5 & & 5 & 1 & 6 & 2 & 6 \\
\hline Metrosideros diffusa & - & & & 7 & 1 & & & 3 & 10 & 14 & 11 \\
\hline Microlaena avanacea & - & 4 & 4 & 41 & 1 & 80 & 25 & 28 & 23 & 12 & 18 \\
\hline Mueblenbeckia complexa & - & & & & & & & & & & \\
\hline \multirow[t]{2}{*}{ Myrsine australis } & $0-100$ & 52 & 7 & & 1 & 16 & 6 & 13 & 2 & & \\
\hline & $100+$ & & & & & & & & 1 & & \\
\hline Nest epiphytes ${ }^{7}$ & - & 2 & 5 & & 19 & 1 & 13 & 17 & 7 & 1 & \\
\hline \multirow{2}{*}{ Nestegis spp. ${ }^{8}$} & $0-100$ & & & & & 2 & & & & & \\
\hline & $100+$ & 2 & 1 & & & 2 & & & 1 & 1 & \\
\hline \multirow[t]{2}{*}{ Olearia rani } & $0-100$ & & & & & & & & & & \\
\hline & $100+$ & & & & & & & & & & \\
\hline Parsonsia heterophylla & - & 1 & & 2 & & 2 & 1 & 1 & 1 & 1 & \\
\hline \multirow{2}{*}{ Pennantia corymbosa } & $0-100$ & & & & & & & & & 1 & 1 \\
\hline & $100+$ & 3 & & & & & & & & & \\
\hline Pittosporum cornifolium & $0-100$ & & & & 1 & & & & & & \\
\hline \multirow[t]{2}{*}{ Pittosporum engenioides } & $0-100$ & & & & & & & & & & \\
\hline & $100+$ & & & & & & & & & & \\
\hline \multirow[t]{2}{*}{ Pittosporum tenuifolium } & $0-100$ & & & & & & & & & & \\
\hline & $100+$ & & & & & & & & & & \\
\hline \multirow[t]{3}{*}{ Podocarpus totara } & $0-100$ & & & & & & & & 2 & & \\
\hline & $100-500$ & & & & & 1 & & & & & \\
\hline & $500+$ & & & & & 1 & & & & & \\
\hline \multirow[t]{3}{*}{ Prumnopitys taxifolia } & $0-100$ & 1 & & 2 & & 1 & & 1 & 6 & & \\
\hline & $100-500$ & 1 & & & 3 & & & & & 1 & \\
\hline & $500+$ & & & & 1 & & & & & & \\
\hline Pseudopanax arboreus & $0-100$ & & & & & & & & & & \\
\hline \multirow[t]{2}{*}{ Pseudopanax crassifolius } & $0-100$ & & & & 1 & 2 & & & 7 & & \\
\hline & $100+$ & & & & & & & & 1 & & \\
\hline Rhopalostylas sapida & $0-100$ & & & & & & & & & & \\
\hline Ripogonum scandens & - & 27 & 32 & 38 & 19 & & 36 & 10 & 20 & 38 & 34 \\
\hline Rubus australis & - & 1 & & & & & & & & & \\
\hline \multirow[t]{2}{*}{ Schefflera digitata } & $0-100$ & & & & & & & & & & 7 \\
\hline & $100+$ & & & & & & & & & & \\
\hline \multirow[t]{2}{*}{ Small leaved divaricates ${ }^{9}$} & $0-100$ & 81 & 16 & 15 & 2 & 72 & 25 & 35 & 16 & 16 & 4 \\
\hline & $100+$ & & & & 1 & & & & & 1 & \\
\hline \multirow[t]{2}{*}{ Sophora tetraptera } & $0-100$ & & & & & & & & & & \\
\hline & $100+$ & & & & & & & & & & \\
\hline Tetrapathaea tetrandra & - & & & & & & & & & 1 & \\
\hline Aspect & & 340 & 168 & 40 & 270 & 0 & 0 & 0 & 0 & 0 & 0 \\
\hline Slope & & 6 & 3 & 11 & 38 & 3 & 9 & 0 & 0 & 0 & 0 \\
\hline Canopy height (m) & & 15 & 15 & 10 & 15 & 15 & 15 & 15 & 10 & 15 & 15 \\
\hline Canopy open/closed (cl) & & $\mathrm{cl}$ & $\mathrm{cl}$ & pen & $\mathrm{cl}$ & open & pen & $\mathrm{cl}$ & pen & $\mathrm{cl}$ & $\mathrm{cl}$ \\
\hline
\end{tabular}


${ }^{1}=$ Blechnum filiforme, Phymatosorus scandens

${ }^{2}=$ Cyathea dealbata, C. smithii

${ }^{3}=$ Standing dead trees

${ }^{4}=$ Earina autumnalis, E. mucronatus

${ }^{5}=$ Asplenium flacidum, $A$. polyodon, Lycopodium varium

${ }^{6}=$ Asplenium bulbiferum, Blechnum spp.

${ }^{7}=$ Astelia solandri, Collospermum bastatum

${ }^{8}=$ Nestegis cunninghamii, N. Lanceolata

${ }^{9}=$ Coprosma ramnoides, Melicope simplex, Melicytus micranthus, Pseudopanax anomalous

Species identification and names sourced from:

Allan (1961)

Healy and Edgar (1980)

Salmon (1990)

B. Sneddon perssonal communication

J. Dawson persersonal communication 


\begin{tabular}{|c|c|c|c|c|c|c|c|c|c|c|c|}
\hline \multirow[t]{2}{*}{ Species } & \multirow{2}{*}{$\begin{array}{c}\text { Stem } \\
\text { diameter } \\
(\mathbf{m m})\end{array}$} & \multicolumn{10}{|c|}{ Plot number } \\
\hline & & 11 & 12 & 13 & 14 & 15 & 16 & 17 & 18 & 19 & 20 \\
\hline \multirow[t]{2}{*}{ Alectryon excelsus } & $0-100$ & 24 & 3 & 6 & 25 & 25 & 2 & 2 & 2 & 5 & $\overline{42}$ \\
\hline & $100+$ & & & 17 & 6 & 2 & 1 & 11 & 9 & 14 & \\
\hline \multirow[t]{2}{*}{ Aristotelia serrata } & $0-100$ & & & & & & & & & & \\
\hline & $100+$ & & & & & & & & & & \\
\hline \multirow[t]{2}{*}{ Beilschmiedia tawa } & $0-100$ & 13 & 1 & 2 & 1 & 5 & & & 6 & 2 & \\
\hline & $100+$ & 4 & 7 & 2 & 6 & & 2 & & 2 & 5 & 2 \\
\hline Brachiglottis repanda & $0-100$ & & 1 & & & & & & & & \\
\hline \multirow[t]{2}{*}{ Carpodetus serratus } & $0-100$ & & & & & & & & & & \\
\hline & $100+$ & & & & & & & & & & \\
\hline Climbing ferns1 & - & 2 & 3 & 16 & 7 & 9 & & 3 & 2 & 2 & 17 \\
\hline Coprosma grandifolia & $0-100$ & & 7 & & 1 & 2 & 6 & & & & \\
\hline \multirow[t]{2}{*}{ Cordyline australis } & $0-100$ & & & & & & 2 & & & & \\
\hline & $100+$ & & & & & & & & & & \\
\hline Corynocarpus laevigatus & $0-100$ & & & & & & & & & & \\
\hline Cyathea spp. ${ }^{2}$ & - & & 1 & & & & & & & & \\
\hline \multirow[t]{3}{*}{ Dacrycarpus dacrydioides } & $0-100$ & 12 & & 1 & 1 & 12 & 1 & & & & \\
\hline & $100-500$ & 1 & 1 & & & 3 & & & & & \\
\hline & $500+$ & 2 & & & 1 & & & 2 & 2 & 1 & 3 \\
\hline \multirow[t]{3}{*}{ Dacrydium cupressinum } & $0-100$ & & & & & & & & & & \\
\hline & $100-500$ & & & & & 1 & & & & & \\
\hline & $500+$ & & & & & & & & & & \\
\hline \multirow[t]{2}{*}{ Dead tree ${ }^{3}$} & $0-100$ & 1 & 3 & & 5 & 2 & & 2 & 2 & & 2 \\
\hline & $100+$ & 4 & 2 & 1 & & & & 1 & & 1 & 3 \\
\hline Dysoxylum spectabile & $0-100$ & 1 & & & & & & & & & \\
\hline Earina spp. ${ }^{4}$ & - & 2 & & 1 & 1 & & & & & & \\
\hline \multirow[t]{2}{*}{ Elaeocarpus dentatus } & $0-100$ & & & & & & & & & & \\
\hline & $100+$ & & & & & & & & & & \\
\hline Elaeocarpus hookerianus & $100+$ & 4 & & & & & & & & & \\
\hline Epiphytic ferns ${ }^{5}$ & - & 1 & & & 4 & & 1 & 3 & 1 & & 2 \\
\hline \multirow[t]{2}{*}{ Geniostoma rupestre } & $0-100$ & 16 & 40 & 1 & 1 & 6 & 15 & 1 & 2 & 2 & 9 \\
\hline & $100+$ & 1 & & & & & & & & & \\
\hline Griselinia lucida & $0-100$ & & & & & & & & & & \\
\hline & - & 44 & 38 & 95 & 80 & 53 & 28 & 41 & 74 & 89 & 59 \\
\hline \multirow[t]{2}{*}{ Hedycarya arborea } & $0-100$ & 2 & & & & & & & & & \\
\hline & $100+$ & & & & & & & & & & \\
\hline \multirow[t]{2}{*}{ Hoheriapopulnea } & $0-100$ & 1 & & 1 & 4 & & & & & 1 & \\
\hline & $100+$ & & & & & & & & & & \\
\hline \multirow[t]{2}{*}{ Knightia excelsa } & $0-100$ & 4 & & 3 & 8 & & & & & 3 & 1 \\
\hline & $100+$ & & & & & & & & & & 2 \\
\hline \multirow[t]{2}{*}{ Kunzea ericoides } & $0-100$ & & & & & & & & & & \\
\hline & $100+$ & & 8 & & & 4 & 7 & & & & 8 \\
\hline Laurelia novae-zelandiae & $0-100$ & & & & & & & & & & \\
\hline & $100+$ & & & & & & & & & & \\
\hline Leucopogon fasciculatus & $0-100$ & & & & & & 2 & & & & \\
\hline Lonicera japonica & - & & & & & & & & & & \\
\hline Lophomyrtus bullata & $0-100$ & 1 & & 1 & & 2 & & & & & 1 \\
\hline Macropiper excelsum & $0-100$ & & & 2 & & & & & & & \\
\hline & $100+$ & & & & & & & & & & \\
\hline Melicytus ramiflorus & $0-100$ & 4 & 28 & 30 & 32 & 26 & 13 & 41 & 7 & 21 & 20 \\
\hline & $100+$ & 3 & 1 & 1 & 4 & 3 & & 3 & 5 & 13 & 3 \\
\hline
\end{tabular}




\begin{tabular}{|c|c|c|c|c|c|c|c|c|c|c|c|}
\hline Metrosideros diffusa & - & & & & 2 & & & & 3 & & \\
\hline Microlaena avanacea & - & 40 & 37 & 14 & 56 & 15 & 16 & 9 & 2 & 63 & 28 \\
\hline Mueblenbeckia complexa & - & & & & 1 & & & 1 & & & 1 \\
\hline \multirow[t]{2}{*}{ Myrsine australis } & $0-100$ & & 18 & 10 & 4 & 5 & 22 & 10 & 14 & 10 & 1 \\
\hline & $100+$ & & & & & & 3 & & & & \\
\hline Nest epiphytes ${ }^{7}$ & - & 14 & & 3 & 15 & 1 & 6 & 4 & 19 & & 19 \\
\hline \multirow[t]{2}{*}{ Nestegis spp. ${ }^{8}$} & $0-100$ & & & & 1 & & & & & & \\
\hline & $100+$ & 2 & 2 & & & 3 & 2 & & & & 1 \\
\hline \multirow[t]{2}{*}{ Olearia rani } & $0-100$ & 6 & 6 & & & & & & & & 1 \\
\hline & $100+$ & & & & & & & & & & \\
\hline Parsonsia beterophylla & - & & 3 & & & 2 & 2 & 1 & & & 1 \\
\hline \multirow[t]{2}{*}{ Pennantia corymbosa } & $0-100$ & & & & 1 & & & & & & \\
\hline & $100+$ & & & & & & & & & & \\
\hline Pittosporum comifolium & $0-100$ & & & & & & & & & & \\
\hline \multirow[t]{2}{*}{ Pittosporum eugenioides } & $0-100$ & & & & & & & & & & \\
\hline & $100+$ & & & & & & & & & & \\
\hline \multirow[t]{2}{*}{ Pittosporum tenuifolium } & $0-100$ & & & & & & & & & & \\
\hline & $100+$ & & & & & & & & & & \\
\hline \multirow[t]{3}{*}{ Podocarpus totara } & $0-100$ & & & & & & & & & & \\
\hline & $100-500$ & & & & & & & & & & \\
\hline & $500+$ & & & & & & & & & & \\
\hline \multirow[t]{3}{*}{ Prumnopitys taxifolia } & $0-100$ & 10 & & & 1 & & 1 & & & & 1 \\
\hline & $100-500$ & 1 & 1 & 1 & & & & & & & 1 \\
\hline & $500+$ & & & & 1 & & & & 1 & & \\
\hline Pseudopanax arboreus & $0-100$ & & & & & & & & & & \\
\hline \multirow[t]{2}{*}{ Pseudopanax crassifolius } & $0-100$ & 3 & 1 & & & & 27 & & 1 & 1 & \\
\hline & $100+$ & & & & & & & & & & \\
\hline Rhopalostylas sapida & $0-100$ & & & & & & & & & & \\
\hline Ripogonum scandens & - & 47 & 5 & 32 & 22 & 33 & & 2 & 29 & 27 & 10 \\
\hline Rubus australis & - & & & & & & 1 & & & & \\
\hline \multirow[t]{2}{*}{ Schefflera digitata } & $0-100$ & & & & & & & & & & \\
\hline & $100+$ & & & & & & & & & & \\
\hline \multirow[t]{2}{*}{ Small leaved divaricates ${ }^{9}$} & $0-100$ & 41 & 33 & 43 & 31 & 53 & 25 & 78 & 19 & 7 & 57 \\
\hline & $100+$ & 1 & 2 & & & 2 & & & & & \\
\hline \multirow[t]{2}{*}{ Sophora tetraptera } & $0-100$ & & & & & & & & & & \\
\hline & $100+$ & & & & & & & & & & \\
\hline Tetrapathaea tetrandra & - & & & 1 & 2 & & & & & 1 & 1 \\
\hline Aspect & & 0 & 330 & 0 & 300 & 300 & 0 & 260 & 300 & 300 & 20 \\
\hline Slope & & 0 & 22 & 0 & 2 & 2 & 15 & 2 & 2 & 2 & 2 \\
\hline Canopy height (m) & & 10 & 15 & 15 & 15 & 10 & 15 & 10 & 15 & 15 & 10 \\
\hline Canopy open/closed (cl) & & $\mathrm{cl}$ & $\mathrm{cl}$ & $\mathrm{cl}$ & $\mathrm{cl}$ & open & pen & open & open & $\mathrm{cl}$ & $\mathrm{cl}$ \\
\hline
\end{tabular}




\begin{tabular}{|c|c|c|c|c|c|c|c|c|c|c|c|}
\hline \multirow[t]{2}{*}{ Species } & \multirow{2}{*}{$\begin{array}{c}\text { Stem } \\
\text { diameter } \\
(\mathrm{mm})\end{array}$} & \multicolumn{10}{|c|}{ Plot number } \\
\hline & & 21 & 22 & 23 & 24 & 25 & 26 & 27 & 28 & 29 & 30 \\
\hline \multirow[t]{2}{*}{ Alectryon excelsus } & $0-100$ & & 21 & 2 & 22 & 15 & 2 & 1 & 10 & 3 & 15 \\
\hline & $100+$ & & & 6 & 2 & 6 & & 14 & 3 & 15 & 6 \\
\hline \multirow[t]{2}{*}{ Aristotelia serrata } & $0-100$ & & & & & & & & & & \\
\hline & $100+$ & & & & & & & & & & \\
\hline \multirow[t]{2}{*}{ Beilschmiedia tawa } & $0-100$ & & 3 & 4 & 5 & 12 & 2 & 3 & 4 & & 6 \\
\hline & $100+$ & & & 12 & 5 & 3 & & 4 & 1 & 3 & \\
\hline Brachiglottis repanda & $0-100$ & 5 & & & & & 2 & & & & \\
\hline \multirow[t]{2}{*}{ Carpodetus serratus } & $0-100$ & & & & & & & & & & \\
\hline & $100+$ & & & & & & & & & & \\
\hline Climbing ferns1 & - & 2 & 2 & 5 & 2 & 6 & 1 & 8 & 7 & 3 & 14 \\
\hline Coprosma grandifolia & $0-100$ & 4 & & & & & & & & & \\
\hline \multirow[t]{2}{*}{ Cordyline australis } & $0-100$ & 2 & & & & & & & & & \\
\hline & $100+$ & & 1 & & & & & & & & \\
\hline Corynocarpus laevigatus & $0-100$ & & & & & & & & & & \\
\hline Gyathea spp. ${ }^{2}$ & - & & & & & & & & & & \\
\hline \multirow[t]{3}{*}{ Dacrycarpus dacrydioides } & $0-100$ & & 5 & 34 & & & 2 & & 58 & 3 & \\
\hline & $100-500$ & & 5 & & & & & & 3 & & \\
\hline & $500+$ & & 1 & & 2 & 4 & & & & 1 & 4 \\
\hline \multirow[t]{3}{*}{ Dacrydium cupressinum } & $0-100$ & & & & & & & & & & \\
\hline & $100-500$ & & & & & & & & & & \\
\hline & $500+$ & & & & & & & & & 1 & \\
\hline \multirow[t]{2}{*}{ Dead tree ${ }^{3}$} & $0-100$ & & 9 & 1 & 1 & 2 & 1 & & 2 & 3 & \\
\hline & $100+$ & 1 & 1 & & 1 & 2 & 1 & 1 & & 1 & 1 \\
\hline Dysoxylum spectabile & $0-100$ & & & & & & & & & & \\
\hline \multirow{3}{*}{ Elaeocarpus dentatus } & - & & & & & 5 & 1 & & & & \\
\hline & $0-100$ & & & & & & & & & & \\
\hline & $100+$ & & & & & & & & & & \\
\hline Elaeocarpus hookerianus & $100+$ & & & & & & & & & & \\
\hline \multirow{3}{*}{$\begin{array}{l}\text { Epiphytic ferns } \\
\text { Geniostoma mpestre }\end{array}$} & - & & 2 & 2 & 1 & 7 & 1 & & 1 & 1 & 6 \\
\hline & $0-100$ & 22 & 1 & 11 & 11 & & 31 & 6 & 15 & 3 & 2 \\
\hline & $100+$ & & & & & & & & & & \\
\hline Griselinia lucida & $0-100$ & & & & & 2 & & & & & \\
\hline Ground ferns ${ }^{6}$ & - & 27 & 43 & 92 & 47 & 65 & 39 & 33 & 89 & 70 & 74 \\
\hline \multirow[t]{2}{*}{ Hedycarya arborea } & $0-100$ & & & & & & & 1 & & & 1 \\
\hline & $100+$ & & & & & & & & & & \\
\hline \multirow[t]{2}{*}{ Hoheria populnea } & $0-100$ & & & & & 2 & & & 1 & & \\
\hline & $100+$ & & & & & & & & & & \\
\hline \multirow[t]{2}{*}{ Knightia excelsa } & $0-100$ & & & & 8 & & 18 & & & & \\
\hline & $100+$ & & & 1 & 1 & & & & & & \\
\hline \multirow[t]{2}{*}{ Kunzea ericoides } & $0-100$ & 2 & & & & & & & & & \\
\hline & $100+$ & 19 & 7 & & & & 24 & & & & \\
\hline Laurelia novae-zelandiae & $0-100$ & & & & & & & & & & \\
\hline & $100+$ & & & & & & & & & & \\
\hline Leucopogon fasciculatus & $0-100$ & 4 & & & & & & & & & \\
\hline Lonicera japonica & - & & & & & & & & & & \\
\hline Lophomyrtus bullata & $0-100$ & & & 1 & & & & & & & \\
\hline Macropiper excelsum & $0-100$ & & & & & & & 1 & & & 2 \\
\hline & $100+$ & & & & & & & & & & \\
\hline Melicytus ramiflorus & $0-100$ & 8 & 24 & 30 & 6 & 16 & 16 & 39 & 38 & 22 & 37 \\
\hline & $100+$ & & 5 & 2 & 6 & 3 & & 1 & 1 & 4 & 6 \\
\hline
\end{tabular}




\begin{tabular}{|c|c|c|c|c|c|c|c|c|c|c|c|}
\hline Metrosideros diffusa & - & & & 5 & 10 & 2 & & 2 & 10 & & \\
\hline Microlaena avanacea & - & 17 & 100 & 12 & 18 & 6 & 46 & 22 & 59 & 35 & 5 \\
\hline Mueblenbeckia complexa & - & 1 & & & & & & & & & \\
\hline \multirow[t]{2}{*}{ Myrsine australis } & $0-100$ & 25 & 10 & 13 & 3 & 4 & 6 & 5 & & 13 & 4 \\
\hline & $100+$ & 1 & & & & & & & 1 & & \\
\hline Nest epiphytes ${ }^{7}$ & - & & 1 & 1 & 3 & 24 & & 1 & 2 & 5 & 23 \\
\hline \multirow[t]{2}{*}{ Nestegis spp. ${ }^{8}$} & $0-100$ & 3 & & & & & 16 & & 5 & 1 & \\
\hline & $100+$ & & & & 1 & & & & & & \\
\hline \multirow[t]{2}{*}{ Olearia rani } & $0-100$ & & & & & & 5 & & & & \\
\hline & $100+$ & & & & & & 2 & & & & \\
\hline Parsonsia beterophylla & - & 1 & & 2 & & 4 & 3 & 2 & 2 & 2 & \\
\hline \multirow[t]{2}{*}{ Pennantia corymbosa } & $0-100$ & & & & & & & & & & \\
\hline & $100+$ & & 1 & & & & & & & & \\
\hline Pittosporum cornifolium & $0-100$ & & & & & & & & & & 1 \\
\hline \multirow[t]{2}{*}{ Pittosporum engenioides } & $0-100$ & & & & & & & & & & \\
\hline & $100+$ & & & & & & & & & & \\
\hline \multirow[t]{2}{*}{ Pittosporum tenuifolium } & $0-100$ & & & & & & 1 & & & & \\
\hline & $100+$ & & & & & & & & & & \\
\hline \multirow[t]{3}{*}{ Podocarpus totara } & $0-100$ & & & & & & & & 1 & & \\
\hline & $100-500$ & & & & & & & & 1 & & \\
\hline & $500+$ & & & & & & & & & & \\
\hline \multirow[t]{3}{*}{ Prumnopitys taxifolia } & $0-100$ & & & 1 & & & 1 & & & & \\
\hline & $100-500$ & & & & & 1 & & & & & 1 \\
\hline & $500+$ & & & & 1 & 2 & & & 1 & & 1 \\
\hline $\begin{array}{l}\text { Pseudopanax arboreus } \\
\text { Pseudopanax crassifolius }\end{array}$ & $0-100$ & & & & & & & & & & \\
\hline \multirow[t]{2}{*}{ Pseudopanax crassifolius } & $0-100$ & 3 & 3 & 1 & & & 2 & & 3 & & \\
\hline & $100+$ & & & & & & & 1 & & & \\
\hline $\begin{array}{l}\text { Rhopalostylas sapida } \\
\text { Ripogonum scandens }\end{array}$ & $0-100$ & & & & & & & 13 & 38 & 10 & 30 \\
\hline $\begin{array}{l}\text { Ripogonum scandens } \\
\text { Rubus australis }\end{array}$ & - & & 2 & 43 & 23 & 22 & $\begin{array}{l}5 \\
1\end{array}$ & 13 & 38 & 10 & 30 \\
\hline \multirow{2}{*}{ Schefflera digitata } & $\begin{array}{c}- \\
0-100\end{array}$ & & & & & & & & & & \\
\hline & $100+$ & & & & & & & & & & \\
\hline \multirow[t]{2}{*}{ Small leaved divaricates ${ }^{9}$} & $0-100$ & 61 & 50 & 29 & 12 & 27 & 49 & 47 & 43 & 15 & 33 \\
\hline & $100+$ & 1 & 1 & & & & & 1 & 1 & & \\
\hline \multirow[t]{2}{*}{ Sophora tetraptera } & $0-100$ & & & & & & & & & & \\
\hline & $100+$ & & & 2 & 1 & & & 2 & 2 & & 1 \\
\hline Aspect & & & & & & & & & & & \\
\hline $\begin{array}{l}\text { Aspect } \\
\text { Slope }\end{array}$ & & 0 & 260 & 300 & 300 & 300 & $\begin{array}{r}60 \\
5\end{array}$ & $\begin{array}{r}260 \\
4\end{array}$ & $\begin{array}{l}0 \\
0\end{array}$ & $\begin{array}{l}0 \\
0\end{array}$ & $\begin{array}{l}0 \\
0\end{array}$ \\
\hline $\begin{array}{l}\text { Slope } \\
\text { Canopy height (m) }\end{array}$ & & 12 & $\begin{array}{r}6 \\
15\end{array}$ & $\begin{array}{r}2 \\
15\end{array}$ & $\begin{array}{r}2 \\
15\end{array}$ & $\begin{array}{r}2 \\
15\end{array}$ & 10 & $\begin{array}{r}4 \\
15\end{array}$ & 15 & 15 & 15 \\
\hline Canopy open/closed (cl) & & open & open & $\mathrm{cl}$ & $\mathrm{cl}$ & open $c$ & pen & $\mathrm{cl}$ & open & $\mathrm{cl}$ & open \\
\hline
\end{tabular}




\begin{tabular}{|c|c|c|c|c|c|c|c|c|c|c|c|}
\hline \multirow[t]{2}{*}{ Species } & \multirow{2}{*}{$\begin{array}{c}\text { Stem } \\
\text { diameter } \\
(\mathbf{m m})\end{array}$} & \multicolumn{10}{|c|}{ Plot number } \\
\hline & & 31 & 32 & 33 & 34 & 35 & 36 & 37 & 38 & 39 & 40 \\
\hline \multirow[t]{2}{*}{ Alectryon excelsus } & $0-100$ & 14 & 26 & 2 & 21 & 28 & 17 & 15 & 14 & 3 & 3 \\
\hline & $100+$ & 4 & & & 2 & 4 & & 7 & 18 & 10 & 5 \\
\hline \multirow[t]{2}{*}{ Aristotelia serrata } & $0-100$ & & & & & & & & & & \\
\hline & $100+$ & & & & & & & & & & \\
\hline \multirow[t]{2}{*}{ Beilschmiedia tawa } & $0-100$ & 3 & 5 & & 2 & 1 & 3 & 5 & 2 & 1 & 3 \\
\hline & $100+$ & 11 & 1 & & 3 & 1 & & 7 & 1 & 6 & 11 \\
\hline Brachiglottis repanda & $0-100$ & & & & & & & 1 & 1 & & \\
\hline \multirow[t]{2}{*}{ Carpodetus serratus } & $0-100$ & & & & & & & & & & \\
\hline & $100+$ & & & & & & & & & & \\
\hline Climbing ferns 1 & - & 11 & 2 & 1 & 3 & & 10 & 9 & 7 & 8 & \\
\hline Coprosma grandifolia & $0-100$ & 2 & & & & & & & & & 1 \\
\hline \multirow[t]{2}{*}{ Cordyline australis } & $0-100$ & & & & & & & & & & \\
\hline & $100+$ & & & & 1 & 7 & & & & & \\
\hline Corynocarpus laevigatus & $0-100$ & & & & & & & & & & \\
\hline Cyathea spp. $^{2}$ & - & 4 & & & & & & & & & \\
\hline \multirow[t]{3}{*}{ Dacrycarpus dacrydioides } & $0-100$ & 7 & 4 & & & & 33 & & & & 8 \\
\hline & $100-500$ & & 10 & & 2 & & 24 & & & & 1 \\
\hline & $500+$ & & & & 1 & 1 & 1 & 2 & 2 & 2 & \\
\hline \multirow[t]{3}{*}{ Dacrydium cupressinum } & $0-100$ & & & & & & & & & & \\
\hline & $100-500$ & & & & & & & & & & \\
\hline & $500+$ & 1 & & & & & & 1 & & & \\
\hline \multirow[t]{2}{*}{ Dead tree ${ }^{3}$} & $0-100$ & 1 & 2 & 2 & 3 & 3 & & 2 & 4 & 1 & 3 \\
\hline & $100+$ & 5 & 2 & & 2 & 2 & 1 & & 2 & & 3 \\
\hline Dysoxylum spectabile & $0-100$ & & & & & & & & & & \\
\hline \multirow{3}{*}{$\begin{array}{l}\text { Earina spp. } \\
\text { Elaeocarpus dentatus }\end{array}$} & - & & & & 1 & & & 2 & & & \\
\hline & $0-100$ & & & & & & & & & & \\
\hline & $100+$ & & & & & & & & & & 1 \\
\hline Elacocarpus bookerianus & $100+$ & & & & & & & & & & 1 \\
\hline \multirow{3}{*}{$\begin{array}{l}\text { Epiphytic ferns } \\
\text { Geniostoma rupestre }\end{array}$} & - & & & & 1 & 2 & & 8 & 1 & 2 & \\
\hline & $0-100$ & 6 & 37 & 6 & 2 & 1 & 8 & 9 & 2 & 2 & 4 \\
\hline & $100+$ & & & & & & & & & & \\
\hline Griselinia Lucida & $0-100$ & & & & & & & & & & \\
\hline \multirow{3}{*}{$\begin{array}{l}\text { Ground ferns } \\
\text { Hedycarya arborea }\end{array}$} & - & 60 & 39 & 11 & 53 & 22 & 6 & 132 & 94 & 67 & 28 \\
\hline & $0-100$ & & & & & 1 & & & & & \\
\hline & $100+$ & & & & & & & & & & \\
\hline \multirow[t]{2}{*}{ Hoberia populnea } & $0-100$ & & 2 & & & 1 & 3 & & & & \\
\hline & $100+$ & & & & & & & & & & \\
\hline \multirow[t]{2}{*}{ Knightia excelsa } & $0-100$ & 12 & 4 & & 1 & & & 3 & & & 1 \\
\hline & $100+$ & 4 & & & 1 & & & & 1 & & 1 \\
\hline \multirow[t]{2}{*}{ Kunzea ericoides } & $0-100$ & & & & & & & & & & \\
\hline & $100+$ & & 1 & 19 & & 6 & 3 & & & & 1 \\
\hline Laurelia novae-zelandiae & $0-100$ & & & & & & & & & & \\
\hline & $100+$ & & & & & & & & & & \\
\hline Leucopogon fasciculatus & $0-100$ & & & & & & & & & & \\
\hline Lonicera japonica & - & & & & & & & & & & \\
\hline Lophomyrtus bullata & $0-100$ & & & & & & 11 & & & & \\
\hline Macropiper excelsum & $0-100$ & & & & & & & 3 & 1 & & \\
\hline & $100+$ & & & & & & & & & & \\
\hline Melicytus ramiflorus & $0-100$ & 39 & 9 & 35 & 22 & 22 & 23 & 36 & 23 & 34 & 4 \\
\hline & $100+$ & 3 & 9 & 1 & 4 & 1 & & 1 & & & 2 \\
\hline
\end{tabular}




\begin{tabular}{|c|c|c|c|c|c|c|c|c|c|c|c|}
\hline Metrosideros diffusa & - & 1 & & & 1 & & & 4 & 3 & & \\
\hline Microlaena avanacea & - & 118 & 45 & 18 & 24 & 25 & 35 & 80 & 12 & 4 & 252 \\
\hline Mueblenbeckia complexa & - & & 1 & & & & & 3 & & & \\
\hline \multirow[t]{2}{*}{ Myrsine australis } & $0-100$ & 14 & 1 & 13 & 7 & 7 & 1 & 20 & 7 & 7 & 2 \\
\hline & $100+$ & 1 & 4 & 1 & & & 1 & & 1 & & \\
\hline Nest epiphytes $^{7}$ & - & & & & 5 & 10 & & 20 & 6 & 11 & \\
\hline \multirow[t]{2}{*}{ Nestegis spp. ${ }^{8}$} & $0-100$ & 1 & 1 & 3 & & & 1 & & & & \\
\hline & $100+$ & & & 2 & 3 & 2 & & 1 & & & \\
\hline \multirow[t]{2}{*}{ Olearia rani } & $0-100$ & & & & & & & & & & 2 \\
\hline & $100+$ & & & & & & & & & & \\
\hline $\begin{array}{l}\text { Parsonsia beterophylla } \\
\text { Pennantia corymbosa }\end{array}$ & - & 2 & & 5 & & 1 & 3 & 4 & 1 & 1 & \\
\hline \multirow[t]{2}{*}{ Pennantia corymbosa } & $0-100$ & & & & & & & & & 1 & \\
\hline & $100+$ & & & & & & & & & & \\
\hline $\begin{array}{l}\text { Pittosporum cornifolium } \\
\text { Pittosporum engenioides }\end{array}$ & $0-100$ & & & & & & & & & & \\
\hline \multirow[t]{2}{*}{ Pittosporum engenioides } & $0-100$ & & & & & & & & & & \\
\hline & $100+$ & & & & & & & & & & \\
\hline Pittosporum tenuifolium & $\begin{array}{l}0-100 \\
100+\end{array}$ & & & & & & & & & & \\
\hline \multirow[t]{3}{*}{ Podocarpus totara } & $\begin{array}{l}100+ \\
0-100\end{array}$ & & & 1 & & 1 & & & & & \\
\hline & $100-500$ & & & & & & & & & & \\
\hline & $500+$ & & & & & & & & & & \\
\hline \multirow{2}{*}{ Prumnopitys taxifolia } & $0-100$ & 2 & & & & & 1 & & & & \\
\hline & $100-500$ & & 1 & 1 & & & & 1 & & 1 & 1 \\
\hline Pseudopanax arboreus & $\begin{array}{l}500+ \\
0-100\end{array}$ & & & & & & & & & & \\
\hline \multirow[t]{2}{*}{ Pseudopanax crassifolius } & $\begin{array}{l}0-100 \\
0-100\end{array}$ & 1 & & & & 1 & 2 & 5 & 2 & & \\
\hline & $100+$ & & & & & & & & & & \\
\hline $\begin{array}{l}\text { Rhopalostylas sapida } \\
\text { Ripogonum scandens }\end{array}$ & $0-100$ & & & & & & & & & & \\
\hline Ripogonum scandens & - & 34 & 68 & & 22 & 11 & 22 & 23 & 24 & 18 & 11 \\
\hline Rubus australis & - & & & & & & & & & & \\
\hline \multirow[t]{2}{*}{ Schefflera digitata } & $0-100$ & & 2 & & & & & & & & \\
\hline & $100+$ & 52 & 31 & 63 & 40 & 36 & 73 & 37 & 17 & 37 & 14 \\
\hline Small leaved divaricates ${ }^{9}$ & $\begin{array}{l}0-100 \\
100+\end{array}$ & 52 & 3 & 1 & 2 & 1 & & 1 & & & 14 \\
\hline \multirow[t]{2}{*}{ Sophora tetraptera } & $0-100$ & & & & & & & & & & \\
\hline & $100+$ & & & & & & & & & & \\
\hline Tetrapathaea tetrandra & - & & 4 & & 5 & 2 & 1 & & & 2 & \\
\hline Aspect & & 40 & 0 & 340 & 0 & 220 & 0 & 0 & 0 & 0 & 20 \\
\hline Slope & & 2 & 0 & 12 & 2 & 4 & 0 & 0 & 1 & 0 & 8 \\
\hline Canopy height (m) & & 15 & 20 & 15 & 10 & 15 & 15 & 15 & 15 & 15 & 15 \\
\hline Canopy open/closed (cl) & & $\mathrm{cl}$ & $\mathrm{cl}$ & open C & pen & $\mathrm{cl}$ & $\mathrm{cl}$ & $\mathrm{cl}$ & $\mathrm{cl}$ & $\mathrm{cl}$ & open \\
\hline
\end{tabular}




\begin{tabular}{|c|c|c|c|c|c|c|c|c|c|c|c|}
\hline \multirow[t]{2}{*}{ Species } & \multirow{2}{*}{$\begin{array}{c}\text { Stem } \\
\text { diameter } \\
(\mathrm{mm})\end{array}$} & \multicolumn{10}{|c|}{ Plot number } \\
\hline & & 41 & 42 & 43 & 44 & 45 & 46 & 47 & 48 & 49 & 50 \\
\hline \multirow[t]{2}{*}{ Alectryon excelsus } & $0-100$ & 14 & 3 & 3 & 11 & 9 & 2 & 7 & 6 & 1 & 8 \\
\hline & $100+$ & 2 & & 7 & & & 3 & 12 & 1 & 7 & 2 \\
\hline \multirow[t]{2}{*}{ Aristotelia serrata } & $0-100$ & & & & & & & & & & \\
\hline & $100+$ & & & & & & & & & & \\
\hline \multirow{2}{*}{ Beilschmiedia tawa } & $0-100$ & 6 & 2 & 3 & & & & 10 & & 1 & 5 \\
\hline & $100+$ & 4 & 6 & 10 & & & 2 & 5 & 1 & 6 & 14 \\
\hline Brachiglottis repanda & $0-100$ & & & & & 1 & & & & & \\
\hline \multirow[t]{2}{*}{ Carpodetus serratus } & $0-100$ & & & & 2 & & & & & & \\
\hline & $100+$ & & & & & & & & & & \\
\hline $\begin{array}{l}\text { Climbing ferns } 1 \\
\text { Coprosma grandifolia }\end{array}$ & - & 5 & 5 & 3 & 1 & 6 & 14 & 8 & 2 & 3 & 6 \\
\hline \multirow{2}{*}{ Cordyline australis } & $0-100$ & & & & & & 1 & 1 & & & 1 \\
\hline & $100+$ & & 2 & & 1 & & 1 & & & & \\
\hline Corynocarpus Laevigatus & $0-100$ & & & & & & & & & & \\
\hline Cyathea spp. ${ }^{2}$ & - & & & & & & 4 & & & & \\
\hline \multirow[t]{3}{*}{ Dacrycarpus dacrydioides } & $0-100$ & 57 & 2 & & 10 & 96 & 8 & 7 & 25 & 5 & 4 \\
\hline & $100-500$ & 1 & & 1 & 1 & 15 & & 2 & 3 & 1 & 3 \\
\hline & $500+$ & & & & & & 1 & 1 & 3 & 1 & \\
\hline \multirow[t]{3}{*}{ Dacrydium cupressinum } & $0-100$ & & & & & & & & & & \\
\hline & $100-500$ & & & & & 1 & & & & & \\
\hline & $500+$ & & & & & & 2 & & & & \\
\hline \multirow[t]{2}{*}{ Dead tree ${ }^{3}$} & $0-100$ & & 2 & 1 & 5 & 2 & & 1 & 1 & & 2 \\
\hline & $100+$ & 1 & & 2 & 1 & & & 2 & 1 & 3 & 3 \\
\hline Dysoxylum spectabile & $0-100$ & & & & & & & & & & \\
\hline Earina spp. & - & & & & & & & & & & \\
\hline \multirow{2}{*}{ Elaeocarpus dentatus } & $0-100$ & & & & & & & & & & \\
\hline & $100+$ & & & & & & & & & & \\
\hline Elaeocarpus hookerianus & $100+$ & 1 & 1 & & & & & & 3 & & \\
\hline Epiphytic ferns ${ }^{5}$ & - & & & & & 1 & 7 & $\begin{array}{l}1 \\
5\end{array}$ & 1 & 1 & 11 \\
\hline \multirow[t]{2}{*}{ Geniostoma mupestre } & $0-100$ & 9 & 5 & & 1 & 11 & 4 & 5 & 1 & 1 & 11 \\
\hline & $100+$ & & & & & & 1 & & & & \\
\hline $\begin{array}{l}\text { Griselinia lucida } \\
\text { Ground ferns }\end{array}$ & $\begin{array}{c}0-100 \\
-\end{array}$ & 38 & 109 & 26 & 36 & 30 & 120 & 79 & 40 & 47 & 62 \\
\hline \multirow[t]{2}{*}{ Hedycarya arborea } & $0-100$ & 1 & & & & & & 1 & & 1 & 1 \\
\hline & $100+$ & & & & & & & & & & \\
\hline \multirow[t]{2}{*}{ Hoberia populnea } & $0-100$ & & & & 1 & 7 & & 2 & & & 1 \\
\hline & $100+$ & & & & 1 & & 1 & & & & \\
\hline \multirow[t]{2}{*}{ Knightia excelsa } & $0-100$ & & 1 & & & 4 & 1 & & & 5 & 1 \\
\hline & $100+$ & & & & & & & & & 1 & \\
\hline \multirow[t]{2}{*}{ Kunzea ericoides } & $0-100$ & & & & 1 & & & & & & \\
\hline & $100+$ & 1 & & & 11 & 1 & & & & 2 & 3 \\
\hline \multirow[t]{2}{*}{ Laurelia novae-zelandiae } & $0-100$ & & & & & & & 1 & & & \\
\hline & $100+$ & & & & & & & & & & \\
\hline Leucopogon fasciculatus & $0-100$ & & & & & & & & & & \\
\hline Lonicera japonica & - & & & & & & & & & & \\
\hline Lophomyrtus bullata & $0-100$ & & & & & 11 & 2 & & & & \\
\hline Macropiper excelsum & $0-100$ & & 1 & & & 1 & 1 & & & 1 & \\
\hline & $100+$ & & & & & & & & & & \\
\hline Melicytus ramiflorus & $0-100$ & 24 & 64 & 34 & 15 & 13 & 20 & 42 & 4 & 11 & 14 \\
\hline & $100+$ & 2 & 4 & 1 & 1 & & 3 & 1 & & 6 & 2 \\
\hline
\end{tabular}




\begin{tabular}{|c|c|c|c|c|c|c|c|c|c|c|c|}
\hline Metrosideros diffusa & - & & 4 & & & & 10 & 4 & 2 & & \\
\hline Microlaena avanacea & - & 13 & 5 & 19 & 63 & 43 & 74 & 7 & 97 & 149 & 148 \\
\hline Mueblenbeckia complexa & - & & & & 1 & & & & & & \\
\hline \multirow[t]{2}{*}{ Myrsine australis } & $0-100$ & & & 69 & & & 8 & 7 & 5 & 3 & 6 \\
\hline & $100+$ & & & & 1 & 1 & & & 1 & & \\
\hline Nest epiphytes ${ }^{7}$ & - & & 2 & & 2 & 1 & 21 & 11 & 9 & & \\
\hline \multirow[t]{2}{*}{ Nestegis spp. ${ }^{8}$} & $0-100$ & & & & & 3 & & 1 & & & \\
\hline & $100+$ & 6 & & & & & & 1 & & & 1 \\
\hline \multirow[t]{2}{*}{ Olearia rani } & $0-100$ & & & & & & & & & & 1 \\
\hline & $100+$ & & & & & & & & & & \\
\hline \multirow{2}{*}{ Pennantia corymbosa } & - & 1 & & 1 & 1 & & 2 & 1 & 1 & & \\
\hline & $\begin{array}{l}0-100 \\
100+\end{array}$ & & & & & & 1 & & & & \\
\hline Pittosporum cornifolium & $\begin{array}{l}100+ \\
0-100\end{array}$ & & 4 & & & & 1 & & 1 & & \\
\hline \multirow{2}{*}{ Pittosporum engenioides } & $0-100$ & & & & & & & & & & \\
\hline & $100+$ & & & & & & & & & & \\
\hline \multirow[t]{2}{*}{ Pittosporum tenuifolium } & $0-100$ & & & 3 & & & & & & & \\
\hline & $100+$ & & & 1 & & & & & & & \\
\hline \multirow[t]{3}{*}{ Podocarpus totara } & $0-100$ & & & & & 1 & & & & & 2 \\
\hline & $100-500$ & & & & & 2 & & & & & 1 \\
\hline & $500+$ & & & & & & & & & & 1 \\
\hline \multirow[t]{3}{*}{ Prumnopitys taxifolia } & $0-100$ & & & & & 1 & & & & & \\
\hline & $100-500$ & & & 1 & & & & 1 & 1 & & 3 \\
\hline & $500+$ & 1 & & & & & & & & & \\
\hline \multirow{2}{*}{ Pseudopanax crassifolius } & $0-100$ & & & & & & & & & & \\
\hline & $\begin{array}{l}0-100 \\
100+\end{array}$ & & & & & 2 & 1 & 2 & & & \\
\hline Rhopalostylas sapida & $0-100$ & & & & & & & & & & \\
\hline Ripogonum scandens & - & 22 & 44 & & 2 & 13 & 27 & 19 & 26 & 26 & 20 \\
\hline Rubus australis & - & & & & & & & & & & \\
\hline \multirow[t]{2}{*}{ Schefflera digitata } & $0-100$ & & & & & & & & & & \\
\hline & $100+$ & & & & & & & & & & \\
\hline \multirow[t]{2}{*}{ Small leaved divaricates ${ }^{9}$} & $0-100$ & 55 & 21 & 52 & 65 & 45 & 16 & 13 & 18 & 10 & 16 \\
\hline & $100+$ & 2 & 3 & 1 & & 1 & 1 & & 1 & & \\
\hline Sophora tetraptera & $0-100$ & & & & & & & & & & \\
\hline Tetrapathaea tetrandra & $100+$ & 2 & 3 & 7 & 3 & & 3 & & 6 & 1 & \\
\hline Aspect & & 8 & 0 & 0 & 290 & 0 & 0 & 0 & 0 & 0 & \\
\hline Slope & & 2 & 6 & 0 & 3 & 0 & 2 & 0 & 0 & 12 & 9 \\
\hline Canopy height (m) & & 15 & 10 & 15 & 15 & 15 & 10 & 15 & 10 & 15 & 15 \\
\hline Canopy open/closed (cl) & & $\mathrm{cl}$ & $\mathrm{cl}$ & $\mathrm{cl}$ & open & $\mathrm{cl}$ & $\mathrm{cl}$ & $\mathrm{cl}$ & open o & open & $\mathrm{cl}$ \\
\hline
\end{tabular}




\begin{tabular}{|c|c|c|c|c|c|c|c|c|c|c|c|}
\hline \multirow[t]{2}{*}{ Species } & \multirow{2}{*}{$\begin{array}{c}\text { Stem } \\
\text { diameter } \\
(\mathbf{m m})\end{array}$} & \multicolumn{10}{|c|}{ Plot number } \\
\hline & & 51 & 52 & 53 & 54 & 55 & 56 & 57 & 58 & 59 & 60 \\
\hline \multirow[t]{2}{*}{ Alectryon excelsus } & $0-100$ & 38 & 7 & 20 & 5 & 22 & 53 & 47 & 8 & 15 & 5 \\
\hline & $100+$ & & & & & 3 & & & 1 & & \\
\hline \multirow[t]{2}{*}{ Aristotelia serrata } & $0-100$ & & & & & & & & & & \\
\hline & $100+$ & & & & & & & & & & \\
\hline \multirow[t]{2}{*}{ Beilschmiedia tawa } & $0-100$ & 6 & 2 & & 7 & 11 & 2 & & 2 & 6 & \\
\hline & $100+$ & & & & & 2 & 8 & 10 & 23 & 14 & \\
\hline Brachiglottis repanda & $0-100$ & & & & 1 & & & & & & \\
\hline \multirow[t]{2}{*}{ Carpodetus serratus } & $0-100$ & & & & & & & & & & \\
\hline & $100+$ & & & & & & & & & & \\
\hline Climbing ferns1 & - & 7 & & 3 & 5 & 8 & 11 & 9 & 2 & 7 & \\
\hline Coprosma grandifolia & $0-100$ & & & & & & & & & 2 & \\
\hline \multirow[t]{2}{*}{ Cordyline australis } & $0-100$ & & & & & & & & & & \\
\hline & $100+$ & & & & 1 & & & & & & \\
\hline Corynocarpus Laevigatus & $0-100$ & & & & & & & 6 & & & \\
\hline Cyathea spp. ${ }^{2}$ & - & 1 & & & & & 1 & & & & \\
\hline \multirow[t]{3}{*}{ Dacrycarpus dacrydioides } & $0-100$ & & 4 & & 13 & 1 & & & & 7 & 1 \\
\hline & $100-500$ & & 1 & & & & & & 1 & 1 & \\
\hline & $500+$ & 3 & & & & 1 & & & & & \\
\hline \multirow[t]{3}{*}{ Dacrydium cupressinum } & $0-100$ & & & & 2 & & & & & & \\
\hline & $100-500$ & & & & & & & & & & \\
\hline & $500+$ & & & & & & & & & & \\
\hline \multirow[t]{2}{*}{ Dead tree ${ }^{3}$} & $0-100$ & 3 & 3 & 1 & 3 & 1 & 1 & 2 & & & \\
\hline & $100+$ & & & 4 & 1 & 1 & & 1 & & & 3 \\
\hline Dysoxylum spectabile & $0-100$ & & & & & & & & & & \\
\hline Earina spp. ${ }^{4}$ & - & & & & & & & & & & \\
\hline \multirow[t]{2}{*}{ Elaeocarpus dentatus } & $0-100$ & & & & & & & & & & \\
\hline & $100+$ & & & & & & & & & & \\
\hline Elaeocarpus bookerianus & $100+$ & & & & & & & & & & \\
\hline Epiphytic ferns ${ }^{5}$ & - & 6 & & 1 & & 2 & 4 & 2 & & & \\
\hline \multirow[t]{2}{*}{ Geniostoma rupestre } & $0-100$ & 1 & 1 & 5 & 7 & 22 & 3 & 1 & 17 & 3 & 1 \\
\hline & $100+$ & & & & & 1 & & & & & 1 \\
\hline Griselinia lucida & $0-100$ & & & & & & & & & & \\
\hline Ground ferns ${ }^{6}$ & - & 92 & 4 & 25 & 17 & 100 & 104 & 136 & 96 & 131 & 30 \\
\hline \multirow[t]{2}{*}{ Hedycarya arborea } & $0-100$ & & & & 2 & 14 & 11 & 2 & 7 & & \\
\hline & $100+$ & & & & & & & & & & \\
\hline \multirow[t]{2}{*}{ Hoheria populnea } & $0-100$ & & & 1 & & 1 & & & & & 2 \\
\hline & $100+$ & & 5 & & & & & & & & 1 \\
\hline \multirow[t]{2}{*}{ Knightia excelsa } & $0-100$ & & & & 2 & & 22 & 14 & 1 & 4 & \\
\hline & $100+$ & & & & & & & 1 & & & \\
\hline \multirow[t]{2}{*}{ Kunzea ericoides } & $0-100$ & & 2 & & & & & & & & \\
\hline & $100+$ & & 5 & 18 & 11 & & & & & & 7 \\
\hline Laurelia novae-zelandiae & $0-100$ & & & & & & & & & & \\
\hline & $100+$ & & & & & & & & & & \\
\hline Leucopogon fasciculatus & $0-100$ & & 1 & 1 & & & & & & & \\
\hline Lonicera japonica & - & & & & & & & & & & \\
\hline Lophomyrtus bullata & $0-100$ & & 1 & 1 & & 2 & & & & & \\
\hline Macropiper excelsum & $0-100$ & & 1 & & & & & & & & \\
\hline & $100+$ & & & & & & & & & & \\
\hline Melicytus ramiflorus & $0-100$ & 9 & 22 & 12 & 13 & 22 & 20 & 26 & 60 & 3 & 20 \\
\hline & $100+$ & 3 & 10 & 2 & & 1 & 4 & 5 & 1 & 2 & 5 \\
\hline
\end{tabular}




\begin{tabular}{|c|c|c|c|c|c|c|c|c|c|c|c|}
\hline Metrosideros diffusa & - & & & & & 5 & 1 & 6 & & & \\
\hline Microlaena avanacea & - & 4 & 69 & 165 & 53 & 33 & 6 & 9 & 8 & 61 & 7 \\
\hline Mueblenbeckia complexa & - & & & & & & & & & & \\
\hline \multirow[t]{2}{*}{ Myrsine australis } & $0-100$ & 12 & 1 & 4 & 13 & 27 & 8 & & 1 & 7 & 6 \\
\hline & $100+$ & & & & & & & & & & 2 \\
\hline Nest epiphytes $^{7}$ & - & 16 & & 1 & & 13 & 21 & 5 & & & 1 \\
\hline \multirow{2}{*}{ Nestegis spp. ${ }^{8}$} & $0-100$ & & & 1 & 4 & & & & & & \\
\hline & $100+$ & & 1 & & & 1 & & & & 3 & \\
\hline \multirow[t]{2}{*}{ Olearia rani } & $0-100$ & & & & & & & & & & \\
\hline & $100+$ & & & & & & & & & & \\
\hline Parsonsia beteropbylla & - & 2 & 2 & 2 & 6 & & & & & & 3 \\
\hline \multirow[t]{2}{*}{ Pennantia corymbosa } & $0-100$ & & & & & & & & & & \\
\hline & $100+$ & & & & 1 & & & & & & \\
\hline Pittosporum cornifolium & $0-100$ & & & & & 2 & & & & & \\
\hline \multirow[t]{2}{*}{ Pittosporum eugenioides } & $0-100$ & & & & & & 1 & & & & \\
\hline & $100+$ & & & & & & & & & & \\
\hline \multirow[t]{2}{*}{ Pittosporum tenuifolium } & $0-100$ & & & & & & & & & & \\
\hline & $100+$ & & & & & & & & & & \\
\hline \multirow[t]{3}{*}{ Podocarpus totara } & $0-100$ & & 1 & & & & & & & & \\
\hline & $100-500$ & & & & & & & & & & \\
\hline & $500+$ & & & & & & & & & & \\
\hline \multirow[t]{3}{*}{ Prumnopitys taxifolia } & $0-100$ & & & & 3 & & & 3 & & 1 & \\
\hline & $100-500$ & & & & & & & & & & \\
\hline & $500+$ & & & & & 1 & & & & & \\
\hline Pseudopanax arboreus & $0-100$ & & & & & & & & & & \\
\hline \multirow[t]{2}{*}{ Pseudopanax crassifolius } & $0-100$ & & & & 3 & 5 & & & 1 & & 2 \\
\hline & $100+$ & & & & & & & & & & \\
\hline Rhopalostylas sapida & $0-100$ & & & & & & & & & & \\
\hline Ripogonum scandens & - & 27 & 1 & & 11 & 32 & 19 & 13 & 11 & 20 & \\
\hline Rubus australis & - & & & & & 2 & & & & & \\
\hline \multirow[t]{2}{*}{ Schefflera digitata } & $0-100$ & & & & & & & & & & \\
\hline & $100+$ & & & & & & & & & & \\
\hline \multirow[t]{2}{*}{ Small leaved divaricates ${ }^{9}$} & $0-100$ & 50 & 49 & 30 & 54 & 79 & 15 & 20 & 10 & 17 & 64 \\
\hline & $100+$ & 1 & 1 & & & 1 & & & & & \\
\hline \multirow[t]{2}{*}{ Sophora tetraptera } & $0-100$ & & & & & & & & & & \\
\hline & $100+$ & & & & & & & & & & \\
\hline Tetrapathaea tetrandra & - & & 2 & & & & & & 5 & & 2 \\
\hline Aspect & & 0 & 0 & 20 & 0 & 0 & 322 & 340 & 0 & 8 & 0 \\
\hline Slope & & 2 & 0 & 5 & 0 & 0 & 20 & 5 & 0 & 6 & 20 \\
\hline Canopy height (m) & & 15 & 15 & 15 & 15 & 15 & 20 & 15 & 15 & 15 & 10 \\
\hline Canopy open/closed (cl) & & $\mathrm{cl}$ & open & open & $\mathrm{cl}$ & $\mathrm{cl}$ & open & $\mathrm{cl}$ & open & ppen $c$ & pen \\
\hline
\end{tabular}




\begin{tabular}{|c|c|c|c|c|c|c|c|c|c|c|c|}
\hline \multirow[t]{2}{*}{ Species } & \multirow{2}{*}{$\begin{array}{c}\text { Stem } \\
\text { diameter } \\
(\mathrm{mm})\end{array}$} & \multicolumn{10}{|c|}{ Plot number } \\
\hline & & 61 & 62 & 63 & 64 & 65 & 66 & 67 & 68 & 69 & 70 \\
\hline \multirow[t]{2}{*}{ Alectryon excelsus } & $0-100$ & 3 & 19 & 18 & 15 & 34 & 3 & 86 & 24 & 14 & 1 \\
\hline & $100+$ & & & 4 & 5 & & & & & & \\
\hline Aristotelia serrata & $0-100$ & & & & & & & & & & \\
\hline \multirow{2}{*}{ Beilschmiedia tawa } & $100+$ & & & 5 & 13 & & 26 & 14 & & & \\
\hline & $\begin{array}{l}0-100 \\
100+\end{array}$ & 2 & & $\begin{array}{l}5 \\
1\end{array}$ & 7 & 6 & 12 & 2 & & & 1 \\
\hline Brachiglottis repanda & $0-100$ & & & 1 & & 1 & & & & 1 & \\
\hline \multirow[t]{2}{*}{ Carpodetus serratus } & $0-100$ & & & 4 & & & & & & & 4 \\
\hline & $100+$ & & & 3 & & & & & & & \\
\hline $\begin{array}{l}\text { Climbing ferns1 } \\
\text { Coprosma grandifolia }\end{array}$ & - & 1 & 4 & 3 & 5 & 3 & 7 & 5 & 1 & 6 & 1 \\
\hline \multirow{2}{*}{ Cordyline australis } & $\begin{array}{l}0-100 \\
0-100\end{array}$ & & & & 1 & & 1 & & & & \\
\hline & $\begin{array}{l}0-100 \\
100+\end{array}$ & & 1 & & & & & & & 3 & \\
\hline $\begin{array}{l}\text { Corynocarpus laevigatus } \\
\text { Cyathea } \text { spp. }^{2}\end{array}$ & $0-100$ & & & & & & & 1 & & & \\
\hline \multirow[t]{2}{*}{ Dacrycarpus dacrydioides } & $\begin{array}{c}- \\
0-100\end{array}$ & 9 & & 2 & & 1 & & & & & \\
\hline & $100-500$ & 1 & & 2 & 2 & 1 & 1 & 1 & $\begin{array}{l}2 \\
1\end{array}$ & & 9 \\
\hline \multirow{3}{*}{ Dacrydium cupressinum } & $\begin{array}{l}500+ \\
0-100\end{array}$ & & & 1 & & & & 1 & & & \\
\hline & $100-500$ & 1 & & & & & & & & & \\
\hline & $500+$ & & & & & & 1 & $\begin{array}{l}2 \\
3\end{array}$ & & & \\
\hline \multirow[t]{2}{*}{ Dead tree ${ }^{3}$} & $0-100$ & & & 1 & 2 & 5 & & & 3 & 2 & \\
\hline & $100+$ & & & & & & & & 3 & 2 & \\
\hline Dysoxylum spectabile & $0-100$ & & & & & & & & & & \\
\hline Earina spp. & - & & & & & & & 1 & & & \\
\hline \multirow{2}{*}{ Elaeocarpus dentatus } & $0-100$ & & & & & & & & & & 1 \\
\hline & $100+$ & & & & & & & & 1 & & \\
\hline Elaeocarpus hookerianus & $100+$ & & & & & & & & & & \\
\hline Epiphytic ferns ${ }^{5}$ & - & & 1 & & 6 & 12 & & 5 & 1 & 5 & \\
\hline Geniostoma mpestre & $0-100$ & 9 & 4 & 28 & 2 & 14 & & 9 & 2 & 3 & 7 \\
\hline $\begin{array}{l}\text { Griselinia lucida } \\
\text { Ground ferns }\end{array}$ & $\begin{array}{c}0-100 \\
-\end{array}$ & 39 & & & & & & & & & \\
\hline \multirow[t]{2}{*}{ Hedycarya arborea } & 0-100 & & 9 & & 86 & 100 & 31 & 112 & 6 & 40 & 37 \\
\hline & $\begin{array}{l}0-100 \\
100+\end{array}$ & & & & & & 7 & & & & \\
\hline \multirow[t]{2}{*}{ Hoheria populnea } & $0-100$ & 6 & & 1 & & & & & & & \\
\hline & $100+$ & & & 1 & & & & & & & \\
\hline \multirow{2}{*}{ Knightia excelsa } & $0-100$ & 1 & & 4 & 6 & 13 & & 2 & & 1 & \\
\hline & $100+$ & & & 1 & 1 & & 2 & & & & \\
\hline Kunzea ericoides & $0-100$ & & & & & & & & & 1 & \\
\hline \multirow{2}{*}{ Laurelia novae-zelandiae } & $100+$ & 8 & 18 & & & & & & 5 & 19 & \\
\hline & $\begin{array}{l}0-100 \\
100+\end{array}$ & & & & & & & & & & \\
\hline Leucopogon fasciculatus & $0-100$ & & & & & & & & & & \\
\hline Lonicera japonica & - & & & & & & & & & & \\
\hline Lophomyrtus bullata & $0-100$ & 1 & & 3 & & & & & & & \\
\hline Macropiper excelsum & $0-100$ & & & 2 & & & & & & & \\
\hline \multirow{2}{*}{ Melicytus ramiflorus } & $\begin{array}{l}100+ \\
0-100\end{array}$ & 10 & 45 & 22 & 31 & 52 & 3 & 6 & 15 & 33 & \\
\hline & $100+$ & & & 1 & 1 & 3 & 3 & 1 & 3 & & \\
\hline
\end{tabular}




\begin{tabular}{|c|c|c|c|c|c|c|c|c|c|c|c|}
\hline Metrosideros diffusa & - & & & 17 & 1 & 1 & & & & & \\
\hline Microlaena avanacea & - & 9 & 28 & 6 & 33 & 18 & 5 & 13 & 2 & 94 & 103 \\
\hline Mueblenbeckia complexa & - & & & & & & & & & & \\
\hline \multirow[t]{2}{*}{ Myrsine australis } & $0-100$ & & & 4 & 12 & 7 & 1 & 1 & & 5 & 7 \\
\hline & $100+$ & 2 & & & & & & & & & \\
\hline Nest epiphytes ${ }^{7}$ & - & & 1 & 1 & 12 & 32 & 1 & 22 & 2 & 8 & \\
\hline \multirow[t]{2}{*}{ Nestegis spp. } & $0-100$ & & 2 & 1 & 1 & 6 & & & & & 2 \\
\hline & $100+$ & 3 & & & & & 4 & 1 & 1 & & \\
\hline \multirow[t]{2}{*}{ Olearia rani } & $0-100$ & & & 1 & & & & & & & 1 \\
\hline & $100+$ & & & & & & & & & & \\
\hline Parsonsia heterophylla & - & 3 & 5 & 5 & 4 & 3 & & & & 1 & \\
\hline \multirow[t]{2}{*}{ Pennantia corymbosa } & $0-100$ & & & & & & & & & & \\
\hline & $100+$ & & & & & & & & 1 & & \\
\hline Pittosporum cornifolium & $0-100$ & & & & & & & & & & \\
\hline \multirow[t]{2}{*}{ Pittosporum engenioides } & $0-100$ & & & & & & & & & & \\
\hline & $100+$ & & & & & & & & & & \\
\hline \multirow[t]{2}{*}{ Pittosporum tenuifolium } & $0-100$ & & & & & & & & & & \\
\hline & $100+$ & & & & & & & & & & \\
\hline \multirow[t]{3}{*}{ Podocarpus totara } & $0-100$ & 1 & & & & & & & & & \\
\hline & $100-500$ & & & & & & & & & 1 & \\
\hline & $500+$ & & & & & & & & & & \\
\hline \multirow[t]{3}{*}{ Prumnopitys taxifolia } & $0-100$ & & & 2 & & & & & & & \\
\hline & $100-500$ & & 1 & & & & & & & & \\
\hline & $500+$ & & & & 2 & & & & & & \\
\hline Pseudopanax arboreus & $0-100$ & & & & & & & & & & \\
\hline \multirow[t]{2}{*}{ Pseudopanax crassifolius } & $0-100$ & & & 4 & & 5 & & & & 2 & \\
\hline & $100+$ & & & & & & & & & & 1 \\
\hline Rhopalostylas sapida & $0-100$ & & & & & & & & & & \\
\hline Ripogonum scandens & - & 2 & 1 & 20 & 15 & 9 & 31 & 5 & 1 & & 3 \\
\hline Rubus australis & - & & & & & & & & & 1 & \\
\hline \multirow[t]{2}{*}{ Schefflera digitata } & $0-100$ & & & & & 2 & & & & & 2 \\
\hline & $100+$ & & & & & 1 & & & & & \\
\hline \multirow[t]{2}{*}{ Small leaved divaricates ${ }^{9}$} & $0-100$ & 90 & 26 & 39 & 34 & 40 & & 6 & 42 & 59 & 34 \\
\hline & $100+$ & & & & & & & & & & \\
\hline \multirow[t]{2}{*}{ Sophora tetraptera } & $0-100$ & & & & & & & & & & \\
\hline & $100+$ & & & & & & & & & & \\
\hline Tetrapathaea tetrandra & - & & & 1 & & & & & 3 & & \\
\hline Aspect & & 0 & 0 & 0 & 144 & 0 & 10 & 10 & 0 & 0 & 180 \\
\hline Slope & & 0 & 0 & 0 & 3 & 5 & 5 & 4 & 0 & 0 & 25 \\
\hline Canopy height (m) & & 10 & 15 & 15 & 20 & 20 & 20 & 10 & 10 & 15 & 15 \\
\hline Canopy open/closed (cl) & & $\mathrm{cl}$ & open & $\mathrm{cl}$ & ppen & $\mathrm{cl}$ & pen & pen & pen & pen & open \\
\hline
\end{tabular}




\begin{tabular}{|c|c|c|c|c|c|c|c|c|c|c|c|}
\hline \multirow[t]{2}{*}{ Species } & \multirow{2}{*}{$\begin{array}{c}\text { Stem } \\
\text { diameter } \\
(\mathrm{mm})\end{array}$} & \multicolumn{10}{|c|}{ Plot number } \\
\hline & & 71 & 72 & 73 & 74 & 75 & 76 & 77 & 78 & 79 & 80 \\
\hline \multirow[t]{2}{*}{ Alectryon excelsus } & $0-100$ & 9 & 23 & 26 & 31 & 5 & 5 & 10 & 16 & 7 & $\overline{10}$ \\
\hline & $100+$ & 3 & & & & & & & 1 & 2 & 5 \\
\hline \multirow[t]{2}{*}{ Aristotelia serrata } & $0-100$ & & & & & & & & & & \\
\hline & $100+$ & & & & & & & & & & \\
\hline \multirow[t]{2}{*}{ Beilschmiedia tawa } & $0-100$ & 14 & 8 & 2 & 14 & & & 7 & & & 2 \\
\hline & $100+$ & 1 & 16 & 5 & & & & & & & 1 \\
\hline Brachiglottis repanda & $0-100$ & & & & & & & & & & \\
\hline \multirow[t]{2}{*}{ Carpodetus serratus } & $0-100$ & & & & & & & 1 & & & \\
\hline & $100+$ & & & & & & & & & & \\
\hline Climbing ferns1 & - & 9 & & 5 & 5 & & 7 & 5 & 16 & 11 & 10 \\
\hline Coprosma grandifolia & $0-100$ & & & & 1 & & 1 & & & & \\
\hline \multirow[t]{2}{*}{ Cordyline australis } & $0-100$ & & & & & & & & & & \\
\hline & $100+$ & & & & & 1 & & & & & \\
\hline Corynocarpus laevigatus & $0-100$ & 6 & & & & & & & & & 1 \\
\hline Cyathea spp. ${ }^{2}$ & - & & & 1 & & & & 3 & & & \\
\hline \multirow[t]{3}{*}{ Dacrycarpus dacrydioides } & $0-100$ & & 1 & 1 & & & & 2 & & & \\
\hline & $100-500$ & 2 & & & 1 & & & & 3 & & 1 \\
\hline & $500+$ & 3 & & & & & & & 2 & 4 & 2 \\
\hline \multirow[t]{3}{*}{ Dacrydium cupressinum } & $0-100$ & & & & & & & & & & \\
\hline & $100-500$ & & & & & & & & & & \\
\hline & $500+$ & 1 & 1 & & & & & & 1 & & 1 \\
\hline \multirow{2}{*}{ Dead tree ${ }^{3}$} & $0-100$ & 6 & & 1 & & 4 & 2 & 5 & 2 & 1 & \\
\hline & $100+$ & 2 & 1 & & 1 & 2 & & 1 & & & \\
\hline Dysoxylum spectabile & $0-100$ & & & & & & & & & & \\
\hline & - & & & & & & & & & & \\
\hline \multirow{2}{*}{$\begin{array}{l}\text { Earna Spp. } \\
\text { Elaeocarpus dentatus }\end{array}$} & $0-100$ & & & & & & & & & & \\
\hline & $100+$ & & & & & & & & & & \\
\hline Elaeocarpus bookerianus & $100+$ & & & & & & 1 & & & & \\
\hline Epiphytic ferns ${ }^{5}$ & - & 10 & 14 & 1 & 1 & 2 & & & 5 & 2 & 3 \\
\hline \multirow[t]{2}{*}{ Geniostoma mpestre } & $0-100$ & 2 & 1 & 5 & 4 & & 2 & 7 & 4 & & 3 \\
\hline & $100+$ & & & & & & & & & & \\
\hline Griselinia lucida & $0-100$ & & 1 & & & & & & & 1 & \\
\hline & - & 83 & 34 & 124 & 92 & 6 & 17 & 39 & 61 & 41 & 54 \\
\hline \multirow[t]{2}{*}{ Hedycarya arborea } & $0-100$ & 40 & & & 16 & & & & & & \\
\hline & $100+$ & & & & & & & & & & \\
\hline \multirow[t]{2}{*}{ Hoberia populnea } & $0-100$ & & & & & 2 & 1 & 2 & & 1 & \\
\hline & $100+$ & & & & & 1 & & & & & \\
\hline \multirow[t]{2}{*}{ Knightia excelsa } & $0-100$ & 1 & & 3 & 4 & & & & & & \\
\hline & $100+$ & 2 & & & & & & & & & 2 \\
\hline \multirow[t]{2}{*}{ Kunzea ericoides } & $0-100$ & & & & & & & 1 & & & \\
\hline & $100+$ & & & & & 7 & 19 & 14 & & & \\
\hline Laurelia novae-zelandiae & $0-100$ & & & & & & & & & & \\
\hline & $100+$ & & & & & & & & & & \\
\hline Leucopogon fasciculatus & $0-100$ & & & & & & & & & & \\
\hline Lonicera japonica & - & & & & & & & & 15 & 4 & \\
\hline Lophomyrtus bullata & $0-100$ & & & & & & & 1 & 1 & 1 & \\
\hline Macropiper excelsum & $0-100$ & & & & & & & & & & \\
\hline & $100+$ & & & & & & & & & & \\
\hline Melicytus ramiflorus & $0-100$ & 41 & 33 & 15 & 11 & 24 & 24 & 24 & 22 & 32 & $\begin{array}{r}28 \\
5\end{array}$ \\
\hline & $100+$ & 3 & 3 & 2 & 5 & 6 & 1 & & & & 5 \\
\hline
\end{tabular}




\begin{tabular}{|c|c|c|c|c|c|c|c|c|c|c|c|}
\hline Metrosideros diffusa & - & & 2 & 4 & 4 & & & 1 & & 2 & 3 \\
\hline Microlaena avanacea & - & 19 & 8 & 4 & 25 & & 17 & 21 & 17 & 6 & 2 \\
\hline Mueblenbeckia complexa & - & & & & & & & & & & \\
\hline \multirow[t]{2}{*}{ Myrsine australis } & $0-100$ & 5 & 4 & 1 & 1 & 1 & 3 & 1 & 56 & 10 & 1 \\
\hline & $100+$ & & & & & & & & & $\begin{array}{l}1 \\
0\end{array}$ & \\
\hline Nest epiphytes & - & 35 & 50 & 7 & 2 & & & & 11 & 9 & 0 \\
\hline \multirow[t]{2}{*}{ Olearia rani } & $\begin{array}{l}100+ \\
0-100\end{array}$ & & & & & 1 & & 1 & & 1 & \\
\hline & $100+$ & & & & & & & & & & \\
\hline $\begin{array}{l}\text { Parsonsia beteropbylla } \\
\text { Pennantia corymbosa }\end{array}$ & - & 3 & 3 & 2 & & & & & 5 & 3 & \\
\hline Pennantia corymbosa & $\begin{array}{l}0-100 \\
100+\end{array}$ & & & & & 2 & & & & & \\
\hline Pittosporum cornifolium & $0-100$ & 1 & & & & 2 & & & & & \\
\hline \multirow{2}{*}{ Pittosporum engenioides } & $0-100$ & & & & & & & & & & \\
\hline & $100+$ & & & & & & & & & & \\
\hline \multirow[t]{2}{*}{ Pittosporum tenuifolium } & $0-100$ & & & & & & & & & & \\
\hline & $100+$ & & & & & & & & & & \\
\hline \multirow{2}{*}{ Podocarpus totara } & $\begin{array}{c}0-100 \\
100-500\end{array}$ & & 1 & & & & & & & & \\
\hline & $500+$ & & & & & & & & & & \\
\hline \multirow{2}{*}{ Prumnopitys taxifolia } & $0-100$ & 1 & 1 & 10 & & & & 1 & 1 & 1 & \\
\hline & $\begin{array}{c}100-500 \\
500+\end{array}$ & & 1 & & & & & & 1 & & 1 \\
\hline Pseudopanax arboreus & $0-100$ & & & & & & & 1 & & & \\
\hline \multirow{2}{*}{ Pseudopanax crassifolius } & $0-100$ & 1 & 1 & & & & & 1 & 3 & & \\
\hline & $100+$ & & & & & & & & & & \\
\hline $\begin{array}{l}\text { Rhopalostylas sapida } \\
\text { Ripogonum scandens }\end{array}$ & $\begin{array}{c}0-100 \\
-\end{array}$ & & & 2 & & & & & & & \\
\hline $\begin{array}{l}\text { Ropogonum scanens } \\
\text { Rubus australis }\end{array}$ & $\begin{array}{l}- \\
-\end{array}$ & 25 & 7 & 10 & 20 & & & 9 & 21 & 9 & 13 \\
\hline \multirow[t]{2}{*}{ Schefflera digitata } & $\begin{array}{c}- \\
0-100\end{array}$ & 1 & & 13 & 6 & & & & 3 & & \\
\hline & $\begin{array}{l}0-100 \\
100+\end{array}$ & & & 1 & & & & & & 1 & \\
\hline \multirow[t]{2}{*}{ Small leaved divaricates ${ }^{9}$} & $0-100$ & 8 & 21 & 9 & 3 & 29 & 39 & 31 & 50 & 31 & \\
\hline & $100+$ & & & & & 2 & & & & 1 & \\
\hline Sophora tetraptera & $\begin{array}{l}0-100 \\
100+\end{array}$ & & & & & & & & & & \\
\hline Tetrapathaea tetrandra & - & 1 & & & 1 & $\begin{array}{l}1 \\
5\end{array}$ & & & & 1 & \\
\hline Aspect & & & & & & & & & & & \\
\hline Slope & & $\begin{array}{l}0 \\
0\end{array}$ & 0 & $\begin{array}{l}0 \\
0\end{array}$ & 0 & 0 & 0 & 350 & 0 & 0 & 0 \\
\hline Canopy height (m) & & $\begin{array}{r}0 \\
15\end{array}$ & $\begin{array}{r}0 \\
15\end{array}$ & $\begin{array}{r}0 \\
10\end{array}$ & $\begin{array}{r}0 \\
20\end{array}$ & 7 & 0 & 5 & 0 & 0 & 0 \\
\hline Canopy open/closed (cl) & & $\mathrm{cl}$ & $\begin{array}{r}15 \\
\text { open }\end{array}$ & $\mathrm{cl}$ & open & 15 & 15 & 15 & $\begin{array}{c}10 \\
\text { open } c\end{array}$ & $\begin{array}{r}15 \\
\text { open }\end{array}$ & 10 \\
\hline
\end{tabular}




\begin{tabular}{|c|c|c|c|c|c|c|c|c|c|c|c|}
\hline \multirow[t]{2}{*}{ Species } & \multirow{2}{*}{$\begin{array}{c}\text { Stem } \\
\text { diameter } \\
(\mathrm{mm})\end{array}$} & \multicolumn{10}{|c|}{ Plot number } \\
\hline & & 81 & 82 & 83 & 84 & 85 & 86 & 87 & 88 & 89 & 90 \\
\hline \multirow[t]{2}{*}{ Alectryon excelsus } & $0-100$ & 46 & 48 & 36 & 5 & 18 & 23 & 11 & 18 & 41 & 43 \\
\hline & $100+$ & & & & & & & & & 2 & 1 \\
\hline \multirow[t]{2}{*}{ Aristotelia serrata } & $0-100$ & & & & & & & 1 & & & \\
\hline & $100+$ & & & & & & & 3 & & & \\
\hline \multirow[t]{2}{*}{ Beilschmiedia tawa } & $0-100$ & 3 & 8 & 1 & 6 & 10 & 4 & 8 & 5 & 7 & 11 \\
\hline & $100+$ & 2 & & & & 9 & 1 & & 1 & 4 & 8 \\
\hline Brachiglottis repanda & $0-100$ & & & & & & 1 & & & & \\
\hline \multirow[t]{2}{*}{ Carpodetus serratus } & $0-100$ & & & & & & 1 & & & & \\
\hline & $100+$ & & & & & & & & & & \\
\hline Climbing ferns1 & - & 8 & 6 & 1 & 13 & 11 & 4 & 13 & 1 & 12 & 1 \\
\hline Coprosma grandifolia & $0-100$ & & & & & & & & & 1 & \\
\hline \multirow[t]{2}{*}{ Cordyline australis } & $0-100$ & & & & & & & & & & \\
\hline & $100+$ & & & & & & & & & & \\
\hline Corynocarpus Laevigatus & $0-100$ & & & & & & & & 1 & & \\
\hline Cyathea spp. ${ }^{2}$ & - & & & & & 1 & 1 & 1 & 2 & & \\
\hline \multirow[t]{3}{*}{ Dacrycarpus dacrydioides } & $0-100$ & 6 & & 6 & 29 & & 24 & 23 & 7 & & \\
\hline & $100-500$ & & 1 & 11 & 2 & & & & & & \\
\hline & $500+$ & & 2 & 1 & & & & 1 & & 2 & 1 \\
\hline \multirow[t]{3}{*}{ Dacrydium cupressinum } & $0-100$ & & & & & & & & & & \\
\hline & $100-500$ & & & & & & & & & & \\
\hline & $500+$ & 1 & & & & 1 & & & & & \\
\hline \multirow[t]{2}{*}{ Dead tree ${ }^{3}$} & $0-100$ & 1 & 1 & 3 & 1 & & 3 & 1 & & & \\
\hline & $100+$ & & & & 4 & & 1 & & 1 & 1 & 2 \\
\hline Dysoxylum spectabile & $0-100$ & & & & & & & & & & \\
\hline Earina spp. ${ }^{4}$ & - & & 1 & & & & & & & & \\
\hline \multirow[t]{2}{*}{ Elaeocarpus dentatus } & $0-100$ & & & & & & & & & & \\
\hline & $100+$ & & & & & & & & & & \\
\hline Elaeocarpus hookerianus & $100+$ & & & & & & & & & & \\
\hline Epiphytic ferns ${ }^{5}$ & - & 11 & 7 & 4 & 1 & 2 & & & & & 2 \\
\hline \multirow[t]{2}{*}{ Geniostoma mpestre } & $0-100$ & 2 & & 4 & 12 & 8 & 8 & 7 & 6 & 2 & 1 \\
\hline & $100+$ & & & & & & & & & & \\
\hline Griselinia lucida & $0-100$ & & & & & & & & & & \\
\hline Ground ferns ${ }^{6}$ & - & 67 & 76 & 17 & 168 & 103 & 79 & 68 & 56 & 51 & 34 \\
\hline \multirow[t]{2}{*}{ Hedycarya arborea } & $0-100$ & & 26 & & & 8 & & & 1 & 19 & 17 \\
\hline & $100+$ & & & & & & & & & & \\
\hline \multirow[t]{2}{*}{ Hoheria populnea } & $0-100$ & & & & 1 & & 1 & & & & \\
\hline & $100+$ & & & & & & & 1 & & & \\
\hline \multirow[t]{2}{*}{ Knightia excelsa } & $0-100$ & 9 & & & 1 & 10 & 6 & 3 & & & \\
\hline & $100+$ & 1 & & & & 1 & 2 & & 1 & 1 & \\
\hline \multirow[t]{2}{*}{ Kunzea ericoides } & $0-100$ & & & & & & & & & & \\
\hline & $100+$ & & & & & & & & & & \\
\hline Laurelia novae-zelandiae & $0-100$ & & & & & & & 37 & & & \\
\hline & $100+$ & & & & & & & & & & \\
\hline Leucopogon fasciculatus & $0-100$ & & & & & & & & & & \\
\hline Lonicera japonica & - & & & 1 & & & & & & & \\
\hline Lophomyrtus bullata & $0-100$ & & & & 3 & & 8 & 11 & & & \\
\hline Macropiper excelsum & $0-100$ & & & & & & 1 & & & & \\
\hline & $100+$ & & & & & & & & & & \\
\hline Melicytus ramiflorus & $0-100$ & 15 & 12 & 6 & 7 & 7 & 16 & 6 & 9 & 14 & 19 \\
\hline & $100+$ & 5 & 7 & & 1 & 6 & 2 & 4 & 7 & 9 & 3 \\
\hline
\end{tabular}




\begin{tabular}{|c|c|c|c|c|c|c|c|c|c|c|c|}
\hline Metrosideros diffusa & - & & 11 & & & 6 & 11 & 1 & & & 2 \\
\hline Microlaena avanacea & - & 2 & 5 & 108 & 22 & 22 & 64 & 53 & 26 & & \\
\hline Mueblenbeckia complexa & - & & & & & & & & & & \\
\hline \multirow[t]{2}{*}{ Myrsine australis } & $0-100$ & & 1 & 1 & & 6 & 1 & 3 & 3 & & 4 \\
\hline & $100+$ & & & & & & 1 & & & & \\
\hline Nest epiphytes $^{7}$ & - & 23 & 21 & 5 & 3 & 7 & & & 1 & 12 & 5 \\
\hline \multirow[t]{2}{*}{ Nestegis spp. ${ }^{8}$} & $0-100$ & 1 & & & 2 & & & & & & \\
\hline & $100+$ & & 3 & 4 & 3 & & & & & & \\
\hline \multirow[t]{2}{*}{ Olearia rani } & $0-100$ & & & & & & & & 1 & & \\
\hline & $100+$ & & & & & & & & & & \\
\hline Parsonsia beterophylla & - & 1 & & 4 & 2 & 2 & 7 & 5 & 2 & 3 & 4 \\
\hline \multirow[t]{2}{*}{ Pennantia corymbosa } & $0-100$ & 2 & & 1 & & & & & & & \\
\hline & $100+$ & & & & & & & & & & \\
\hline Pittosporum cornifolium & $0-100$ & & & & & & & & & & \\
\hline \multirow[t]{2}{*}{ Pittosporum eugenioides } & $0-100$ & & & & & & & & & & \\
\hline & $100+$ & & & & & & & & & & \\
\hline \multirow[t]{2}{*}{ Pittosporum tenuifolium } & $0-100$ & & & & & & & & & & \\
\hline & $100+$ & & & & & & & & & & \\
\hline \multirow[t]{3}{*}{ Podocarpus totara } & $0-100$ & & & & & & & & & & \\
\hline & $100-500$ & & & & & & & & & & \\
\hline & $500+$ & & & & & & & & & & \\
\hline \multirow[t]{3}{*}{ Prumnopitys taxifolia } & $0-100$ & 2 & 1 & & & & 4 & 2 & 3 & & \\
\hline & $100-500$ & & & & & & & & 2 & 1 & \\
\hline & $500+$ & & & & & & & & & & 2 \\
\hline Pseudopanax arboreus & $0-100$ & & & & & & & & & & \\
\hline \multirow[t]{2}{*}{ Pseudopanax crassifolius } & $0-100$ & 1 & & & & & & & & 1 & 1 \\
\hline & $100+$ & & & & & & & & 1 & & \\
\hline Rhopalostylas sapida & $0-100$ & & 1 & & & & & & & & \\
\hline Ripogonum scandens & - & 17 & 22 & 4 & 26 & 10 & 31 & 25 & 24 & 14 & 13 \\
\hline Rubus australis & - & & & & & & & & & & \\
\hline \multirow[t]{2}{*}{ Schefflera digitata } & $0-100$ & & & & & 1 & 27 & 9 & 9 & 2 & \\
\hline & $100+$ & 1 & & & & & 1 & 1 & & & \\
\hline \multirow[t]{2}{*}{ Small leaved divaricates ${ }^{9}$} & $0-100$ & 13 & 6 & 46 & 25 & 10 & 15 & 11 & 9 & & 1 \\
\hline & $100+$ & & & 3 & & & & & & & \\
\hline \multirow[t]{2}{*}{ Sophora tetraptera } & $0-100$ & & & & & & & & & & \\
\hline & $100+$ & & & & & & & & & & \\
\hline Tetrapathaea tetrandra & - & & & & & & & & 2 & & \\
\hline Aspect & & 0 & 0 & 0 & 0 & 350 & 0 & 0 & 0 & 0 & 0 \\
\hline Slope & & 4 & 0 & 0 & 0 & 10 & 0 & 0 & 0 & 0 & 0 \\
\hline Canopy height (m) & & 10 & 10 & 15 & 10 & 15 & 10 & 10 & 10 & 15 & 15 \\
\hline Canopy open/closed (cl) & & open & pen & open & $\mathrm{cl}$ & open & $\mathrm{cl}$ & open & pen 0 & pen 0 & pen \\
\hline
\end{tabular}




\begin{tabular}{|c|c|c|c|c|c|c|c|c|c|c|c|}
\hline \multirow[t]{2}{*}{ Species } & \multirow{2}{*}{$\begin{array}{c}\text { Stem } \\
\text { diameter } \\
(\mathbf{m m})\end{array}$} & \multicolumn{10}{|c|}{ Plot number } \\
\hline & & 91 & 92 & 93 & 94 & 95 & 96 & 97 & 98 & 99 & 100 \\
\hline \multirow[t]{2}{*}{ Alectryon excelsus } & $0-100$ & 5 & 48 & 14 & 16 & 11 & 33 & 16 & 52 & 25 & 22 \\
\hline & $100+$ & & 1 & & 1 & & & 2 & & 2 & 1 \\
\hline \multirow[t]{2}{*}{ Aristotelia serrata } & $0-100$ & & & & & & & & & & \\
\hline & $100+$ & & & & & & & & & & \\
\hline \multirow[t]{2}{*}{ Beilschmiedia tawa } & $0-100$ & 2 & 2 & 6 & & & 1 & 2 & 1 & 7 & 8 \\
\hline & $100+$ & 22 & 4 & 4 & & 8 & 2 & 7 & 7 & 4 & 1 \\
\hline Brachiglottis repanda & $0-100$ & & & & & & & & & & \\
\hline \multirow[t]{2}{*}{ Carpodetus serratus } & $0-100$ & & & & & & & & & & \\
\hline & $100+$ & & & & & & & & & & \\
\hline Climbing ferns1 & - & 3 & 5 & 13 & 9 & 7 & 10 & 9 & 9 & 6 & 8 \\
\hline Coprosma grandifolia & $0-100$ & & & & & & & & & & \\
\hline \multirow[t]{2}{*}{ Cordyline australis } & $0-100$ & & & & & & & & & & \\
\hline & $100+$ & & & & & & & & & & \\
\hline Corynocarpus laevigatus & $0-100$ & & & & & 1 & & & 1 & & \\
\hline Cyathea spp. ${ }^{2}$ & - & & 1 & 1 & 6 & 1 & & & & 1 & \\
\hline \multirow[t]{3}{*}{ Dacrycarpus dacrydioides } & $0-100$ & & & 2 & 14 & 9 & 1 & 9 & & & \\
\hline & $100-500$ & 1 & & & & & & & & & 1 \\
\hline & $500+$ & 1 & & & & & & & 1 & & 1 \\
\hline \multirow[t]{3}{*}{ Dacrydium cupressinum } & $0-100$ & & & & & & & & & & \\
\hline & $100-500$ & & & & 3 & & & & 1 & & \\
\hline & $500+$ & & 2 & & & & & & & 1 & 2 \\
\hline \multirow{2}{*}{ Dead tree $^{3}$} & $0-100$ & 5 & 1 & 4 & 4 & & & 2 & 1 & & 1 \\
\hline & $100+$ & & 1 & & & & & 1 & 1 & 1 & \\
\hline $\begin{array}{l}\text { Dysoxylum spectabile } \\
\text { Earina spp. }{ }^{4}\end{array}$ & $0-100$ & & & & & & & & & & \\
\hline $\begin{array}{l}\text { Earina spp. }{ }^{4} \\
\text { Elaeocarpus dentatus }\end{array}$ & - & & & & & & & & & & \\
\hline \multirow{2}{*}{ Elaeocarpus dentatus } & $0-100$ & & & & & & & & & & \\
\hline & $100+$ & & & & & & & & & & \\
\hline $\begin{array}{l}\text { Elaeocarpus hookeranus } \\
\text { Epiphytic ferns }{ }^{5}\end{array}$ & $100+$ & 1 & 3 & & 2 & 4 & & 1 & 7 & & 6 \\
\hline \multirow{2}{*}{ Geniostoma mpestre } & $\begin{array}{c}- \\
0-100\end{array}$ & $\begin{array}{l}1 \\
8\end{array}$ & $\begin{array}{l}3 \\
6\end{array}$ & 2 & 10 & 10 & 1 & 2 & 7 & 8 & 19 \\
\hline & $100+$ & & & & & & & & & & \\
\hline Griselinia lucida & $0-100$ & & & & & & & & & & \\
\hline Ground ferns ${ }^{6}$ & - & & & 192 & 180 & & 72 & 36 & & 77 & \\
\hline \multirow[t]{2}{*}{ Hedycarya arborea } & $0-100$ & & 7 & 1 & & 19 & 7 & 8 & 5 & 2 & 3 \\
\hline & $100+$ & & & & & & & & 2 & & \\
\hline \multirow[t]{2}{*}{ Hoberia populnea } & $0-100$ & & & 1 & 2 & & 2 & & & & \\
\hline & $100+$ & & & & 2 & & & & 1 & & \\
\hline \multirow[t]{2}{*}{ Knightia excelsa } & $0-100$ & & 3 & 7 & 1 & 13 & 1 & 3 & 14 & 2 & 1 \\
\hline & $100+$ & 1 & & & & & 1 & 4 & & 3 & 5 \\
\hline \multirow[t]{2}{*}{ Kunzea ericoides } & $0-100$ & & & & & & & & & & \\
\hline & $100+$ & & & & & & & & & & \\
\hline \multirow[t]{2}{*}{ Laurelia novae-zelandiae } & $0-100$ & & & & & & & & & & \\
\hline & $100+$ & & & & & & & & & & \\
\hline Leucopogon fasciculatus & $0-100$ & & & & & & & & & & \\
\hline Lonicera japonica & - & & & & & & & & & & \\
\hline Lophomyrtus bullata & $0-100$ & & & & & & & & & & \\
\hline Macropiper excelsum & $0-100$ & & & & & & & & & & \\
\hline & $100+$ & & & & & & & 25 & 19 & 11 & 20 \\
\hline Melicytus ramiflorus & $\begin{array}{l}0-100 \\
100+\end{array}$ & 49 & $\begin{array}{r}23 \\
3\end{array}$ & $\begin{array}{r}18 \\
2\end{array}$ & $\begin{array}{r}17 \\
1\end{array}$ & $\begin{array}{r}29 \\
1\end{array}$ & $\begin{array}{l}5 \\
8\end{array}$ & $\begin{array}{r}25 \\
3\end{array}$ & 2 & 2 & 0 \\
\hline
\end{tabular}




\begin{tabular}{|c|c|c|c|c|c|c|c|c|c|c|c|}
\hline Metrosideros diffusa & - & & & 2 & 5 & 3 & 3 & 4 & 1 & 3 & \\
\hline Microlaena avanacea & - & 4 & 20 & 39 & 11 & 39 & 1 & 39 & 50 & 11 & 2 \\
\hline Mueblenbeckia complexa & - & & & & 3 & 4 & & & & 2 & \\
\hline Myrsine australis & $\begin{array}{l}0-100 \\
100+\end{array}$ & 8 & 9 & 1 & 2 & & & 12 & 22 & 1 & 4 \\
\hline Nest epiphytes ${ }^{7}$ & - & 6 & 10 & & 2 & 5 & 3 & 1 & 18 & 3 & 33 \\
\hline Nestegis spp. ${ }^{8}$ & $\begin{array}{l}0-100 \\
100+\end{array}$ & & 4 & & & & & & 3 & & \\
\hline Olearia rani & $\begin{array}{l}0-100 \\
100+\end{array}$ & & & & & & & & & 2 & \\
\hline Parsonsia beteropbylla & - & & 2 & & 1 & 3 & 5 & 3 & 5 & & 6 \\
\hline Pennantia corymbosa & $\begin{array}{l}0-100 \\
100+\end{array}$ & & & & & & & & & & \\
\hline Pittosporum cornifolium & $0-100$ & & & & & & & & 1 & & 1 \\
\hline Pittosporum eugenioides & $\begin{array}{l}0-100 \\
100+\end{array}$ & & & & & & 1 & & & & \\
\hline Pittosporum tenuifolium & $\begin{array}{l}0-100 \\
100+\end{array}$ & & & & & & & & & & \\
\hline Podocarpus totara & $\begin{array}{c}0-100 \\
100-500 \\
500+\end{array}$ & & & & & & & & & & \\
\hline Prumnopitys taxifolia & $\begin{array}{c}0-100 \\
100-500\end{array}$ & & & & & 3 & 2 & 1 & & & \\
\hline Pseudopanax arboreus & $\begin{array}{l}500+ \\
0-100\end{array}$ & & & & & & & & 1 & & \\
\hline $\begin{array}{l}\text { Pseudopanax arboreus } \\
\text { Pseudopanax crassifolius }\end{array}$ & $\begin{array}{l}0-100 \\
0-100 \\
100+\end{array}$ & & 3 & 2 & & 1. & & & 10 & & \\
\hline Rhopalostylas sapida & $0-100$ & & & & & & & & & & 2 \\
\hline Ripogonum scandens & - & 7 & 6 & 26 & 21 & 9 & 20 & 15 & 12 & 26 & 20 \\
\hline Rubus australis & - & & & & & & & & & & \\
\hline Schefflera digitata & $\begin{array}{l}0-100 \\
100+\end{array}$ & & & $\begin{array}{l}2 \\
2\end{array}$ & $\begin{array}{l}7 \\
1\end{array}$ & $\begin{array}{l}9 \\
4\end{array}$ & & & & & \\
\hline Small leaved divaricates ${ }^{9}$ & $\begin{array}{l}0-100 \\
100+\end{array}$ & 66 & 27 & 22 & 9 & 19 & 8 & 20 & 25 & 10 & 31 \\
\hline Sophora tetraptera & $\begin{array}{l}0-100 \\
100+\end{array}$ & & & & & & & & & & \\
\hline Aspect & & 0 & 220 & 0 & 0 & 320 & 20 & 0 & 140 & 0 & 0 \\
\hline Slope & & 0 & 8 & 0 & 0 & 8 & 8 & 10 & 5 & 0 & 0 \\
\hline Canopy height (m) & & 15 & 15 & 15 & 10 & 15 & 15 & 15 & 15 & 20 & 15 \\
\hline Canopy open/closed (cl) & & pen & open & $\mathrm{cl}$ & open & open $\mathrm{c}$ & pen $c$ & pen & pen 0 & open 0 & spen \\
\hline
\end{tabular}

